\title{
ipen
}

AUTARQUIA ASSOCIADA À UNIVERSIDADE DE SÃO PAULO

HIDROGENAÇÃO DE LIGAS À BASE DE TERRAS RARAS PARA FABRICAÇÃO DE ELETRODOS NEGATIVOS DE BATERIAS DE NÍQUEL-HIDRETO METÁLICO

\author{
JULIO CÉSAR SERAFIM CASINI
}

Dissertação apresentada como parte dos requisitos para obtenção do Grau de Mestre em Ciências na Área de Tecnologia Nuclear - Materiais

Orientador:

Prof. Dr. Hidetoshi Takiishi 
INSTITUTO DE PESQUISAS ENERGÉTICAS E NUCLEARES

Autarquia Associada à Universidade de São Paulo

\section{HIDROGENAÇÃO DE LIGAS À BASE DE TERRAS RARAS PARA FABRICAÇÃO DE ELETRODOS NEGATIVOS DE BATERIAS DE NÍQUEL-HIDRETO METÁLICO}

\section{JULIO CÉSAR SERAFIM CASINI}

Dissertação apresentada como parte dos requisitos para obtenção do Grau de Mestre em Ciências na Área de Tecnologia Nuclear-Materiais

Orientador:

Dr. HIDETOSHI TAKIISHI 


\section{DEDICATÓRIA}

À minha mãe Maria Inês Serafim Casini, meu pai João César Lorenzetti Casini e minha irmã Maira Carolina Serafim Casini pelo amor, carinho, incentivo, formação e principalmente pelo esforço dedicado para que não desistisse nos momentos mais complicados dessa árdua caminhada.

À Bruna Bottiglieri Ventura Seco pelo amor, compreensão e por agüentar meus momentos de ansiedade e estresse nos meses que me dediquei a este trabalho.

Aos meus tios Josué Brito de Moura e Silvana Lúcia Serafim de Moura pela ajuda e incentivo nesta caminhada.

A todos da minha família que estiveram comigo nesta jornada

A todos que contribuíram para a realização deste trabalho. 


\section{AGRADECIMENTOS}

Ao Dr. Hidetoshi Takiishi pela orientação, amizade e compreensão ao longo deste trabalho.

Ao Dr. Rubens Nunes de Faria Jr. pela amizade e Co-orientação.

A todos do Laboratório de Materiais Magnéticos pela amizade, companheirismo e incentivo na realização deste trabalho.

Ao Instituto de Pesquisas Energéticas e Nucleares (IPEN/CNEN) pela oportunidade concedida.

A CAPES, CNPq e FAPESP pelo suporte financeiro.

A todos os bolsistas, técnicos e pesquisadores do Centro de Ciência e Tecnologia de Materiais do IPEN que me auxiliaram na realização das análises deste trabalho.

A todos os colegas dos demais centros do IPEN que direta ou indiretamente ajudaram na realização deste trabalho. 


\title{
HIDROGENAÇÃO DE LIGAS À BASE DE TERRAS RARAS PARA \\ FABRICAÇÃO DE ELETRODOS NEGATIVOS DE BATERIAS DE NÍQUEL- HIDRETO METÁLICO
}

\author{
Julio César Serafim Casini
}

\begin{abstract}
RESUMO
Neste trabalho foi estudado as ligas $\mathrm{La}_{0,7-x} \mathrm{Mg}_{\mathrm{x}} \mathrm{Pr}_{0,3} \mathrm{Al}_{0,3} \mathrm{Mn}_{0,4} \mathrm{Co}_{0,5} \mathrm{Ni}_{3,8}(\mathrm{x}=0$ a 0,7$)$ como eletrodo negativo de baterias de níquel - hidreto metálico. A hidrogenação das ligas foi realizada com duas pressões de $\mathrm{H}_{2}$ (2 bar e 10 bar) e temperaturas (ambiente e $500^{\circ}$ C). A capacidade de descarga das baterias de níquel hidreto metálico foram analisadas pelo equipamento de testes elétricos ARBIN BT-4. As ligas, no estado bruto de fusão, foram analisadas por microscopia eletrônica de varredura (MEV), espectroscopia de energia dispersiva (EDS) e difração de Raios-X. Com o aumento da concentração de $\mathrm{Mg}$ nas ligas aumenta-se a capacidade de descarga, porém nota-se a diminuição a estabilidade cíclica das baterias. A capacidade de descarga máxima obtida foi para a liga $\mathrm{Mg}_{0,7} \mathrm{Pr}_{0,3} \mathrm{Al}_{0,3} \mathrm{Mn}_{0,4} \mathrm{Co}_{0,5} \mathrm{Ni}_{3,8}$ (60 mAh) e a bateria que apresentou a melhor performance foi $\mathrm{La}_{0,4} \mathrm{Mg}_{0,3} \mathrm{Pr}_{0,3} \mathrm{Al}_{0,3} \mathrm{Mn}_{0,4} \mathrm{Co}_{0,5} \mathrm{Ni}_{3,8}$ (53 mAh e 150 ciclos). A capacidade de absorção de hidrogênio diminui quando se adiciona $\mathrm{Mg}$, não ocorrendo tal efeito para a liga $\mathrm{Mg}_{0,7} \mathrm{Pr}_{0,3} \mathrm{Al}_{0,3} \mathrm{Mn}_{0,4} \mathrm{Co}_{0,5} \mathrm{Ni}_{3,8}$.
\end{abstract}




\title{
HIDROGENATION OF THE RARE EARTH ALLOYS FOR PRODUCTION NEGATIVE ELECTRODES OF NICKEL-METAL HYDRIDE BATTERIES
}

\author{
Julio César Serafim Casini
}

\begin{abstract}
In this work were studied of $\mathrm{La}_{0.7-x} \mathrm{Mg}_{\mathrm{x}} \mathrm{Pr}_{0.3} \mathrm{Al}_{0.3} \mathrm{Mn}_{0.4} \mathrm{Co}_{0.5} \mathrm{Ni}_{3.8}(\mathrm{x}=0$ and 0.7$)$ alloys for negative electrodes of the nickel-metal hydride batteries. The hydrogenation of the alloys was performed varying pressing of $\mathrm{H}_{2}$ (2 and $10 \mathrm{bar}$ ) and temperature (room and $500^{\circ} \mathrm{C}$ ). The discharge capacity of the nic kel-metal hydride batteries were analyzed in ARBIN BT- 4 electrical test equipment. The as-cast alloys were analyzed by scanning electron microscopy (SEM), energy disperse spectroscopy (EDX) and X-Ray diffraction. The increasing $M g$ addition in the alloy increases maximum discharge capacity but decrease cycle life of the batteries. The maximum discharge capacity was obtained with the $\mathrm{Mg}_{0.7} \mathrm{Pr}_{0.3} \mathrm{Al}_{0.3} \mathrm{Mn}_{0.4} \mathrm{Co}_{0.5} \mathrm{Ni}_{3.8}$ alloy (60 $\mathrm{mAh}$ ) and the battery which presented the best performance was $\mathrm{La}_{0.4} \mathrm{Mg}_{0.3} \mathrm{Pr}_{0.3} \mathrm{Al}_{0.3} \mathrm{Mn}_{0.4} \mathrm{Co}_{0.5} \mathrm{Ni}_{3.8}$ alloy (53 mAh and 150 cycles). The $\mathrm{H}_{2}$ capability of absorption was diminished for increased $\mathrm{Mg}$ addition and no such effect occurs for $\mathrm{Mg}_{0.7} \mathrm{Pr}_{0.3} \mathrm{Al}_{0.3} \mathrm{Mn}_{0.4} \mathrm{Co}_{0.5} \mathrm{Ni}_{3.8}$ alloy.
\end{abstract}




\section{ÍNDICE DE TABELAS}

Página

TABELA 1. Características das principais baterias do mercado mundial.

TABELA 2. Vantagens e desvantagens do uso de ligas do tipo $A B_{2}$ e $A B_{5}$ em baterias de Ni-HM.

TABELA 3. Capacidades de descarga obtidas para as ligas

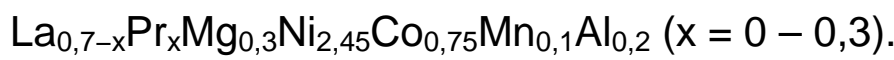

TABELA 4. Capacidades de descarga obtidas para as ligas $\mathrm{La}_{0,7} \mathrm{Mg}_{0,3} \mathrm{Ni}_{2,55-x} \mathrm{Co}_{0,45} \mathrm{Mn}_{\mathrm{x}}(\mathrm{x}=0-0,5)$.....

TABELA 5. Capacidades de descarga obtidas para as ligas $\mathrm{La}_{0,7} \mathrm{Mg}_{0,3} \mathrm{Ni}_{3,4-x} \mathrm{Mn}_{0,1} \mathrm{Co}_{\mathrm{x}}(\mathrm{x}=0-1,6) \ldots$

TABELA 6. Capacidades de descarga obtidas para as ligas $\operatorname{La}_{2} M g\left(\mathrm{Ni}_{1-\mathrm{x}} \mathrm{A} \mathrm{I}_{\mathrm{x}}\right)_{9}(\mathrm{x}$ $=0-0,05)$.

TABELA 7. Efeito capacidade descarga da liga $\mathrm{La}_{0,7} \mathrm{Mg}_{0,3} \mathrm{Ni}_{2,45} \mathrm{Co}_{0,75} \mathrm{Mn}_{0,1} \mathrm{Al}_{0,2}$ tratadas termicamente em diferentes temperaturas.

TABELA 8. Capacidade máxima de descarga das principais ligas a base de magnésio com substituição dos elementos.

TABELA 9. Análise química das ligas $\mathrm{La}_{0,7-x} \mathrm{Mg}_{\times} \mathrm{Pr}_{0,3} \mathrm{Al}_{0,3} \mathrm{Mn}_{0,4} \mathrm{Co}_{0,5} \mathrm{Ni}_{3,8}(\mathrm{x}=0$ a 0,7$)$ onde: (a) porcentagem em peso e (b) porcentagem atômica.

TABELA 10. Composição determinada da fase matriz (M).

TABELA 11. Composição determinada da fase cinza (C). 55

TABELA 12. Composição determinada da fase cinza escura (CE). 56

TABELA 13. Composição determinada da fase escura $(E)$ 
TABELA 14. Dados cristalográficos das ligas $\mathrm{La}_{0,7-x} \mathrm{Mg}_{x} \operatorname{Pr}_{0,3} \mathrm{Al}_{0,3} \mathrm{Mn}_{0,4} \mathrm{Co}_{0,5} \mathrm{Ni}_{3,8}(\mathrm{x}=0 \mathrm{a}$ $0,7)$

TABELA 15. Tamanho médio de partículas das ligas $\mathrm{La}_{0,7-x} \operatorname{Mg}_{x} \operatorname{Pr}_{0,3} \mathrm{Al}_{0,3} \mathrm{Mn}_{0,4} \mathrm{Co}_{0,5} \mathrm{Ni}_{3,8}$ $(0$ a 0,3$)$

TABELA 16. Capacidade máxima de descarga, retenção da capacidade de descarga e número de ciclos das baterias fabricadas com as ligas $\mathrm{La}_{0,7}$ ${ }_{x} \mathrm{Mg}_{\mathrm{x}} \mathrm{Pr}_{0,3} \mathrm{Al}_{0,3} \mathrm{Mn}_{0,4} \mathrm{Co}_{0,5} \mathrm{Ni}_{3,8}(\mathrm{x}=0$ a 0,7$)$.

TABELA 17. Resistências internas iniciais e finais das baterias fabricadas com as

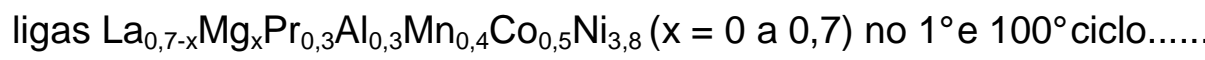

TABELA 18.

Variação e média da resistência interna das baterias fabricadas com as ligas $\mathrm{La}_{0,7-x} \mathrm{Mg}_{\mathrm{x}} \mathrm{Pr}_{0,3} \mathrm{Al}_{0,3} \mathrm{Mn}_{0,4} \mathrm{Co}_{0,5} \mathrm{Ni}_{3,8}(\mathrm{x}=0$ a 0,7$)$ no $1^{\circ} \mathrm{e} 100^{\circ}$ ciclo...... 


\section{ÍNDICE DE FIGURAS}

Página

FIGURA 1. Sistema interno de uma bateria de Ni-HM cilíndrica do tipo "AA", onde: 1 - contato positivo, 2 - carcaça metálica (contato negativo), 3 - eletrodo positivo, 4 - eletrodo negativo com coletor de corrente (tela de níquel conectada a carcaça) e 5 - separador entre os eletrodos

FIGURA 2. Diagrama do funcionamento de uma bateria de Ni-HM.

FIGURA 3. Perfil de descarga de uma bateria de Ni-HM.

FIGURA 4. Capacidades de descarga dos eletrodos negativos das ligas $\mathrm{La}_{0,7-\mathrm{x}} \mathrm{Pr}_{\mathrm{x}} \mathrm{Mg}_{0,3} \mathrm{Ni}_{2,45} \mathrm{Co}_{0,75} \mathrm{Mn}_{0,1} \mathrm{Al}_{0,2} \quad(\mathrm{x}=0$ - 0,3); onde: (a) capacidade de descarga em função do número de ciclos e (b) capacidade de descarga máxima em função do teor praseodímio...

FIGURA 5. Capacidades de descarga dos eletrodos negativos das ligas $\mathrm{La}_{0,7} \mathrm{Mg}_{0,3} \mathrm{Ni}_{2,55-\mathrm{x}} \mathrm{Co}_{0,45} \mathrm{Mn}_{\mathrm{x}}$ ( $\mathrm{x}=0$ - 0,5); onde: (a) capacidade de descarga em função do número de ciclos e (b) capacidade de descarga máxima em função do teor de manganês.

FIGURA 6. Capacidades de descarga dos eletrodos negativos das ligas $\mathrm{La}_{0,7} \mathrm{Mg}_{0,3} \mathrm{Ni}_{3,4-x} \mathrm{Mn}_{0,1} \mathrm{Co}_{x}(\mathrm{x}=0-1,6)$; onde: (a) capacidade de descarga em função do número de ciclos e (b) capacidade de descarga máxima em função da teor de cobalto.

FIGURA 7. Capacidades de descarga dos eletrodos negativos das ligas $\mathrm{La}_{2} \mathrm{Mg}\left(\mathrm{Ni}_{1-\mathrm{X}} \mathrm{Al} \mathrm{I}_{\mathrm{x}}\right)_{9}(\mathrm{x}=0$ - 0,05); onde: (a) capacidade de descarga em função do número de ciclos e (b) capacidade de descarga máxima em função da teor de alumínio. 
FIGURA 8. Capacidade de descarga em função do número de ciclos dos eletrodos negativos produzidos com as ligas ( $\mathrm{La}, \mathrm{Ce}, \mathrm{Pr}, \mathrm{Nd})_{1}$. ${ }_{x} \mathrm{Mg}_{\mathrm{x}} \mathrm{Al}_{0,1} \mathrm{Mn}_{0,1} \mathrm{Co}_{0,55} \mathrm{Ni}_{3,0}(\mathrm{x}=0,05-0,30)$.

FIGURA 9. Retenção da capacidade de descarga em função do aumento do teor de magnésio nas ligas ( $\mathrm{La}, \mathrm{Ce}, \mathrm{Pr}, \mathrm{Nd})_{1-x} \mathrm{Mg}_{\mathrm{X}} \mathrm{Al}_{0,1} \mathrm{Mn}_{0,1} \mathrm{Co}_{0,55} \mathrm{Ni}_{3,0}$ $(x=0,05-0,30)$

FIGURA 10. Capacidade de descarga em função do número de ciclos dos eletrodos negativo produzido com a liga $\mathrm{La}_{0,7} \mathrm{Mg}_{0,3} \mathrm{Ni}_{2,45} \mathrm{Co}_{0,75} \mathrm{Mn}_{0,1} \mathrm{Al}_{0,2}$

FIGURA 11. Fluxograma utilizado na hidrogenação das ligas metálicas.

FIGURA 12. Fluxograma utilizado para hidrogenação das ligas metálicas com elevação da temperatura a $500^{\circ} \mathrm{C}$ e resfriamento rápido.

FIGURA 13. (a) Liga metálica no estado bruto de fusão (b) $5 \mathrm{~g}$ da liga metálica utilizada na hidrogenação.

FIGURA 14. Sistema de vácuo utilizado na hidrogenação das ligas, onde: (a) forno (EDG), (b) vaso de hidrogenação, (c) bomba de vácuo mecânica, (d) medidor pirani e (e) válvula injeção de hidrogênio

FIGURA 15. Etapas para montagem das baterias de Ni-HM

FIGURA 16. Processo de fabricação do eletrodo negativo, onde: (a) pó da liga classificada $<45 \mu \mathrm{m}$, (b) mistura de $67 \%$ em massa de carbono de alta área superficial e $33 \%$ em massa de PTFE e (c) mistura composta pela liga metálica, PTFE e carbono de alta área superficial.

FIGURA 17. (a) Eletrodo positivo $(\mathrm{NiOH})_{2}$ (b) separador, retirados de baterias de Ni-HM comerciais da marca Sony modelo AA 2500 mAh. 
FIGURA 19. Etapas de montagem das baterias de Ni-HM.

FIGURA 20. Sistema experimental para estudo em célula eletroquímica; onde (1) representa a célula eletroquímica, (2) eletrodo de referência com $\mathrm{Hg} / \mathrm{HgO}$, (3) eletrodo de trabalho e (4) contra eletrodo (platina).

FIGURA 21. Equipamento de testes elétricos, onde: (a) canal de medidas, (b) analisador digital de quatro canais (Arbin BT4)

FIGURA 22. Curva da tensão em função do tempo utilizada para cálculo da resistência interna de uma bateria

FIGURA 23. Micrografias da liga $\mathrm{La}_{0,7} \mathrm{Pr}_{0,3} \mathrm{Al}_{0,3} \mathrm{Mn}_{0,4} \mathrm{Co}_{0,5} \mathrm{Ni}_{3,8}$; onde: (a) visão geral (500x) e (b) detalhada (1000x).

FIGURA 24. Micrografias da liga $\mathrm{La}_{0,6} \mathrm{Mg}_{0,1} \mathrm{Pr}_{0,3} \mathrm{Al}_{0,3} \mathrm{Mn}_{0,4} \mathrm{Co}_{0,5} \mathrm{Ni}_{3,8}$; onde: (a) visão geral (500x) e (b) detalhada (1000x).

FIGURA 25. Micrografias da liga $\mathrm{La}_{0,4} \mathrm{Mg}_{0,3} \mathrm{Pr}_{0,3} \mathrm{Al}_{0,3} \mathrm{Mn}_{0,4} \mathrm{Co}_{0,5} \mathrm{Ni}_{3,8}$; onde: (a) visão geral (500x) e (b) detalhada (1000x).

FIGURA 26. Micrografias da liga $\mathrm{La}_{0,2} \mathrm{Mg}_{0,5} \mathrm{Pr}_{0,3} \mathrm{Al}_{0,3} \mathrm{Mn}_{0,4} \mathrm{Co}_{0,5} \mathrm{Ni}_{3,8}$; onde: (a) visão geral (500x) e (b) detalhada (1000x).

FIGURA 27. Micrografias da liga $\mathrm{Mg}_{0,7} \mathrm{Pr}_{0,3} \mathrm{Al}_{0,3} \mathrm{Mn}_{0,4} \mathrm{Co}_{0,5} \mathrm{Ni}_{3,8}$; onde: (a) visão geral (500x) e (b) detalhada (1000x).

FIGURA 28.

Difratogramas de raios- $X$ das ligas $\mathrm{La}_{0,7}$

${ }_{x} \mathrm{Mg}_{\mathrm{x}} \mathrm{Pr}_{0,3} \mathrm{Al}_{0,3} \mathrm{Mn}_{0,4} \mathrm{Co}_{0,5} \mathrm{Ni}_{3,8}(\mathrm{x}=0$ a 0,7$)$.

FIGURA 29. Curvas da absorção de hidrogênio em função do tempo com pressão inicial de 0,2 $\mathrm{MPa}$, à temperatura ambiente, das ligas $\mathrm{La}_{0,7-x} \mathrm{Mg}_{\mathrm{x}} \mathrm{Pr}_{0,3} \mathrm{Al}_{0,3} \mathrm{Mn}_{0,4} \mathrm{Co}_{0,5} \mathrm{Ni}_{3,8}(\mathrm{x}=0$ a 0,7$)$.

FIGURA 30. Pós obtidos da liga $\mathrm{La}_{0,7} \mathrm{Pr}_{0,3} \mathrm{Al}_{0,3} \mathrm{Mn}_{0,4} \mathrm{Co}_{0,5} \mathrm{Ni}_{3,8}$ a $0,2 \mathrm{MPa}$ de pressão de hidrogênio a temperatura ambiente; onde: (a) visão geral (50x) e (b) visão detalhada (500x).

FIGURA 31. Curvas da absorção de hidrogênio em função do tempo com pressão inicial de $0,2 \mathrm{MPa}$, à temperatura inicial de $500{ }^{\circ} \mathrm{C}$, após resfriamento rápido, das ligas $\mathrm{La}_{0,7-x} \mathrm{Mg}_{\mathrm{x}} \mathrm{Pr}_{0,3} \mathrm{Al}_{0,3} \mathrm{Mn}_{0,4} \mathrm{Co}_{0,5} \mathrm{Ni}_{3,8}(\mathrm{x}$ $=0,1-0,7)$. 
FIGURA 32. Pós obtidos da liga $\mathrm{La}_{0,6} \mathrm{Mg}_{0,1} \mathrm{Pr}_{0,3} \mathrm{Al}_{0,3} \mathrm{Mn}_{0,4} \mathrm{Co}_{0,5} \mathrm{Ni}_{3,8}$ a $200 \mathrm{MPa}$ de hidrogênio a $500{ }^{\circ} \mathrm{C}$ com resfriamento rápido; onde: (a) visão geral (50x) e (b) visão detalhada (500x).

FIGURA 33. Liga La ${ }_{0,4} \mathrm{Mg}_{0,3} \mathrm{Pr}_{0,3} \mathrm{Al}_{0,3} \mathrm{Mn}_{0,4} \mathrm{Co}_{0,5} \mathrm{Ni}_{3,8}$ após a exposição a $0,2 \mathrm{MPa}$ de hidrogênio a $500{ }^{\circ} \mathrm{C}$ com resfriamento rápido; onde: (a) visão geral (50x) e (b) visão detalhada (500x).

FIGURA 34. Liga La $\mathrm{La}_{0,2} \mathrm{Mg}_{0,5} \mathrm{Pr}_{0,3} \mathrm{Al}_{0,3} \mathrm{Mn}_{0,4} \mathrm{Co}_{0,5} \mathrm{Ni}_{3,8}$ após a exposição a $0,2 \mathrm{MPa}$ de hidrogênio a $500{ }^{\circ} \mathrm{C}$ com resfriamento rápido; onde: (a) visão geral (50x) e (b) visão detalhada (500x).

FIGURA 35. Liga $\mathrm{Mg}_{0,7} \mathrm{Pr}_{0,3} \mathrm{Al}_{0,3} \mathrm{Mn}_{0,4} \mathrm{Co}_{0,5} \mathrm{Ni}_{3,8}$ após a exposição a $0,2 \mathrm{MPa}$ de hidrogênio a $500^{\circ} \mathrm{C}$ com resfriamento rápido; onde: (a) visão geral (50x) e (b) visão detalhada (500x).....

FIGURA 36. Curvas da absorção de hidrogênio a pressão de $1 \mathrm{MPa}$ em função do tempo à temperatura ambiente das ligas $\mathrm{La}_{0,7-x} \mathrm{Mg}_{\mathrm{x}}$ $\operatorname{Pr}_{0,3} \mathrm{Al}_{0,3} \mathrm{Mn}_{0,4} \mathrm{Co}_{0,5} \mathrm{Ni}_{3,8}(\mathrm{x}=0$ a 0,7$)$.

FIGURA 37. Pós obtidos da liga $\mathrm{La}_{0,7} \mathrm{Pr}_{0,3} \mathrm{Al}_{0,3} \mathrm{Mn}_{0,4} \mathrm{Co}_{0,5} \mathrm{Ni}_{3,8}$ a $1 \mathrm{MPa}$ de hidrogênio a temperatura ambiente; onde: (a) visão geral (50x) e (b) visão detalhada (500x).

FIGURA 38. Pós obtidos da liga $\mathrm{La}_{0,6} \mathrm{Mg}_{0,1} \mathrm{Pr}_{0,3} \mathrm{Al}_{0,3} \mathrm{Mn}_{0,4} \mathrm{Co}_{0,5} \mathrm{Ni}_{3,8}$ a $1 \mathrm{MPa}$ de hidrogênio a temperatura ambiente; onde: (a) visão geral (50x) e (b) visão detalhada (500x).

FIGURA 39. Pós obtidos da liga $\mathrm{La}_{0,4} \mathrm{Mg}_{0,3} \mathrm{Pr}_{0,3} \mathrm{Al}_{0,3} \mathrm{Mn}_{0,4} \mathrm{Co}_{0,5} \mathrm{Ni}_{3,8}$ a $1 \mathrm{MPa}$ de hidrogênio a temperatura ambiente; onde: (a) visão geral (50x) e (b) visão detalhada (500x).

FIGURA 40. Curva da absorção de hidrogênio de pressão $1 \mathrm{MPa}$ em função do tempo à temperatura de $500^{\circ} \mathrm{C}$ com resfriamento rápid o das ligas $\mathrm{La}_{0,7-x} \mathrm{Mg}_{\mathrm{x}} \mathrm{Pr}_{0,3} \mathrm{Al}_{0,3} \mathrm{Mn}_{0,4} \mathrm{Co}_{0,5} \mathrm{Ni}_{3,8}(\mathrm{x}=0,5$ e 0,7$)$.

FIGURA 41. Liga La $\mathrm{La}_{0,2} \mathrm{Mg}_{0,5} \mathrm{Pr}_{0,3} \mathrm{Al}_{0,3} \mathrm{Mn}_{0,4} \mathrm{Co}_{0,5} \mathrm{Ni}_{3,8}$ após a exposição a $10^{3} \mathrm{MPa}$ de hidrogênio a $500{ }^{\circ} \mathrm{C}$ com resfriamento rápido; onde: (a) visão geral (50x) e (b) visão detalhada (500x). 
FIGURA 42. Liga $\mathrm{Mg}_{0,7} \operatorname{Pr}_{0,3} \mathrm{Al}_{0,3} \mathrm{Mn}_{0,4} \mathrm{Co}_{0,5} \mathrm{Ni}_{3,8}$ após a exposição a $10^{3} \mathrm{MPa}$ de hidrogênio a $500{ }^{\circ} \mathrm{C}$ com resfriamento rápido; onde: (a) visão geral (50x) e (b) visão detalhada (500x)

FIGURA 43. Distribuição de tamanho de partícula obtida por CILAS para a liga $\mathrm{La}_{0,7} \mathrm{Pr}_{0,3} \mathrm{Al}_{0,3} \mathrm{Mn}_{0,4} \mathrm{Co}_{0,5} \mathrm{Ni}_{3,8}$, onde: (a) hidrogenação a pressão de $0,2 \mathrm{MPa}$ e (b) hidrogenação a pressão de $1 \mathrm{MPa}$

FIGURA 44. Distribuição de tamanho de partícula obtida por CILAS para a liga $\mathrm{La}_{0,6} \mathrm{Mg}_{0,1} \mathrm{Pr}_{0,3} \mathrm{Al}_{0,3} \mathrm{Mn}_{0,4} \mathrm{Co}_{0,5} \mathrm{Ni}_{3,8}$, onde: (a) hidrogenação a pressão de $0,2 \mathrm{MPa}$ a temperatura de $500^{\circ} \mathrm{C}$ e resfria mento rápido e (b) hidrogenação a pressão de $1 \mathrm{MPa}$ a temperatura ambiente.

FIGURA 45.

Distribuição de tamanho de partícula obtida por CILAS para a liga $\mathrm{La}_{0,4} \mathrm{Mg}_{0,3} \mathrm{Pr}_{0,3} \mathrm{Al}_{0,3} \mathrm{Mn}_{0,4} \mathrm{Co}_{0,5} \mathrm{Ni}_{3,8}$ a pressão de $1 \mathrm{MPa}$ a temperatura ambiente.

FIGURA 46. Capacidade de descarga dos 15 ciclos iniciais das baterias fabricadas com as ligas $\mathrm{La}_{0,7-x} \mathrm{Mg}_{\mathrm{x}} \mathrm{Pr}_{0,3} \mathrm{Al}_{0,3} \mathrm{Mn}_{0,4} \mathrm{Co}_{0,5} \mathrm{Ni}_{3,8}(\mathrm{x}=0 \mathrm{a}$ $0,7)$

FIGURA 47. Capacidade de descarga máxima obtidos das ligas as ligas La,7${ }_{x} \mathrm{Mg}_{\mathrm{x}} \mathrm{Pr}_{0,3} \mathrm{Al}_{0,3} \mathrm{Mn}_{0,4} \mathrm{Co}_{0,5} \mathrm{Ni}_{3,8}$ ( $x=0$ a 0,7) em função do aumento do teor de magnésio, onde: (a) mostra capacidade de descarga em mAh e (b) em mAhg ${ }^{-1}$

FIGURA 48. Capacidade de descarga em função do número de ciclos da bateria fabricada com a liga $\mathrm{La}_{0,7} \mathrm{Pr}_{0,3} \mathrm{Al}_{0,3} \mathrm{Mn}_{0,4} \mathrm{Co}_{0,5} \mathrm{Ni}_{3,8}$

FIGURA 49. Capacidade de descarga em função do número de ciclos da bateria fabricada com a liga $\mathrm{La}_{0,6} \mathrm{Mg}_{0,1} \mathrm{Pr}_{0,3} \mathrm{Al}_{0,3} \mathrm{Mn}_{0,4} \mathrm{Co}_{0,5} \mathrm{Ni}_{3,8}$

FIGURA 50. Capacidade de descarga em função do número de ciclos da bateria fabricada com a liga $\mathrm{La}_{0,4} \mathrm{Mg}_{0,3} \mathrm{Pr}_{0,3} \mathrm{Al}_{0,3} \mathrm{Mn}_{0,4} \mathrm{Co}_{0,5} \mathrm{Ni}_{3,8}$

FIGURA 51. Capacidade de descarga em função do número de ciclos da bateria fabricada com a liga $\mathrm{La}_{0,2} \mathrm{Mg}_{0,5} \mathrm{Pr}_{0,3} \mathrm{Al}_{0,3} \mathrm{Mn}_{0,4} \mathrm{Co}_{0,5} \mathrm{Ni}_{3,8}$

FIGURA 52. Capacidade de descarga em função do número de ciclos da bateria fabricada com a liga $\mathrm{Mg}_{0,7} \mathrm{Pr}_{0,3} \mathrm{Al}_{0,3} \mathrm{Mn}_{0,4} \mathrm{Co}_{0,5} \mathrm{Ni}_{3,8}$ 
FIGURA 53. Retenção da capacidade de descarga no ciclo $100\left(\mathrm{C}_{100}\right) \mathrm{em}$ função do aumento do teor de magnésio nas ligas $\operatorname{La}_{0,7-x} M_{g_{x}}$ $\operatorname{Pr}_{0,3} \mathrm{Al}_{0,3} \mathrm{Mn}_{0,4} \mathrm{Co}_{0,5} \mathrm{Ni}_{3,8}(\mathrm{x}=0$ a 0,7$)$.

FIGURA 54. Resistência interna inicial $\left(R_{\text {in }}\right.$ Inicial) e resistência interna final $\left(R_{\text {in }}\right.$ Final) em função do número de ciclos para a bateria fabricada com a liga $\mathrm{La}_{0,7} \mathrm{Pr}_{0,3} \mathrm{Al}_{0,3} \mathrm{Mn}_{0,4} \mathrm{Co}_{0,5} \mathrm{Ni}_{3,8}$

FIGURA 55. Resistência interna inicial $\left(R_{\text {in }}\right.$ Inicial) e resistência interna final $\left(R_{\text {in }}\right.$ Final) em função do número de ciclos para a bateria fabricada com a liga $\mathrm{La}_{0,6} \mathrm{Mg}_{0,1} \mathrm{Pr}_{0,3} \mathrm{Al}_{0,3} \mathrm{Mn}_{0,4} \mathrm{Co}_{0,5} \mathrm{Ni}_{3,8}$.

FIGURA 56. Resistência interna inicial $\left(R_{\text {in }}\right.$ Inicial) e resistência interna final $\left(R_{\text {in }}\right.$ Final) em função do número de ciclos para a bateria fabricada com a liga $\mathrm{La}_{0,4} \mathrm{Mg}_{0,3} \mathrm{Pr}_{0,3} \mathrm{Al}_{0,3} \mathrm{Mn}_{0,4} \mathrm{Co}_{0,5} \mathrm{Ni}_{3,8} \ldots$

FIGURA 57. Resistência interna inicial $\left(R_{\text {in }}\right.$ Inicial) e resistência interna final $\left(R_{\text {in }}\right.$ Final) em função do número de ciclos para a bateria fabricada com a liga $\mathrm{La}_{0,2} \mathrm{Mg}_{0,5} \mathrm{Pr}_{0,3} \mathrm{Al}_{0,3} \mathrm{Mn}_{0,4} \mathrm{Co}_{0,5} \mathrm{Ni}_{3,8}$.

FIGURA 58. Resistência interna inicial ( $R_{\text {in }}$ Inicial) e resistência interna final $\left(R_{\text {in }}\right.$ Final) em função do número de ciclos para a bateria fabricada com a liga $\mathrm{Mg}_{0,7} \mathrm{Pr}_{0,3} \mathrm{Al}_{0,3} \mathrm{Mn}_{0,4} \mathrm{Co}_{0,5} \mathrm{Ni}_{3,8}$

FIGURA 59. Variação da resistência interna $\left(\Delta \mathrm{R}_{\text {interna }}\right)$ e resistência interna média ( $R_{\text {interna }}$ Média) em função do número de ciclos da bateria fabricada com a liga $\mathrm{La}_{0,7} \mathrm{Pr}_{0,3} \mathrm{Al}_{0,3} \mathrm{Mn}_{0,4} \mathrm{Co}_{0,5} \mathrm{Ni}_{3,8}$.

FIGURA 60. Variação da resistência interna $\left(\Delta R_{\text {interna }}\right)$ e resistência interna

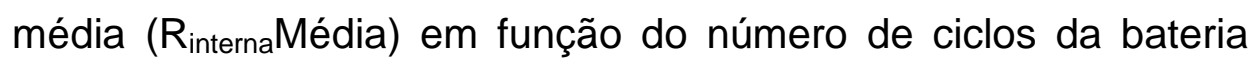
fabricada com a liga $\mathrm{La}_{0,6} \mathrm{Mg}_{0,1} \mathrm{Pr}_{0,3} \mathrm{Al}_{0,3} \mathrm{Mn}_{0,4} \mathrm{Co}_{0,5} \mathrm{Ni}_{3,8}$

FIGURA 61. Variação da resistência interna $\left(\Delta R_{\text {interna }}\right)$ e resistência interna média ( $R_{\text {interna }}$ Média) em função do número de ciclos da bateria fabricada com a liga $\mathrm{La}_{0,4} \mathrm{Mg}_{0,3} \mathrm{Pr}_{0,3} \mathrm{Al}_{0,3} \mathrm{Mn}_{0,4} \mathrm{Co}_{0,5} \mathrm{Ni}_{3,8}$

FIGURA 62. Variação da resistência interna $\left(\Delta R_{\text {interna }}\right)$ e resistência interna média ( $R_{\text {interna }}$ Média) em função do número de ciclos da bateria fabricada com a liga $\mathrm{La}_{0,2} \mathrm{Mg}_{0,5} \mathrm{Pr}_{0,3} \mathrm{Al}_{0,3} \mathrm{Mn}_{0,4} \mathrm{Co}_{0,5} \mathrm{Ni}_{3,8}$ 
FIGURA 63. Variação da resistência interna $\left(\Delta R_{\text {internaa }}\right)$ e resistência interna

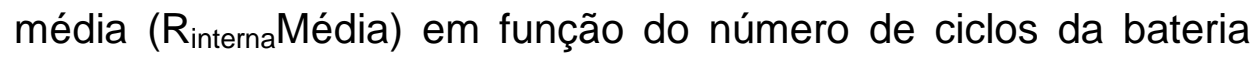
fabricada com a liga $\mathrm{Mg}_{0,7} \mathrm{Pr}_{0,3} \mathrm{Al}_{0,3} \mathrm{Mn}_{0,4} \mathrm{Co}_{0,5} \mathrm{Ni}_{3,8}$

FIGURA 64. Capacidade de descarga em função do número de ciclos para a liga $\mathrm{La}_{0,7} \mathrm{Pr}_{0,3} \mathrm{Al}_{0,3} \mathrm{Mn}_{0,4} \mathrm{Co}_{0,5} \mathrm{Ni}_{3,8}$ moída mecanicamente e hidrogenada a $1 \mathrm{MPa}$.

FIGURA 65. Capacidade de descarga em função do número de ciclos para a liga $\mathrm{La}_{0,7} \mathrm{Mg}_{0,1} \mathrm{Pr}_{0,3} \mathrm{Al}_{0,3} \mathrm{Mn}_{0,4} \mathrm{Co}_{0,5} \mathrm{Ni}_{3,8}$ moída mecanicamente e hidrogenada a $1 \mathrm{MPa}$.

FIGURA 66. Capacidade de descarga em função do número de ciclos para a liga $\mathrm{La}_{0,4} \mathrm{Mg}_{0,3} \mathrm{Pr}_{0,3} \mathrm{Al}_{0,3} \mathrm{Mn}_{0,4} \mathrm{Co}_{0,5} \mathrm{Ni}_{3,8}$ moída mecanicamente e hidrogenada.

FIGURA 67. Eletrodo negativo fabricado com a liga $\mathrm{La}_{0,4} \mathrm{Mg}_{0,3} \mathrm{Pr}_{0,3} \mathrm{Al}_{0,3} \mathrm{Mn}_{0,4} \mathrm{Co}_{0,5} \mathrm{Ni}_{3,8}$ moída mecanicamente, antes da ciclagem (0 ciclos); onde: (a) visão geral $(250 \mathrm{x})$ e (b) visão detalhada (500x).

FIGURA 68. Eletrodo negativo fabricado com a liga $\mathrm{La}_{0,4} \mathrm{Mg}_{0,3} \mathrm{Pr}_{0,3} \mathrm{Al}_{0,3} \mathrm{Mn}_{0,4} \mathrm{Co}_{0,5} \mathrm{Ni}_{3,8}$ moída mecanicamente após 50 ciclos de carga e descarga; onde: (a) visão geral (250x) e (b) visão detalhada (500x).

FIGURA 69. Eletrodo negativo fabricado com a liga $\mathrm{La}_{0,4} \mathrm{Mg}_{0,3} \mathrm{Pr}_{0,3} \mathrm{Al}_{0,3} \mathrm{Mn}_{0,4} \mathrm{Co}_{0,5} \mathrm{Ni}_{3,8}$ hidrogenada a $10^{3} \mathrm{MPa}$, antes da ciclagem (0 ciclos); onde: (a) visão geral $(250 \mathrm{x})$ e (b) visão detalhada (500x).

FIGURA 70. Eletrodo negativo fabricado com a liga $\mathrm{La}_{0,4} \mathrm{Mg}_{0,3} \mathrm{Pr}_{0,3} \mathrm{Al}_{0,3} \mathrm{Mn}_{0,4} \mathrm{Co}_{0,5} \mathrm{Ni}_{3,8}$ hidrogenada a $10^{3} \mathrm{MPa}$, após 50 ciclos de carga e descarga; onde: (a) visão geral (250x) e (b) visão detalhada (500x).

FIGURA 71. Capacidade de descarga em função do número de ciclos dos eletrodos negativos das ligas $\mathrm{La}_{0,7-x} \mathrm{Mg}_{\mathrm{x}} \mathrm{Pr}_{0,3} \mathrm{Al}_{0,3} \mathrm{Mn}_{0,4} \mathrm{Co}_{0,5} \mathrm{Ni}_{3,8}(\mathrm{x}=$ 0 a 0,5 ) realizadas em célula eletroquímica.

FIGURA 72. Eletrodo negativo, em célula eletroquímica, fabricado com a liga sem magnésio, antes da ciclagem; onde: (a) visão geral (250x) e (b) visão detalhada (500x). 
FIGURA 73. Eletrodo negativo, em célula eletroquímica, fabricado com a liga sem magnésio, após 15 ciclos de carga e descarga; onde: (a) visão geral (250x) e (b) visão detalhada (500x).

FIGURA 74. Eletrodo negativo, em célula eletroquímica, fabricado com a liga $\mathrm{Mg}_{0,5}$, antes da ciclagem; onde: (a) visão geral (250x) e (b) visão detalhada (500x)

FIGURA 75. Eletrodo negativo, em célula eletroquímica, fabricado com a liga $\mathrm{Mg}_{0,5}$, após 15 ciclos de carga e descarga; onde: (a) visão geral (250x) e (b) visão detalhada (500x) 


\section{SUMÁRIO}

Página

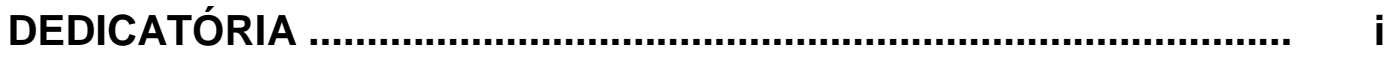

AGRADECIMENTOS …............................................................ ii

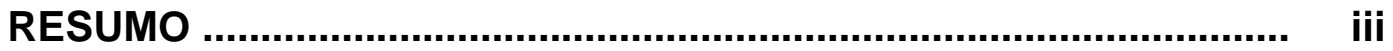

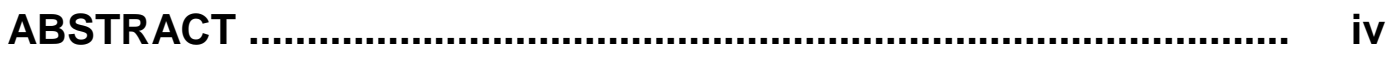

ÍNDICE DE TABELAS ….........................................................

ÍNDICE DE FIGURAS .................................................................. vii

1. INTRODUÇÃO .................................................................... 1

1.1 Economia do Hidrogênio ........................................................ 1

1.2 Estocagem de hidrogênio em metais ......................................... 2

1.3 Baterias de níquel hidreto metálico (Ni-HM) ............................... 2

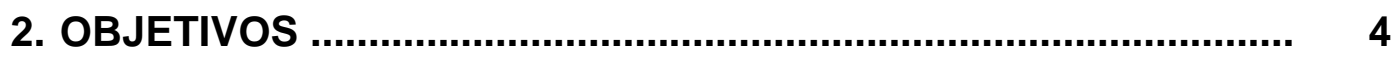

3. REVISÃO BIBLIOGRÁFICA …….......................................... 5

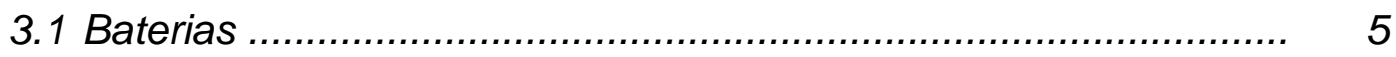

3.2 Componentes das Baterias de Ni-HM ...................................... 6

3.3 Mecanismos de reações das baterias de Ni-HM .......................... 7

3.4 Hidretos metálicos em baterias de Ni-HM................................... 9

3.5 Performance de uma bateria de Ni-HM..................................... 11

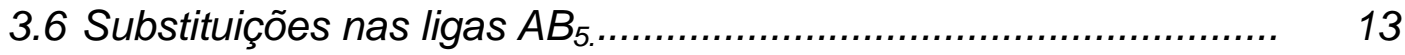

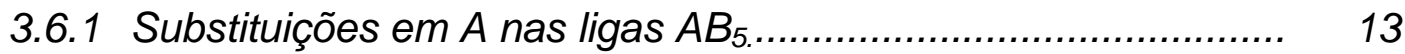

3.6.1.1 Efeito do Praseodímio e Neodímio........................................ 13

3.6.1.2 Efeito do Cério............................................................... 16

3.6.1.3 Efeito do Titânio e Zircônio..................................................... 17

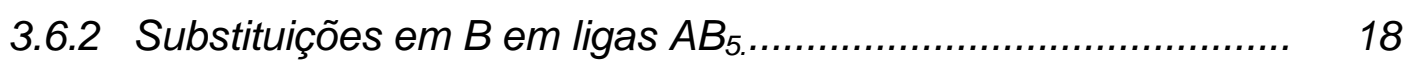


3.6.2.1 Efeito do manganês........................................................... 18

3.6.2.2 Efeito do cobalto.............................................................. 21

3.6.2.3 Efeito do alumínio........................................................... 23

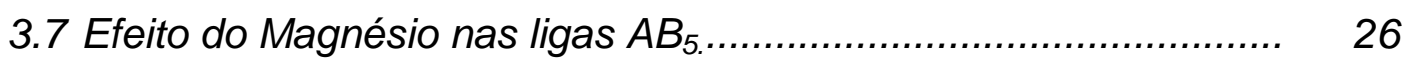

3.7.1 Tratamento térmico em ligas com magnésio............................ $\quad 30$

3.8 Capacidade de descarga em baterias de Ni-HM.......................... 32

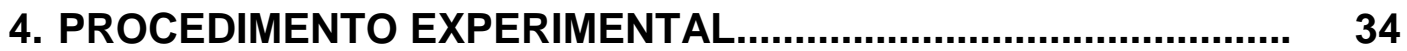

4.1 Caracterização das ligas metálicas............................................. 34

4.1.1 Microscopia eletrônica de varredura......................................... 34

4.1.2 Difração de raios-X.......................................................... 35

4.1.3 Distribuição do tamanho de partículas - CILAS........................ 35

4.2 Hidrogenação das ligas metálicas.............................................. 36

4.3 Montagem das baterias de Ni-HM........................................ 40

4.3.1 Fabricação do eletrodo negativo............................................. 40

4.3.2 Montagem da bateria de Ni-HM.......................................... 42

4.3.2.1 Célula eletroquímica........................................................ 45

4.3.3 Testes elétricos................................................................ 45

4.4 Resistência Interna.............................................................. 48

5. RESULTADOS E DISCUSSÃO.................................................

5.1 Composição das ligas............................................................. 50

5.2 Caracterização microestrutural................................................ 50

5.3 Hidrogenação das ligas.......................................................... 61

5.4 Capacidade de descarga para baterias seladas............................ 78

5.5 Influência da hidrogenação nas baterias de Ni-HM...................... 92

5.6 Capacidade de descarga para célula eletroquímica....................... 99

6. CONCLUSÕES............................................................................ 106

7. REFERENCIAS BIBLIOGRÁFICAS............................................. 108 


\section{INTRODUÇÃO}

\subsection{Economia do Hidrogênio}

O hidrogênio é uma fonte altamente promissora de energia, especialmente quando se leva em conta a diminuição do abastecimento de energia por fontes não renováveis e o aumento da preocupação com o meio ambiente, devido à poluição, é levado em consideração.

Existem recursos para produção de hidrogênio em abundância. A eletrólise da água, por exemplo, é uma tecnologia que existe há mais de um século e apresenta vantagens como a utilização da água como principal insumo e a inexistência de emissões quando a fonte de energia elétrica é a hidroeletricidade ou as fontes renováveis.

Duas excelentes vantagens que tornam mais atraente a energia do hidrogênio são:

1. O hidrogênio possui maior densidade de energia por unidade de peso do que outros elementos químicos.

2. O hidrogênio não polui nossa atmosfera durante a combustão porque seu subproduto é a água.

Além disso, o hidrogênio possui uma vasta variedade de usos práticos, como por exemplo, células a combustível, motores térmicos, etc. No entanto, seu transporte e armazenamento continuam a ser um grande problema para utilização técnicas móveis e estacionárias [2].

Os hidretos metálicos, por exemplo, podem absorver hidrogênio pressurizado e depois liberá-lo em ambiente por aplicação de calor. Alguns destes materiais, como compostos de ferro-titânio ou de lantânio-níquel e ligas à base de magnésio podem guardar mais hidrogênio atômico que o equivalente contentor criogênico do mesmo volume, sem a necessidade de refrigerá-lo [1,2]. 
Sendo assim, verifica-se ainda a necessidade de investigações adicionais referente aos hidretos metálicos para explorar o potencial de armazenamento e o seu uso conveniente [2].

\subsection{Estocagem de hidrogênio em metais}

Atualmente existem ligas metálicas que possuem a capacidade de absorver hidrogênio e condições normais de temperatura e pressão, formando os hidretos metálicos [2].

As vantagens do armazenamento utilizando hidretos metálicos estão no fato de que o hidrogênio passa a fazer parte da estrutura do metal e assim não precisa de altíssimas pressões ou estar no estado criogênico para operar.

Há muitos tipos de hidretos metálicos, como por exemplo, as ligas a base de $\mathrm{LaNi}_{5}$. Esta liga foi inicialmente estudada em 1969, nos laboratórios da Philips. Os estudos mostraram as boas propriedades do armazenamento de hidrogênio em ligas do tipo $\mathrm{LaNi}_{5}$, chamando a atenção de muitos cientistas sobre o armazenamento de hidrogênio com alta capacidade e boa reversibilidade, à temperatura ambiente [3].

\subsection{Baterias de níquel hidreto metálico (Ni-HM)}

A importância do estudo em combustíveis alternativos é importante devido a alguns fatores, como o aumento do preço e a escassez dos combustíveis fósseis.

As baterias são uma forma alternativa aos combustíveis fósseis, que têm sido estudadas há vários anos visando o melhoramento do seu desempenho.

Raramente é possível encontrar um produto que possa funcionar idealmente para toda e qualquer aplicação. O mesmo vale para as baterias. Existem diversos tipos de baterias diferentes e cada tipo oferece diferentes características.

As baterias de Ni-HM empregam ligas formadoras de hidreto metálico, como ânodo em um de seus componentes, oferecendo melhorias significativas sobre as baterias recarregáveis convencionais, em termos de desempenho e meio ambiente $[4,5]$. Além das vantagens ambientais, oferecem mais energia por 
unidade de volume que as baterias de níquel cádmio (Ni-Cd) [6]. Embora as baterias de íons de lítio (Li-íon) e as baterias de lítio polímero (Li-íon polímero) apresentem diversas vantagens, tais como a alta tensão e alta densidade de energia, não podem ser trabalhadas sem um controle eletrônico por razões de segurança. A TAB. 1 compara as características das cinco principais baterias do mercado mundial $[7,8]$.

TABELA 1 - Características das principais baterias do mercado mundial.

\begin{tabular}{lcccc}
\hline & Ni-Cd & Ni-HM & Li-íon & $\begin{array}{c}\text { Li-íon } \\
\text { polímero }\end{array}$ \\
\hline Densidade energia (Wh/kg) & $45-80$ & $60-120$ & $110-160$ & $100-130$ \\
Duração (ciclos) & $>300$ & $>500$ & $>1000$ & $>1000$ \\
Tempo de carga & $10-14 \mathrm{~h}$ & $2-5 \mathrm{~h}$ & $2-5 \mathrm{~h}$ & $1-2 \mathrm{~h}$ \\
Tensão nominal & $1,25 \mathrm{~V}$ & $1,25 \mathrm{~V}$ & $3,6 \mathrm{~V}$ & $3,6 \mathrm{~V}$ \\
Custo (US\$) & 50 & 60 & 100 & 100 \\
Taxa de descarga/mês & $30 \%$ & $20 \%$ & $20 \%$ & $10 \%$ \\
Modelo cilíndrico & $\mathrm{Sim}$ & $\mathrm{Sim}$ & $\mathrm{Sim}$ & $\mathrm{Não}$ \\
Modelo Prismático & $\mathrm{Sim}$ & $\mathrm{Sim}$ & $\mathrm{Sim}$ & $\mathrm{Sim}$ \\
Ano uso comercial & 1950 & 1990 & 1991 & 1999 \\
\hline
\end{tabular}

A TAB. 1 mostra que as baterias de Ni-HM são superiores as baterias de Ni-Cd em relação a duração e densidade de energia, mas mostram-se inferiores as baterias de Li-íon e Li-íon polímero.

As vantagens das baterias de Ni-HM em relação a sua concorrente Liíons é o custo. Outro fator importante é que sua alta densidade de energia requer alguns cuidados como: evitar curtos-circuitos, sobrecargas, esmagamento, exposição a altas temperaturas ou desmontar. Sua ruptura pode causar a combustão, além de o eletrólito ser altamente inflamável. O circuito de controle das baterias de Li-íon e das baterias de Li-íon polímero torna o custo de fabricação destas baterias elevado [8]. 


\section{OBJETIVOS}

O objetivo principal deste trabalho é estudar e caracterizar as ligas metálicas $\mathrm{La}_{0,7-x} \mathrm{Mg}_{\mathrm{x}} \mathrm{Pr}_{0,3} \mathrm{Al}_{0,3} \mathrm{Mn}_{0,4} \mathrm{Co}_{0,5} \mathrm{Ni}_{3,8}(\mathrm{x}=0$ a 0,7 ), no estado bruto de fusão, bem como fabricar as baterias de níquel - hidreto metálico (Ni-HM) produzidas com as respectivas ligas. Será realizado a hidrogenação destas ligas utilizando pressões de 0,2 $\mathrm{MPa}$ (2 bar) e $1 \mathrm{MPa}$ (10 bar) de hidrogênio. Será feito um estudo comparativo entre as baterias fabricadas seladas e os eletrodos fabricados em célula eletroquímica com as respectivas ligas deste trabalho.

As ligas metálicas serão caracterizadas por microscopia eletrônica de varredura, espectroscopia de energia dispersiva (EDS) e difração de raios-X para determinar as fases presentes e correlacionar estes resultados com a caracterização elétrica das baterias de Ni-HM. 


\section{REVISÃo BIBLIOGRÁFICA}

\subsection{Baterias}

Uma bateria é um dispositivo que converte energia química, contida em seus materiais ativos, diretamente em energia elétrica por meio de uma reação de oxidação-redução (redox). No caso de um sistema recarregável, a bateria é recarregada pela inversão do processo. Este tipo de reação envolve a transferência de elétrons de um material para outro por meio de um circuito elétrico.

Bateria é um dispositivo que converte energia química em energia elétrica, não sujeita à limitação do ciclo de Carnot ditada pela segunda lei da termodinâmica.

Podemos classificar as pilha, baterias e células eletroquímicas em:

- Primárias (não recarregáveis);

- Secundárias (recarregáveis)

- Células a combustível (alimentação externa).

Os três principais componentes de uma bateria são:

1. Ânodo é o eletrodo negativo das baterias ou eletrodo de redução, ou seja, cede elétrons para um circuito externo e é oxidado durante a reação eletroquímica.

2. Cátodo é eletrodo positivo das baterias ou eletrodo de oxidação, ou seja, recebe os elétrons de um circuito externo e é reduzido durante a reação eletroquímica.

3. Eletrólito é o condutor iônico, fornece meios de transferência de carga dentro das baterias entre o ânodo e o cátodo [9]. 


\subsection{Componentes das Baterias de Ni-HM}

As baterias de Ni-HM são classificadas como uma bateria secundária. O ânodo utilizado é a base de uma liga de armazenamento de hidrogênio junto a uma mistura contendo negro de fumo ("Carbon Black") e politetrafluoretileno (PTFE) e o cátodo a base de hidróxido de níquel $\left(\mathrm{NiOH}_{2}\right)$. O eletrólito empregado neste tipo de bateria é o hidróxido de potássio $(\mathrm{KOH})$.

As baterias de Ni-HM são produzidas em três diferentes geometrias: cilíndrica, prismática e botão. A construção em formato cilíndrico é a mais conhecida e utilizada comercialmente. Esta forma é feita por meio de uma embalagem metálica que envolve os eletrodos positivo, negativo e o separador. 0 eletrólito é injetado no separador.

Na FIG. 1 está mostrada uma imagem do sistema interno de uma bateria de Ni-HM cilíndrica do tipo "AA".

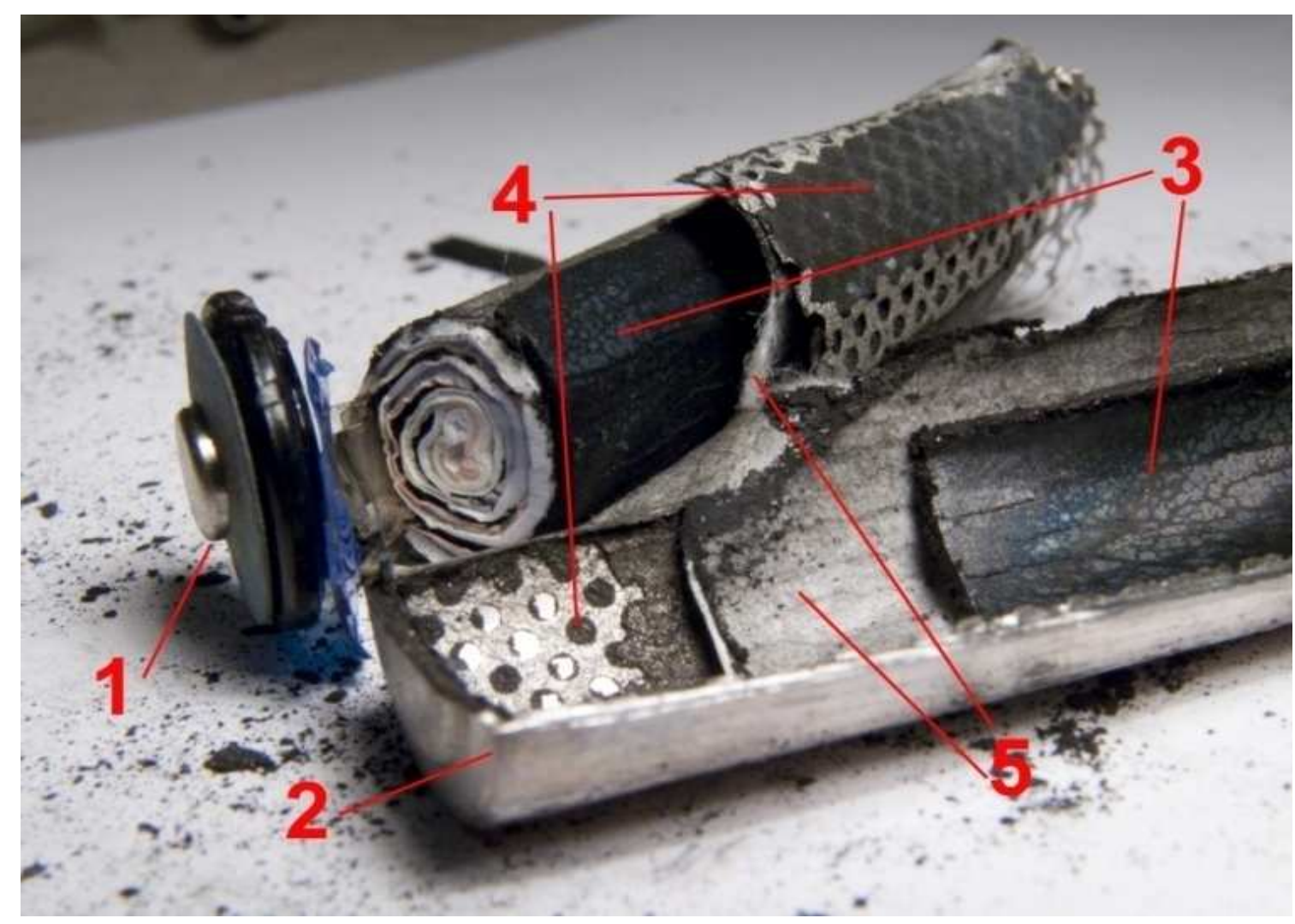

FIGURA 1 - Sistema interno de uma bateria de Ni-HM cilíndrica do tipo "AA", onde: 1 - contato positivo, 2 - carcaça metálica (contato negativo), 3 - eletrodo positivo, 4 - eletrodo negativo com coletor de corrente (tela de níquel conectada a carcaça) e 5 - separador entre os eletrodos. 


\subsection{Mecanismos de reações das baterias de $\mathrm{Ni}-\mathrm{HM}$}

O eletrodo negativo é composto por ligas metálicas que possuem propriedades de armazenar hidrogênio de forma reversível, absorvendo e dessorvendo íons de hidrogênio quando ocorre o processo de carga/descarga das baterias.

No processo de carga de uma bateria de Ni-HM, no eletrodo positivo ocorre a combinação do $\mathrm{Ni}(\mathrm{OH})_{2}$ com o hidróxido $\left(\mathrm{OH}^{-}\right)$do eletrólito, gerando o oxihidróxido de níquel $(\mathrm{NiOOH})$, água $\left(\mathrm{H}_{2} \mathrm{O}\right)$ e um elétron $\left(\mathrm{e}^{-}\right)$. No eletrodo negativo, a liga metálica $(\mathrm{M})$, a água do eletrólito e o elétron interagem para produzir o hidreto metálico $(\mathrm{MH})$.

No processo de descarga da bateria de Ni-HM as reações químicas são inversas das que ocorrem no processo de carga. O hidrogênio armazenado no hidreto metálico é liberado no eletrólito para formar água. A água do eletrólito libera um íon de hidrogênio que é absorvido pelo eletrodo positivo formando $\mathrm{Ni}(\mathrm{OH})_{2}$

As Eq. 1.1 e 1.2 mostram reações químicas reversíveis que ocorrem na carga e descarga do eletrodo positivo e negativo, respectivamente, e na Eq. $1.3 \mathrm{a}$ reação global da bateria de Ni-HM (e o potencial de cada reação):

$$
\begin{array}{ll}
\mathrm{Ni}(\mathrm{OH})_{2}+\mathrm{OH}^{-} \stackrel{\text { carga/descarga }}{\Longleftrightarrow} \mathrm{NiOOH}+\mathrm{H}_{2} \mathrm{O} & \mathrm{E}_{0}=0,52 \mathrm{~V} \\
\mathrm{M}+\mathrm{H}_{2} \mathrm{O}+\mathrm{e}^{-} \stackrel{\text { carga/descarga }}{\Longleftrightarrow} \mathrm{MH}+\mathrm{OH}^{-} & \mathrm{E}_{0}=0,83 \mathrm{~V} \\
\mathrm{M}+\mathrm{Ni}(\mathrm{OH})_{2} \stackrel{\text { carga/descarga }}{\Longleftrightarrow} \mathrm{MH}+\mathrm{NiOOH} & \mathrm{E}_{0}=1,35 \mathrm{~V}
\end{array}
$$


Na FIG. 2 estão mostradas esquematicamente as reações que ocorrem na carga e descarga de uma bateria de Ni-HM que facilita a compreensão do processo de absorção/dessorção do hidrogênio na liga metálica do eletrodo negativo.

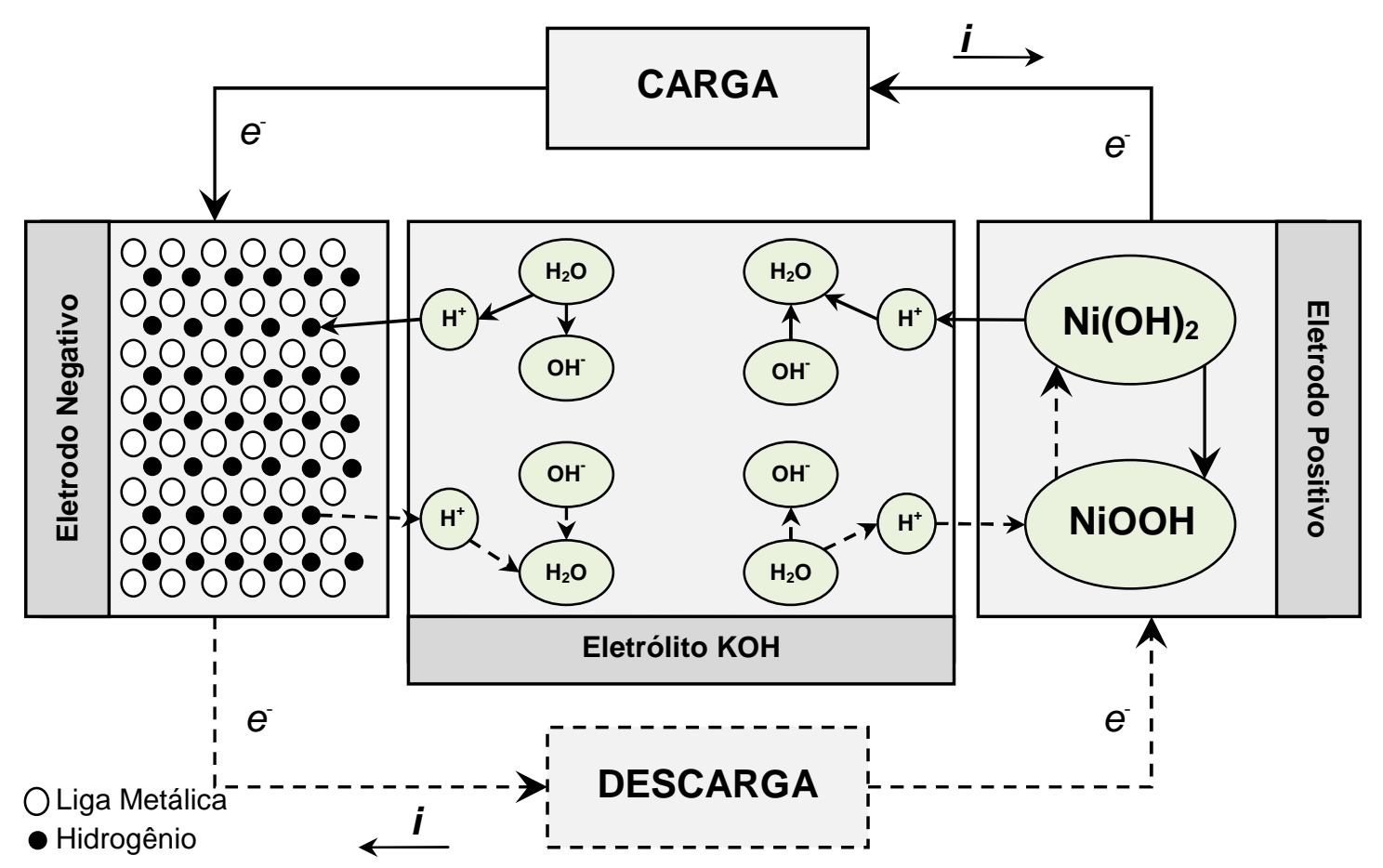

FIGURA 2 - Diagrama do funcionamento de uma bateria de Ni-HM [10].

A FIG. 2 mostra que no processo de carga, o átomo de hidrogênio dissocia do $\mathrm{Ni}(\mathrm{OH})_{2}$ e é absorvido pela liga metálica. No processo de descarga, o átomo de hidrogênio é liberado da liga metálica e reage com $\mathrm{NiOOH}$ para formar $\mathrm{Ni}(\mathrm{OH})_{2}$. 


\subsection{Hidretos metálicos em baterias de Ni-HM}

O componente fundamental das baterias de $\mathrm{Ni}-\mathrm{HM}$ são as ligas de armazenamento de hidrogênio. A composição da liga é formulada para que a bateria possa obter a maior capacidade de descarga e uma alta estabilidade de ciclos de carga - descarga.

Dois tipos de ligas metálicas são geralmente utilizados. A primeira são as compostas de lantânio e níquel ( $\left.\mathrm{LaNi}_{5}\right)$ conhecidas como ligas da classe $A B_{5}$. $A$ segunda são do tipo $A B_{2}$, onde tanto a parte $A$ quanto a parte $B$ podem ser um metal de transição, sendo apresentados em geral como $\mathrm{ZrNi}_{2}$.

Em ambos os casos, os metais são substituídos por outros com a finalidade de melhorar as características de desempenho. Estas substituições são os principais métodos de desenvolvimento de novas ligas de armazenamento de hidrogênio.

No caso das ligas tipo $A B_{5}$, algumas substituições melhoram as baterias na seguinte forma $[11,12]$ :

1. $\mathrm{Ce}, \mathrm{Nd}, \mathrm{Pr}, \mathrm{Gd}$ e $\mathrm{Y}$ foram utilizados estudados antigamente (19941997) substituindo o lantânio puro por outras terras raras, para redução de custos. Atualmente esta redução de custos é feita através da mistura de varias terras raras ("Mischmetal").

2. Al, Ti, Zr, Si e Co são utilizados como substitutos do Ni para diminuir a corrosão resultando em uma maior estabilidade e maior duração.

3. Mg é utilizado para promover aumento na capacidade de descarga das baterias.

No caso de ligas tipos $A B_{2}$ são [13]:

1. $\mathrm{V}, \mathrm{Ti}, \mathrm{Zr}$ são responsáveis pelo melhoramento no armazenamento do hidrogênio.

2. Ni e $\mathrm{Cr}$ são os principais constituintes que diminuem a corrosão e oferecem um melhor desempenho.

$\mathrm{O}$ desempenho das baterias de Ni-HM é determinado por alguns parâmetros, como a capacidade de descarga e o numero de ciclos das baterias. Estes parâmetros dependem da liga $\left(A_{5}\right.$ ou $\left.A B_{2}\right)$ que vai ser utilizado como material ativo do eletrodo negativo das baterias de Ni-HM. As características eletroquímicas podem ser alteradas dependendo do tipo de liga que será utilizado e também das substituições dos elementos para aperfeiçoar seu desempenho. 
Ligas do tipo $A B_{5}$ são significativamente mais comuns, apesar de possuírem menor capacidade de armazenamento de hidrogênio em relação às do tipo $A_{2}$ (320 vs $440 \mathrm{mAng}^{-1}$ ) [9]. A TAB. 2 mostra as principais características das ligas do tipo $A B_{2}$ e $A B_{5}$.

TABELA 2 - Vantagens e desvantagens do uso de ligas do tipo $A B_{2}$ e $A B_{5}$ em baterias de Ni-HM.

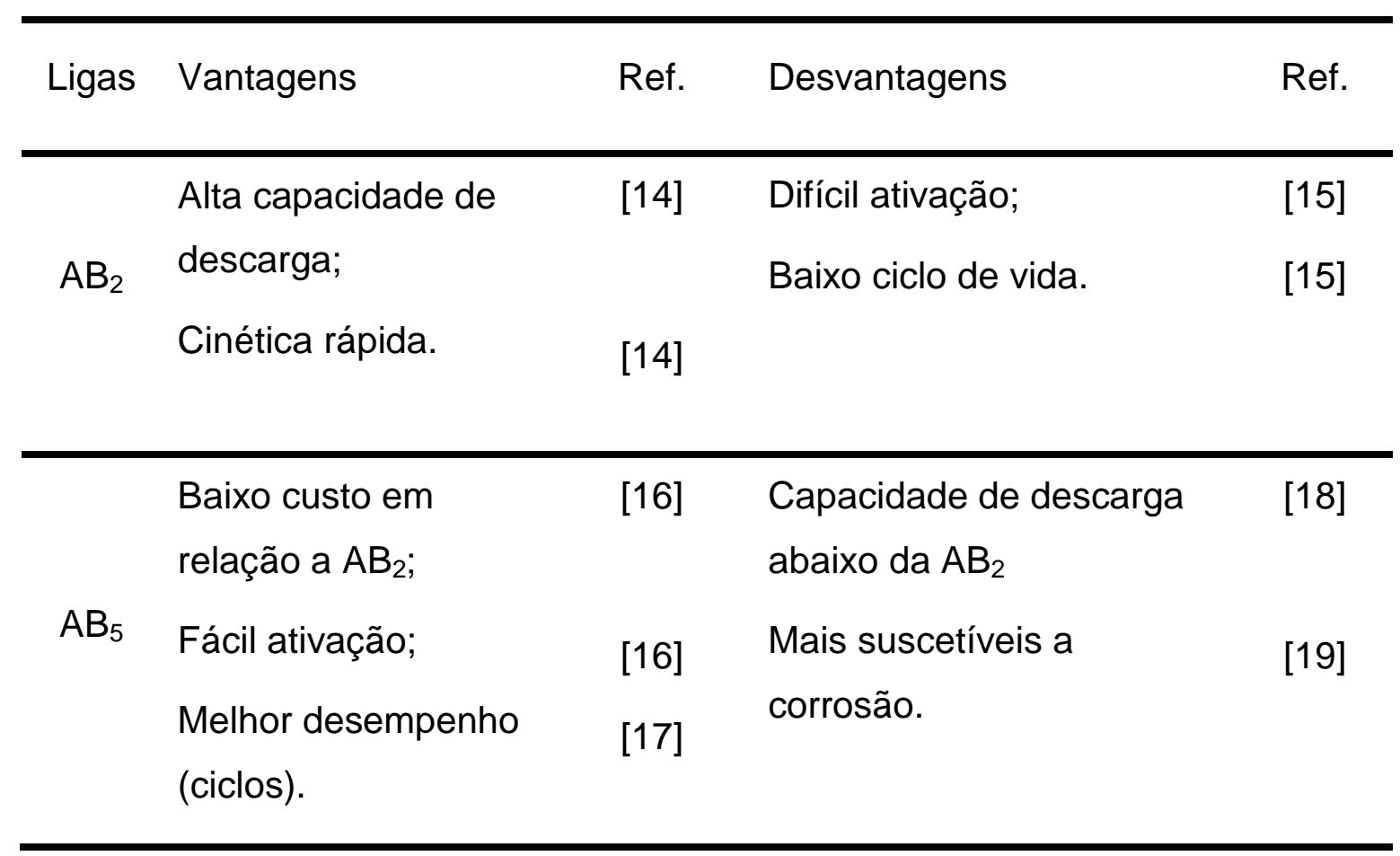




\subsection{Desempenho de uma bateria de Ni-HM}

Os estudos envolvendo a melhoria no desempenho das baterias de $\mathrm{Ni}$ HM visam principalmente adequar as necessidades dos produtos eletrônicos, principalmente aqueles que exigem tensão estável por longos períodos de operação.

A capacidade de uma bateria é a quantidade de energia que a mesma pode oferecer em condições específicas. É representado por ampéres-horas (Ah) ou ampéres-hora/grama $(\mathrm{Ah} / \mathrm{g})$. Neste último caso, indica que um grama do material ativo do eletrodo negativo (liga de hidreto metálico) pode fornecer uma quantidade de corrente por um determinado período de tempo. Uma bateria de 50 Ah pode fornecer 50 ampéres por 1 hora ou 5 ampéres por 10 horas, por exemplo.

A FIG. 3 mostra o perfil de descarga de uma típica bateria de Ni-HM [20].

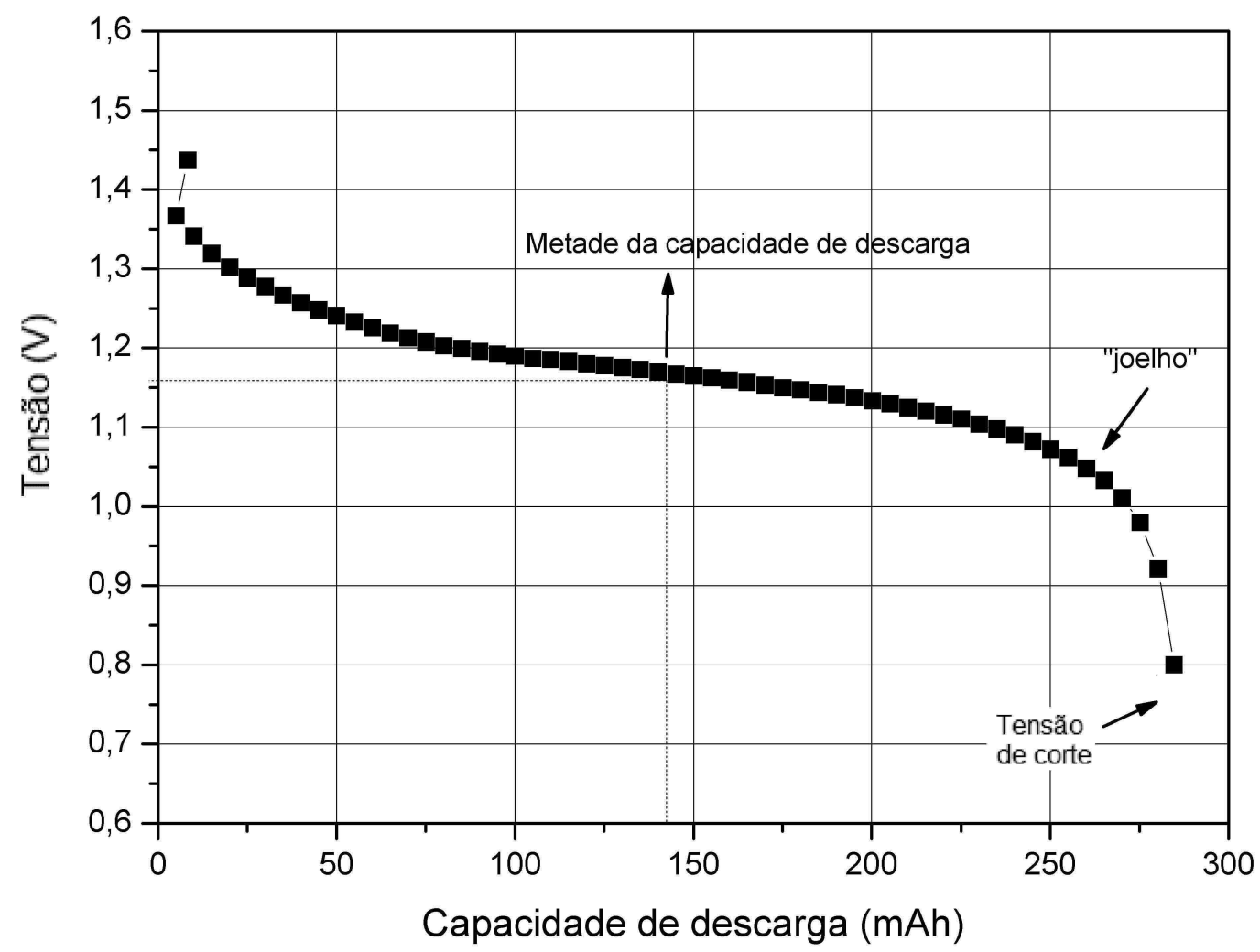

FIGURA 3 - Perfil de descarga de uma bateria de Ni-HM [20]. 
A queda inicial do potencial de circuito aberto foi de 1,45 volts para 1,35 volts.

Ao final do perfil de descarga de uma bateria de Ni-HM mostra o chamado joelho ("knee"), onde ocorre a queda acentuada da capacidade de descarga.

A tensão de corte mostra o final do perfil de descarga, ou seja, é o valor onde cessa o processo de descarga da bateria para evitar danos como a sobredescarga. O valor que geralmente é utilizado depende do experimento que está se realizando, mas para baterias seladas de Ni-HM o valor é de 0,9 volts [9].

O MPV ("mid-point voltage"), mostrado na FIG. 3, é estabelecido quando se tem a metade da capacidade de descarga de uma bateria de Ni-HM, que é o parâmetro que fornece uma aproximação da tensão da bateria.

As baterias podem sofrer dois efeitos restritivos durante sua operação: a sobrecarga e a sobredescarga. Sobrecarga é o efeito causado quando se mantém uma alta corrente passando por um longo período de tempo pela bateria. Este longo período pode ser contínuo ou com interrupções.

Quando se aumenta a corrente de carga de uma bateria, estamos aumentando a velocidade da reação de carga. Existe um ponto em que a quantidade de energia fornecida à bateria supera a capacidade de ser absorvida pelos materiais ativos e esta energia excedente é transformada em calor. A temperatura elevada leva à deterioração dos elementos das baterias. Os principais efeitos da sobrecarga são: diminuição da quantidade de eletrólito, carcaça da bateria estufada, diminuição na duração da bateria (número de ciclos) e diminuição na capacidade de descarga.

A sobredescarga é o efeito que ocorre quando há a remoção total da carga da bateria. Quando a bateria é danificada permanentemente devido à sobredescarga, hidrogênio em gás se acumula no interior da célula, causando freqüentemente liberação do mesmo. Normalmente, há um limite inferior de tensão especificado para descarga que é a tensão de corte.

Existem outros fatores que afetam a vida útil das baterias de Ni-HM. Alguns deles são: temperatura de operação, tipo de material utilizado, correntes de carga e descarga e condições de armazenamento. Alguns destes fatores podem causar geração de gás nas baterias ativando sua válvula de segurança. Em condições ideais as baterias podem durar por muitos ciclos, no entanto, os 
fatores acima mencionados podem levar a um impacto negativo sobre o número total de ciclos a ser obtido [20].

\subsection{Substituições nas ligas $\mathrm{AB}_{5}$}

A liga de armazenamento de hidrogênio é o material ativo do eletrodo negativo das baterias de Ni-HM. Estas ligas desempenham várias funções importantes, como catalisador eletroquímico e um reservatório de hidrogênio no processo de carga/descarga. Contudo, muitas mudanças e substituições de composição são realizadas visando o aperfeiçoamento de algumas propriedades desejáveis como aumento da capacidade de descarga, aumento da atividade eletroquímica e aumento da resistência a corrosão.

\subsubsection{Substituições em $A$ nas ligas $A B_{5}$}

\subsubsection{Efeito do praseodímio e neodímio}

Pan et al. [21] investigaram o efeito do praseodímio nas ligas $\mathrm{La}_{0,7-\mathrm{x}} \mathrm{Pr}_{\mathrm{x}} \mathrm{Mg}_{0,3} \mathrm{Ni}_{2,45} \mathrm{Co}_{0,75} \mathrm{Mn}_{0,1} \mathrm{Al}_{0,2}(\mathrm{x}=0-0,3)$ após tratamento térmico a $1173 \mathrm{~K}$ por 8 horas. Verificaram que as ligas com diferentes teores de $\mathrm{Pr}$ apresentaram padrão de difração similares e consistiram das fases ( $\mathrm{La}, \mathrm{Mg}) \mathrm{Ni}_{3}$ (estrutura romboédrica tipo- $\mathrm{PuNi}_{3}$ ) e $\mathrm{LaNi}_{5}$ (estrutura hexagonal tipo-CaCu ) mas, com uma diminuição no parâmetro de rede. O resultado da capacidade de descarga das baterias mostrou decréscimo de $366 \mathrm{mAhg}^{-1}(\mathrm{x}=0)$ para $346 \mathrm{mAhg}^{-1}(\mathrm{x}=0,3)$ [21]. $O$ mesmo comportamento foi encontrado nas ligas $\operatorname{La}_{0,75}$ ${ }_{x} \mathrm{Pr}_{x} \mathrm{Mg}_{0,25} \mathrm{Ni}_{3,2} \mathrm{Co}_{0,2} \mathrm{Al}_{0,1}(x=0-0,4)$ [30].

Na FIG. 4 (a) estão apresentados as capacidades de descarga em função do número de ciclos dos eletrodos negativos das ligas $\mathrm{La}_{0,7-x} \mathrm{Pr}_{\mathrm{x}} \mathrm{Mg}_{0,3} \mathrm{Ni}_{2,45} \mathrm{Co}_{0,75} \mathrm{Mn}_{0,1} \mathrm{Al}_{0,2}(\mathrm{x}=0-0,3)$ e na FIG. 4 (b) estão mostradas as capacidades de descarga máxima obtidas em função do teor de praseodímio nas ligas [21]. 


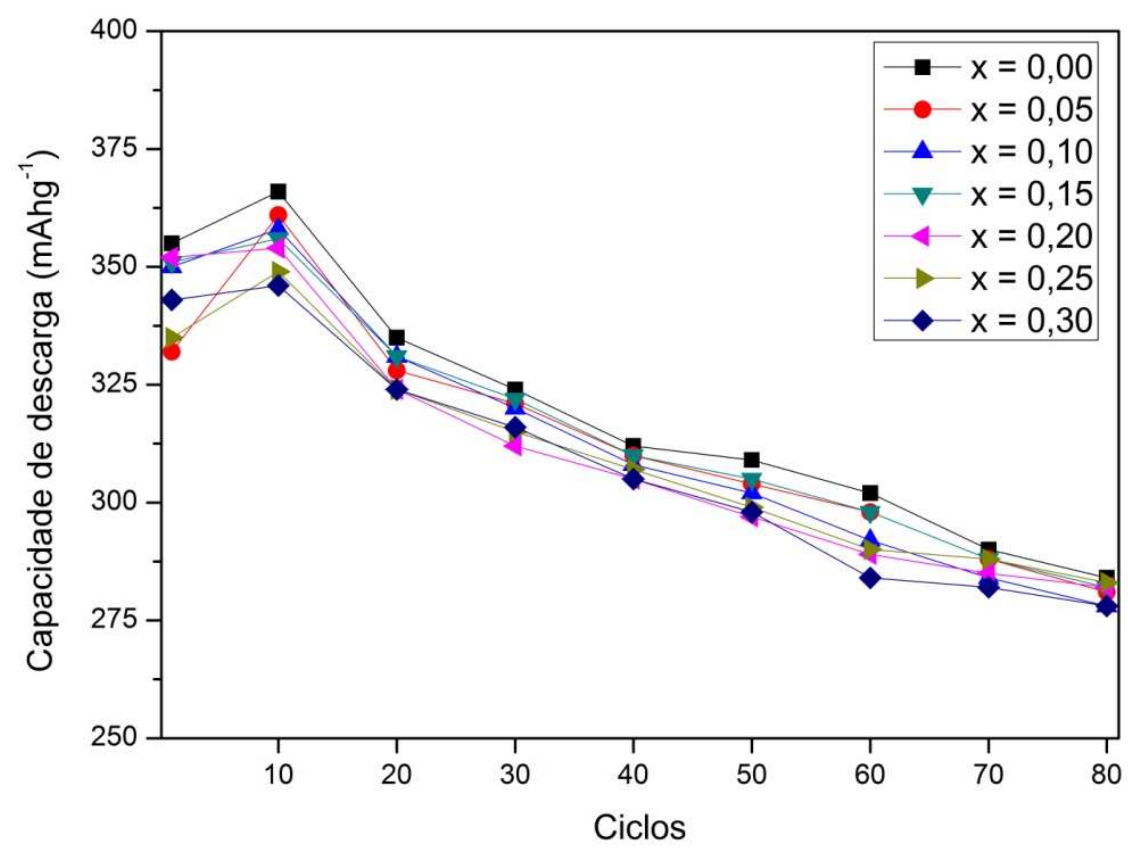

(a)

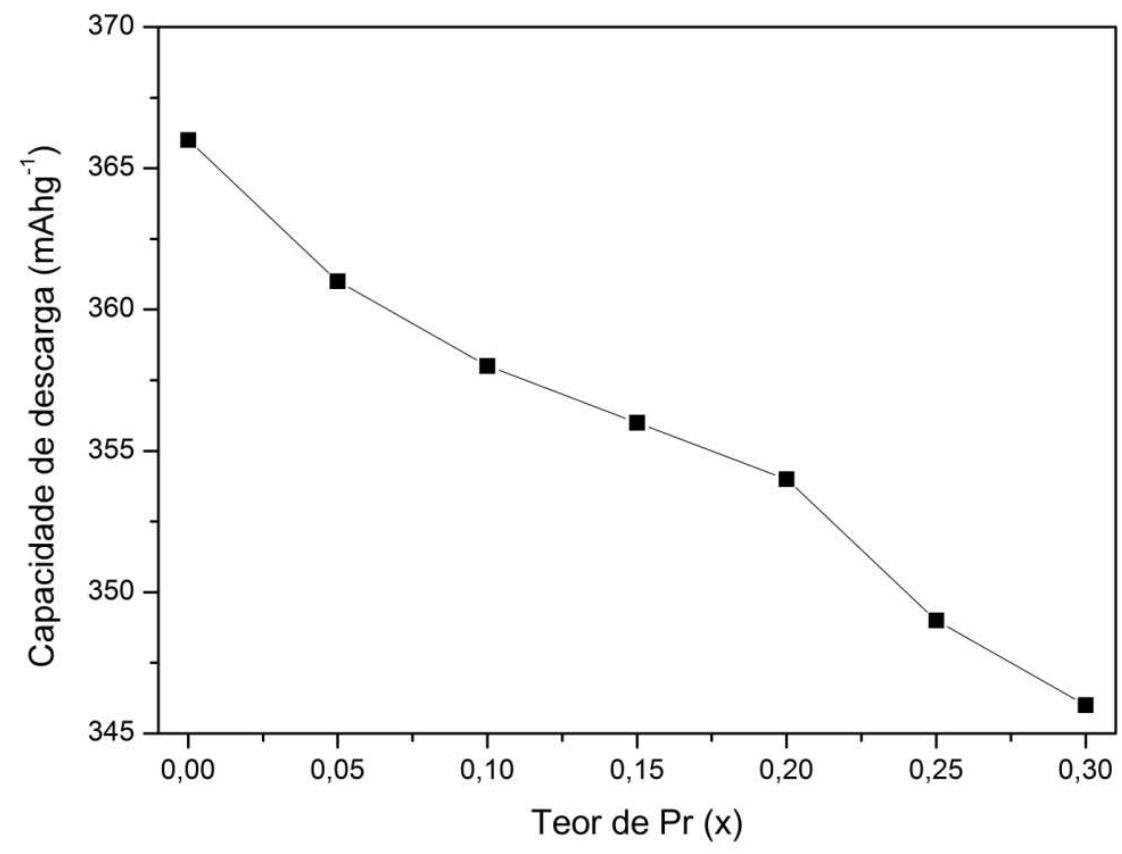

(b)

FIGURA 4 - Capacidades de descarga dos eletrodos negativos das ligas $\mathrm{La}_{0,7-x} \operatorname{Pr}_{x} \mathrm{Mg}_{0,3} \mathrm{Ni}_{2,45} \mathrm{Co}_{0,75} \mathrm{Mn}_{0,1} A \mathrm{l}_{0,2} \quad(x=0$ - 0,3); onde: (a) capacidade de descarga em função do número de ciclos e (b) capacidade de descarga máxima em função do teor de praseodímio [21]. 
Na TAB. 3 estão apresentadas as capacidades de descarga máxima $\left(\mathrm{C}_{\text {máx }}\right)$ e as capacidades de descarga no ciclo $\mathrm{n}^{\circ} 80\left(\mathrm{C}_{80}\right)$ obtidas para os eletrodos negativos das ligas $\mathrm{La}_{0,7-x} \mathrm{Pr}_{x} \mathrm{Mg}_{0,3} \mathrm{Ni}_{2,45} \mathrm{Co}_{0,75} \mathrm{Mn}_{0,1} \mathrm{Al}_{0,2}(\mathrm{x}=0-0,3)$ [21].

TABELA 3 - Capacidades de descarga obtidas para as ligas

$$
\mathrm{La}_{0,7-x} \mathrm{Pr}_{x} \mathrm{Mg}_{0,3} \mathrm{Ni}_{2,45} \mathrm{Co}_{0,75} \mathrm{Mn}_{0,1} \mathrm{Al}_{0,2}(\mathrm{x}=0 \text { - 0,3) [21]. }
$$

\begin{tabular}{cccc}
\hline $\mathrm{x}$ & $\mathrm{C}_{\text {máx }}\left(\mathrm{mAhg}^{-1}\right)$ & $\mathrm{C}_{80}\left(\mathrm{mAhg}^{-1}\right)$ & $\mathrm{C}_{80} / \mathrm{C}_{\text {máx }}(\%)$ \\
\hline 0,00 & 366 & 284 & 77,7 \\
0,05 & 361 & 281 & 77,9 \\
0,10 & 358 & 278 & 77,8 \\
0,15 & 356 & 282 & 79,4 \\
0,20 & 354 & 282 & 79,9 \\
0,25 & 349 & 283 & 81,1 \\
0,30 & 346 & 278 & 80,6 \\
\hline
\end{tabular}

Os resultados de difração de raios- $X$ das ligas $\mathrm{La}_{0,7-x} \mathrm{Nd}_{x} \mathrm{Mg}_{0,3} \mathrm{Ni}_{2,45} \mathrm{Co}_{0,75} \mathrm{Mn}_{0,1} \mathrm{Al}_{0,2}(\mathrm{x}=0,0$ - 3,0) foram similares ao encontrado para o praseodímio, apresentando duas principais fases ( $\mathrm{La}, \mathrm{Mg}) \mathrm{Ni}_{3}$ e $\mathrm{LaNi}_{5}$, com diminuição no parâmetro de rede no aumento do teor de neodímio. A capacidade de descarga das baterias com neodímio diminui de $377 \mathrm{mAhg}^{-1}(x=0)$ para 357 $\operatorname{mAng}^{-1}(x=0,3)$ [22].

Por outro lado, para ambos os elementos ( $\operatorname{Pr}$ ou $\mathrm{Nd}$ ), houve uma melhora na estabilidade cíclica e na cinética eletroquímica [21,22].

A diminuição da capacidade de descarga foi atribuída à redução da fase ( $\mathrm{La}, \mathrm{Mg}) \mathrm{Ni}_{3}$. A mudança na quantidade desta fase provoca uma diminuição do volume da célula unitária levando a melhoria nas propriedades eletroquímicas.

Considerando todos os efeitos envolvidos na substituição parcial do La pelo $\mathrm{Pr}$ ou pelo $\mathrm{Nd}$ nas ligas $\mathrm{La}_{0,7-x} \mathrm{R}_{x} \mathrm{Mg}_{0,3} \mathrm{Ni}_{2,45} \mathrm{Co}_{0,75} \mathrm{Mn}_{0,1} \mathrm{Al}_{0,2}(\mathrm{x}=0,0-3,0)$, os melhores resultados foram obtidas para $\mathrm{x}=0,15$ para praseodímio $\mathrm{e} x=0,1$ para neodímio [21, 22]. 


\subsubsection{Efeito do cério}

Estudos envolvendo a substituição do lantânio por cério tiveram como principal finalidade a redução de custos das ligas de La-Mg-Ni e melhoria na estabilidade cíclica.

Pan et al. [23] estudaram o efeito da substituição do lantânio pelo cério nas ligas $\mathrm{La}_{0,7-x} \mathrm{Ce}_{x} \mathrm{Mg}_{0,3} \mathrm{Ni}_{2,875} \mathrm{Mn}_{0,1} \mathrm{Co}_{0,525}(\mathrm{x}=0-0,5)$. Os resultados de difração de raios- $X$ mostraram a presença de duas fases principais: $\mathrm{La}\left(\mathrm{La}, \mathrm{Mg}{ }_{2} \mathrm{Ni}_{9}\right.$ com estrutura romboédrica tipo- $\mathrm{PuNi}_{3}$ e $\mathrm{LaNi}_{5}$ com estrutura hexagonal tipo-CaCu 5 . Foi observada a diminuição do parâmetro de rede à medida que aumenta o teor de cério, obtendo como conseqüência uma menor capacidade de estocagem de hidrogênio. A capacidade de descarga das baterias diminuiu de $382 \mathrm{mAhg}^{-1}$ ( $\mathrm{x}=$ 0) para $49 \mathrm{mAhg}^{-1}(\mathrm{x}=0,5)$.

Os autores relatam que há dois principais fatores que regulam os efeitos do Ce sobre a estabilidade das baterias. A primeira é que com o aumento no teor de Ce e com a diminuição da célula unitária, há uma redução das partículas durante a carga/descarga. A segunda está na formação de uma película superficial de proteção diminuindo a taxa de corrosão. Os íons de $\mathrm{Ce}^{3+}$ são oxidados passando a $\mathrm{Ce}^{4+}$ em eletrólito alcalino, formando uma película densa de $\mathrm{CeO}_{2}$ na superfície da liga. No entanto, o grande problema encontrado na utilização do Ce como substituto do La é que a capacidade de descarga é drasticamente diminuída de $382 \mathrm{mAhg}^{-1}(\mathrm{x}=0)$ para $48 \mathrm{mAhg}^{-1}(\mathrm{x}=0,5)$ [23].

Zhang et al. [24] estudaram as ligas $\mathrm{La}_{0,7-x} \mathrm{Ce}_{x} \mathrm{Mg}_{0,3} \mathrm{Ni}_{2,8} \mathrm{Co}_{0,5}(x=0,1$ $0,5)$ e encontraram resultados semelhantes. Os resultados da quantidade de fases analisada pelo método de Rietveld mostrou que há uma diminuição da fase $\mathrm{La}(\mathrm{La}, \mathrm{Mg})_{2} \mathrm{Ni}_{9}$ com o aumento do teor de cério nas ligas. A capacidade de descarga das baterias diminui drasticamente com o aumento do cério, passando de $367 \mathrm{mAhg}^{-1}(\mathrm{x}=0)$ para $68 \mathrm{mAhg}^{-1}(\mathrm{x}=0,5)$. 


\subsubsection{Efeito do titânio e zircônio}

$A$ adição de zircônio nas ligas $\mathrm{La}_{0,7-x} \mathrm{Zr}_{x} \mathrm{Mg}_{0,3} \mathrm{Ni}_{2,45} \mathrm{Co}_{0,75} \mathrm{Mn}_{0,1} \mathrm{Al}_{0,2}(\mathrm{x}=0$ - 0,1) mostrou uma diminuição na capacidade de descarga das baterias. As fases determinadas por difração de raios-X foram: ( $\mathrm{La}, \mathrm{Mg}) \mathrm{Ni}_{3}$ e $\mathrm{LaNi}_{5}$. Os resultados eletroquímicos mostraram que a capacidade de descarga diminui de $364 \mathrm{mAhg}^{-1}$ $(x=0)$ para $306 \mathrm{mAhg}^{-1}(x=0,1)$. Este fato foi explicado pela diminuição na quantidade da fase ( $\mathrm{La}, \mathrm{Mg}) \mathrm{Ni}_{3}$ com aumento do teor de zircônio. No entanto a estabilidade cíclica mostrou-se inalterada ao longo da mudança de composição [25].

Dong et al. [26] estudaram a substituição do lantânio pelo titânio, em pequenas quantidades, nas ligas $\left(\mathrm{La}_{1-\mathrm{x}} \mathrm{Ti}_{\mathrm{x}}\right)_{0,67} \mathrm{Mg}_{0,33} \mathrm{Ni}_{2,75} \mathrm{Co}_{0,25}(\mathrm{x}=0-0,20)$. As fases encontradas foram as mesmas das obtidas nas ligas de zircônio, com exceção da fase $\mathrm{TiNi}_{3}$, que foi observada em pequenas quantidades a partir da liga com $\mathrm{Ti}_{0,1}$. Com o aumento do teor de $\mathrm{Ti}$, os valores de capacidade de descarga máxima diminuem de $384 \mathrm{mAhg}^{-1}(\mathrm{x}=0)$ para $321 \mathrm{mAhg}^{-1}(\mathrm{x}=0,2)$. Os autores verificaram que ativações rápidas foram obtidas para as ligas com titânio, da ordem de três a quatro ciclos. A capacidade de retenção de descarga $\left(\mathrm{C}_{100} / \mathrm{C}_{\text {máx }}\right)$ aumentou de $51,7 \%(\mathrm{x}=0)$ para $63,0 \%(\mathrm{x}=0,15)$, e depois diminuiu para $56,9 \%$ em $(x=0,20)[26]$. 


\subsubsection{Substituições em $B$ em ligas $A B_{5}$}

Para as ligas de armazenamento de hidrogênio, a substituição do componente $B$ consiste, em geral, nos metais de transição da tabela periódica.

\subsubsection{Efeito do manganês}

Os trabalhos envolvendo a substituição do níquel por manganês em ligas do tipo La-Mg-Ni-Co apresentaram boas melhorias na ativação das baterias, além de aumentarem a capacidade de descarga das mesmas [27,28,29,30,31].

$\mathrm{Em}$ estudos das ligas $\mathrm{La}_{0,7} \mathrm{Mg}_{0,3} \mathrm{Ni}_{2,55-\mathrm{x}} \mathrm{Co}_{0,45} \mathrm{Mn}_{\mathrm{x}}(\mathrm{x}=0-0,5)$ apresentaram somente a presença das fases ( $\mathrm{La}, \mathrm{Mg}) \mathrm{Ni}_{3}$ e $\mathrm{LaNi}_{5}$. A capacidade de descarga das baterias aumentou de $342 \mathrm{mAhg}^{-1}(\mathrm{x}=0)$ para $368 \mathrm{mAhg}^{-1}(\mathrm{x}=$ $0,3)$ e decaiu para $333 \mathrm{mAhg}^{-1}(x=0,5)[27]$.

Na FIG. 5 (a) estão apresentados as capacidades de descarga em função do número de ciclos para os eletrodos negativos das ligas $\mathrm{La}_{0,7} \mathrm{Mg}_{0,3} \mathrm{Ni}_{2,55-\mathrm{x}} \mathrm{Co}_{0,45} \mathrm{Mn}_{\mathrm{x}}(\mathrm{x}=0-0,5)$ e na FIG. 5 (b) estão mostradas as capacidades de descarga máxima obtidas em função do teor de manganês nas ligas [27].

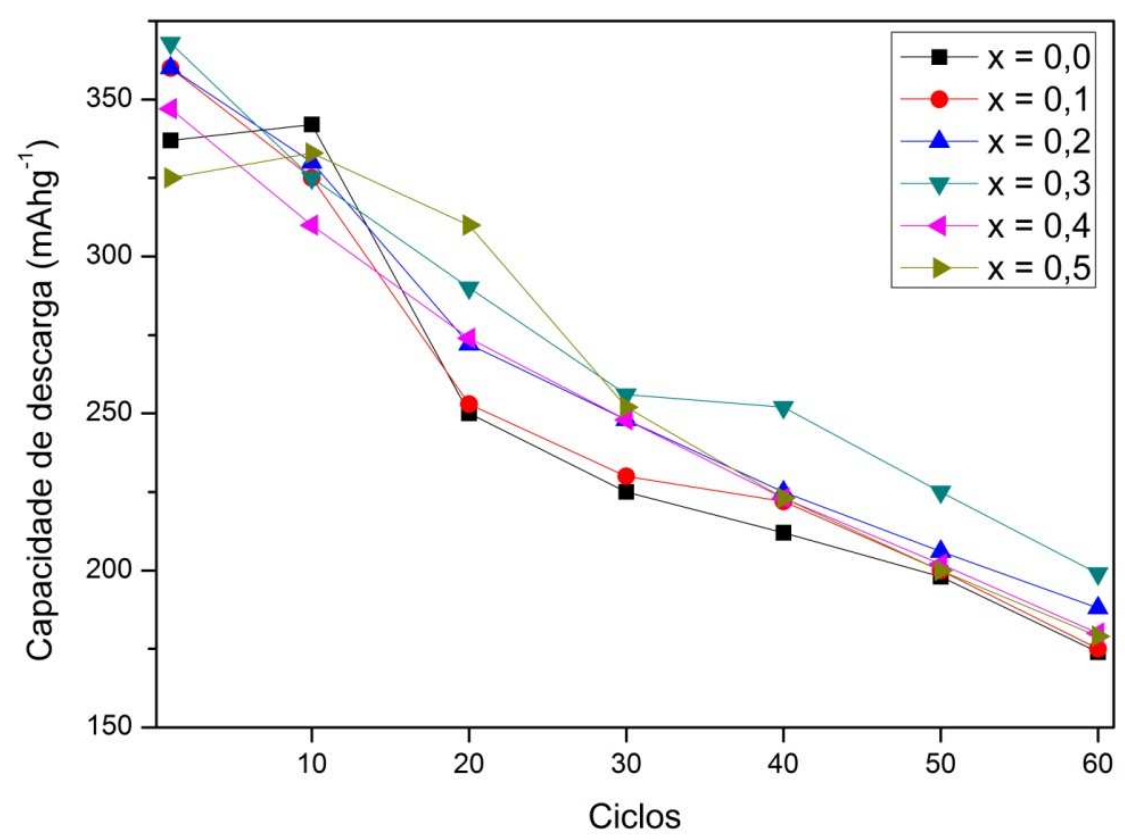

(a) 


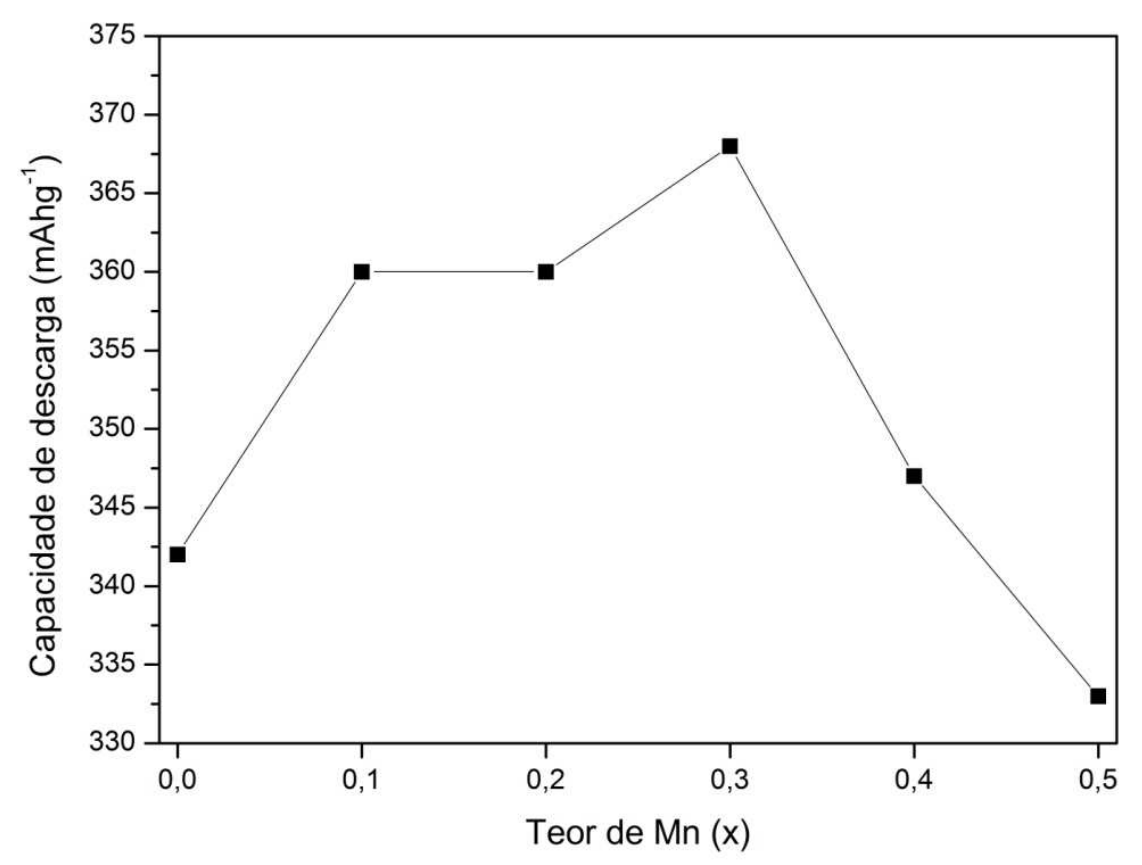

(b)

FIGURA 5 - Capacidades de descarga dos eletrodos negativos das ligas $\mathrm{La}_{0,7} \mathrm{Mg}_{0,3} \mathrm{Ni}_{2,55-x} \mathrm{Co}_{0,45} \mathrm{Mn}_{x}$ ( $x=0$ - 0,5); onde: (a) capacidade de descarga em função do número de ciclos e (b) capacidade de descarga máxima em função do teor de manganês [27].

Na TAB. 4 estão apresentadas as capacidades de descarga máxima $\left(\mathrm{C}_{\text {máx }}\right)$ e as capacidades de descarga no ciclo $\mathrm{n}^{\circ} 60\left(\mathrm{C}_{60}\right)$ obtidas para os eletrodos negativos das ligas $\mathrm{La}_{0,7} \mathrm{Mg}_{0,3} \mathrm{Ni}_{2,55-x} \mathrm{Co}_{0,45} \mathrm{Mn}_{x}(\mathrm{x}=0$ - 0,5) [27].

TABELA 4 - Capacidades de descarga obtidas para as ligas $\mathrm{La}_{0,7} \mathrm{Mg}_{0,3} \mathrm{Ni}_{2,55-x} \mathrm{Co}_{0,45} \mathrm{Mn}_{\mathrm{x}}(\mathrm{x}=0$ - 0,5) [27].

\begin{tabular}{cccc}
\hline $\mathrm{x}$ & $\mathrm{C}_{\text {máx }}\left(\mathrm{mAhg}^{-1}\right)$ & $\mathrm{C}_{60}\left(\mathrm{mAhg}^{-1}\right)$ & $\mathrm{C}_{60} / \mathrm{C}_{\text {máx }}(\%)$ \\
\hline 0,0 & 342 & 174 & 51,1 \\
0,1 & 360 & 175 & 48,7 \\
0,2 & 360 & 188 & 52,3 \\
0,3 & 368 & 199 & 54,1 \\
0,4 & 347 & 180 & 52,1 \\
0,5 & 333 & 174 & 54,0 \\
\hline
\end{tabular}


$O$ efeito do manganês nas ligas $\left(\mathrm{La}_{0,7} \mathrm{Ce}_{0,2} \mathrm{Pr}_{0,1}\right) \mathrm{Ni}_{2,6-x} \mathrm{Mn}_{x} \mathrm{Co}_{0,9}(x=0,0$; $0,225 ; 0,45 ; 0,675 ; 0,90)$ mostraram resultados similares. A capacidade de descarga aumenta até uma determinada concentração de manganês e depois decai. A capacidade de descarga máxima obtida foi $352 \mathrm{mAhg}^{-1}(\mathrm{x}=0,45)$, e depois diminui para $307 \mathrm{mAhg}^{-1}$ para $\mathrm{x}=0,9$ [30]. Estudos das ligas $\mathrm{La}_{0,7} \mathrm{Mg}_{0,3} \mathrm{Ni}_{2,975-x} \mathrm{Co}_{0,525} \mathrm{Mn}_{x}(\mathrm{x}=0$ - 0,4) mostraram que há um aumento no coeficiente de difusão do hidrogênio causado pela expansão do volume da célula unitária. A capacidade de descarga máxima encontrada foi para a liga com $x=0,3$ (356 $\left.\mathrm{mAhg}^{-1}\right)$ [31].

\subsubsection{Efeito do cobalto}

O cobalto é um dos elementos de adição mais importantes utilizados de adição para a melhoria nas propriedades eletroquímicas de ligas à base de terras raras para eletrodos de baterias de $\mathrm{Ni}-\mathrm{HM}$, especialmente no prolongamento da vida útil (número de ciclos) das baterias. Estudos do efeito do cobalto em eletrodos a base de La-Mg-Ni têm sido extensivamente estudados $[32,33,34]$.

Liao et al. estudaram o efeito da substituição do níquel pelo cobalto nas ligas $\mathrm{La}_{2} \mathrm{Mg}\left(\mathrm{Ni}_{1-\mathrm{x}} \mathrm{Co}_{\mathrm{x}}\right)_{9}(\mathrm{x}=0,1-0,5)$. Os resultados de difração de raios- $\mathrm{X}$ mostraram a presença da fase principal ( $\mathrm{La}, \mathrm{Mg}) \mathrm{Ni}_{3}$ (estrutura romboédrica tipo$\mathrm{PuNi}_{3}$ ) e duas fases em pequenas quantidades ( $\mathrm{LaNi}$ e $\left.\mathrm{La}_{2} \mathrm{Ni}_{7}\right)$. A capacidade de descarga das baterias mostrou um aumento de $400 \mathrm{mAhg}^{-1}(x=0)$ para 404 $\operatorname{mAng}^{-1}(x=0,2)$. Para a liga com $\mathrm{Co}_{0,5}$ a capacidade de descarga diminuiu para $328 \mathrm{mAhg}^{-1}$, porém apresentou melhor estabilidade cíclica. Este resultado foi explicado à baixa expansão da célula unitária quando se aumenta o teor de cobalto nas ligas, causando uma baixa taxa de decrepitação e corrosão das partículas durante a carga e descarga das baterias [33].

Liu et al. [32,34], mostraram o efeito da substituição do níquel pelo cobalto nas ligas $\mathrm{La}_{0,7} \mathrm{Mg}_{0,3} \mathrm{Ni}_{3,4-x} \mathrm{Mn}_{0,1} \mathrm{Co}_{x}(x=0-1,6)$. Com o aumento do teor de cobalto a capacidade de descarga máxima das baterias aumenta de 397 $\mathrm{mAhg}^{-1}(\mathrm{x}=0)$ para $403 \mathrm{mAhg}^{-1}(\mathrm{x}=0,75)$ e depois diminui para $380 \mathrm{mAhg}^{-1}(\mathrm{x}=$ $1,6)$. Com altos teores de cobalto nas ligas a cinética eletroquímica diminui, devido à diminuição do coeficiente de difusão do hidrogênio [32,34]. 
A melhoria na estabilidade cíclica foi atribuída à baixa expansão do volume da célula unitária durante a hidrogenação/desidrogenação e o aumento da superfície de passivação durante a carga e descarga das baterias. A substituição adequada do Ni pelo Co aumenta a cinética eletroquímica dos eletrodos devido à concentração de Co e Ni na superfície das partículas da liga, e com conseqüente formação de um filme de Ni-Co [32,34].

Na FIG. 6 (a) estão apresentados as capacidades de descarga em função do número de ciclos para os eletrodos negativos das ligas $\mathrm{La}_{0,7} \mathrm{Mg}_{0,3} \mathrm{Ni}_{3,4-x} \mathrm{Mnn}_{0,1} \mathrm{Co}_{\mathrm{x}}(\mathrm{x}=0-1,6)$ e na FIG. 6 (b) estão mostradas as capacidades de descarga máxima obtidas em função do teor de cobalto nas ligas [34].

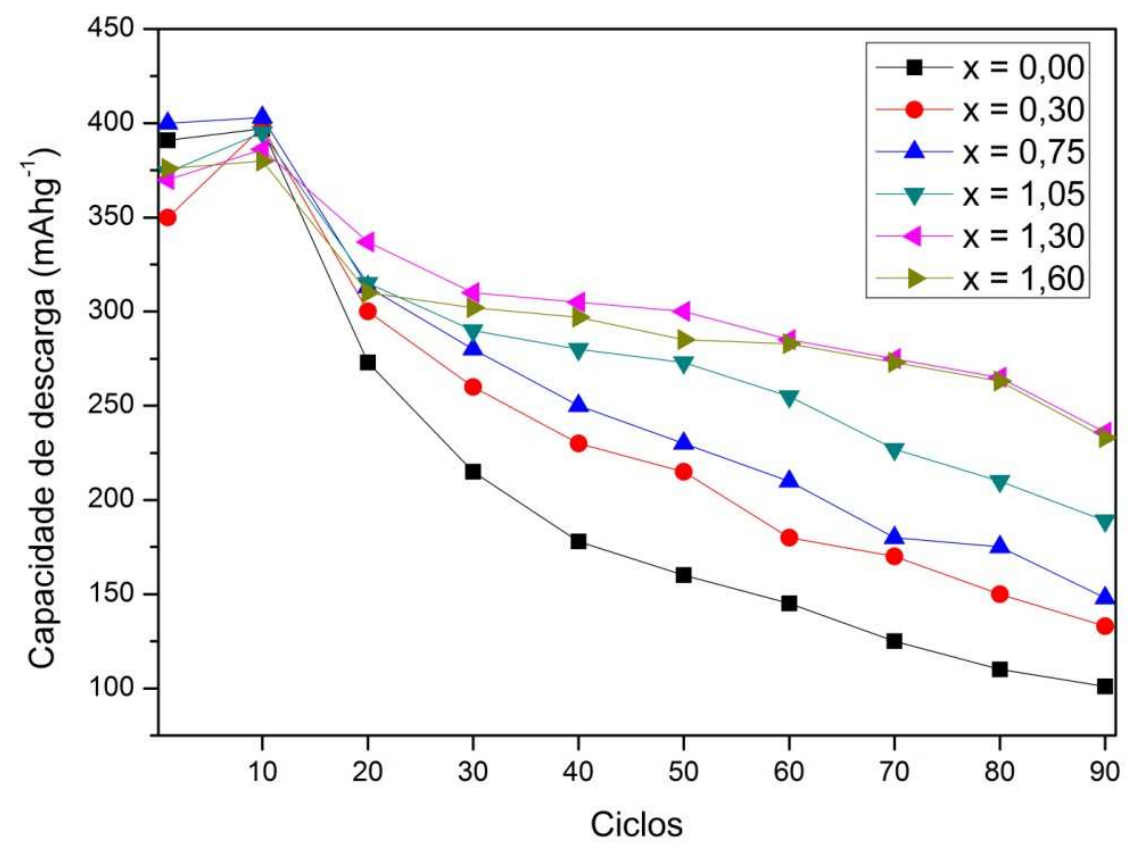

(a) 


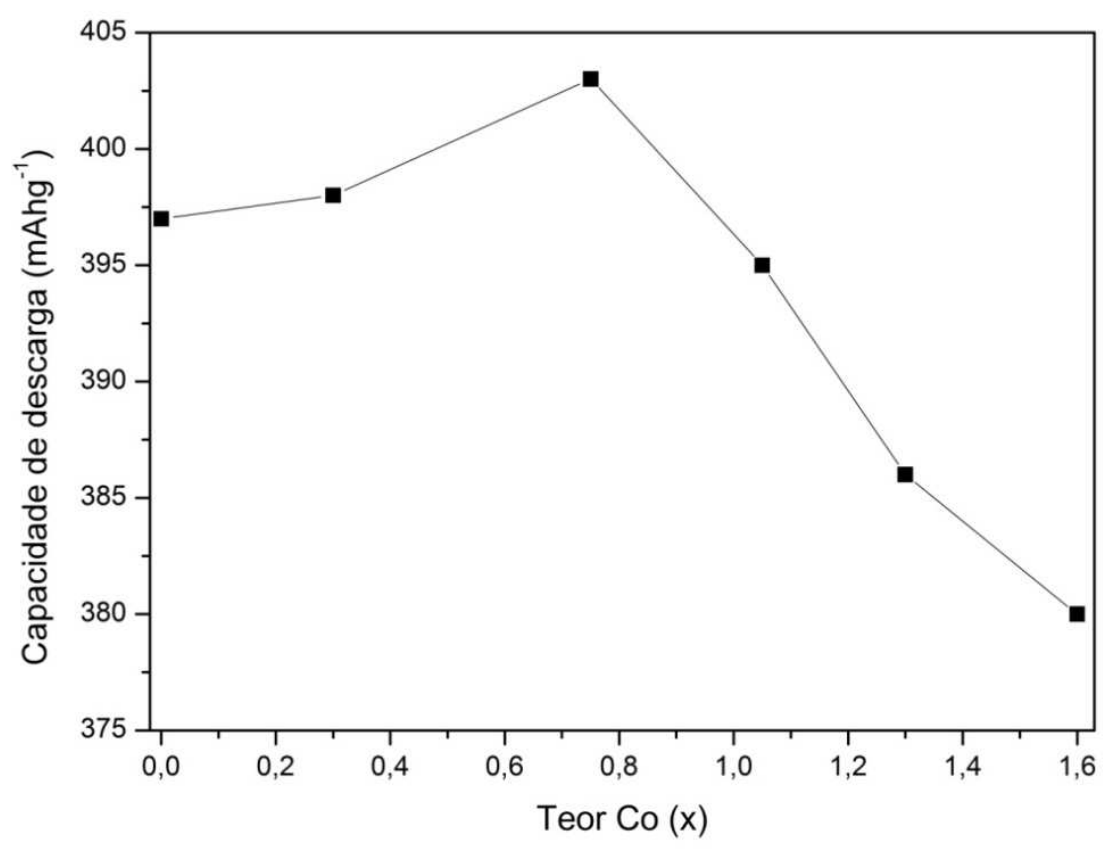

(b)

FIGURA 6 - Capacidades de descarga dos eletrodos negativos das ligas $\mathrm{La}_{0,7} \mathrm{Mg}_{0,3} \mathrm{Ni}_{3,4-x} \mathrm{Mn}_{0,1} \mathrm{Co}_{x}$ ( $x=0$ - 1,6); onde: (a) capacidade de descarga em função do número de ciclos e (b) capacidade de descarga máxima em função da teor de cobalto [34].

Na TAB. 5 estão apresentadas as capacidades de descarga máxima $\left(\mathrm{C}_{\text {máx }}\right)$ e as capacidades de descarga no ciclo $\mathrm{n}^{\circ} 90\left(\mathrm{C}_{90}\right)$ obtidas para os eletrodos negativos das ligas $\mathrm{La}_{0,7} \mathrm{Mg}_{0,3} \mathrm{Ni}_{3,4-x} \mathrm{Mn}_{0,1} \mathrm{Co}_{x}(x=0-1,6)$ [34].

TABELA 5 - Capacidades de descarga obtidas para as ligas $\mathrm{La}_{0,7} \mathrm{Mg}_{0,3} \mathrm{Ni}_{3,4-x} \mathrm{Mn}_{0,1} \mathrm{Co}_{x}(\mathrm{x}=0-1,6)$ [34].

\begin{tabular}{cccc}
\hline $\mathrm{x}$ & $\mathrm{C}_{\text {máx }}\left(\mathrm{mAhg}^{-1}\right)$ & $\mathrm{C}_{90}\left(\mathrm{mAhg}^{-1}\right)$ & $\mathrm{C}_{90} / \mathrm{C}_{\text {máx }}(\%)$ \\
\hline 0,00 & 397 & 101 & 25,5 \\
0,30 & 398 & 133 & 33,6 \\
0,75 & 403 & 148 & 36,9 \\
1,05 & 395 & 189 & 47,9 \\
1,30 & 386 & 236 & 61,3 \\
1,60 & 380 & 233 & 61,5 \\
\hline
\end{tabular}




\subsubsection{Efeito do alumínio}

Trabalhos envolvendo a substituição do Ni pelo Al (que não faz parte da família dos metais de transição) nas ligas à base de La-Mg-Ni mostram uma melhoria significativa na estabilidade cíclica das baterias de $\mathrm{Ni}-\mathrm{HM}[35,36]$.

Os estudos realizados nas ligas $\operatorname{La}_{2} \operatorname{Mg}\left(\mathrm{Ni}_{1-x} \mathrm{Al}_{\mathrm{x}}\right)_{9}(\mathrm{x}=0-0,05)$ mostraram a presença da fase principal, do tipo- $\mathrm{PuNi}_{3}$, e pequenas quantidades da fase $\mathrm{La}_{2} \mathrm{Ni}_{7}$, citada como impureza. A capacidade de descarga das baterias mostrou decréscimo de $400 \mathrm{mAhg}^{-1}(\mathrm{x}=0)$ para $374 \mathrm{mAhg}^{-1}(\mathrm{x}=0,02)$, atingindo um ponto mais baixo a $\mathrm{x}=0,05\left(221 \mathrm{mAhg}^{-1}\right)$ [35].

Na FIG. 7 (a) estão apresentados as capacidades de descarga em função do número de ciclos para os eletrodos negativos das ligas $\mathrm{La}_{2} \mathrm{Mg}\left(\mathrm{Ni}_{1-\mathrm{x}} \mathrm{Al} \mathrm{I}_{\mathrm{x}}\right)_{9}$ $(x=0-0,05)$ e na FIG. 7 (b) estão mostradas as capacidades de descarga máxima obtidas em função do teor de alumínio nas ligas [35].

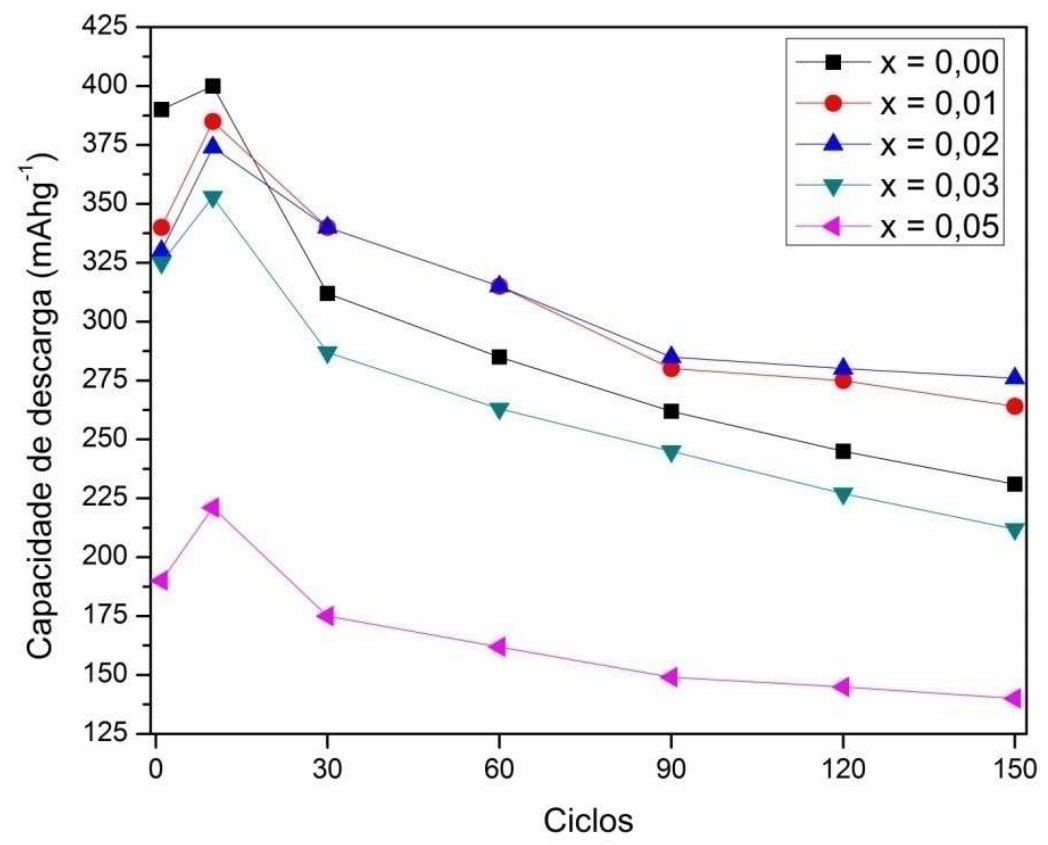

(a) 


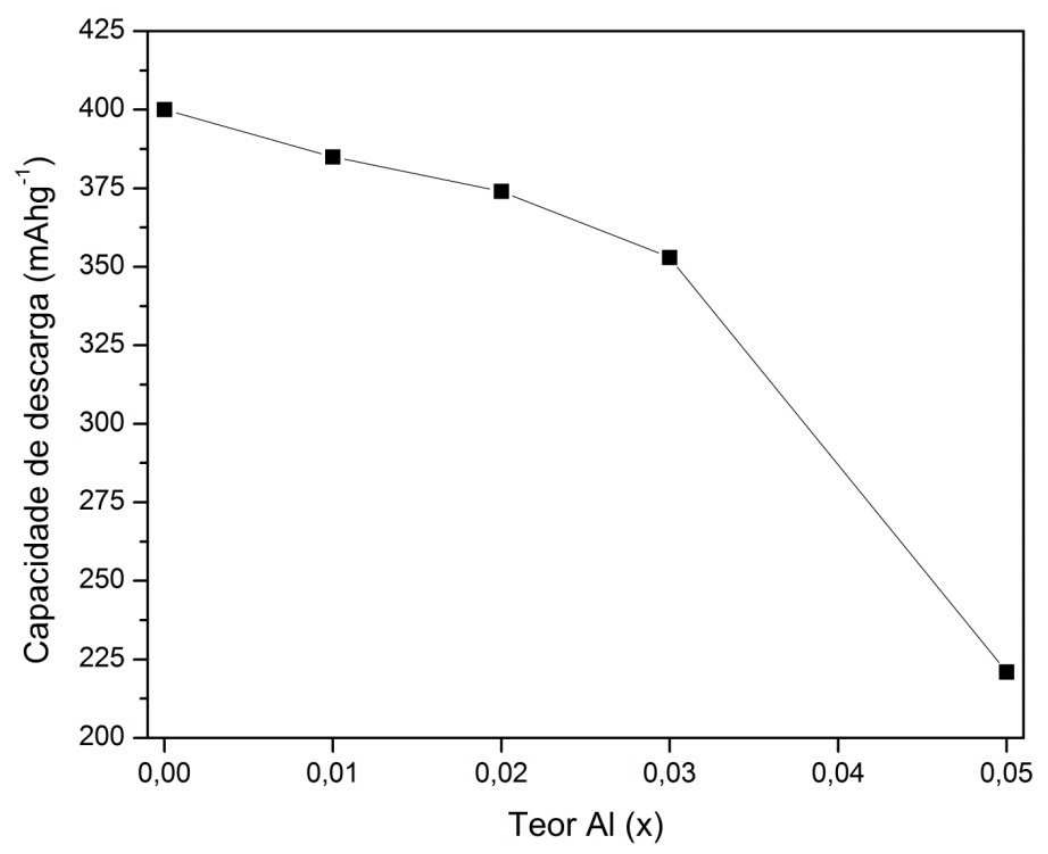

(b)

FIGURA 7 - Capacidades de descarga dos eletrodos negativos das ligas $\mathrm{La}_{2} \mathrm{Mg}\left(\mathrm{Ni}_{1-\mathrm{x}} \mathrm{Al} \mathrm{I}_{\mathrm{x}}\right)_{9}(\mathrm{x}=0$ - 0,05); onde: (a) capacidade de descarga em função do número de ciclos e (b) capacidade de descarga máxima em função da teor de alumínio [35].

Na TAB. 6 estão apresentadas as capacidades de descarga máxima $\left(C_{\text {máx }}\right)$ e as capacidades de descarga no ciclo $n^{\circ} 150\left(C_{150}\right)$ obtidas para os eletrodos negativos das ligas $\mathrm{La}_{2} \mathrm{Mg}\left(\mathrm{Ni}_{1-\mathrm{x}} \mathrm{A} \mathrm{Al}_{\mathrm{x}}\right)_{9}(\mathrm{x}=0-0,05)$ [35]. Os resultados obtidos para ligas com Al mostram que a capacidade de descarga diminui, mas por outro lado, há um incremento significante na estabilidade cíclica $[35,36]$.

TABELA 6 - Capacidades de descarga obtidas para as ligas $\operatorname{La}_{2} \mathrm{Mg}_{(\mathrm{Ni}}\left(\mathrm{Ni}_{1-\mathrm{x}} \mathrm{Al}_{\mathrm{x}}\right)_{9}(\mathrm{x}=$ $0-0,05)$ [35].

\begin{tabular}{cccc}
\hline $\mathrm{x}$ & $\mathrm{C}_{\text {máx }}\left(\mathrm{mAhg}^{-1}\right)$ & $\mathrm{C}_{150}\left(\mathrm{mAhg}^{-1}\right)$ & $\mathrm{C}_{150} / \mathrm{C}_{\text {máx }}(\%)$ \\
\hline 0,00 & 400 & 231 & 57,7 \\
0,01 & 385 & 264 & 68,6 \\
0,02 & 374 & 276 & 73,8 \\
0,03 & 353 & 212 & 60,3 \\
0,05 & 221 & 140 & 63,5 \\
\hline
\end{tabular}


Pan et al. encontraram resultados semelhantes para as ligas $\mathrm{La}_{0,7} \mathrm{Mg}_{0,3} \mathrm{Ni}_{2,65-x} \mathrm{Mn}_{0,1} \mathrm{Co}_{0,75} \mathrm{Al}_{\mathrm{x}}$ ( $\left.\mathrm{x}=0-0,5\right)$. Os resultados mostraram uma boa melhoria na estabilidade da capacidade de descarga após 100 ciclos a retenção de carga aumentou de $32 \%(x=0)$ para $74 \%(x=0,3)[36]$.

Liu et al. atribuíram o aumento da estabilidade cíclica à formação de uma camada de óxido de alumínio dificultando a corrosão e decrepitação das partículas durante os ciclos de carga/descarga. Porém, em grandes quantidades de alumínio esta camada de óxido dificulta a difusão do hidrogênio no interior da liga [37]. 


\subsection{Efeito do magnésio nas ligas $\mathrm{AB}_{5}$}

O magnésio tem sido reportado como um dos elementos mais promissores na utilização em ligas de armazenamento de hidrogênio, especialmente em aplicações veiculares. O magnésio metálico é bem acessível e de baixo custo. Além disso, os hidretos à base de $\mathrm{Mg}$ possuem boas propriedades, tais como a resistência ao calor, aumento da capacidade de descarga e facilidade de reciclagem após utilização [38]. Ligas à base de $\mathrm{Mg}$ possuem alta capacidade de armazenamento de hidrogênio e também é um metal bastante resistente e leve, aproximadamente $30 \%$ menos denso que o alumínio $[39,40,41]$.

Em 1980, Oesterreicher e Bittner [21] foram os primeiros a preparar ligas ternárias com substituição do $\mathrm{La}$ por $\mathrm{Mg}$ na liga $\mathrm{LaNi}_{2}$. As composições estudadas foram $\mathrm{La}_{1-x} \mathrm{Mg}_{x} \mathrm{Ni}_{2}(x=0$ - 1) obtidas por forno de indução em atmosfera de argônio. Realizaram hidretação das ligas a $1 \mathrm{MPa}$ (10 bar) a temperatura ambiente e os resultados mostraram que $x=0,67$ foi o limite para que ocorresse a absorção de hidrogênio [42].

$\mathrm{O}$ desenvolvimento de novas ligas ternárias à base de $\mathrm{Mg}\left(\mathrm{RMg}_{2} \mathrm{Ni}_{9}\right)$, onde $\mathrm{R}=\mathrm{La}, \mathrm{Ce}, \mathrm{Pr}, \mathrm{Nd}, \mathrm{Sm}, \mathrm{Gd}$ e $\mathrm{Y}$, foi obtido por meio da mistura dos compostos intermetálicos $\mathrm{RNi}_{5}$ com $\mathrm{MgNi}_{2}$ ou pela combinação direta dos elementos na razão atômica, $\mathrm{R}: \mathrm{Mg}: \mathrm{Ni}=1: 2: 9$ [42,43]. As ligas foram preparadas conforme as Eq. 1.4 e 1.5:

$$
\begin{aligned}
& \mathrm{RNi}_{5}+2 \mathrm{MgNi}_{2} \stackrel{900^{\circ} \mathrm{C}-1100^{\circ} \mathrm{C}}{\longrightarrow} \mathrm{RMg}_{2} \mathrm{Ni}_{9} \\
& \mathrm{R}+2 \mathrm{Mg}+9 \mathrm{Ni} \stackrel{900^{\circ} \mathrm{C}-1100^{\circ} \mathrm{C}}{\longrightarrow} \mathrm{RMg}_{2} \mathrm{Ni}_{9}
\end{aligned}
$$


O interesse no desenvolvimento de ligas ternária do tipo $\mathrm{R}-\mathrm{Mg}-\mathrm{Ni}(\mathrm{R}=$ elementos de terras raras) com formula geral $\mathrm{RMg}_{2} \mathrm{Ni}_{9}$ (tipo $\mathrm{PuNi}_{3}$ e estrutura romboédrica) foi devido a mesma apresentar melhor capacidade de estocagem de hidrogênio comparado com a liga LaNi $[44,45,46,47,48]$.

Liao et al. [49,50] estudaram ligas ternárias com as composições $\mathrm{La}_{x} \mathrm{Mg}_{3-\mathrm{x}} \mathrm{Nig}_{9}(\mathrm{x}=1,0-2,2)$. Verificaram que com o aumento do La na liga há um aumento no volume da célula unitária. Verificaram também que os eletrodos negativos das ligas ricas em lantânio (1,8 - 2,1) mostraram ser promissoras, incluindo alta capacidade de descarga $\left(\sim 00 \mathrm{mAhg}^{-1}\right)$ e ativação inicial rápida, embora sua estabilidade cíclica tenha diminuído. Os resultados de difração de raios-X mostraram a presença de três fases: $\operatorname{LaMg}_{2} \mathrm{Ni}_{9}, \mathrm{LaNi}_{5}$ e $\mathrm{MgNi}_{2}$. A fase principal, $\mathrm{LaMg}_{2} \mathrm{Ni}_{9}$, é hexagonal do tipo $\mathrm{PuNi}_{3}$ e grupo espacial R-3m.

Zhang et al. [51] estudaram o efeito da substituição do lantânio pelo magnésio nas ligas (La,Ce, $\mathrm{Pr}, \mathrm{Nd})_{1-x} \mathrm{Mg}_{x} \mathrm{Al}_{0,1} \mathrm{Mn}_{0,1} \mathrm{Co}_{0,55} \mathrm{Ni}_{3,0}(\mathrm{x}=0,05-0,30)$. As fases determinadas por difração de raios-X foram ( $\mathrm{La}, \mathrm{Mg}) \mathrm{Ni}_{3}$ e $\mathrm{LaNi}_{5}$. Com o incremento na concentração de magnésio nas ligas houve um aumentou de fração volumétrica da fase $(\mathrm{La}, \mathrm{Mg}) \mathrm{Ni}_{3}$. A capacidade de descarga máxima das baterias aumentou de $355 \mathrm{mAhg}^{-1}(\mathrm{x}=0,05)$ para $363 \mathrm{mAhg}^{-1}(\mathrm{x}=0,20)$ e depois decaiu para $334 \mathrm{mAhg}^{-1}(\mathrm{x}=0,30)$. Na FIG. 8 está mostrada a relação entre a capacidade de descarga em função do número de ciclos das ligas ( $\mathrm{La}, \mathrm{Ce}, \mathrm{Pr}, \mathrm{Nd})_{1 \text { - }}$ ${ }_{x} \mathrm{Mg}_{x} \mathrm{Al}_{0,1} \mathrm{Mn}_{0,1} \mathrm{Co}_{0,55} \mathrm{Ni}_{3,0}(x=0,05-0,30)$ [51]. Na FIG. 9 estão apresentadas as retenções da capacidade de descarga $\left(\mathrm{C}_{200} / \mathrm{C}_{\text {máx }}\right)$ em função do aumento do teor de magnésio nas ligas ( $\mathrm{La}, \mathrm{Ce}, \mathrm{Pr}, \mathrm{Nd})_{1-\mathrm{x}} \mathrm{Mg}_{\mathrm{x}} \mathrm{Al}_{0,1} \mathrm{Mn}_{0,1} \mathrm{Co}_{0,55} \mathrm{Ni}_{3,0}(\mathrm{x}=0,05-0,30)$ [51]. 


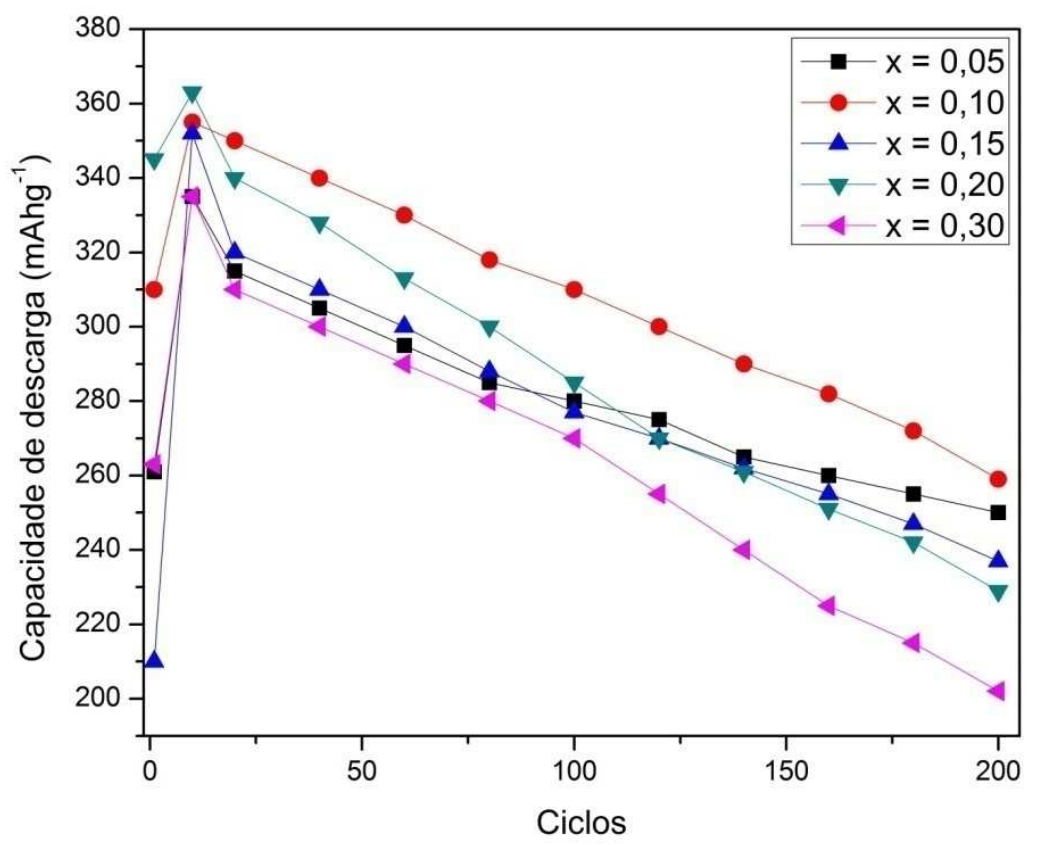

FIGURA 8 - Capacidade de descarga em função do número de ciclos dos eletrodos negativos produzidos com as ligas ( $\mathrm{La}, \mathrm{Ce}, \mathrm{Pr}, \mathrm{Nd})_{1}$. ${ }_{x} \mathrm{Mg}_{x} \mathrm{Al}_{0,1} \mathrm{Mn}_{0,1} \mathrm{Co}_{0,5} \mathrm{Ni}_{3,0}(x=0,05-0,30)[51]$.

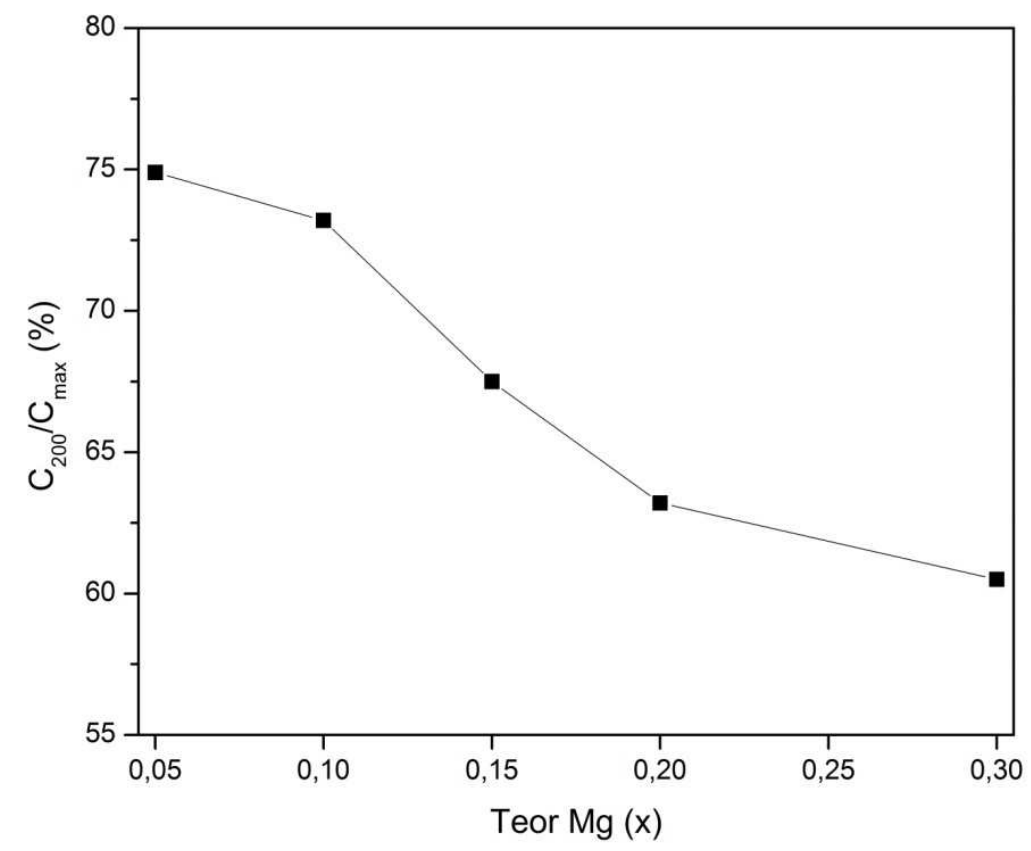

FIGURA 9 - Retenção da capacidade de descarga em função do aumento do teor de magnésio nas ligas ( $\mathrm{La}, \mathrm{Ce}, \mathrm{Pr}, \mathrm{Nd})_{1-x} \mathrm{Mg}_{x} \mathrm{Al}_{0,1} \mathrm{Mn}_{0,1} \mathrm{Co}_{0,55} \mathrm{Ni}_{3,0}(x=0,05-0,30)$ [51]. 
Os resultados obtidos da retenção da capacidade de descarga $\left(\mathrm{C}_{200} / \mathrm{C}_{\text {máx }}\right)$ mostraram a deterioração da estabilidade cíclica dos eletrodos com 0 aumento do teor de magnésio causados pela decrepitação e oxidação das partículas durante o carregamento e descarregamento das baterias. Em eletrólito alcalino de $\mathrm{KOH}$, o magnésio é oxidado formando $\mathrm{Mg}(\mathrm{OH})_{2}$. A formação deste hidróxido nas partículas das ligas leva à redução da capacidade de descarga nos eletrodos negativos a base de magnésio [51].

Muitos esforços têm sido feitos no sentido de melhorar o desempenho de hidretação/desidrogenação destas ligas, mas ainda há necessidade de mais pesquisa para melhorar o desempenho da absorção/dessorção eletroquímica de ligas baseadas em Mg em solução alcalina [52,53].

A oxidação da superfície do Mg formando hidróxido de magnésio $\left(\mathrm{Mg}(\mathrm{OH})_{2}\right)$ é o principal fator que reduz a capacidade de armazenamento de hidrogênio, além de dificultar o processo de hidrogenação. $\mathrm{O} M g(O H)_{2}$ forma sobre a superfície da liga uma camada que dificulta à absorção de hidrogênio. Portanto, para melhorar as propriedades e superar a limitação cinética das ligas baseadas em Mg, o controle da oxidação das ligas é de fundamental importância. No intuito de reduzir o efeito da formação do $\mathrm{Mg}(\mathrm{OH})_{2}$, alguns autores $[54,55,56]$ estudaram a incorporação do titânio em ligas amorfas de MgNi obtidas por moagem de alta energia ("mechanical alloying") e de alta velocidade.

Han et al. estudaram a série de ligas $\mathrm{Mg}_{1-x} \mathrm{Ti}_{x} \mathrm{Ni}$ (onde $0,1 \leq \mathrm{x} \leq 0,3$ ). Os resultados mostraram uma melhoria no ciclo de vida da bateria fabricada com $\mathrm{x}=$ 0,3. Análises por espectroscopia de impedância eletroquímica (EIS) mostraram que a resistência de transferência de carga não aumentou com o avanço dos ciclos de carga e descarga [54].

A adição de paládio ( $\mathrm{Pd}$ ) em ligas à base de MgNi têm sido também estudados $[57,58]$. Foi notada uma melhora nas propriedades eletroquímicas da liga $\mathrm{MgNi}$, quando $\mathrm{Pd}$ é adicionado como elemento de liga, pela eficácia deste elemento em diminuir a degradação das ligas decorrente da redução na formação do $\mathrm{Mg}(\mathrm{OH})_{2}$. Os autores estudaram o decaimento da capacidade de descarga das ligas com e sem paládio. A capacidade de descarga no $1^{\circ}$ ciclo resultou em 400 $\mathrm{mAhg}^{-1}$ para as ligas $\mathrm{MgNi}$ e $(\mathrm{MgNi}){ }_{90} \mathrm{Pd}_{10}$. Após o $10^{\circ}$ ciclo, a liga $\mathrm{MgNi}$ reduziu drasticamente sua capacidade para $100 \mathrm{mAh} / \mathrm{g}$, enquanto que, para a liga contendo Pd a capacidade foi de $300 \mathrm{mAhg}^{-1}$ [57]. 


\subsubsection{Tratamento térmico em ligas com magnésio}

As propriedades eletroquímicas gerais do armazenamento de hidrogênio de ligas do tipo La-Mg-Ni-Co devem ser melhorados para a sua aplicação prática, em particular, sua estabilidade cíclica. $O$ tratamento térmico é um meio muito eficaz para melhorar as propriedades gerais das ligas de armazenamento de hidrogênio, tais como a capacidade máxima de descarga e estabilidade cíclica $[59,60]$. O tratamento térmico pode diminuir os defeitos cristalinos e aumentar a homogeneização da composição da liga e, conseqüentemente, aumentar a capacidade de descarga e estabilidade cíclica das baterias de Ni-HM [59].

Para melhorar a estabilidade cíclica da liga $\mathrm{La}_{0,7} \mathrm{Mg}_{0,3} \mathrm{Ni}_{2,45} \mathrm{Co}_{0,75} \mathrm{Mn}_{0,1} \mathrm{Al}_{0,2}$ os autores estudaram o tratamento térmico a $9^{\circ} 0^{\circ} \mathrm{C}, 1^{1000} \mathrm{C}$ e $1100^{\circ} \mathrm{C}$ por 8 horas. As análises de difração de raios-X e Rietveld indicaram que a estrutura das ligas manteve a presença das duas principais fases após o tratamento térmico, ou seja, as fases ( $\mathrm{La}, \mathrm{Mg} \mathrm{Ni}_{3}$ e $\mathrm{LaNi}_{5}$. Com o aumento da temperatura de tratamento térmico, os parâmetros de rede e os volumes da célula unitária, nas duas fases, aumentaram. Porém, houve variação no teor das duas fases, com a redução da fase (La,Mg) $\mathrm{Ni}_{3}$ e conseqüentemente, aumento da fase $\mathrm{LaNi}_{5}$. Os estudos eletroquímicos indicaram melhorias na estabilidade cíclica devido à maior homogeneização da composição, mostrando um aumento de 65,5\% (liga no estado bruto de fusão) para 75,0\% (liga tratada termicamente a $1100^{\circ} \mathrm{C}$ ) na retenção da capac idade de descarga após 100 ciclos de carga e descarga. A capacidade de descarga máxima da liga no estado bruto de fusão (350 mAhg ${ }^{-1}$ ) aumentou para $370 \mathrm{mAhg}^{-1}$ após tratamento térmico a $900^{\circ} \mathrm{C}$, reduzindo para $359 \mathrm{mAhg}^{-1}$ a $1100{ }^{\circ} \mathrm{C}$ [60].

Na FIG. 10 estão apresentados os resultados obtidos por Pan et al. da capacidade de descarga em função do número de ciclos [60]. 


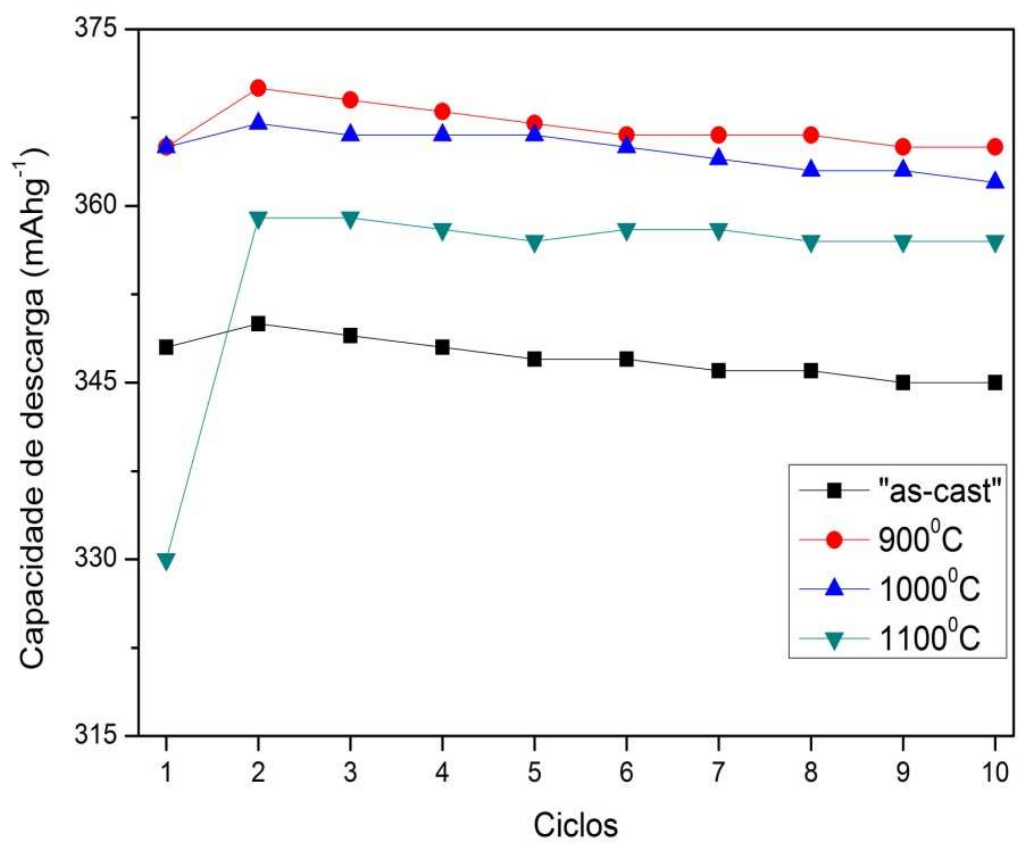

FIGURA 10 - Capacidade de descarga em função do número de ciclos do eletrodo negativo produzido com a liga $\mathrm{La}_{0,7} \mathrm{Mg}_{0,3} \mathrm{Ni}_{2,45} \mathrm{Co}_{0,75} \mathrm{Mn}_{0,1} \mathrm{Al}_{0,2}[60]$.

Na TAB. 7 estão apresentadas as capacidades de descarga máxima $\left(C_{\text {máx }}\right)$ e as capacidades de descarga no ciclo $n^{\circ} 100\left(C_{100}\right)$ obtidas para o eletrodo negativo da liga $\mathrm{La}_{0,7} \mathrm{Mg}_{0,3} \mathrm{Ni}_{2,45} \mathrm{Co}_{0,75} \mathrm{Mn}_{0,1} \mathrm{Al}_{0,2}$ sem e com tratamento térmico $\left(900^{\circ} \mathrm{C}, 1000^{\circ} \mathrm{C}\right.$ e $1100^{\circ} \mathrm{C}$ por 8 horas) [60].

TABELA 7 - Efeito capacidade descarga da liga $\mathrm{La}_{0,7} \mathrm{Mg}_{0,3} \mathrm{Ni}_{2,45} \mathrm{Co}_{0,75} \mathrm{Mn}_{0,1} \mathrm{Al}_{0,2}$ tratadas termicamente em diferentes temperaturas [60].

\begin{tabular}{cccc}
\hline $\begin{array}{c}\text { Temperatura de } \\
\text { tratamento térmico }\left({ }^{0} \mathrm{C}\right)\end{array}$ & $\mathrm{C}_{\text {máx }}\left(\mathrm{mAhg}^{-1}\right)$ & $\mathrm{C}_{100}\left(\mathrm{mAhg}^{-1}\right)$ & $\mathrm{C}_{100} / \mathrm{C}_{\text {máx }}(\%)$ \\
\hline Padrão & 350 & 229 & 65,5 \\
900 & 370 & 249 & 67,5 \\
1000 & 367 & 264 & 72,1 \\
1100 & 359 & 269 & 75,0 \\
\hline
\end{tabular}




\subsection{Capacidade de descarga em baterias de Ni-HM}

As propriedades das baterias como capacidade de descarga, ativação e estabilidade cíclica são dependentes das composições das ligas e suas características microestruturais. Nas ultimas décadas o efeito da substituição dos elementos têm sido amplamente estudado com o objetivo principal de melhorar o desempenho e reduzir custos das baterias de Ni-HM. A TAB. 8 mostra os principais elementos que foram estudados, em ligas a base de magnésio, utilizados em baterias de Ni-HM e a capacidade de descarga máxima obtida nas baterias. 
TABELA 8 - Capacidade máxima de descarga das principais ligas a base de magnésio com substituição dos elementos.

\begin{tabular}{|c|c|c|c|}
\hline Elementos & Ligas & $\begin{array}{l}\text { Capacidade máxima } \\
\text { de descarga }\left(\mathrm{mAhg}^{-1}\right)\end{array}$ & Ref. \\
\hline \multirow{3}{*}{$\operatorname{Pr}$} & $\mathrm{La}_{0,7} \mathrm{Mg}_{0,3} \mathrm{Ni}_{2,45} \mathrm{Co}_{0,75} \mathrm{Mn}_{0,1} \mathrm{Al}_{0,2}$ & 366 & \multirow{3}{*}{ [21] } \\
\hline & $\mathrm{La}_{0,55} \operatorname{Pr}_{0,15} \mathrm{Mg}_{0,3} \mathrm{Ni}_{2,45} \mathrm{Co}_{0,75} \mathrm{Mn}_{0,1} \mathrm{Al}_{0,2}$ & 356 & \\
\hline & $\mathrm{La}_{0,4} \mathrm{Pr}_{0,3} \mathrm{Mg}_{0,3} \mathrm{Ni}_{2,45} \mathrm{Co}_{0,75} \mathrm{Mn}_{0,1} \mathrm{Al}_{0,2}$ & 346 & \\
\hline \multirow{3}{*}{$\mathrm{Nd}$} & $\mathrm{La}_{0,7} \mathrm{Mg}_{0,3} \mathrm{Ni}_{2,45} \mathrm{Co}_{0,75} \mathrm{Mn}_{0,1} \mathrm{Al}_{0,2}$ & 377 & \multirow{3}{*}{ [22] } \\
\hline & $\mathrm{La}_{0,55} \mathrm{Nd}_{0,15} \mathrm{Mg}_{0,3} \mathrm{Ni}_{2,45} \mathrm{Co}_{0,75} \mathrm{Mn}_{0,1} \mathrm{Al}_{0,2}$ & 371 & \\
\hline & $\mathrm{La}_{0,4} \mathrm{Nd}_{0,3} \mathrm{Mg}_{0,3} \mathrm{Ni}_{2,45} \mathrm{Co}_{0,75} \mathrm{Mn}_{0,1} \mathrm{Al}_{0,2}$ & 357 & \\
\hline \multirow{3}{*}{$\mathrm{Ce}$} & $\mathrm{La}_{0,7} \mathrm{Mg}_{0,3} \mathrm{Ni}_{2,875} \mathrm{Mn}_{0,1} \mathrm{Co}_{0,525}$ & 382 & \multirow{3}{*}{ [23] } \\
\hline & $\mathrm{La}_{0,5} \mathrm{Ce}_{0,2} \mathrm{Mg}_{0,3} \mathrm{Ni}_{2,875} \mathrm{Mn}_{0,1} \mathrm{Co}_{0,525}$ & 295 & \\
\hline & $\mathrm{La}_{0,2} \mathrm{Ce}_{0,5} \mathrm{Mg}_{0,3} \mathrm{Ni}_{2,875} \mathrm{Mn}_{0,1} \mathrm{Co}_{0,525}$ & 48 & \\
\hline \multirow{3}{*}{$\mathrm{Ti}$} & $\mathrm{La}_{0,67} \mathrm{Mg}_{0,33} \mathrm{Ni}_{2,75} \mathrm{Co}_{0,25}$ & 384 & \multirow{3}{*}{ [26] } \\
\hline & $\mathrm{La}_{0,603} \mathrm{Ti}_{0,067} \mathrm{Mg}_{0,33} \mathrm{Ni}_{2,75} \mathrm{Co}_{0,25}$ & 359 & \\
\hline & $\mathrm{La}_{0,536} \mathrm{Ti}_{0,134} \mathrm{Mg}_{0,33} \mathrm{Ni}_{2,75} \mathrm{Co}_{0,25}$ & 321 & \\
\hline \multirow{3}{*}{$\mathrm{Zr}$} & $\mathrm{La}_{0,7} \mathrm{Mg}_{0,3} \mathrm{Ni}_{2,45} \mathrm{Co}_{0,75} \mathrm{Mn}_{0,1} \mathrm{Al}_{0,2}$ & 364 & \multirow{3}{*}{ [25] } \\
\hline & $\mathrm{La}_{0,66} \mathrm{Zr}_{0,04} \mathrm{Mg}_{0,3} \mathrm{Ni}_{2,45} \mathrm{Co}_{0,75} \mathrm{Mn}_{0,1} \mathrm{Al}_{0,2}$ & 343 & \\
\hline & $\mathrm{La}_{0,6} \mathrm{Zr}_{0,1} \mathrm{Mg}_{0,3} \mathrm{Ni}_{2,45} \mathrm{Co}_{0,75} \mathrm{Mn}_{0,1} \mathrm{Al}_{0,2}$ & 306 & \\
\hline \multirow{3}{*}{$\mathrm{Mn}$} & $\mathrm{La}_{0,7} \mathrm{Mg}_{0,3} \mathrm{Ni}_{2,55} \mathrm{Co}_{0,45}$ & 342 & \multirow{3}{*}{ [27] } \\
\hline & $\mathrm{La}_{0,7} \mathrm{Mg}_{0,3} \mathrm{Ni}_{2,25} \mathrm{Co}_{0,45} \mathrm{Mn}_{0,3}$ & 368 & \\
\hline & $\mathrm{La}_{0,7} \mathrm{Mg}_{0,3} \mathrm{Ni}_{2,05} \mathrm{Co}_{0,45} \mathrm{Mn}_{0,5}$ & 333 & \\
\hline \multirow{4}{*}{ Co } & $\mathrm{La}_{0,7} \mathrm{Mg}_{0,3} \mathrm{Ni}_{3,4} \mathrm{Mn}_{0,1}$ & 397 & \multirow{4}{*}{ [34] } \\
\hline & $\mathrm{La}_{0,7} \mathrm{Mg}_{0,3} \mathrm{Ni}_{2,65} \mathrm{Mn}_{0,1} \mathrm{Co}_{0,75}$ & 403 & \\
\hline & $\mathrm{La}_{0,7} \mathrm{Mg}_{0,3} \mathrm{Ni}_{2,25} \mathrm{Mn}_{0,1} \mathrm{Co}_{1,15}$ & 389 & \\
\hline & $\mathrm{La}_{0,7} \mathrm{Mg}_{0,3} \mathrm{Ni}_{1,8} \mathrm{Mn}_{0,1} \mathrm{Co}_{1,6}$ & 380 & \\
\hline \multirow{3}{*}{$\mathrm{Al}$} & $\mathrm{La}_{2} \mathrm{MgNi}_{9}$ & 400 & \multirow{3}{*}{ [35] } \\
\hline & $\mathrm{La}_{2} \mathrm{MgNi}_{8,82} \mathrm{Al}_{0,18}$ & 374 & \\
\hline & $\mathrm{La}_{2} \mathrm{MgNi}_{8,55} \mathrm{Al}_{0,45}$ & 221 & \\
\hline
\end{tabular}




\section{PROCEDIMENTO EXPERIMENTAL}

Este trabalho foi realizado no Laboratório de Materiais Magnéticos e Elétricos, localizado no Centro de Ciências e Tecnologia de Materiais (CCTM) do Instituto de Pesquisas Energéticas e Nucleares (IPEN). As ligas metálicas estudadas neste trabalho foram obtidas da LCM (Less Commom Metals) no estado bruto de fusão, sem tratamento térmico.

As composições químicas das ligas utilizadas no trabalho foram:

- $\mathrm{La}_{0,7} \mathrm{Pr}_{0,3} \mathrm{Al}_{0,3} \mathrm{Mn}_{0,4} \mathrm{Co}_{0,5} \mathrm{Ni}_{3,8}$

- $\mathrm{La}_{0,6} \mathrm{Mg}_{0,1} \mathrm{Pr}_{0,3} \mathrm{Al}_{0,3} \mathrm{Mn}_{0,4} \mathrm{Co}_{0,5} \mathrm{Ni}_{3,8}$;

- $\mathrm{La}_{0,4} \mathrm{Mg}_{0,3} \mathrm{Pr}_{0,3} \mathrm{Al}_{0,3} \mathrm{Mn}_{0,4} \mathrm{Co}_{0,5} \mathrm{Ni}_{3,8}$

- $\mathrm{La}_{0,2} \mathrm{Mg}_{0,5} \mathrm{Pr}_{0,3} \mathrm{Al}_{0,3} \mathrm{Mn}_{0,4} \mathrm{Co}_{0,5} \mathrm{Ni}_{3,8}$

- $\mathrm{Mg}_{0,7} \mathrm{Pr}_{0,3} \mathrm{Al}_{0,3} \mathrm{Mn}_{0,4} \mathrm{Co}_{0,5} \mathrm{Ni}_{3,8}$

\subsection{Caracterização das ligas metálicas}

\subsubsection{Microscopia eletrônica de varredura}

A microscopia eletrônica de varredura (MEV) foi utilizada para estudo da superfície dos materiais, permitindo a análise de regiões irregulares, como e superfície de uma fratura ou a morfologia de uma partícula.

Para realizar a caracterização microestrutural das ligas e determinar a composição das fases presentes, as amostras foram preparadas utilizando as técnicas convencionais de metalografia: embutimento em resina Epóxi, lixamento e polimento final das amostras para um posterior recobrimento. Foi utilizado um microscópio eletrônico de varredura (Philips XL 30) com EDS. 


\subsubsection{Difração de raios- $X$}

Os ensaios foram realizados utilizando o equipamento RIGAKU modelo Multiflex no intervalo $10^{\circ} \leq 2 \theta \leq 100^{\circ}$ usando radiação CuK a (com taxa de varredura de $1^{\circ} \min ^{-1}$ ). A identificação das fases foi realizada por meio do programa Crystallographica Search-Match (CSM). A quantificação de fases foi realizada através do programa PowderCell versão 2.3.

\subsubsection{Distribuição do tamanho de partículas - CILAS}

Para determinação do tamanho do tamanho médio de partículas foi utilizado o equipamento CILAS 1064, com pirofosfato de sódio como agente dispersante e ultra-som por 3 minutos anterior à análise. 


\subsection{Hidrogenação das ligas metálicas}

N FIG. 11 é mostrado o fluxograma utilizado para hidrogenação das ligas metálicas. A massa utilizada na hidrogenação foi de 5 gramas. A hidrogenação foi realizada utilizando uma pressão de $\mathrm{H}_{2}$ de $0,2 \mathrm{MPa}$ (2 bar) e 1 MPa (10 bar).

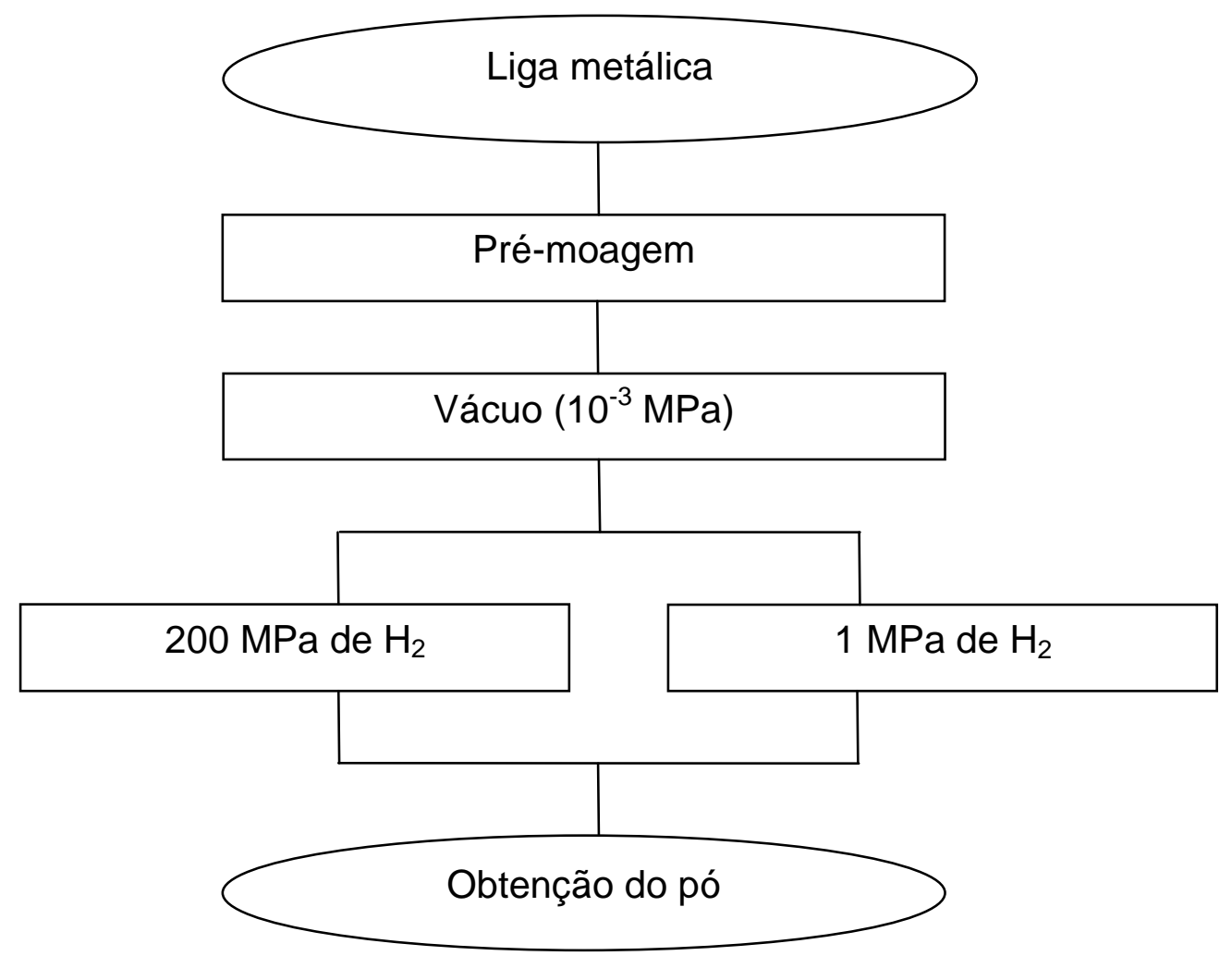

FIGURA 11 - Fluxograma utilizado na hidrogenação das ligas metálicas.

Na FIG. 12 é mostrado o fluxograma utilizado para hidrogenação das ligas a $500^{\circ} \mathrm{C}$ e um posterior resfriamento com fluxo de ar e taxa de resfriamento de $30^{\circ} \mathrm{C} / \mathrm{min}$, nas mesmas condições de pressão $(0,2 \mathrm{MPa}$ e $1 \mathrm{MPa})$. 


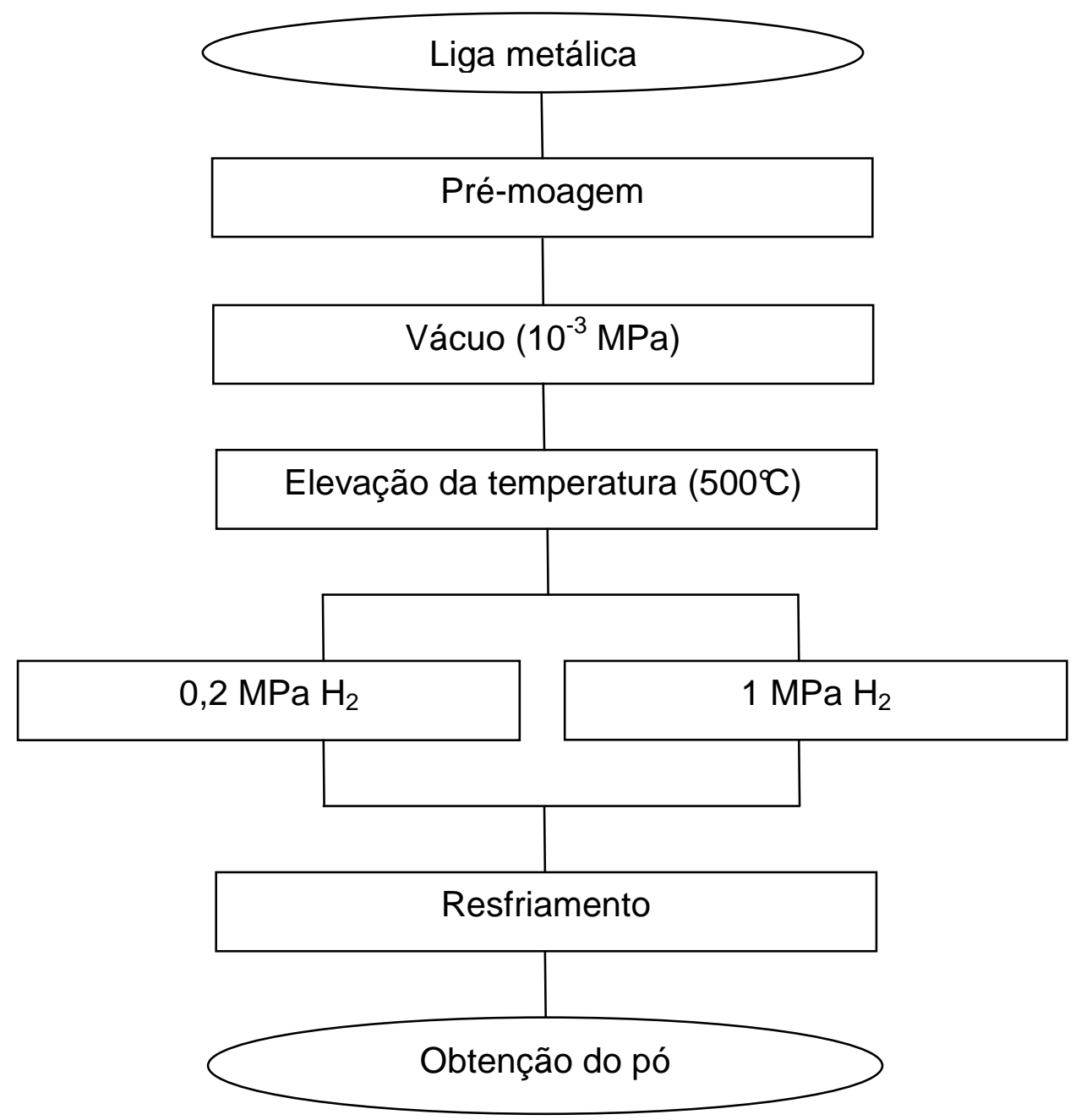

FIGURA 12 - Fluxograma utilizado para hidrogenação das ligas metálicas com elevação da temperatura a $500{ }^{\circ} \mathrm{C}$ e resfriamento.

Na FIG. 13 (a) está mostrado a liga metálica no estado bruto de fusão e na FIG. 13 (b) 5 gramas da liga utilizada na hidrogenação. 

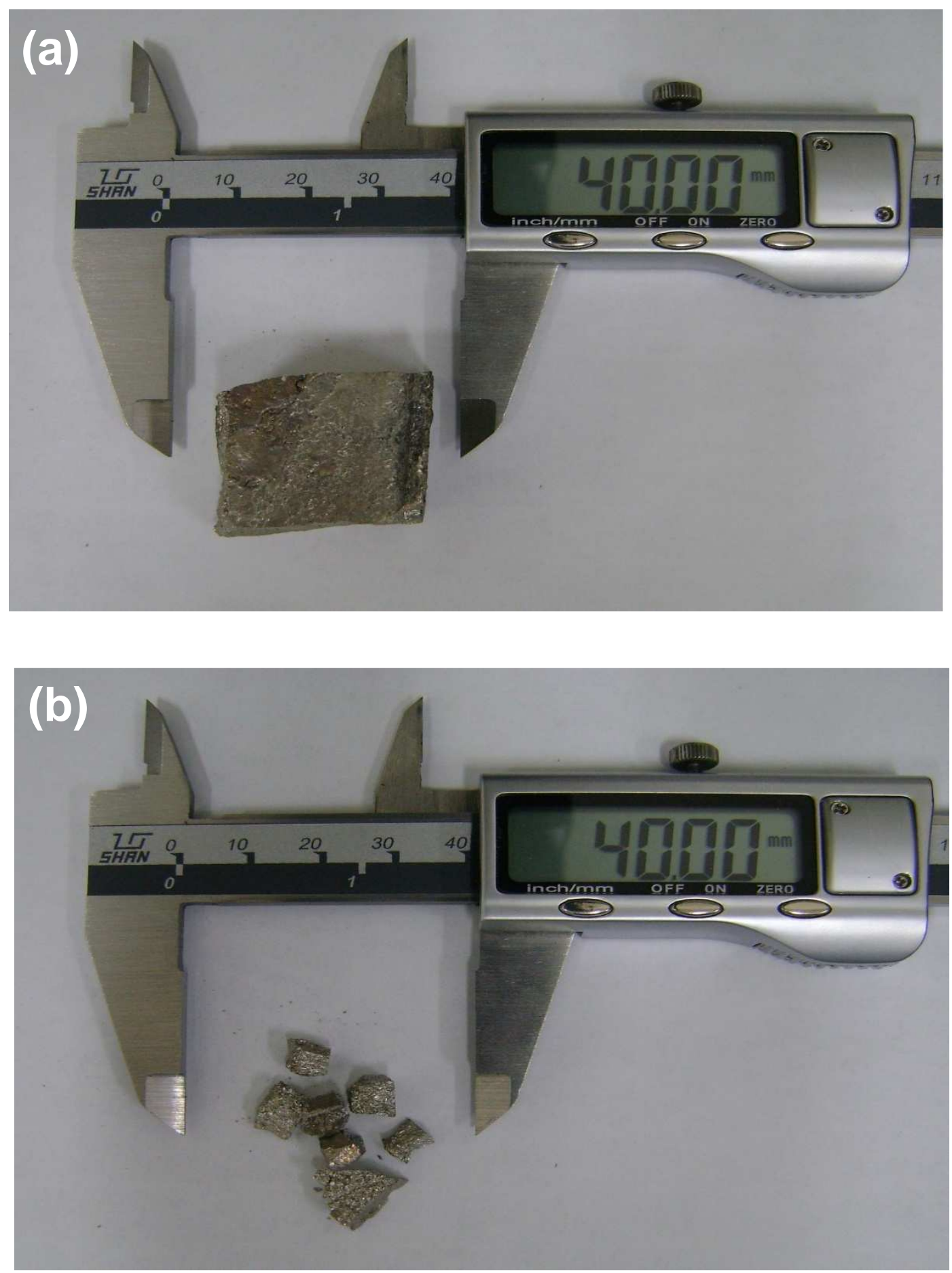

FIGURA 13 - (a) Liga metálica no estado bruto de fusão (b) $5 g$ da liga metálica utilizada na hidrogenação. 
Para o processo de hidrogenação, a liga metálica é inserida em um cadinho de aço inox posicionado no interior de um vaso de pressurização. $O$ procedimento de hidrogenação foi realizado sem a presença da liga metálica, denominada branco, para comparação.

Na FIG. 14 está mostrado o sistema utilizado para hidrogenação das ligas, constituído do vaso de hidrogenação de aço 316L, válvula de injeção de hidrogênio HyLok série NV, forno EDG modelo F-1800 e uma bomba de vácuo mecânica de dois estágios Edwards modelo E2M5 acoplado ao um medidor Pirani

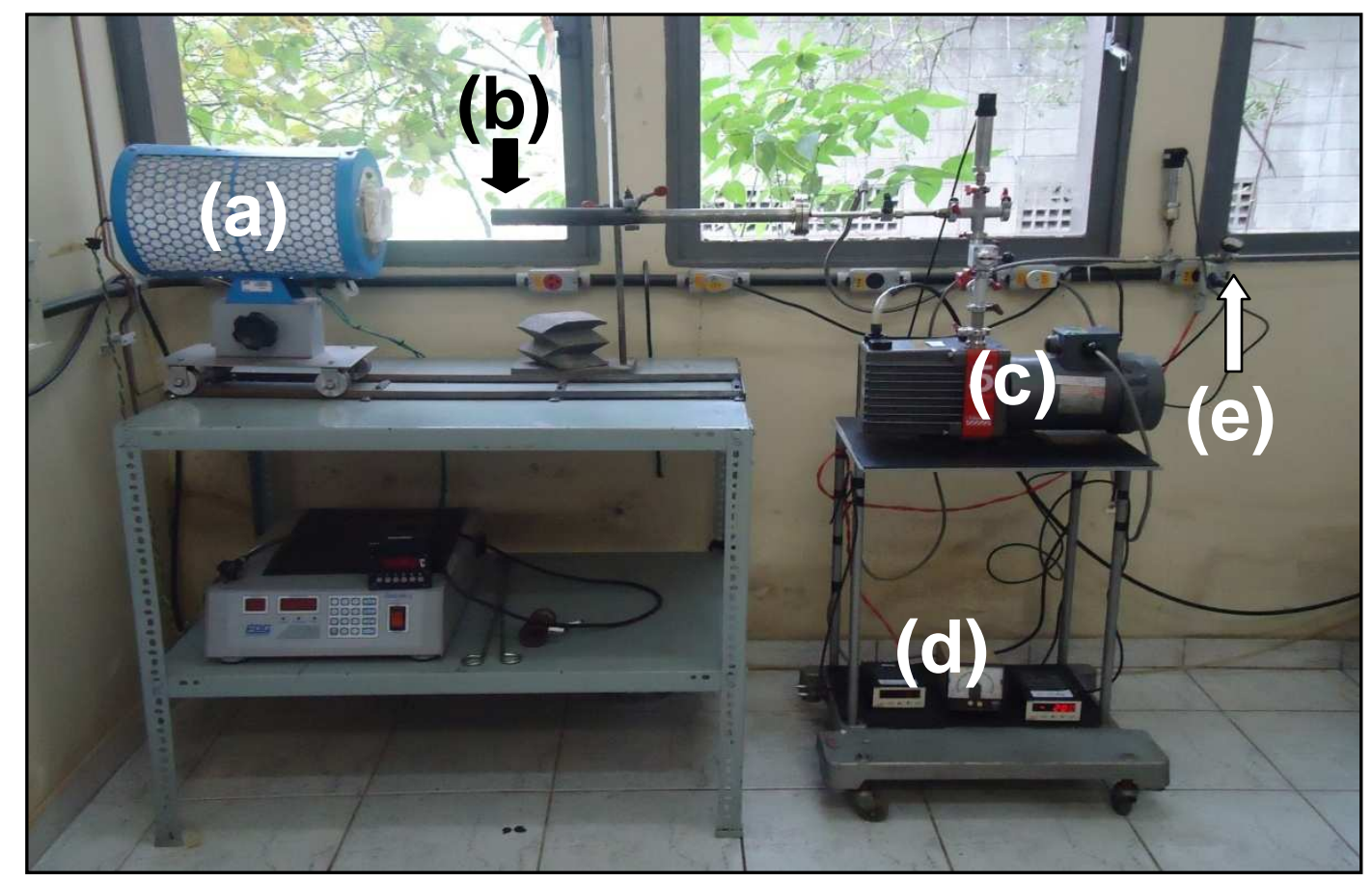

FIGURA 14 - Sistema de vácuo utilizado na hidrogenação das ligas, onde: (a) forno (EDG), (b) vaso de hidrogenação, (c) bomba de vácuo mecânica, (d) medidor Pirani e (e) válvula para injeção de hidrogênio. 


\subsection{Montagem das baterias de Ni-HM}

Para a montagem das baterias de Ni-HM foi utilizado às seguintes etapas, conforme mostrado na FIG. 15.

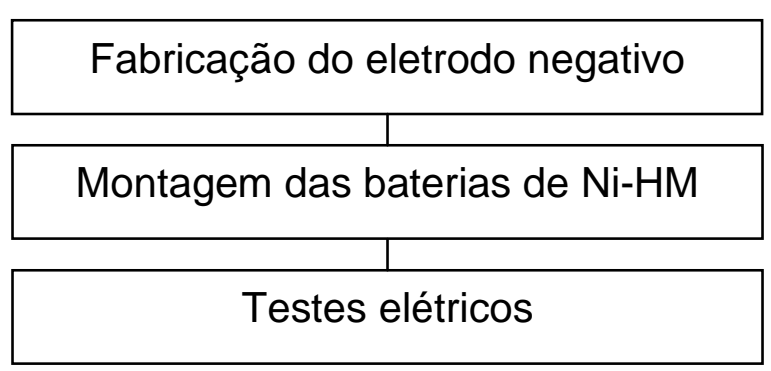

FIGURA 15 - Etapas para montagem das baterias de Ni-HM.

\subsubsection{Fabricação do eletrodo negativo}

O eletrodo negativo das baterias de Ni-HM foi fabricado utilizando 140 mg da liga metálica, moída e classificada em uma peneira com abertura de $45 \mu \mathrm{m}$, e $140 \mathrm{mg}$ de uma mistura contendo $67 \%$ de carbono de alta área superficial (negro de fumo - Vulcan XC 72R) e 33\% do agente ligante politetrafluoretileno (PTFE, Teflon T30, Daikin). Na FIG. 16 são mostrados os materiais descritos [61].

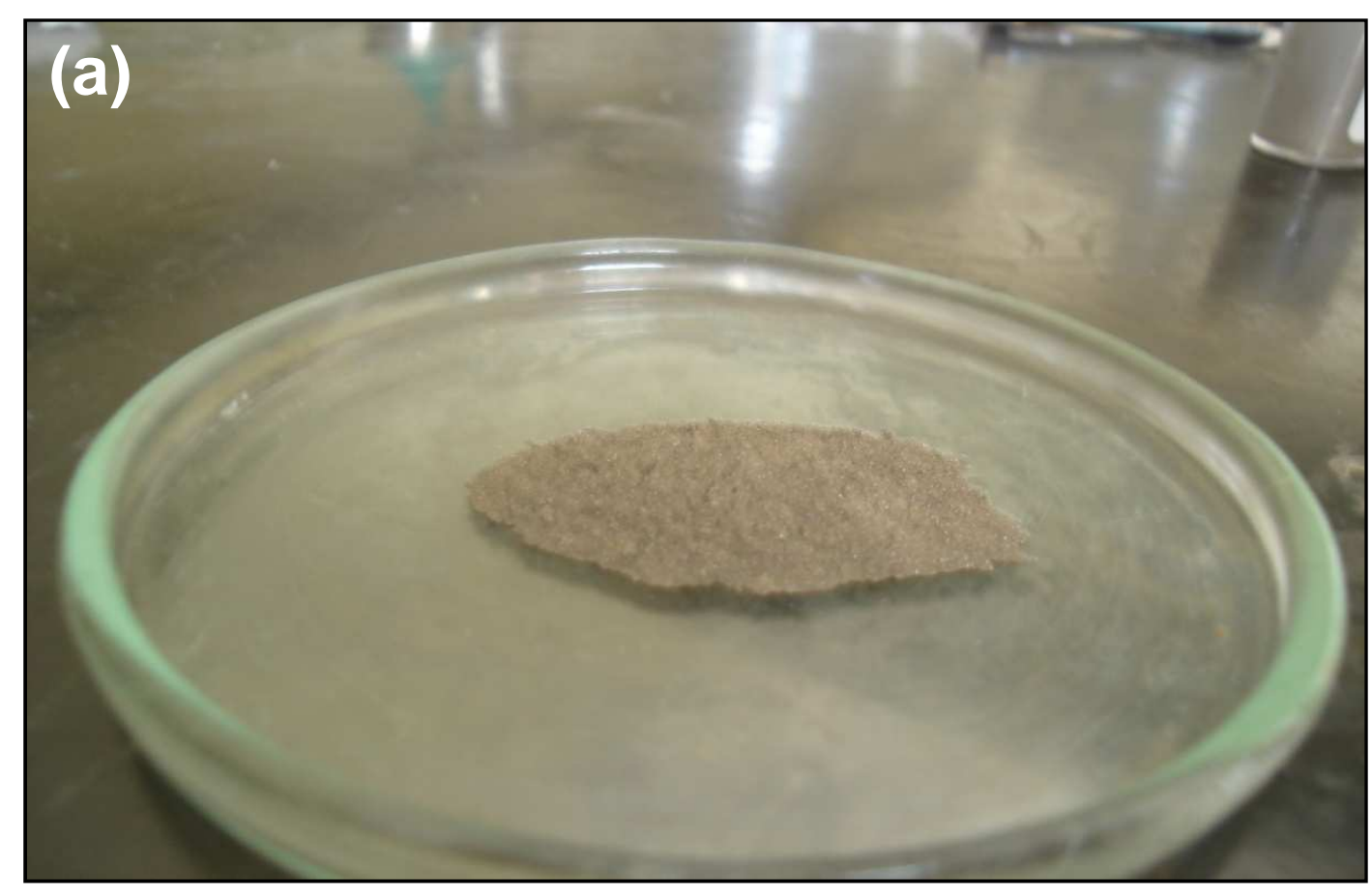



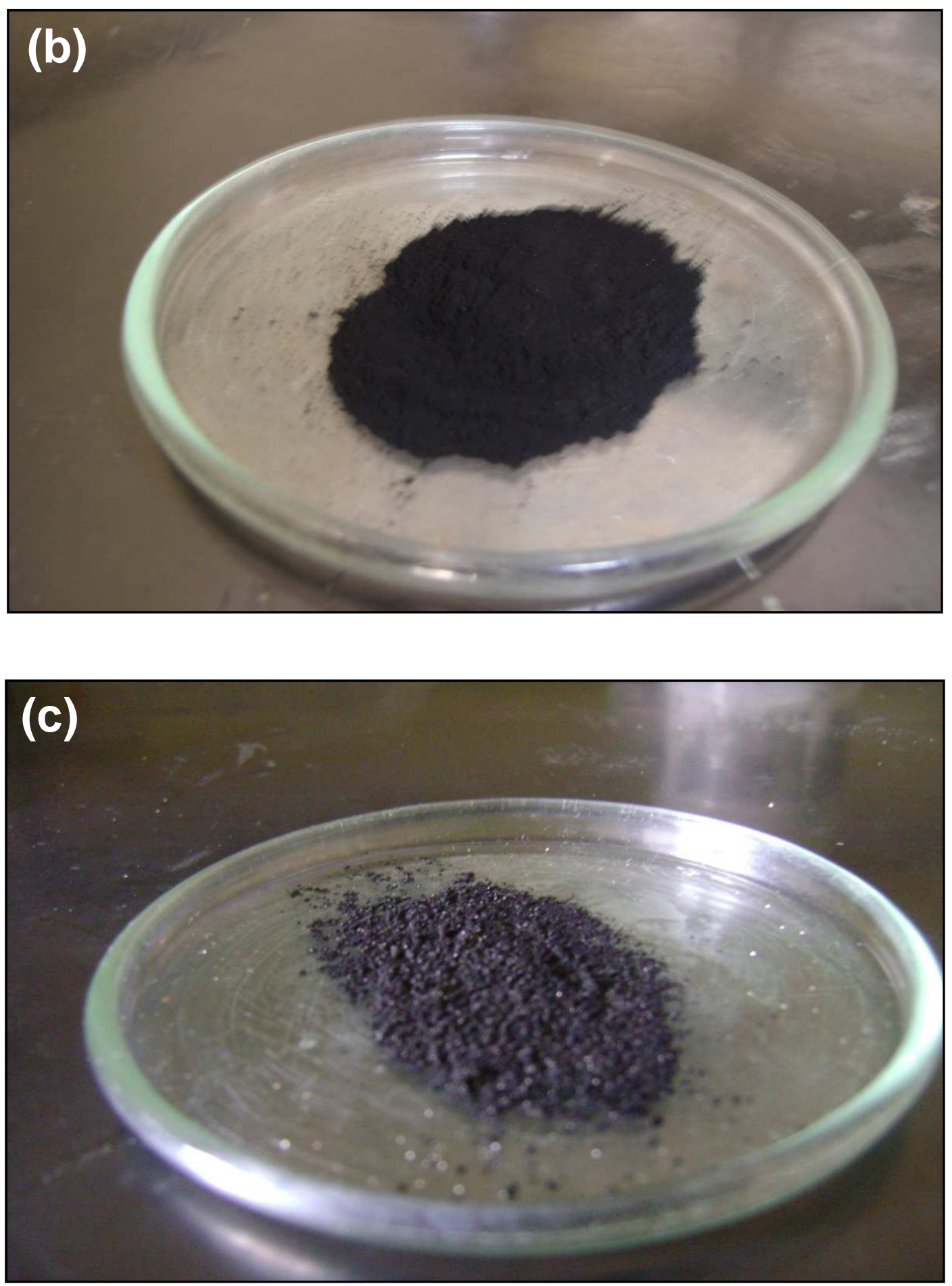

FIGURA 16 - Processo de fabricação do eletrodo negativo, onde: (a) pó da liga

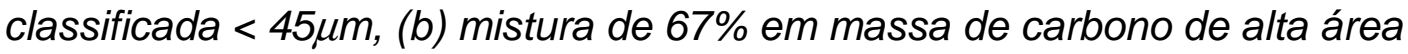
superficial e 33\% em massa de PTFE e (c) mistura composta pela liga metálica, PTFE e carbono de alta área superficial. 


\subsubsection{Montagem da bateria de Ni-HM}

O eletrodo positivo de $\mathrm{Ni}(\mathrm{OH})_{2}$ e o separador, utilizados no desenvolvimento deste trabalho, foram retirados de baterias de $\mathrm{Ni}-\mathrm{HM}$ comerciais da marca Sony modelo AA 2500 mAh. Tais materiais são mostrados na FIG. 17.
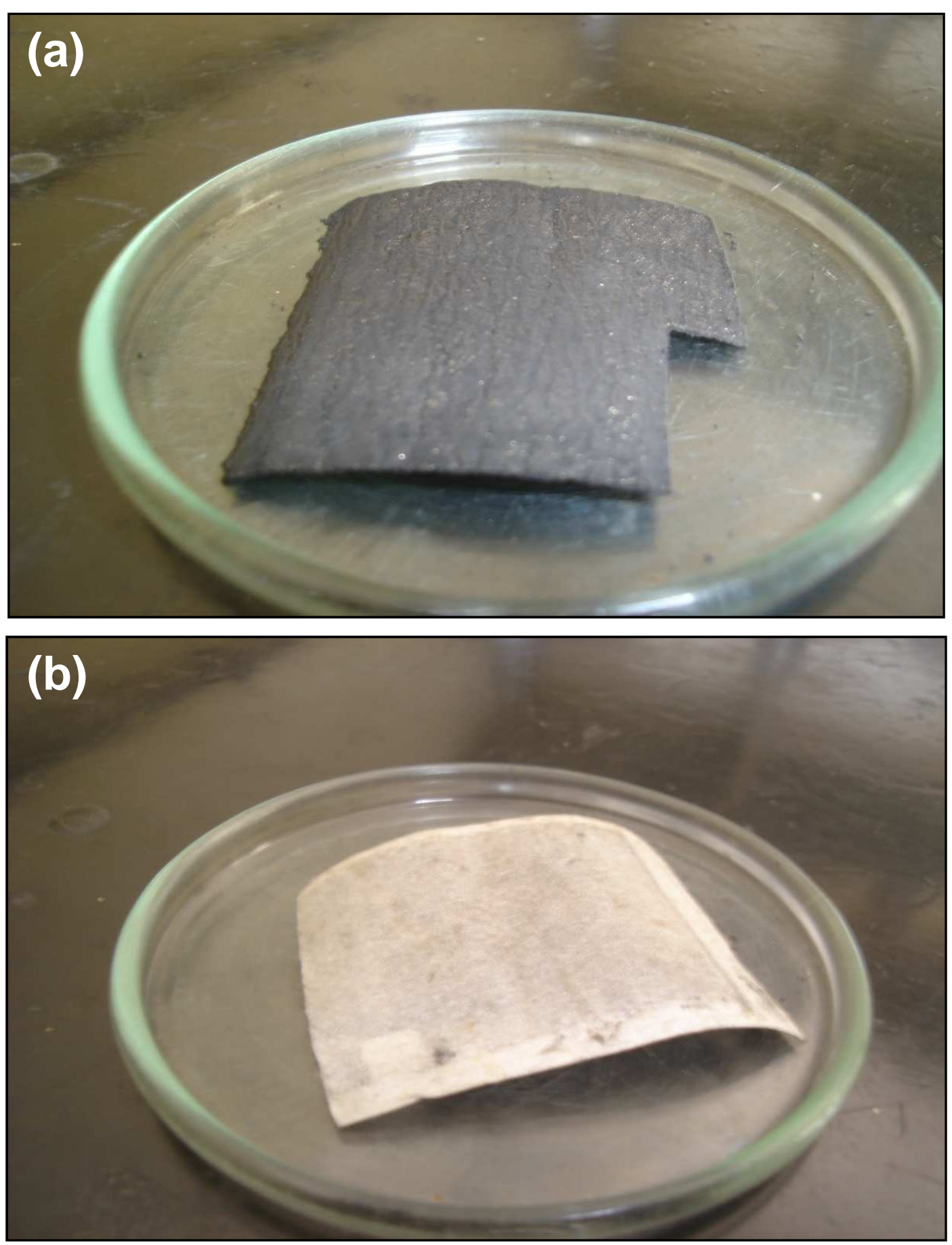

FIGURA 17 - (a) Eletrodo positivo de $\mathrm{Ni}(\mathrm{OH})_{2}$ (b) separador.Ambos foram retirados de baterias de Ni-HM comerciais. 
No separador é colocado o eletrólito que é uma solução composta de $\mathrm{KOH} 6 \mathrm{~mol} \mathrm{~L}^{-1}$. A quantidade de eletrólito utilizada foi de 0,25 $\mathrm{ml}$ [61].

Após a prensagem do eletrodo negativo no molde de aço inox, o separador e o eletrodo positivo são recortados e colocados na bateria.

A utilização de vedações de polietileno foi necessária para selar as partes da bateria e evitar o curto-circuito interno. Na FIG. 18 são mostradas as regiões onde são colocadas as vedações.

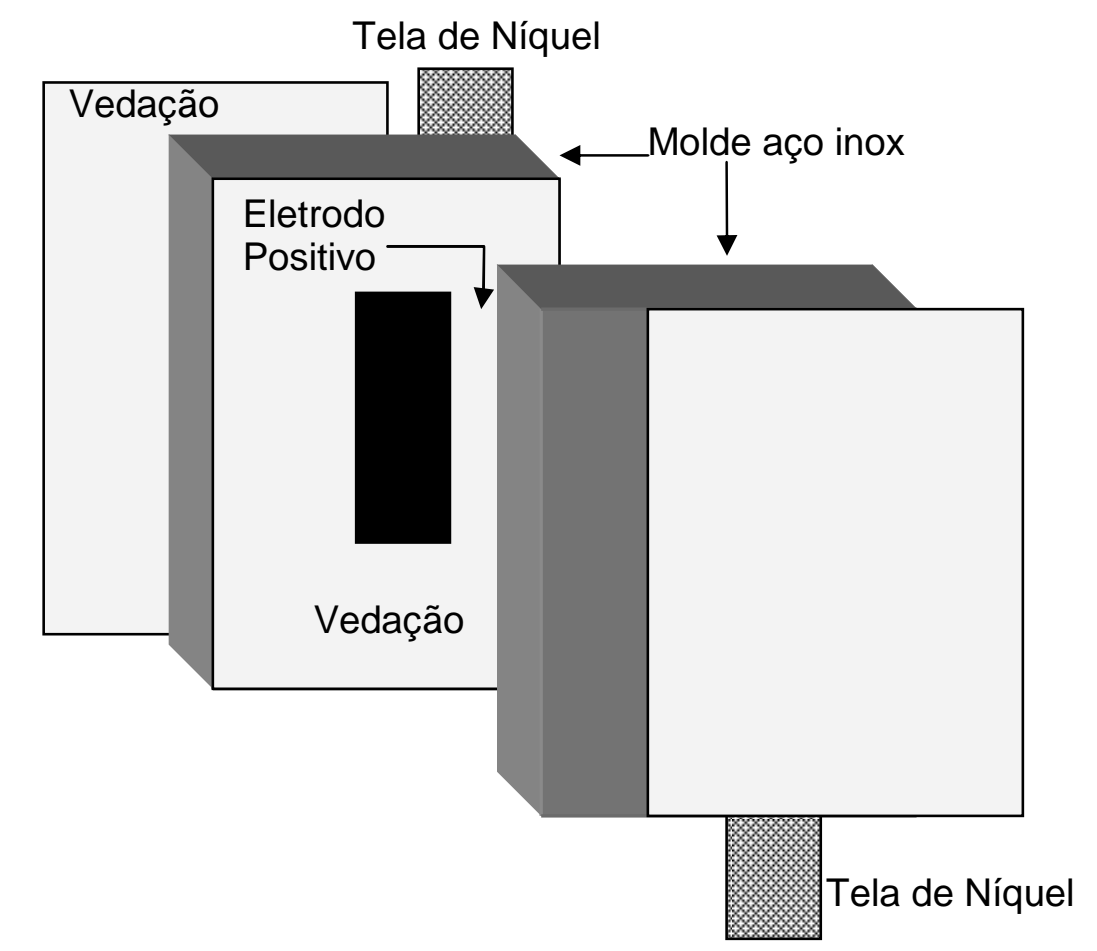

FIGURA 18 - Representação esquemática da região das vedações.

Na FIG. 19 (a - f) são mostradas os as etapas de montagem das baterias seladas de $\mathrm{Ni}-\mathrm{HM}$. 


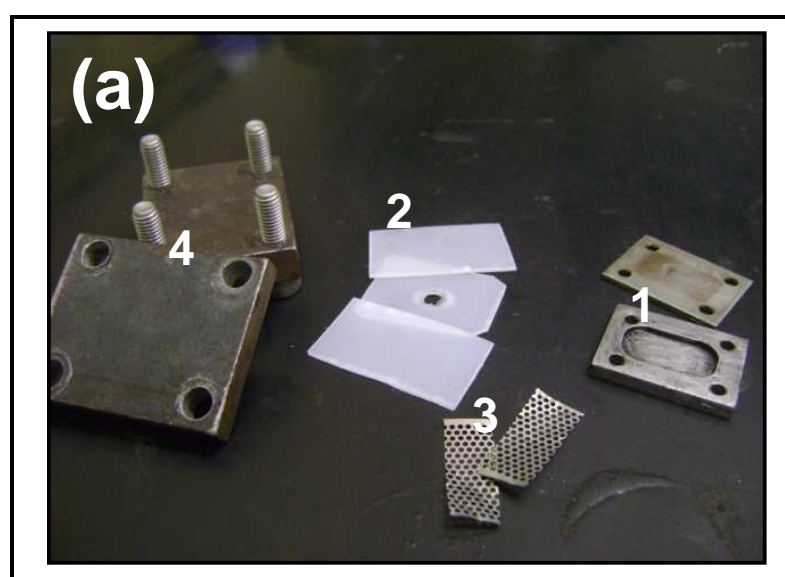

(a) 1 - molde aço inox, 2 - vedações, 3 - contatos de níquel, 4 - chapas para selagem.

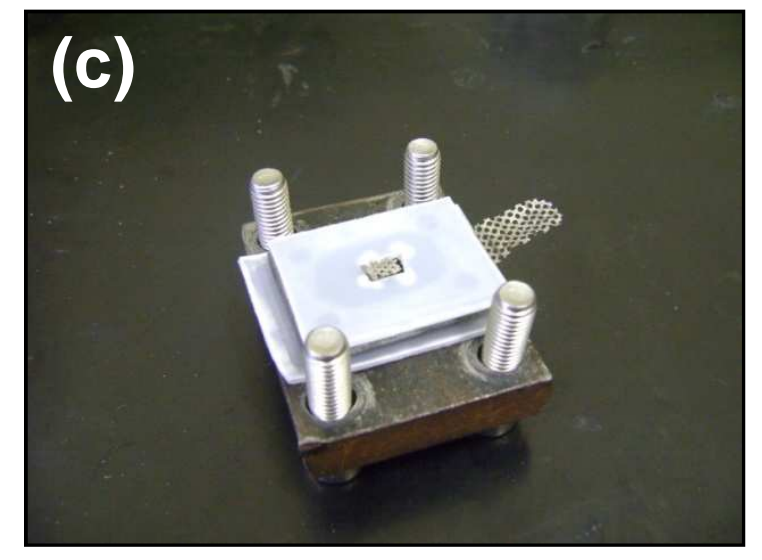

(c) Molde após montagem do separador, eletrólito, eletrodo positivo e vedação.

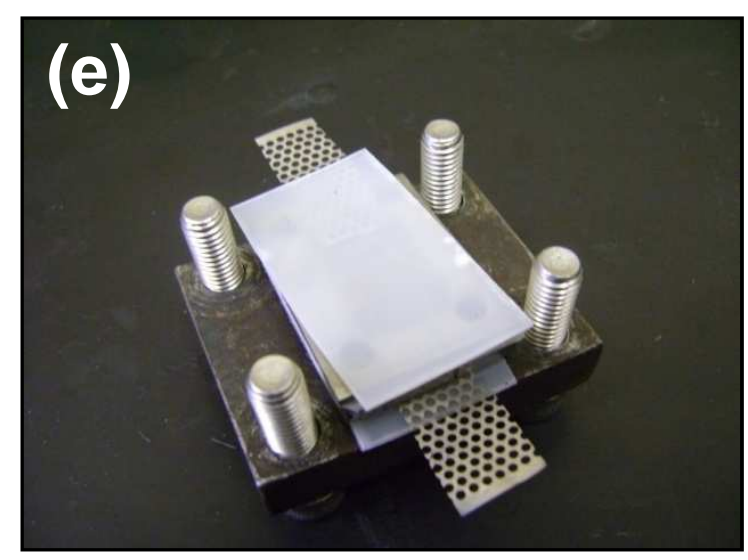

(e) Montagem do contato de níquel e vedação.

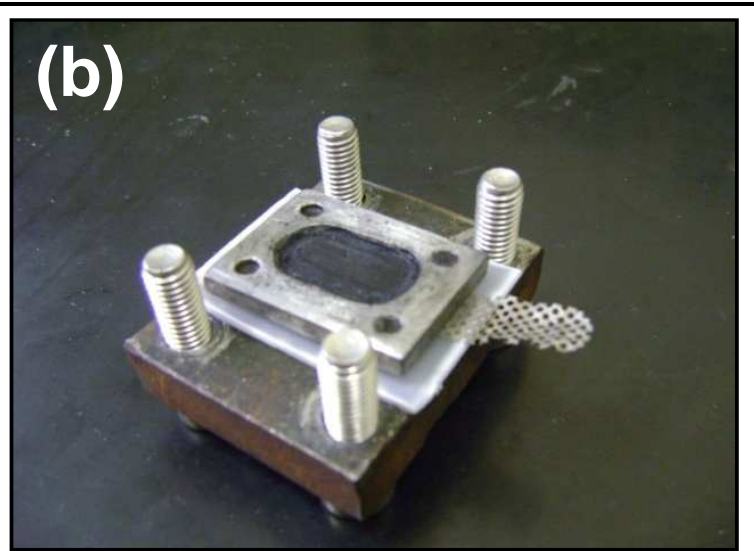

(b) Mistura (eletrodo negativo) prensada no molde e parte inferior da vedação e contato.

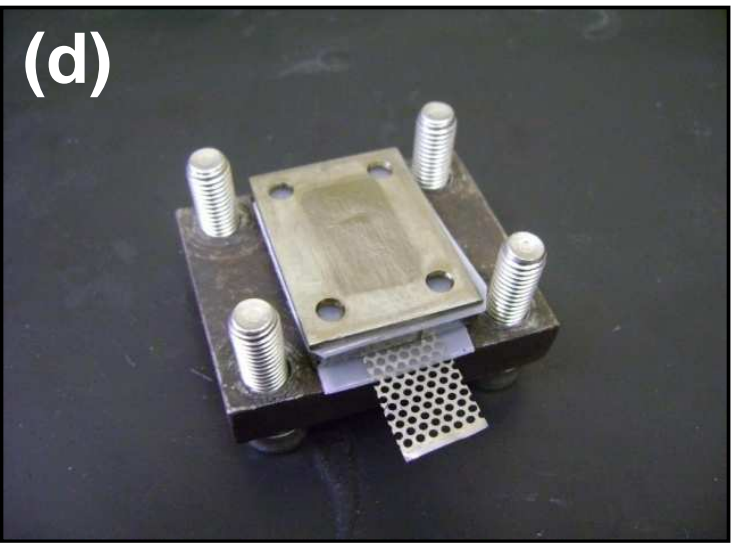

(d) Montagem da parte superior do molde de aço inox.

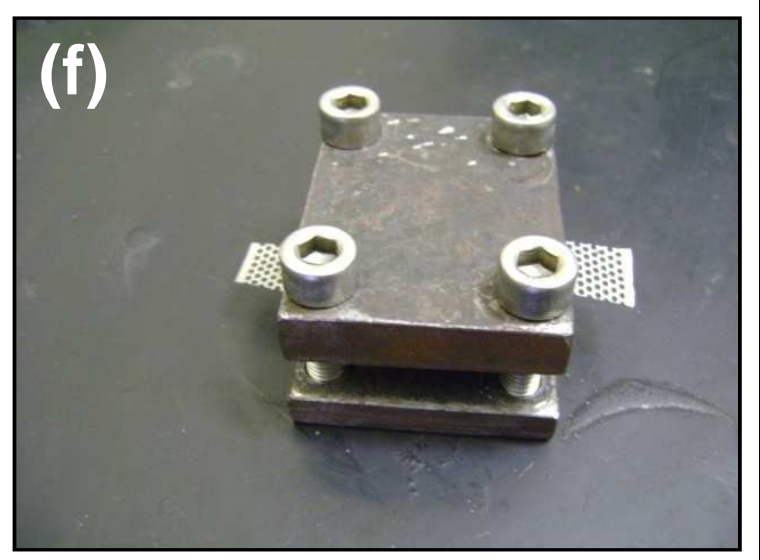

(f) Selagem da bateria.

FIGURA 19 - Etapas de montagem das baterias de Ni-HM. 


\subsubsection{Célula eletroquímica}

Foram utilizados os mesmos parâmetros para a montagem da célula eletroquímica, onde se manteve a mesma proporção no eletrodo negativo (50 \% de liga metálica $+50 \%$ da mistura de carbono com PTFE) e o mesmo eletrólito $\left(\mathrm{KOH} 6 \mathrm{~mol} \mathrm{~L}^{-1}\right)$.

O eletrodo negativo foi preparado utilizando uma matriz metálica com diâmetro de $14 \mathrm{~mm}$ (área $=1,5 \mathrm{~cm}^{2}$ ). Em ambos os lados do eletrodo negativo foi colocado uma tela de níquel para auxiliar na condução elétrica. $O$ contra eletrodo utilizado foi de platina com área aproximada de $3,0 \mathrm{~cm}^{2}$. O eletrodo de referência utilizado foi a base de $\mathrm{Hg} / \mathrm{HgO}$. Na FIG. 20 é mostrada a célula eletroquímica com os eletrodos.

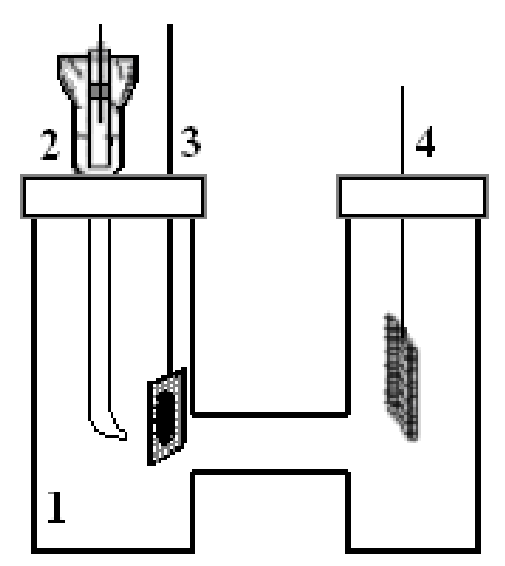

FIGURA 20 - Sistema experimental para estudo em célula eletroquímica; onde (1) representa a célula eletroquímica, (2) eletrodo de referência com $\mathrm{Hg} / \mathrm{HgO}$, (3) eletrodo de trabalho e (4) contra eletrodo (platina).

\subsubsection{Testes elétricos}

Para os experimentos de carga-descarga das baterias foi utilizado o analisador digital de quatro canais (Arbin BT4) conectado a um computador com o programa MTSPro versão 4.0, como mostrado na FIG. 21.

As medidas realizadas nas baterias de Ni-HM incluem a determinação da capacidade de descarga máxima das baterias e a durabilidade cíclica, ou seja, total de ciclos de carga/descarga. Foi utilizado uma densidade de corrente de 
carga de $100 \mathrm{mAg}^{-1}$ (14 mA durante 5 horas), densidade de corrente de descarga de $50 \mathrm{mAg}^{-1}(7 \mathrm{~mA})$ e um potencial de corte de $0,9 \mathrm{~V}$. Para o experimento realizado em célula eletroquímica o potencial de corte foi 0,6 $\mathrm{V}$.
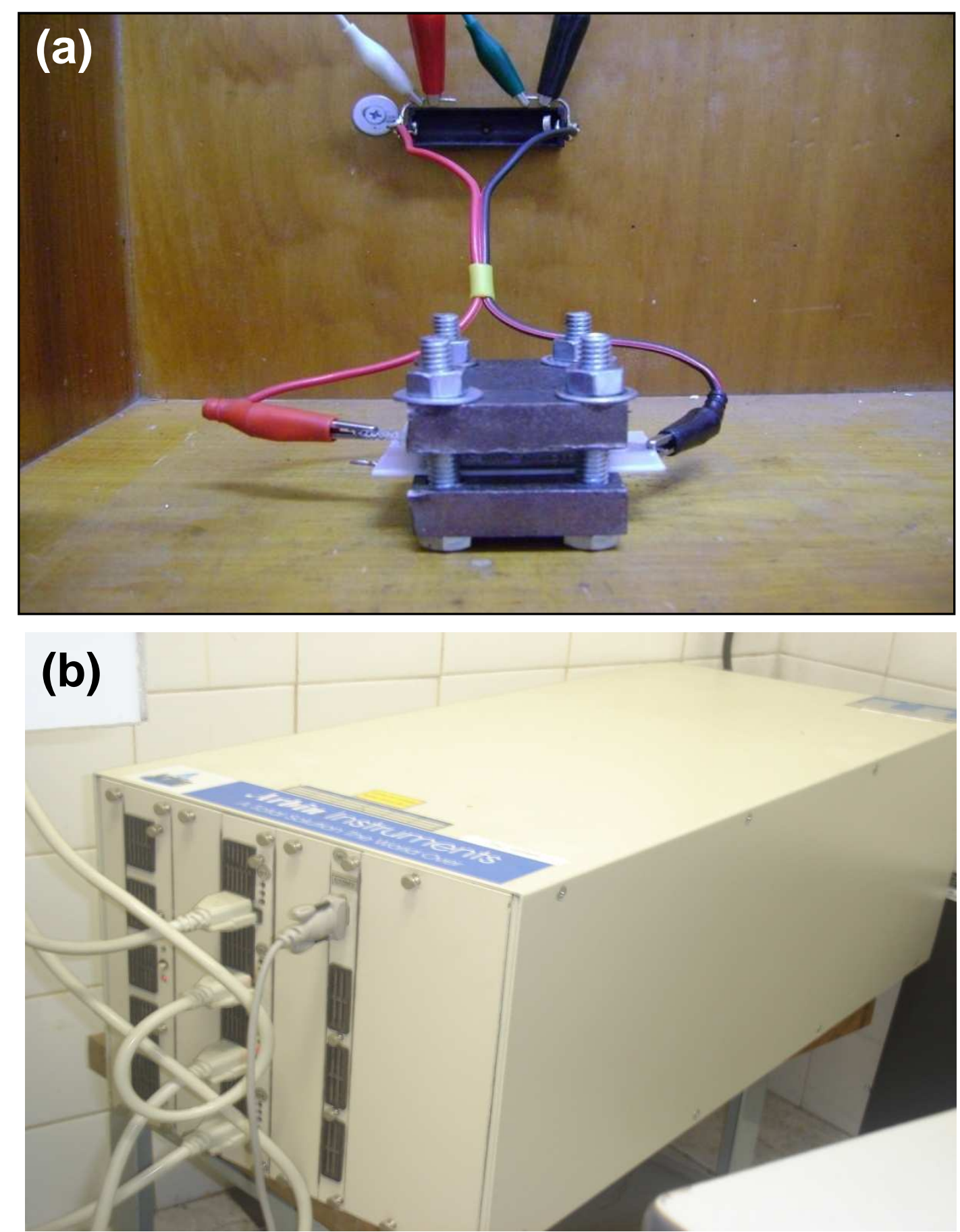

FIGURA 21 - Equipamento de testes elétricos, onde: (a) canal de medidas, (b) analisador digital de quatro canais (Arbin BT4). 


\subsection{Resistência Interna}

Os resultados da resistência interna das baterias foram analisados através da curva da tensão em função do tempo nos ciclos, como mostrado na FIG. 22.

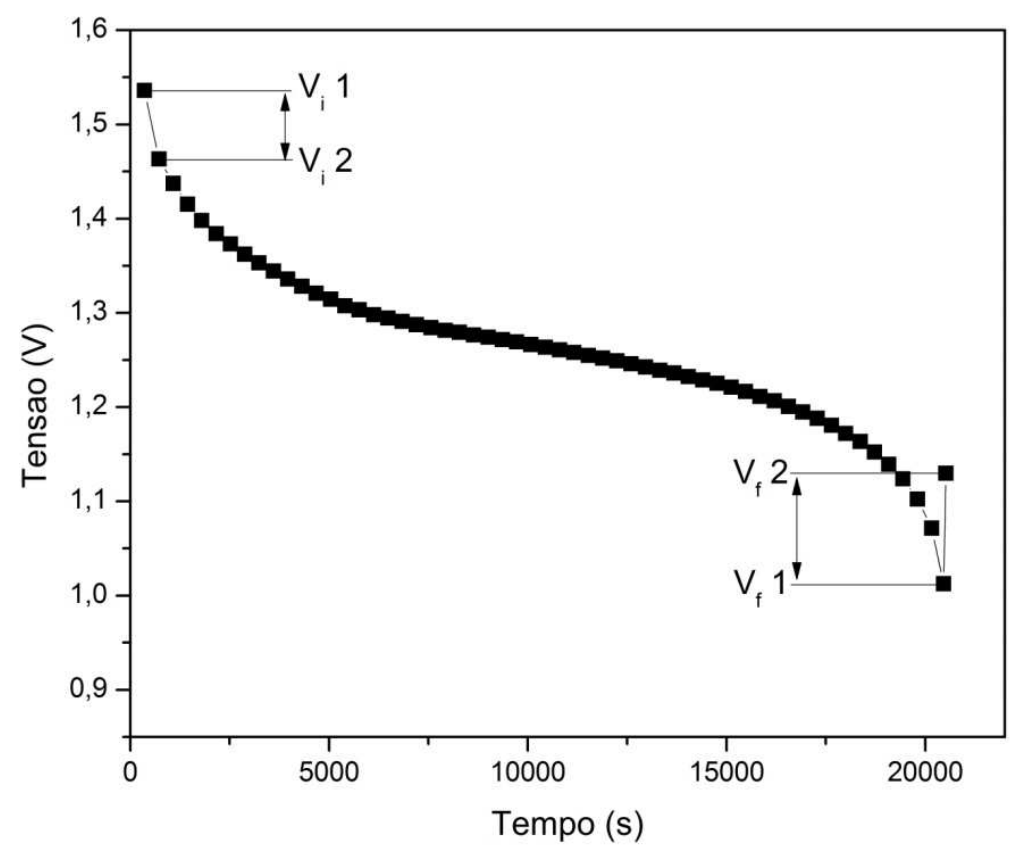

FIGURA 22 - Curva da tensão em função do tempo utilizada para cálculo da resistência interna de uma bateria.

Os valores da resistência interna, no inicio e no final do ciclo, são calculados através das eq. 1.6 e 1.7:

$$
\begin{aligned}
& \mathrm{R}_{\text {in }} \text { Inicial }=\frac{\Delta \mathrm{V}}{\Delta \mathrm{l}}=\frac{\mathrm{V}_{\mathrm{i}} 2-\mathrm{V}_{\mathrm{i}} 1}{\Delta \mathrm{l}}(\Omega) \\
& \mathrm{R}_{\text {in }} \text { Final }=\frac{\Delta \mathrm{V}}{\Delta \mathrm{l}}=\frac{\mathrm{V}_{\mathrm{f}} 2-\mathrm{V}_{\mathrm{f}} 1}{\Delta \mathrm{l}}(\Omega)
\end{aligned}
$$

A variação da corrente $(\Delta \mathrm{I})$ é constante $(7 \mathrm{~mA})$, que é a corrente de descarga utilizado nas medidas. 
A partir dos valores da resistência interna inicial e final em cada ciclo é realizado o cálculo da variação $\left(\Delta R_{\text {interna }}\right)$ e a média ( $R_{\text {interna }}$ Média) entre as resistências, como mostrado nas eq. 1.8 e 1.9:

$$
\begin{gathered}
\Delta R_{\text {interna }}=R_{\text {in }} \text { Final }-R_{\text {in }} \text { Inicial } \\
\Delta R_{\text {interna }} \text { Media }=\frac{\mathrm{R}_{\text {in }} \text { Final }+R_{\text {in }} \text { Inicial }}{2}
\end{gathered}
$$




\section{$5 \quad$ RESULTADOS E DISCUSSÃO}

\subsection{Composição das ligas}

$\mathrm{Na}$ TAB. 9 está mostrada a análise química das ligas $\mathrm{La}_{0,7-}$ ${ }_{x} \mathrm{Mg}_{x} \mathrm{Pr}_{0,3} \mathrm{Al}_{0,3} \mathrm{Mn}_{0,4} \mathrm{Co}_{0,5} \mathrm{Ni}_{3,8}$ ( $\mathrm{x}=0$ a 0,7 ), onde: (a) representa a porcentagem em peso e (b) representa a porcentagem atômica. As análises foram fornecidas pelo fabricante LCM, e foram realizadas por Espectrometria de Emissão Atômica por Plasma Acoplado Indutivamente (ICP-AES - "Inductively Coupled Plasma - Atomic Emission Spectrometry").

TABELA 9 - Análise química das ligas $\mathrm{La}_{0,7-x} \mathrm{Mg}_{x} \mathrm{Pr}_{0,3} \mathrm{Al}_{0,3} \mathrm{Mn}_{0,4} \mathrm{Co}_{0,5} \mathrm{Ni}_{3,8}(\mathrm{x}=0 \mathrm{a}$ $0,7)$ onde: (a) porcentagem em peso e (b) porcentagem atômica.

\begin{tabular}{c|c|c|c|c|c|c|c|c}
\hline \multirow{2}{*}{\multicolumn{2}{c|}{}} & \multicolumn{7}{c}{ Composição (erro \pm 1\%) } \\
\cline { 3 - 9 } \multicolumn{2}{c|}{} & La & Mg & Pr & Al & Mn & Co & Ni \\
\hline \multirow{2}{*}{$\mathbf{0}$} & (a) & 23,04 & - & 10,02 & 1,92 & 5,21 & 6,98 & 52,84 \\
& (b) & 11,7 & - & 5,0 & 5,0 & 5,2 & 6,6 & 63,3 \\
\hline \multirow{2}{*}{$\mathbf{0 , 1}$} & (a) & 20,3 & 0,59 & 10,3 & 1,97 & 5,35 & 7,18 & 54,32 \\
& (b) & 10,0 & 1,67 & 5,0 & 5,0 & 6,0 & 6,6 & 63,3 \\
\hline \multirow{2}{*}{$\mathbf{0 , 3}$} & (a) & 14,33 & 1,88 & 10,9 & 2,09 & 5,67 & 7,6 & 57,53 \\
& (b) & 6,7 & 5,0 & 5,0 & 5,0 & 6,8 & 6,6 & 63,3 \\
\hline \multirow{2}{*}{$\mathbf{0 , 5}$} & (a) & 7,62 & 3,33 & 11,59 & 2,22 & 6,02 & 8,08 & 61,14 \\
& (b) & 3,3 & 8,3 & 5,0 & 5,0 & 6,5 & 6,6 & 63,3 \\
\hline \multirow{2}{*}{$\mathbf{0 , 7}$} & (a) & - & 4,98 & 11,7 & 2,37 & 6,43 & 8,62 & 65,24 \\
& (b) & - & 11,6 & 5,0 & 5,0 & 6,3 & 6,6 & 63,3 \\
\hline
\end{tabular}

\subsection{Caracterização microestrutural}

As micrografias obtidas por MEV das ligas $\mathrm{La}_{0,7-}$ ${ }_{x} \mathrm{Mg}_{\times} \mathrm{Pr}_{0,3} \mathrm{Al}_{0,3} \mathrm{Mn}_{0,4} \mathrm{Co}_{0,5} \mathrm{Ni}_{3,8}$ ( $\mathrm{x}=0$ a 0,7) estão mostradas nas FIG. $23-27$, onde: (a) representa a visão geral (500x) e (b) detalhada (1000x). 


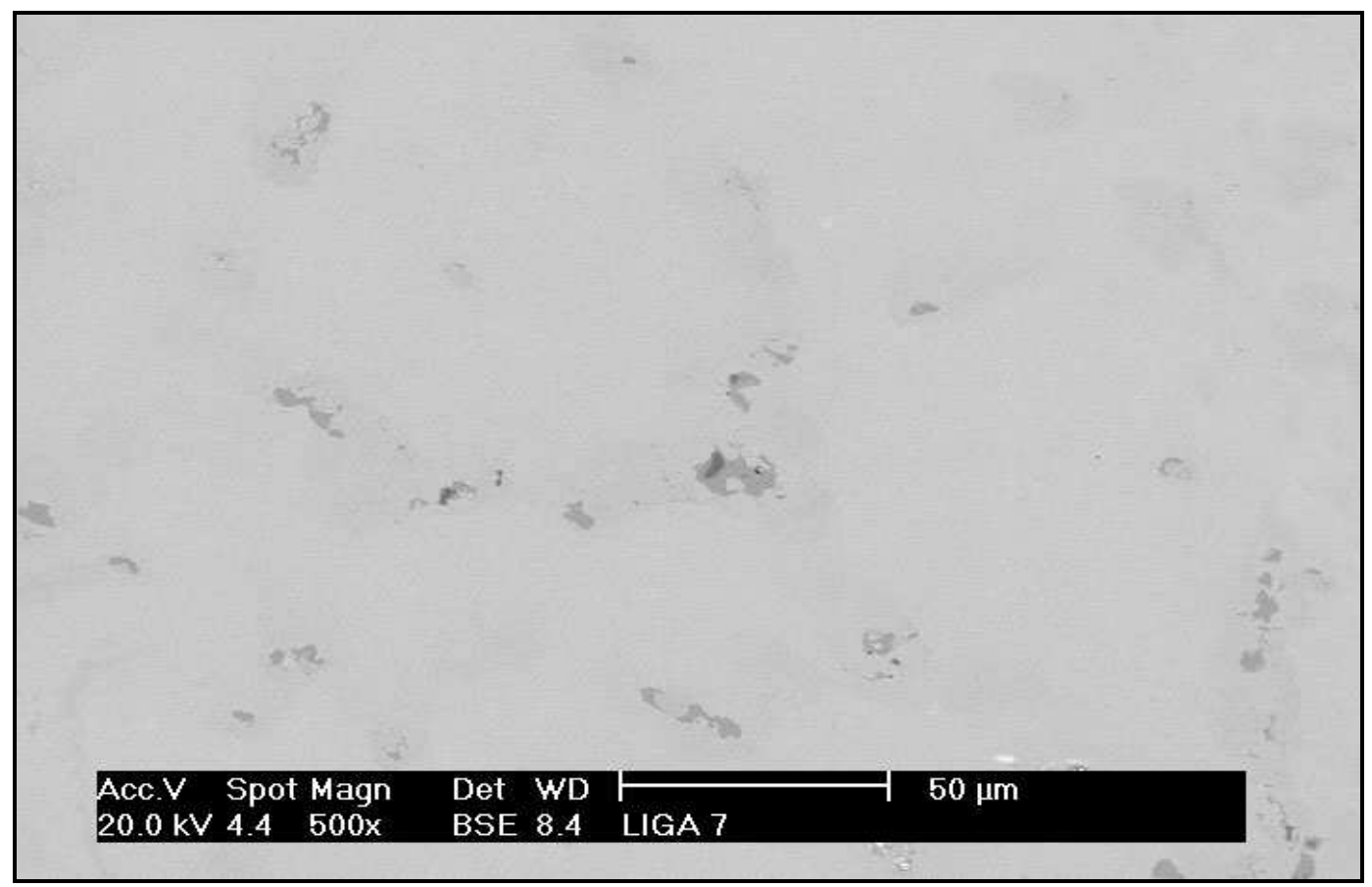

(a)

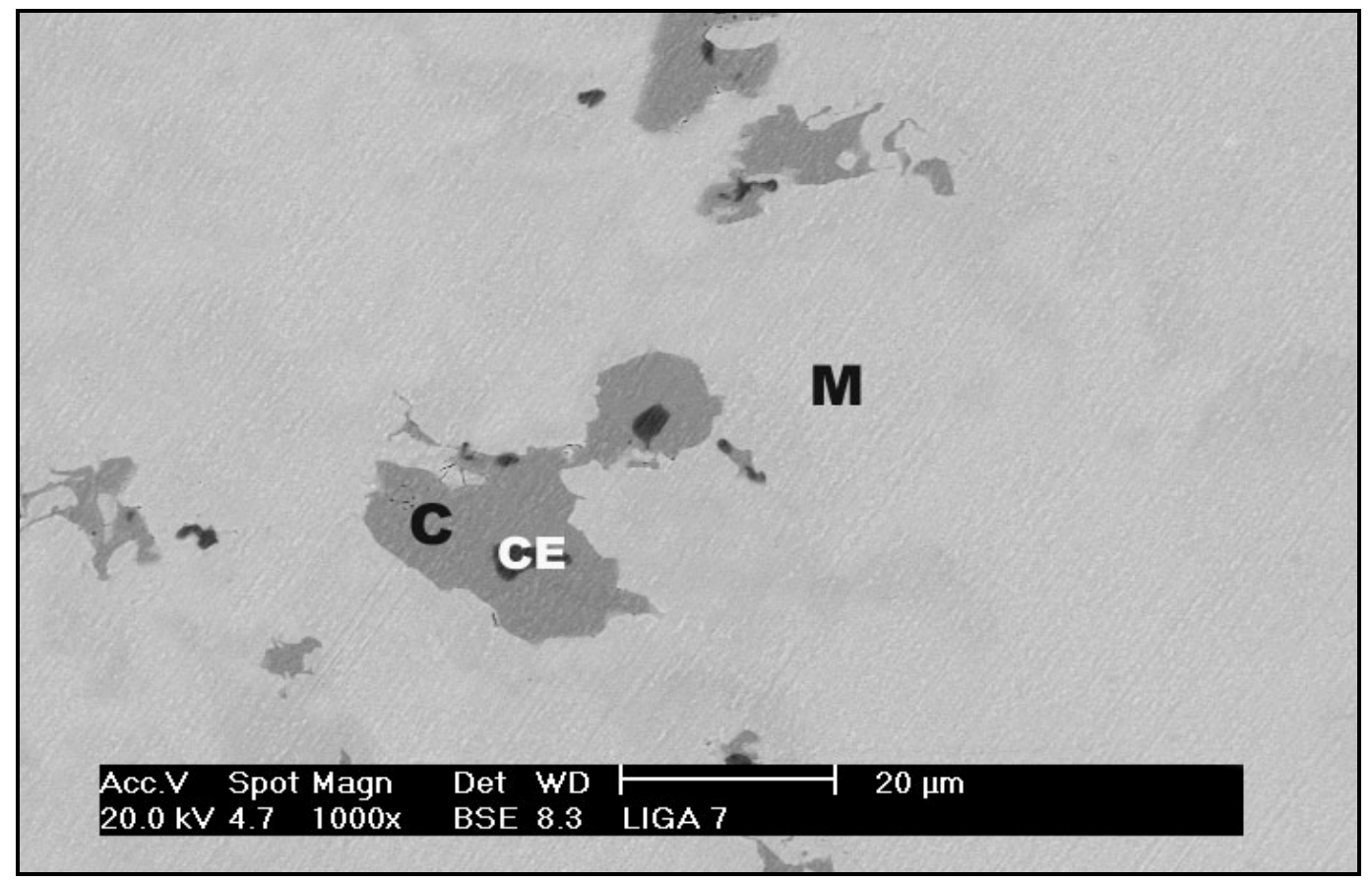

(b)

FIGURA 23 - Micrografias da liga $\mathrm{La}_{0,7} \mathrm{Pr}_{0,3} \mathrm{Al}_{0,3} \mathrm{Mn}_{0,4} \mathrm{Co}_{0,5} \mathrm{Ni}_{3,8}$; onde: (a) visão geral (500x) e (b) detalhada (1000x). 


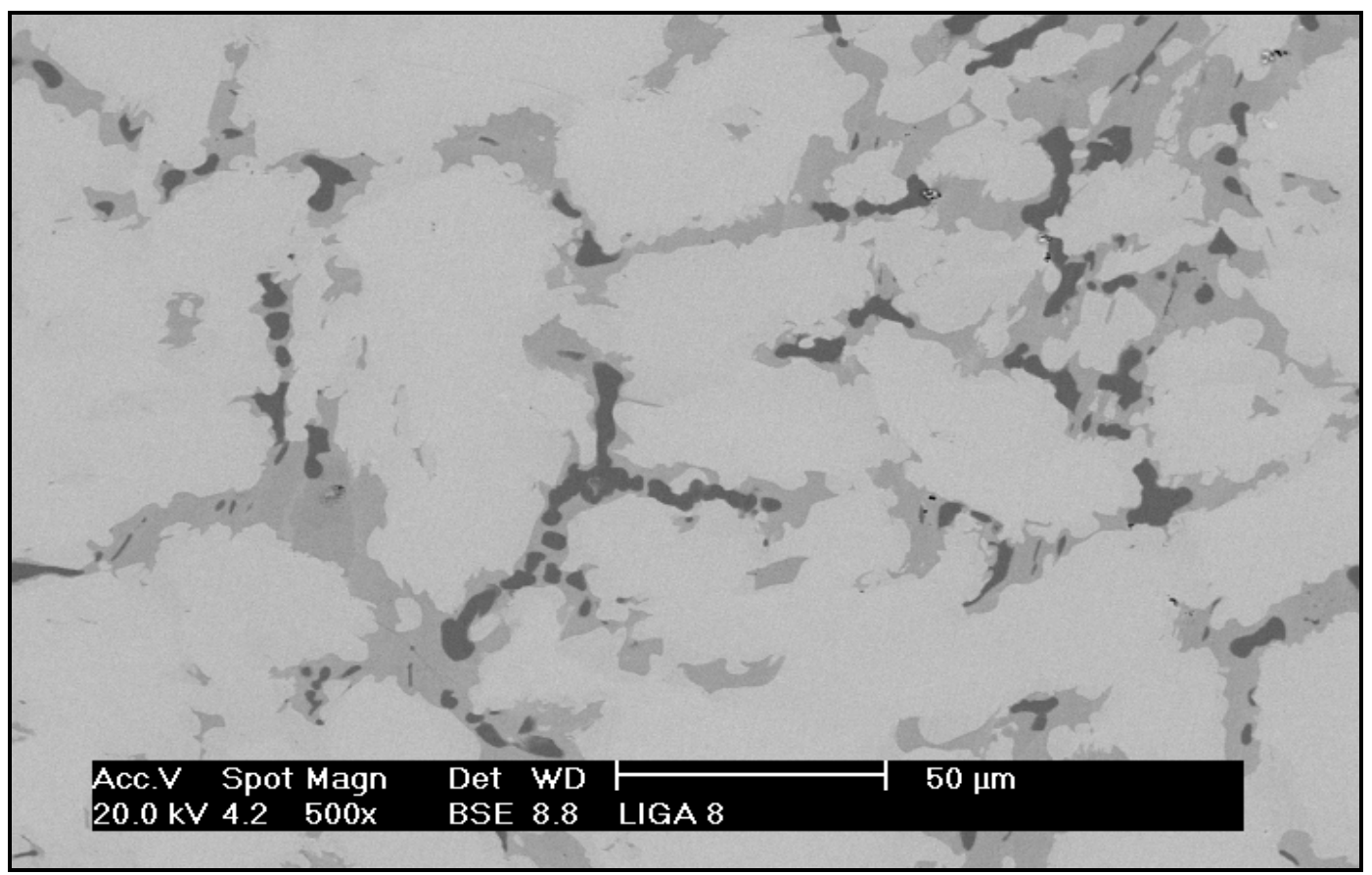

(a)

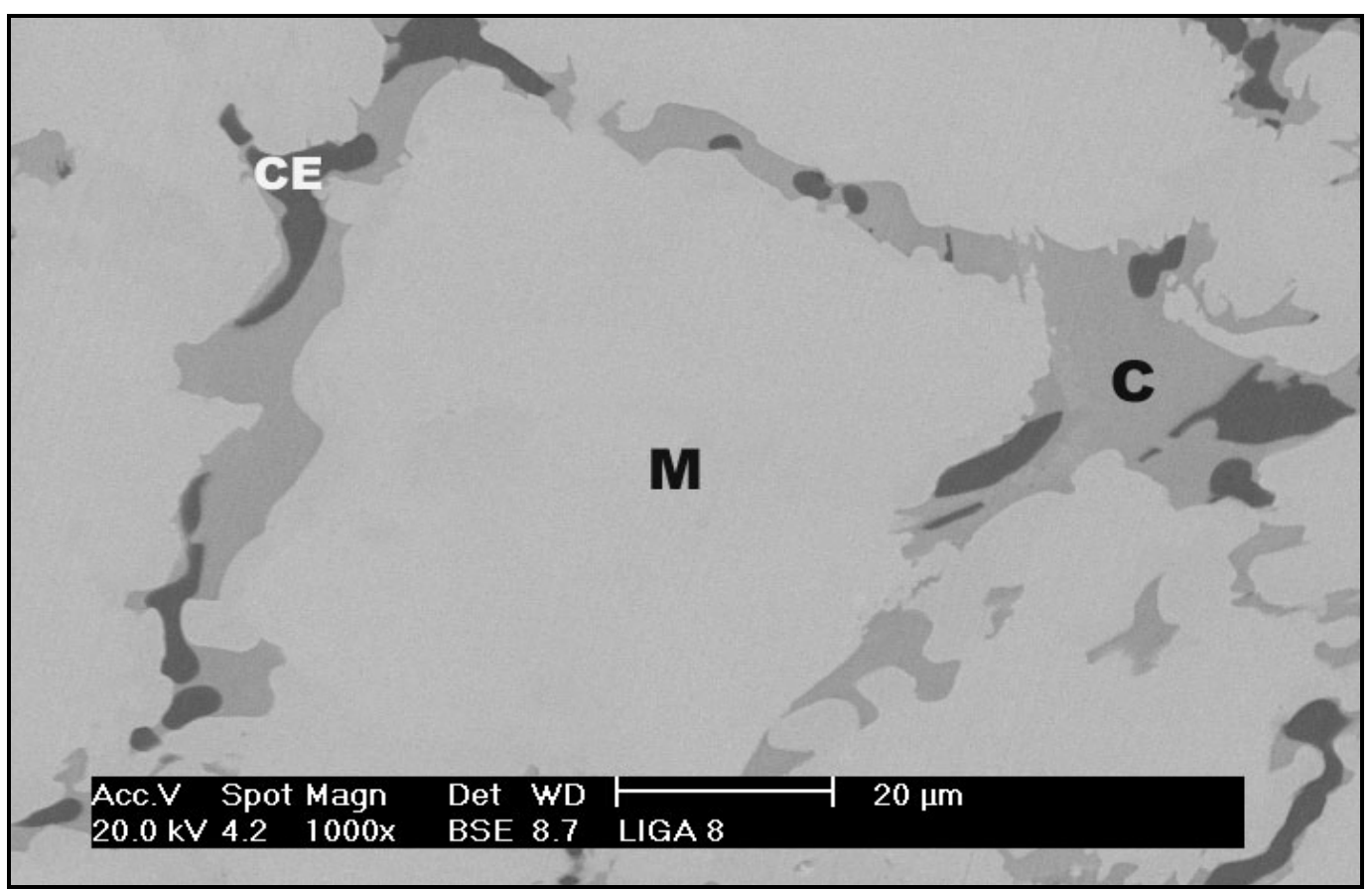

(b)

FIGURA 24 - Micrografias da liga $\mathrm{La}_{0,6} \mathrm{Mg}_{0,1} \mathrm{Pr}_{0,3} \mathrm{Al}_{0,3} \mathrm{Mn}_{0,4} \mathrm{Co}_{0,5} \mathrm{Ni}_{3,8}$; onde: (a) visão geral (500x) e (b) detalhada (1000x). 


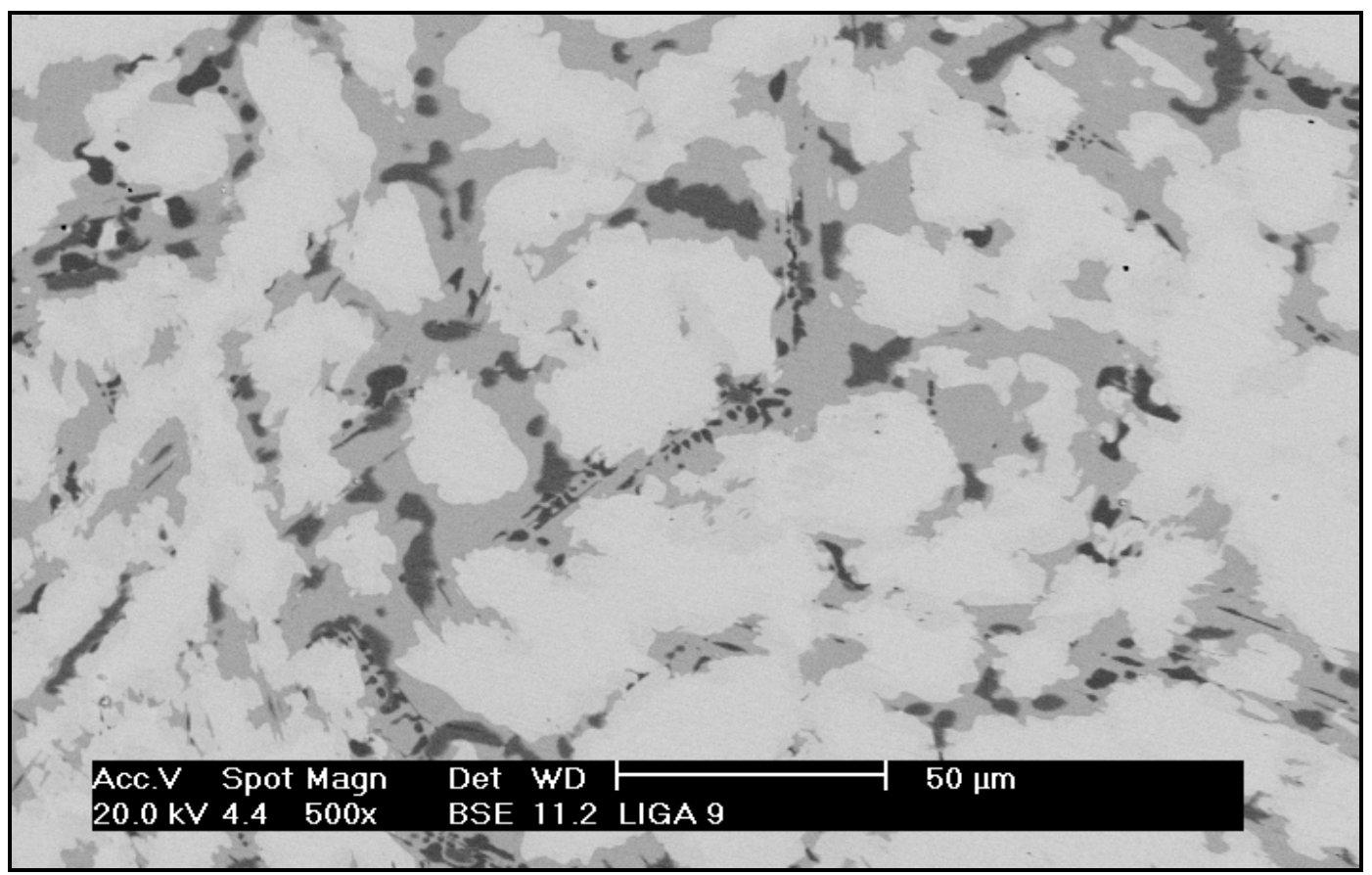

(a)

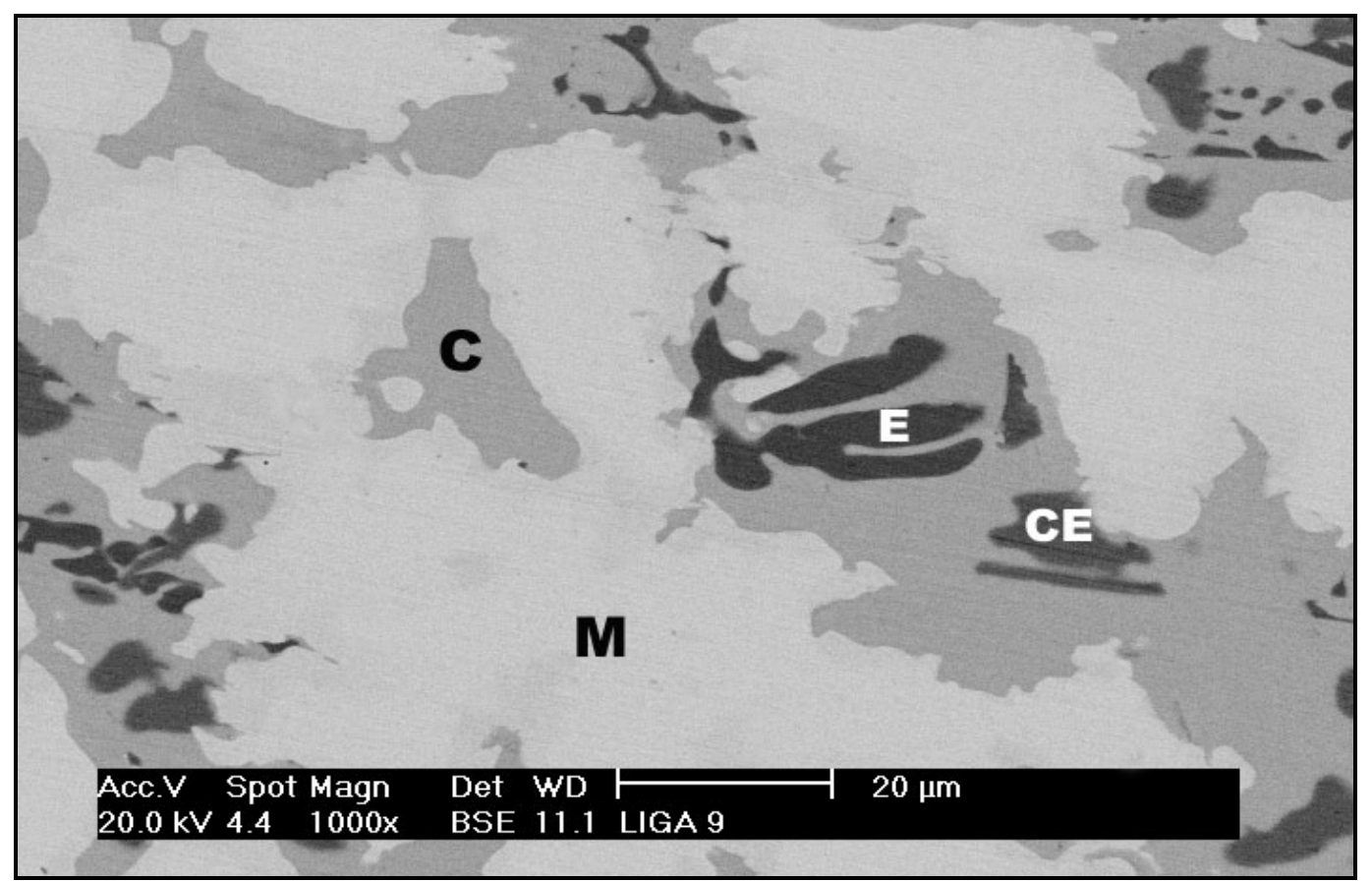

(b)

FIGURA 25 - Micrografias da liga $\mathrm{La}_{0,4} \mathrm{Mg}_{0,3} \operatorname{Pr}_{0,3} \mathrm{Al}_{0,3} \mathrm{Mn}_{0,4} \mathrm{Co}_{0,5} \mathrm{Ni}_{3,8}$; onde: (a) visão geral (500x) e (b) detalhada (1000x). 


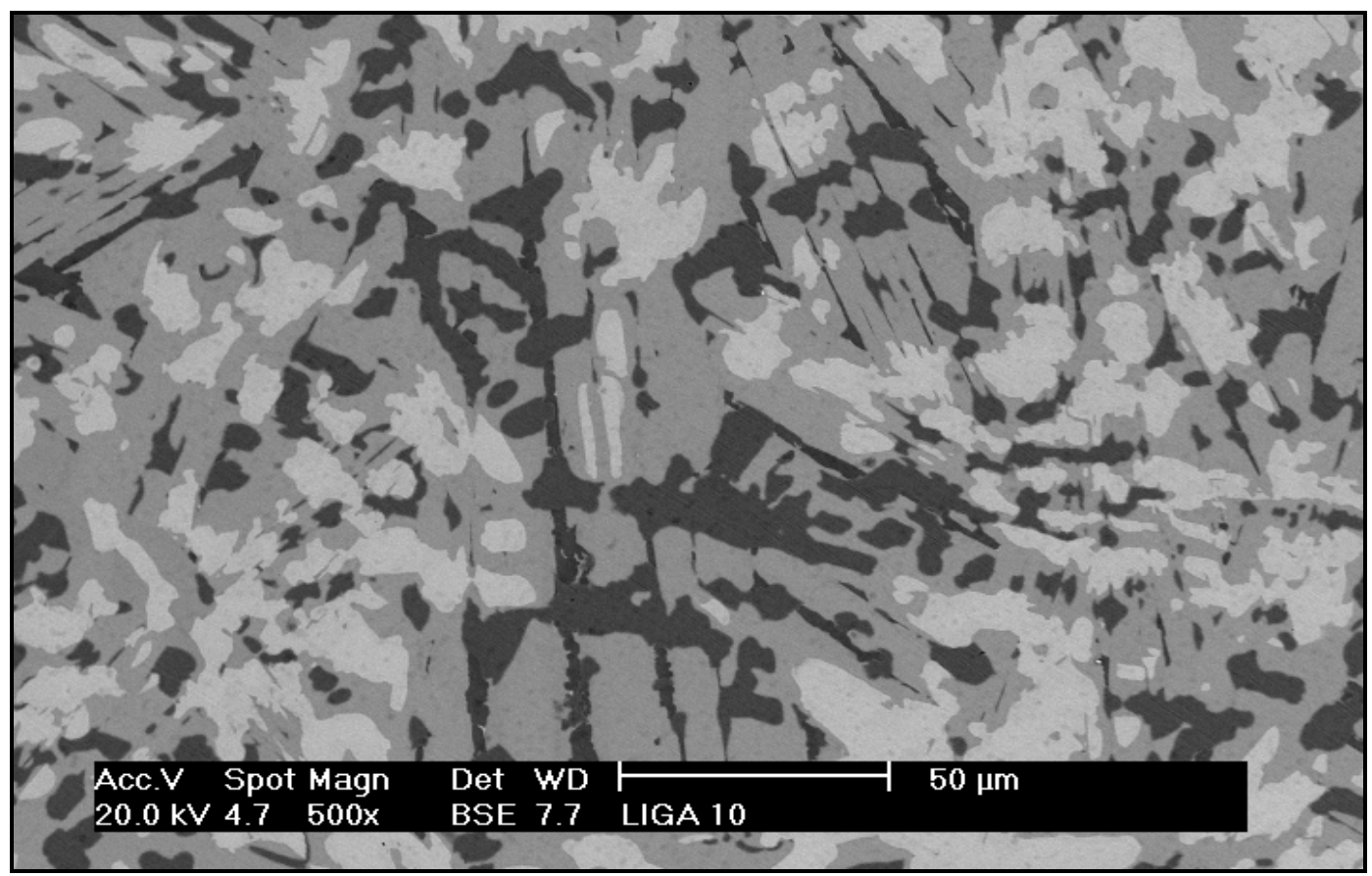

(a)

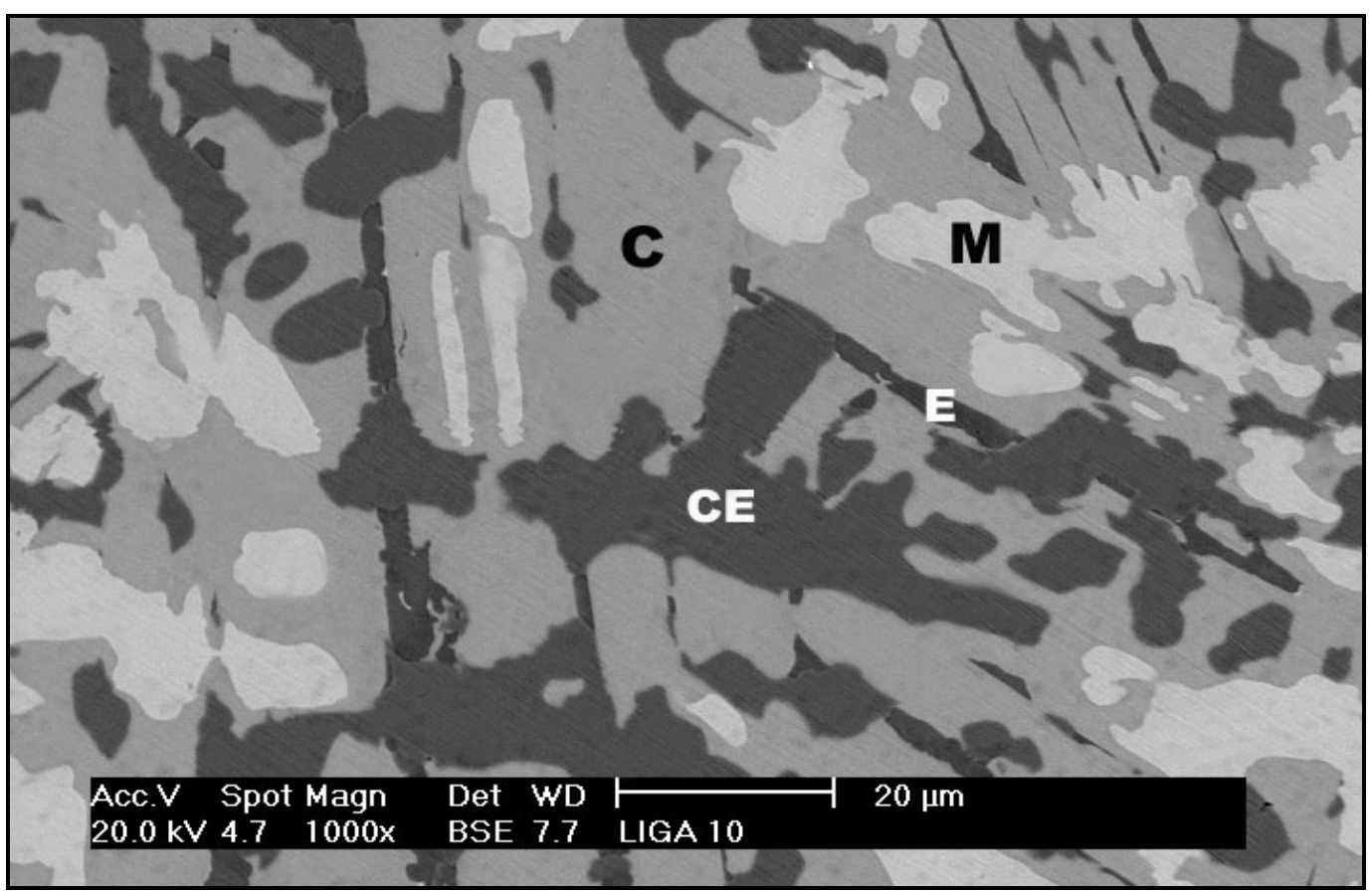

(b)

FIGURA 26 - Micrografias da liga $\mathrm{La}_{0,2} \mathrm{Mg}_{0,5} \mathrm{Pr}_{0,3} \mathrm{Al}_{0,3} \mathrm{Mn}_{0,4} \mathrm{Co}_{0,5} \mathrm{Ni}_{3,8}$; onde: (a) visão geral (500x) e (b) detalhada (1000x). 


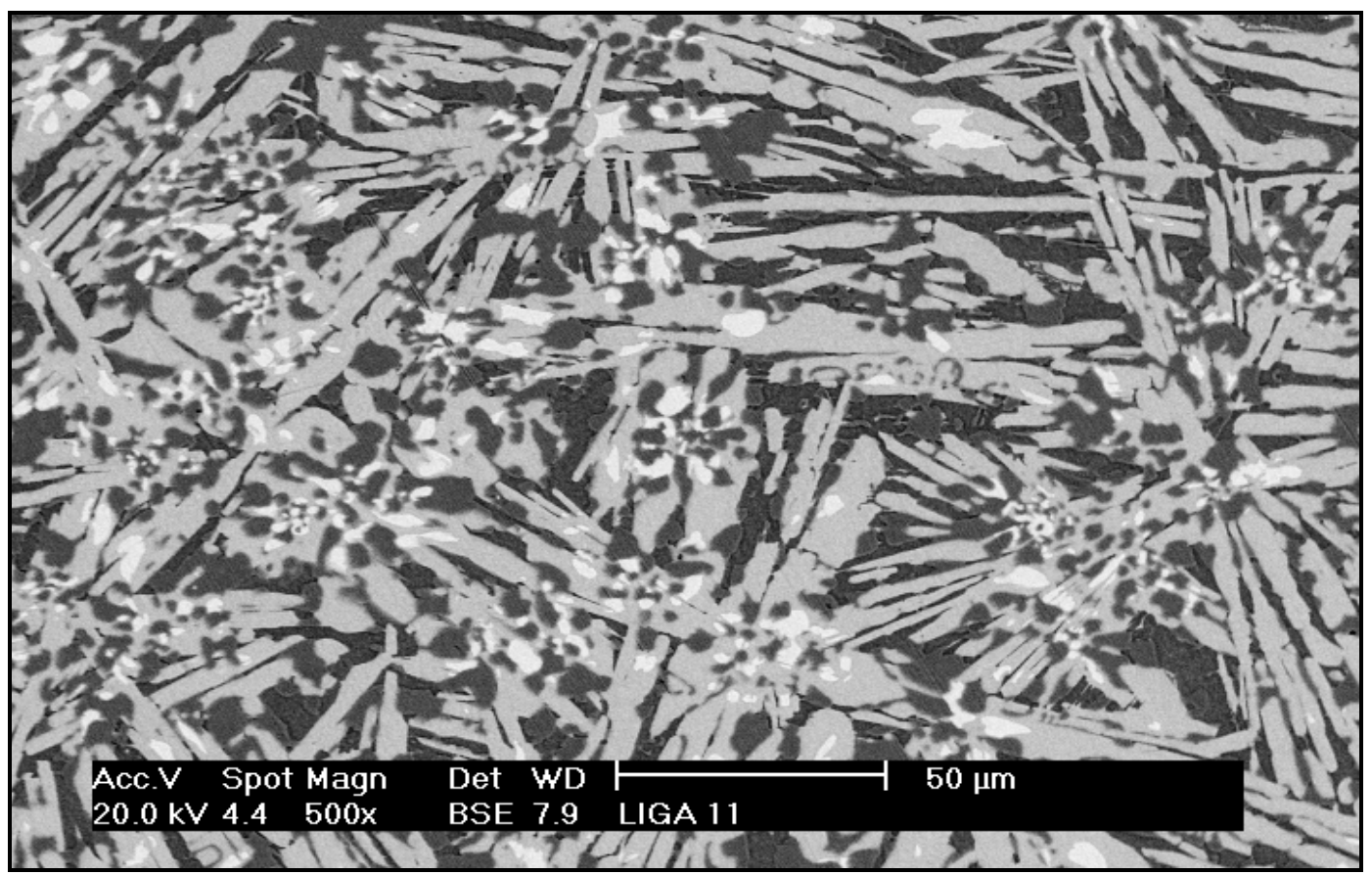

(a)

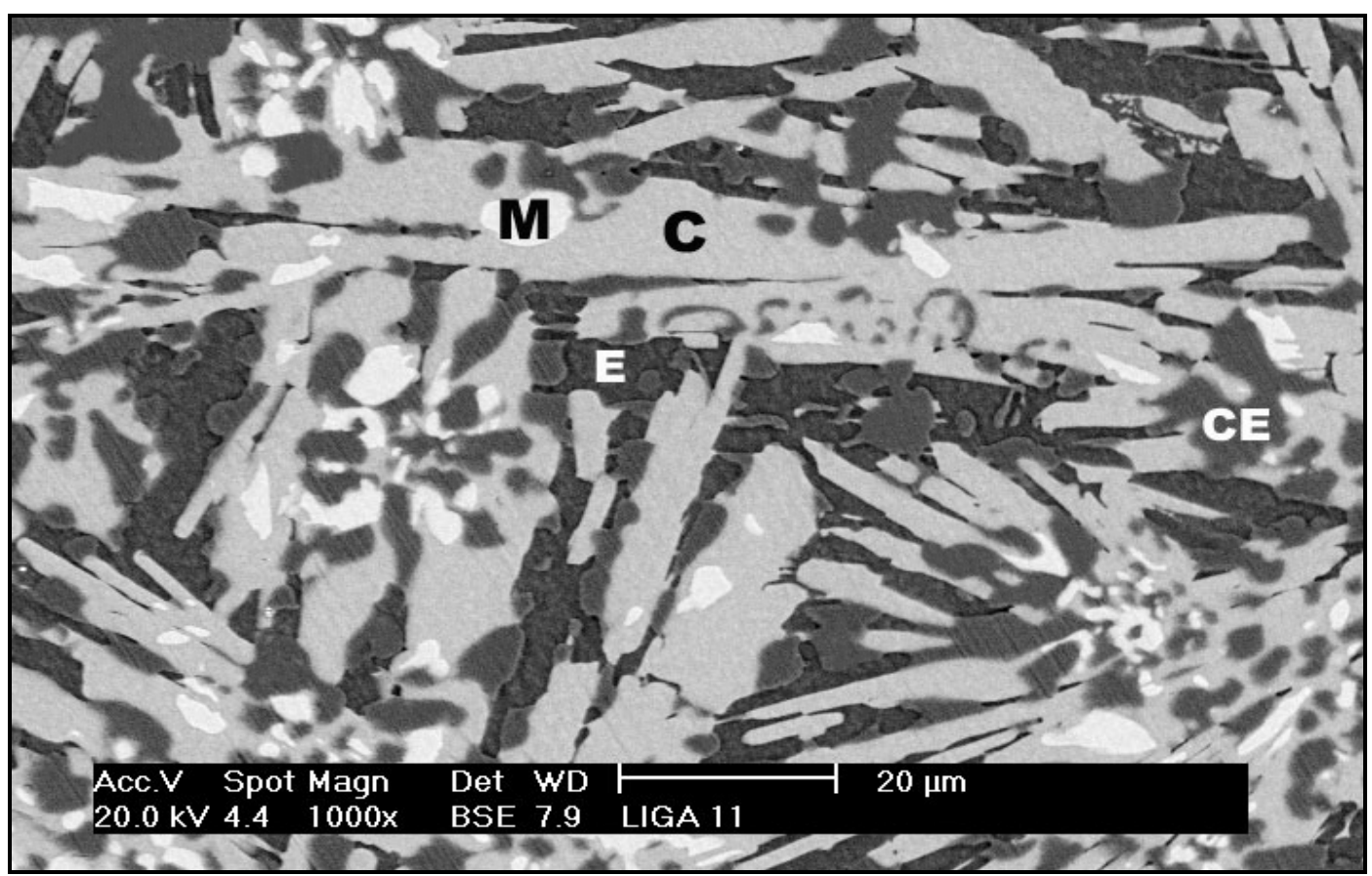

(b)

FIGURA 27 - Micrografias da liga $\mathrm{Mg}_{0,7} \mathrm{Pr}_{0,3} \mathrm{Al}_{0,3} \mathrm{Mn}_{0,4} \mathrm{Co}_{0,5} \mathrm{Ni}_{3,8}$; onde: (a) visão geral (500x) e (b) detalhada (1000x). 
Para as ligas sem $\mathrm{Mg}$ e $\mathrm{Mg}_{0,1}$ foram encontradas três fases distintas: a fase matriz (M), fase cinza (C) e a fase cinza escura (CE). Para as outras ligas foram encontradas quatro fases: $M, C, C E$ e a fase escura (E).

$\mathrm{Na}$ TAB. 10 - 13 estão mostradas as análises por EDS das fases encontradas para as ligas $\mathrm{La}_{0,7-x} \mathrm{Mg}_{\mathrm{x}} \mathrm{Pr}_{0,3} \mathrm{Al}_{0,3} \mathrm{Mn}_{0,4} \mathrm{Co}_{0,5} \mathrm{Ni}_{3,8}(\mathrm{x}=0$ a 0,7 ). Foram realizadas cinco medidas para cada fase, através destes valores foram calculado as médias e os desvios padrões.

TABELA 10 - Composição determinada da fase matriz (M).

\begin{tabular}{ccccccccc}
\hline \multicolumn{7}{c}{ Composição analisada (at.\%) } \\
$\mathrm{X}$ & La & $\mathrm{Pr}$ & $\mathrm{Mg}$ & $\mathrm{Al}$ & $\mathrm{Mn}$ & $\mathrm{Co}$ & $\mathrm{Ni}$ & Razão* \\
\hline 0,0 & $14,2 \pm 0,3$ & $4,4 \pm 0,3$ & - & $4,5 \pm 0,1$ & $5,5 \pm 0,3$ & $7,3 \pm 0,5$ & $64,1 \pm 0,3$ & $1: 4,4$ \\
0,1 & $10,5 \pm 0,2$ & $5,7 \pm 0,4$ & - & $4,1 \pm 0,2$ & $5,5 \pm 0,4$ & $7,9 \pm 0,5$ & $66,3 \pm 0,9$ & $1: 5,4$ \\
0,3 & $8,8 \pm 0,2$ & $7,4 \pm 0,4$ & - & $4,3 \pm 0,4$ & $3,1 \pm 0,7$ & $8,1 \pm 0,2$ & $68,3 \pm 1,3$ & $1: 5,1$ \\
0,5 & $6,1 \pm 0,4$ & $10,2 \pm 0,4$ & $<1$ & $4,5 \pm 0,2$ & $3,2 \pm 0,5$ & $6,9 \pm 0,3$ & $68,5 \pm 0,5$ & $1: 5,1$ \\
0,7 & - & $16,8 \pm 0,2$ & $<1$ & $3,7 \pm 0,2$ & $2,2 \pm 0,5$ & $7,3 \pm 0,1$ & $69,9 \pm 0,6$ & $1: 4,9$ \\
\hline
\end{tabular}

*(La, $\mathrm{Pr}):(\mathrm{Mn}, \mathrm{Al}, \mathrm{Co}, \mathrm{Ni})$

TABELA 11 - Composição determinada da fase cinza (C).

\begin{tabular}{ccccccccc}
\hline \multicolumn{8}{c}{ Composição analisada (at.\%) } \\
$\mathrm{X}$ & La & $\operatorname{Pr}$ & $\mathrm{Mg}$ & $\mathrm{Al}$ & $\mathrm{Mn}$ & $\mathrm{Co}$ & $\mathrm{Ni}$ & Razão* \\
\hline 0,0 & $9,8 \pm 0,3$ & $2,7 \pm 0,1$ & - & $3,8 \pm 0,2$ & $13,5 \pm 0,7$ & $8,6 \pm 0,2$ & $61,9 \pm 0,7$ & $1:-: 7,0$ \\
0,1 & $8,1 \pm 0,3$ & $3,3 \pm 0,1$ & $8,6 \pm 0,3$ & $2,5 \pm 0,1$ & $10,9 \pm 0,4$ & $6,9 \pm 0,6$ & $59,7 \pm 0,4$ & $1,3: 1: 7$ \\
0,3 & $5,4 \pm 0,2$ & $4,8 \pm 0,2$ & $10,5 \pm 0,4$ & $3,4 \pm 0,3$ & $6,7 \pm 0,2$ & $7,5 \pm 0,4$ & $61,7 \pm 1,5$ & $1: 1: 7,5$ \\
0,5 & $4,4 \pm 0,2$ & $6,8 \pm 0,2$ & $12,6 \pm 0,4$ & $3,1 \pm 0,3$ & $4,9 \pm 0,3$ & $6,5 \pm 0,4$ & $61,5 \pm 1,1$ & $1: 1: 6,7$ \\
0,7 & - & $10,6 \pm 0,4$ & $10,5 \pm 0,4$ & $2,1 \pm 0,1$ & $3,7 \pm 0,3$ & $5,6 \pm 0,4$ & $67,5 \pm 0,3$ & $1: 1: 7,5$ \\
\hline
\end{tabular}

${ }^{*}(\mathrm{La}, \mathrm{Pr}):(\mathrm{Mg}):(\mathrm{Mn}, \mathrm{Al}, \mathrm{Co}, \mathrm{Ni})$ 
TABELA 12 - Composição determinada da fase cinza escura (CE).

\begin{tabular}{cccccccc}
\hline & & \multicolumn{5}{c}{ Composição analisada (at.\%) } \\
$X$ & La & Pr & Mg & Al & Mn & Co & $N i$ \\
\hline 0,0 & $<1$ & $<1$ & - & $9,5 \pm 0,3$ & $35,9 \pm 1,3$ & $6,7 \pm 0,4$ & $47,2 \pm 0,7$ \\
0,1 & $<1$ & $<1$ & $<1$ & $17,1 \pm 0,6$ & $23,5 \pm 0,8$ & $7,3 \pm 0,4$ & $50,1 \pm 0,4$ \\
0,3 & $<1$ & $<1$ & $<1$ & $10,4 \pm 0,5$ & $16,1 \pm 0,5$ & $16,1 \pm 0,5$ & $56,7 \pm 0,9$ \\
0,5 & $<1$ & $<1$ & $<1$ & $9,4 \pm 0,4$ & $11,3 \pm 0,4$ & $15,8 \pm 0,5$ & $62,6 \pm 1,1$ \\
0,7 & - & $<1$ & $1,4 \pm 0.2$ & $8,9 \pm 0,4$ & $11,3 \pm 0,4$ & $13,2 \pm 0,5$ & $65,2 \pm 0,3$ \\
\hline
\end{tabular}

TABELA 13 - Composição determinada da fase escura (E).

\begin{tabular}{ccccccccc}
\hline \multicolumn{7}{c}{ X } & \multicolumn{7}{c}{ Composição analisada (at.\%) } \\
& La & $\operatorname{Pr}$ & $\mathrm{Mg}$ & $\mathrm{Al}$ & $\mathrm{Mn}$ & $\mathrm{Co}$ & $\mathrm{Ni}$ & Razão* \\
\hline 0,0 & - & - & - & - & - & - & - & - \\
0,1 & - & - & - & - & - & - & - & - \\
0,3 & $<1$ & $<1$ & $17,7 \pm 0,2$ & $3,9 \pm 0,3$ & $13,8 \pm 0,6$ & $7,3 \pm 0,1$ & $56,5 \pm 0,3$ & $1: 4,6$ \\
0,5 & $<1$ & $<1$ & $18,3 \pm 0,4$ & $2,9 \pm 0,3$ & $13,4 \pm 0,2$ & $6,7 \pm 0,1$ & $57,9 \pm 0,7$ & $1: 4,4$ \\
0,7 & - & $<1$ & $21,2 \pm 0,1$ & $1,7 \pm 0,3$ & $8,6 \pm 0,2$ & $5,5 \pm 0,1$ & $61,5 \pm 0,3$ & $1: 3,6$ \\
\hline${ }^{*}(\mathrm{Mg}):(\mathrm{Mn}, \mathrm{Al}, \mathrm{Co}, \mathrm{Ni})$ & & & & & & &
\end{tabular}

A fase matriz (M) está presente em todas as ligas. Sua composição, mostrada na TAB. 10, apresentou a razão de aproximadamente 1:5 para todas as ligas, o que provavelmente representa a fase $\mathrm{LaNi}_{5}$.

Com a substituição do lantânio pelo magnésio foi possível observar visualmente o aumento das fases $C$ e CE. As composições da fase cinza (C) mostrada na TAB. 11 apresentaram a razão de aproximadamente 1:1:7.

A fase CE se mostra presente em todas as ligas. É uma fase que apresenta somente os metais da liga ( $\mathrm{Al}, \mathrm{Mn}, \mathrm{Co}, \mathrm{Ni})$ com alta concentração de $\mathrm{Ni}$.

A fase $E$, com alta concentração em magnésio, surge na medida em que aumenta a concentração de magnésio nas ligas. Sua composição, mostrada na TAB. 13, apresentou a razão de aproximadamente 1:4. A formação desta fase deve-se ao magnésio não substituir o lantânio nas ligas. 
Com a substituição do lantânio pelo magnésio a fase cinza (C) aumenta, tornando-se a matriz da liga. As ligas, com esta nova matriz, passam a ser do grupo $\mathrm{AB}_{2} \mathrm{C}_{9}[43,50]$.

$\mathrm{Na}$ FIG. 28 apresenta-se os difratogramas de raios-X das ligas $L a_{0,7}$ ${ }_{x} \mathrm{Mg}_{\mathrm{x}} \operatorname{Pr}_{0,3} \mathrm{Al}_{0,3} \mathrm{Mn}_{0,4} \mathrm{Co}_{0,5} \mathrm{Ni}_{3,8}(\mathrm{x}=0$ a 0,7$)$. As fases encontradas para estas ligas foram: (La,Pr) $\mathrm{Ni}_{5}$ (grupo espacial: P6/mmm - PDF: 50-7777), (La, $\mathrm{Pr}$ ) $\mathrm{Mg}_{2} \mathrm{Ni}_{9}$ (grupo espacial: R3m - PDF 50-1454), $\mathrm{MgNi}_{2}$ (grupo espacial: P63/mmc - PDF: 65-3630) e Ni (grupo espacial: P63/mmc - PDF: 89-7129).

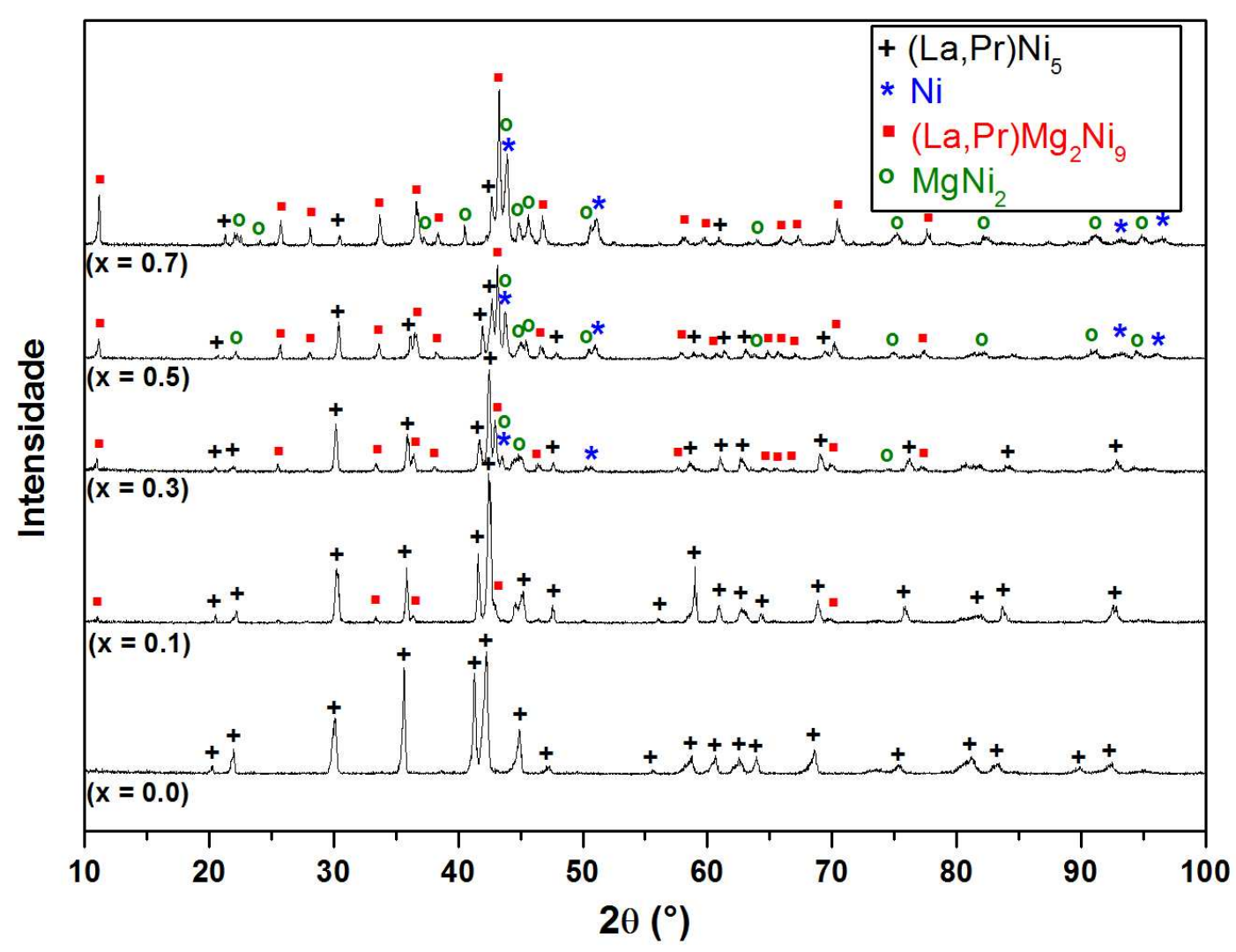

FIGURA 28 - Difratogramas de raios- $X$ das ligas $\mathrm{La}_{0,7-x} \mathrm{Mg}_{x} \operatorname{Pr}_{0,3} \mathrm{Al}_{0,3} \mathrm{Mn}_{0,4} \mathrm{Co}_{0,5} \mathrm{Ni}_{3,8}$ $(x=0$ a 0,7$)$. 
Para a liga sem magnésio, o resultado apresentou somente a fase correspondente à ( $\mathrm{La}, \mathrm{Pr}) \mathrm{Ni}_{5}$. As outras fases, mostradas na FIG. 23, não foram identificadas devido à pequena presença das mesmas (C e CE). Neste caso, as fases $C$ e CE estão presentes, provavelmente, pela falta de homogeneidade na fabricação da liga e a fase $C$ não deve ser considerada como do tipo $A B_{2} C_{9}$.

A fase ( $\mathrm{La}, \mathrm{Pr}) \mathrm{Mg}_{2} \mathrm{Ni}_{9}(\mathrm{C})$ começa a ser observada à partir da liga $\mathrm{La}_{0,6} \mathrm{Mg}_{0,1} \mathrm{Pr}_{0,3} \mathrm{Al}_{0,3} \mathrm{Mn}_{0,4} \mathrm{Co}_{0,5} \mathrm{Ni}_{3,8}$. Para as ligas com substituição do La por Mg a partir de $0,3 \%$ at. foi observada a presença das quatro fases mostradas na FIG. 25, com a diminuição dos picos da fase (La, $\mathrm{Pr}) \mathrm{Ni}_{5}(\mathrm{M})$ e aumento da fase (La,Pr) $\mathrm{Mg}_{2} \mathrm{Ni}_{9}$ (C).

Para as ligas com alto teor de magnésio $\left(\mathrm{Mg}_{0,5}\right.$ e $\left.\mathrm{Mg}_{0,7}\right)$ a fase matriz (M) ainda permanece devido à presença do praseodímio nas ligas como observado nas FIG. 26 e 27.

A fase $\mathrm{MgNi}_{2}$ foi encontrada a partir da liga com $\mathrm{Mg}_{0,3}$, em verde na FIG. 28, e comparando com os resultados obtidos na TAB. 13 pode ser considerada como onde a fase escura $(\mathrm{E})$.

Na TAB. 14 apresenta-se os valores dos parâmetros de rede e volume das fases obtidos por refinamento das ligas $\mathrm{La}_{0,7-x} \mathrm{Mg}_{\mathrm{x}} \mathrm{Pr}_{0,3} \mathrm{Al}_{0,3} \mathrm{Mn}_{0,4} \mathrm{Co}_{0,5} \mathrm{Ni}_{3,8}(\mathrm{x}=$ 0 a 0,7$)$. 
TABELA 14 - Dados cristalográficos das ligas $\mathrm{La}_{0,7-x} \mathrm{Mg}_{x} \mathrm{Pr}_{0,3} \mathrm{Al}_{0,3} \mathrm{Mn}_{0,4} \mathrm{Co}_{0,5} \mathrm{Ni}_{3,8}(\mathrm{x}$ $=0$ a 0,7$)$.

\begin{tabular}{ccccc}
\hline $\mathrm{X}$ & Fases & \multicolumn{2}{c}{ Parâmetros (A) } & Volume (\%) \\
\hline 0,0 & $\mathrm{LaNi}_{5}$ & $\mathrm{a}=5,046$ & $\mathrm{c}=4,045$ & 100 \\
0,1 & $\mathrm{LaNi}_{5}$ & $\mathrm{a}=5,013$ & $\mathrm{c}=4,028$ & 89 \\
& $\mathrm{LaMg}_{2} \mathrm{Ni}_{9}$ & $\mathrm{a}=4,936$ & $\mathrm{c}=23,975$ & 11 \\
0,3 & $\mathrm{LaNi}_{5}$ & $\mathrm{a}=5,000$ & $\mathrm{c}=4,056$ & 62 \\
& $\mathrm{LaMg}_{2} \mathrm{Ni}_{9}$ & $\mathrm{a}=4,938$ & $\mathrm{c}=24,075$ & 38 \\
0,5 & $\mathrm{LaNi}_{5}$ & $\mathrm{a}=4,973$ & $\mathrm{c}=4,033$ & 38 \\
& $\mathrm{LaMg}_{2} \mathrm{Ni}_{9}$ & $\mathrm{a}=4,921$ & $\mathrm{c}=23,986$ & 62 \\
0,7 & $\mathrm{PrNi}_{5}$ & $\mathrm{a}=4,932$ & $\mathrm{c}=4,034$ & 15 \\
& $\mathrm{PrMg}_{2} \mathrm{Ni}_{9}$ & $\mathrm{a}=4,910$ & $\mathrm{c}=23,875$ & 85 \\
\hline
\end{tabular}

O volume da fase $\mathrm{LaNi}_{5}$ diminui drasticamente com o aumento do teor de magnésio, o contrario ocorre para a fase LaMg2Ni9. Vale ressaltar que para $x$ $=0,7$ foi utilizados as fases similares a $\mathrm{LaNi}_{5}$ e $\mathrm{LaMg}_{2} \mathrm{Ni}_{9}[62]$.

No refinamento foi possível observar uma diminuição drástica da fase $\mathrm{LaNi}_{5}$ com o aumento da concentração do magnésio, mostrada na TAB. 14 (\% em volume). Não foi possível realizar o refinamento para as fases $\mathrm{Ni}$ e $\mathrm{MgNi}_{2}$, pois se apresentaram em pequenas quantidades. 


\subsection{Hidrogenação das ligas}

Na FIG. 29 apresenta-se a curva da variação na absorção de hidrogênio em função do tempo em que o material ficou exposto a uma pressão inicial de 0,2 $\mathrm{MPa}$ (2 bar) a temperatura ambiente. Os resultados mostraram que somente a liga sem magnésio apresentou hidrogenação espontânea. Não foi observada absorção de hidrogênio para as ligas com magnésio.

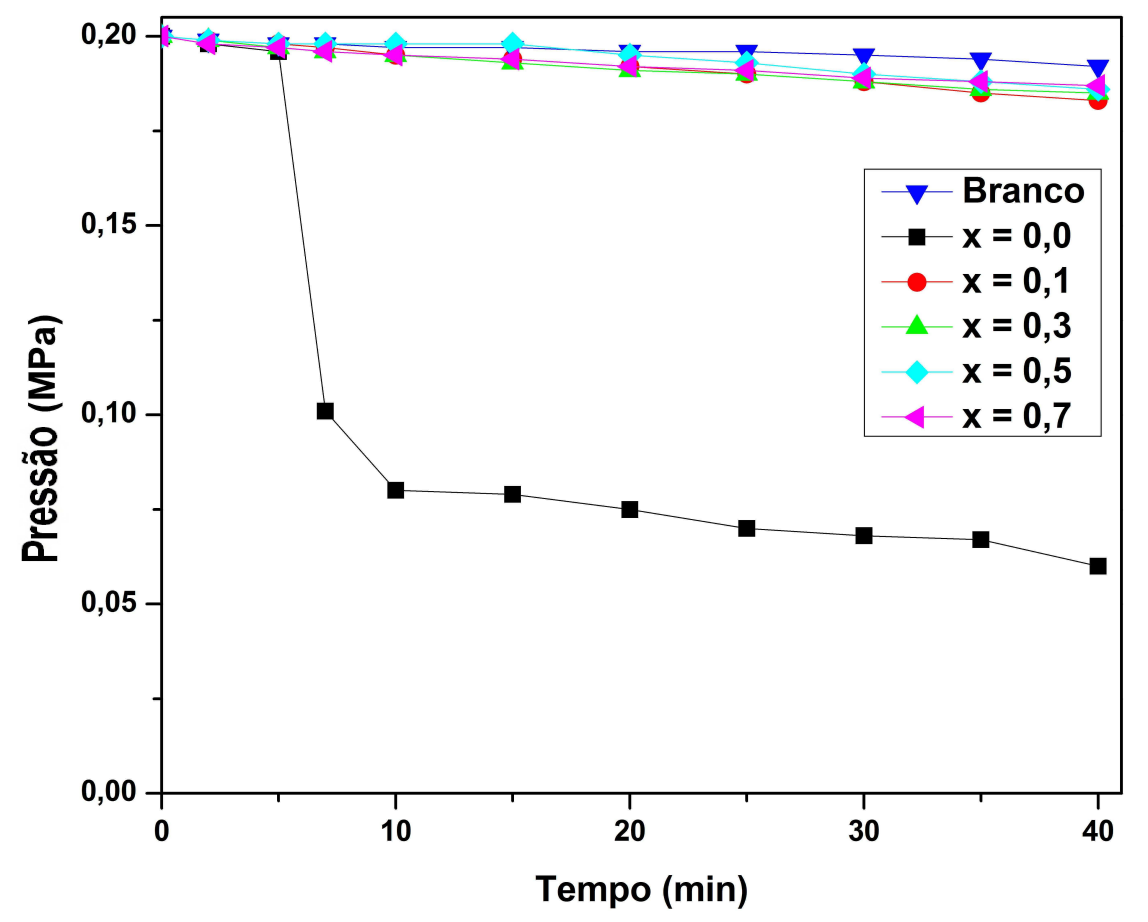

FIGURA 29 - Curvas da absorção de hidrogênio em função do tempo com pressão inicial de 0,2 $\mathrm{MPa}$, à temperatura ambiente, das ligas $\mathrm{La}_{0,7-x} M g_{x}$ $\operatorname{Pr}_{0,3} \mathrm{Al}_{0,3} \mathrm{Mn}_{0,4} \mathrm{Co}_{0,5} \mathrm{Ni}_{3,8}(x=0$ a 0,7$)$.

Na FIG. 30 está mostrada o pó da liga $\mathrm{La}_{0,7} \mathrm{Pr}_{0,3} \mathrm{Al}_{0,3} \mathrm{Mn}_{0,4} \mathrm{Co}_{0,5} \mathrm{Ni}_{3,8}$ após hidrogenação sob 0,2 MPa e a temperatura ambiente. 


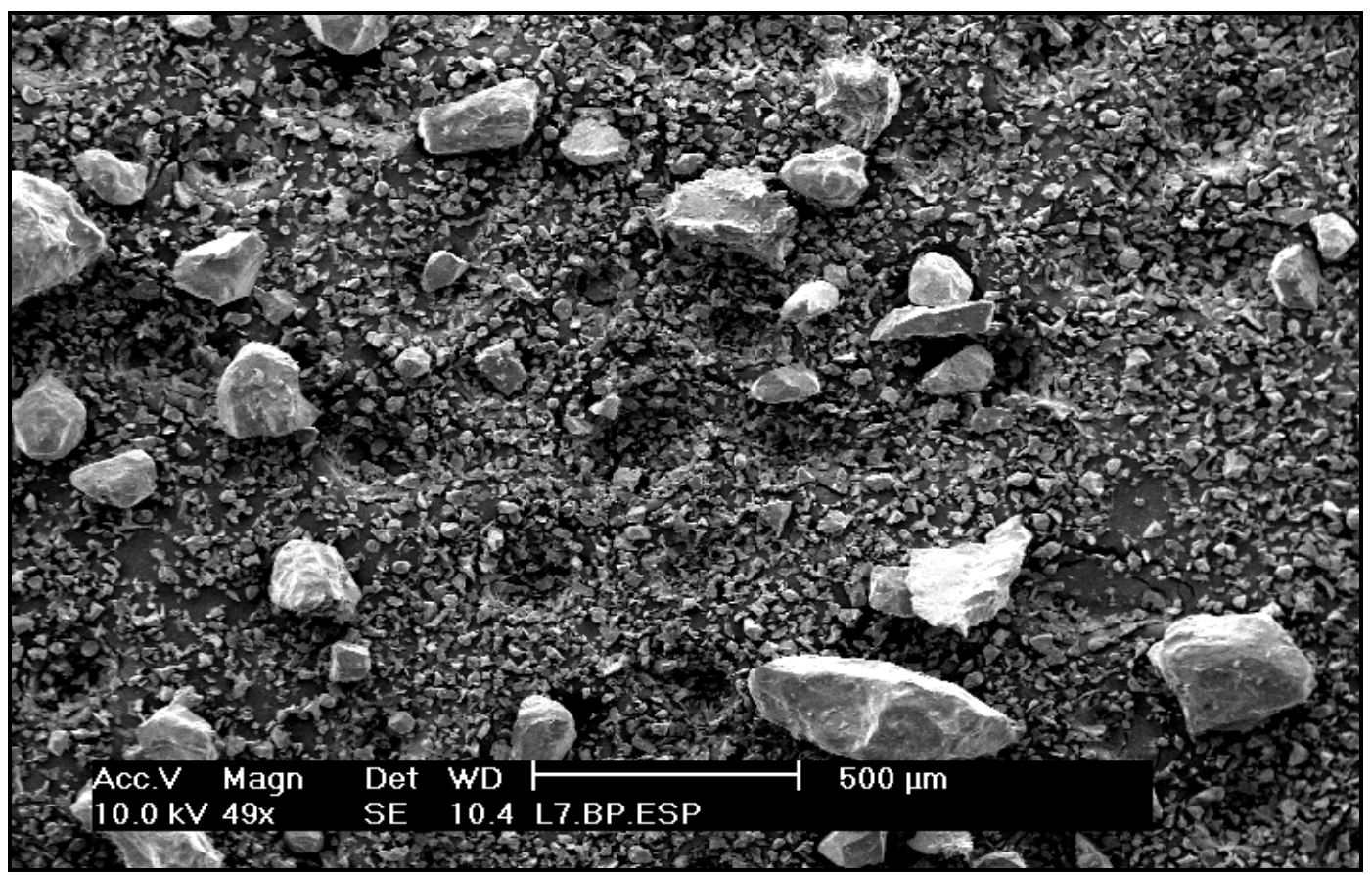

(a)

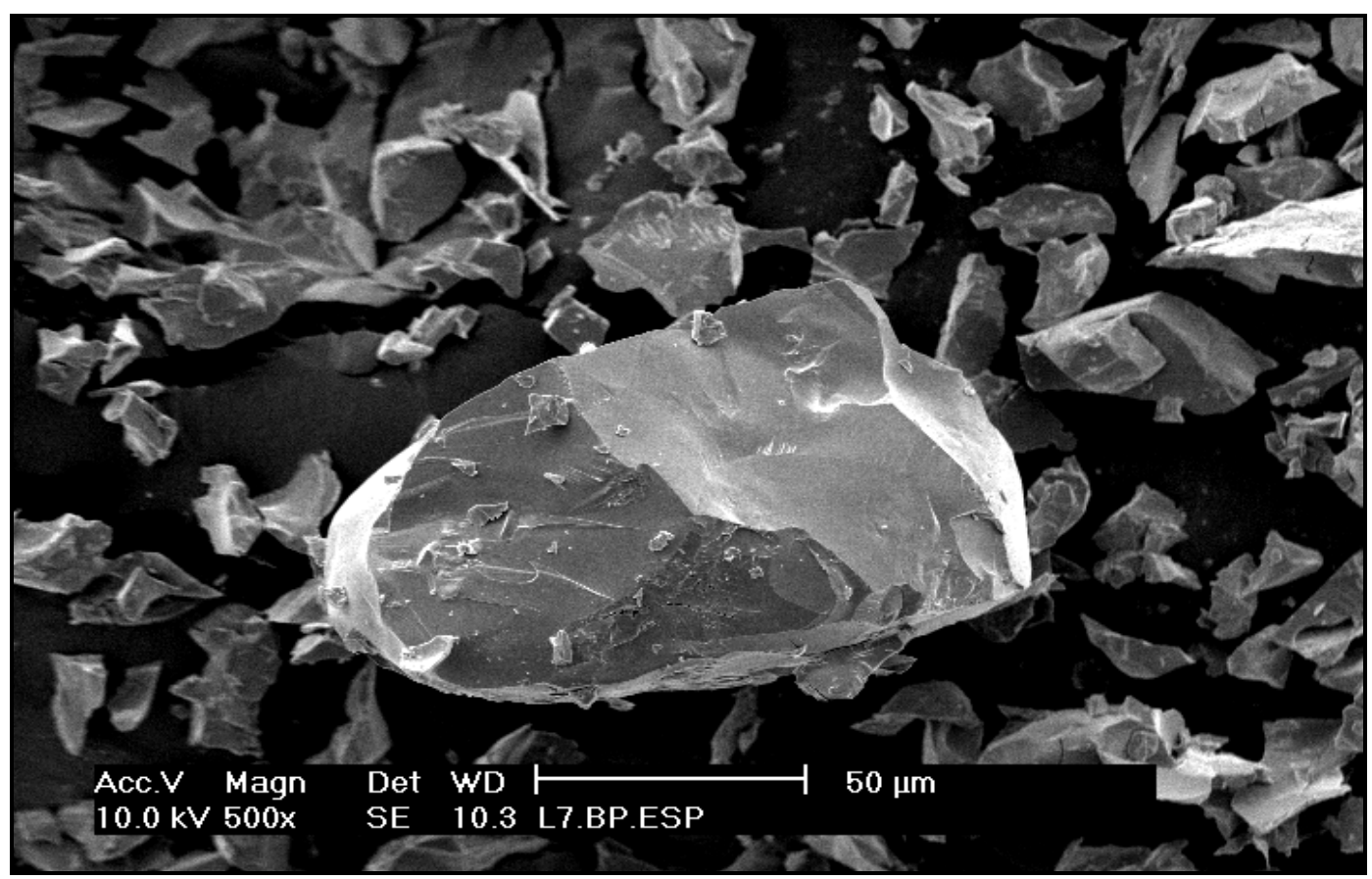

(b)

FIGURA 30 - Pós obtidos da liga $\mathrm{La}_{0,7} \mathrm{Pr}_{0,3} \mathrm{Al}_{0,3} \mathrm{Mn}_{0,4} \mathrm{Co}_{0,5} \mathrm{Ni}_{3,8}$ a $0,2 \mathrm{MPa}$ de pressão de hidrogênio a temperatura ambiente; onde: (a) visão geral (50x) e (b) visão detalhada (500x). 
Na FIG. 31 apresenta-se a variação na absorção de hidrogênio das ligas em função do tempo em que o material ficou exposto, a uma pressão inicial de $0,2 \mathrm{MPa}$ e a temperatura inicial de $500^{\circ} \mathrm{C}$ (não foi u tilizada a liga sem Mg). Os resultados mostram que após resfriamento rápido ocorre a absorção de $\mathrm{H}_{2}$ para as ligas com $\mathrm{Mg}_{0,1}$ e $\mathrm{Mg}_{0,3}$. Para as ligas com alto teor de magnésio não foi observada absorção de hidrogênio.



FIGURA 31 - Curvas da absorção de hidrogênio em função do tempo com pressão inicial de 0,2 MPa, à temperatura inicial de $500{ }^{\circ}$, após resfriamento rápido, das ligas $\mathrm{La}_{0,7-x} \mathrm{Mg}_{x} \operatorname{Pr}_{0,3} \mathrm{Al}_{0,3} \mathrm{Mn}_{0,4} \mathrm{Co}_{0,5} \mathrm{Ni}_{3,8}(x=0,1-0,7)$.

Nas FIG 32 - 35 estão mostrados os pós das ligas La $_{0,7-x} M_{g_{x}}$ $\operatorname{Pr}_{0,3} \mathrm{Al}_{0,3} \mathrm{Mn}_{0,4} \mathrm{Co}_{0,5} \mathrm{Ni}_{3,8}(\mathrm{x}=0,1$ - 0,7) obtidos após hidrogenação a 0,2 MPa e temperatura inicial de $500^{\circ} \mathrm{C}$. 


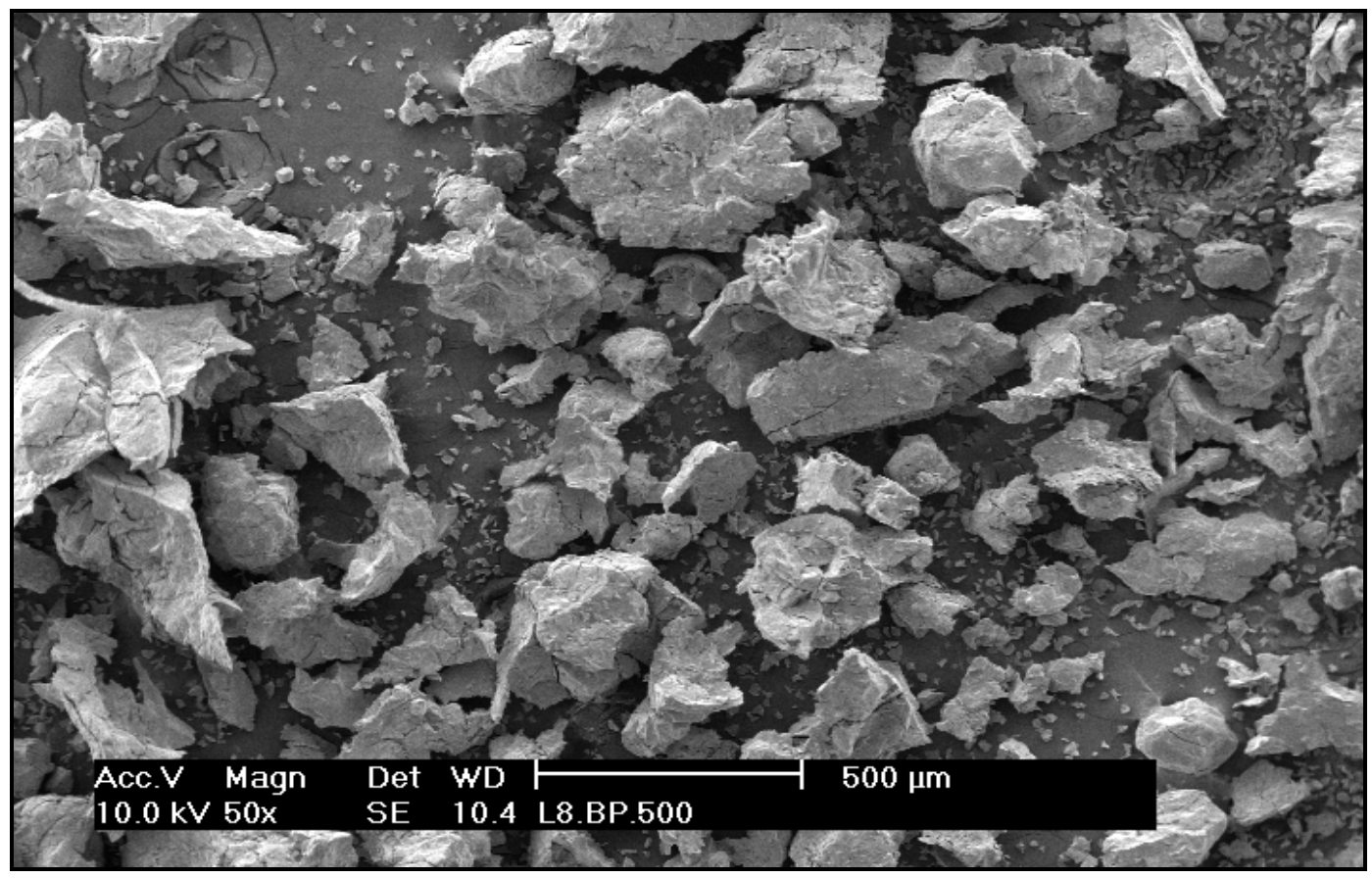

(a)

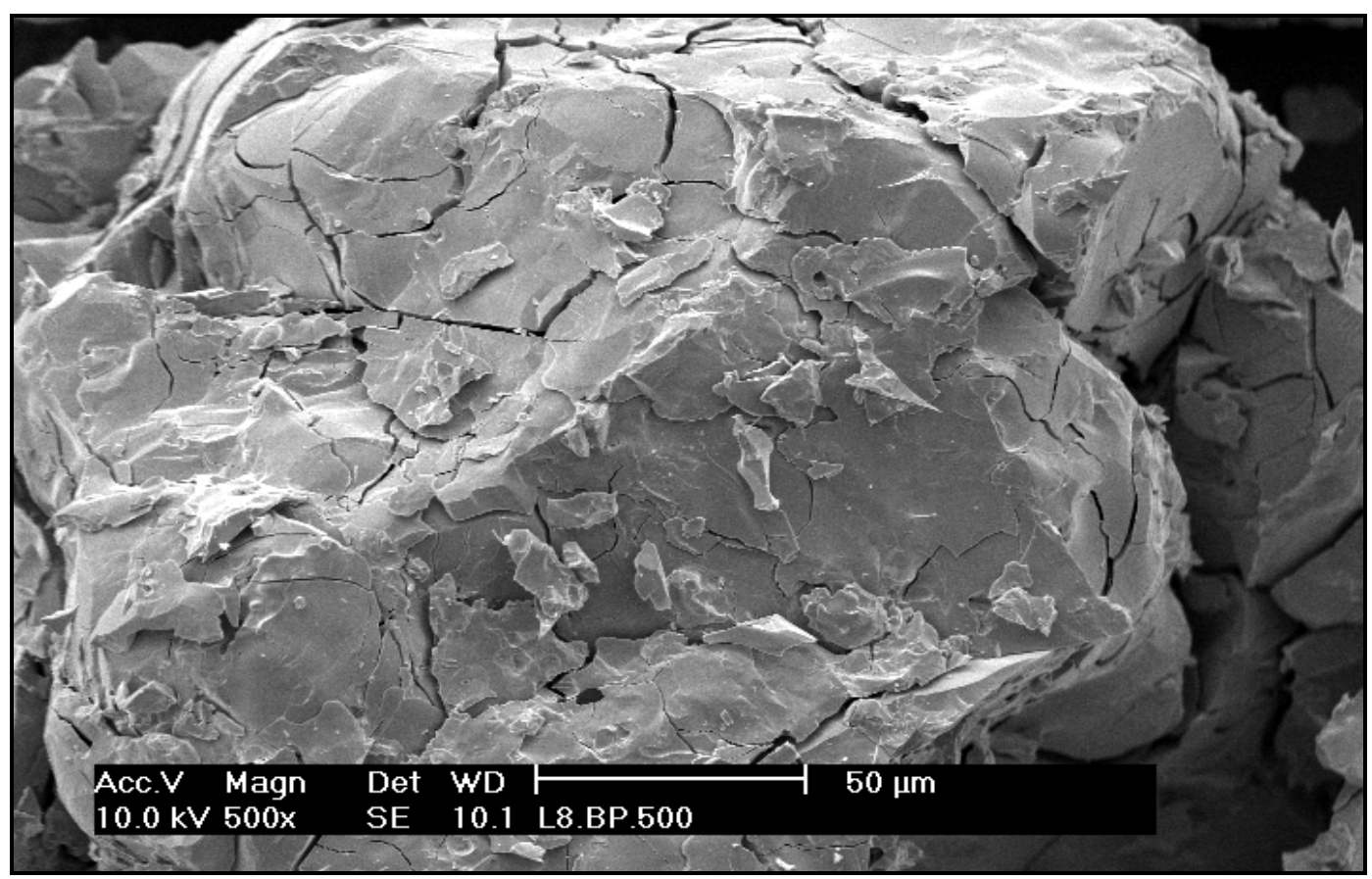

(b)

FIGURA 32 - Pós obtidos da liga $\mathrm{La}_{0,6} \mathrm{Mg}_{0,1} \operatorname{Pr}_{0,3} \mathrm{Al}_{0,3} \mathrm{Mn}_{0,4} \mathrm{Co}_{0,5} \mathrm{Ni}_{3,8}$ sob 0,2 MPa de hidrogênio a $500^{\circ} \mathrm{C}$ com resfriamento rápido; onde: (a) visão geral (50x) e (b) visão detalhada (500x). 


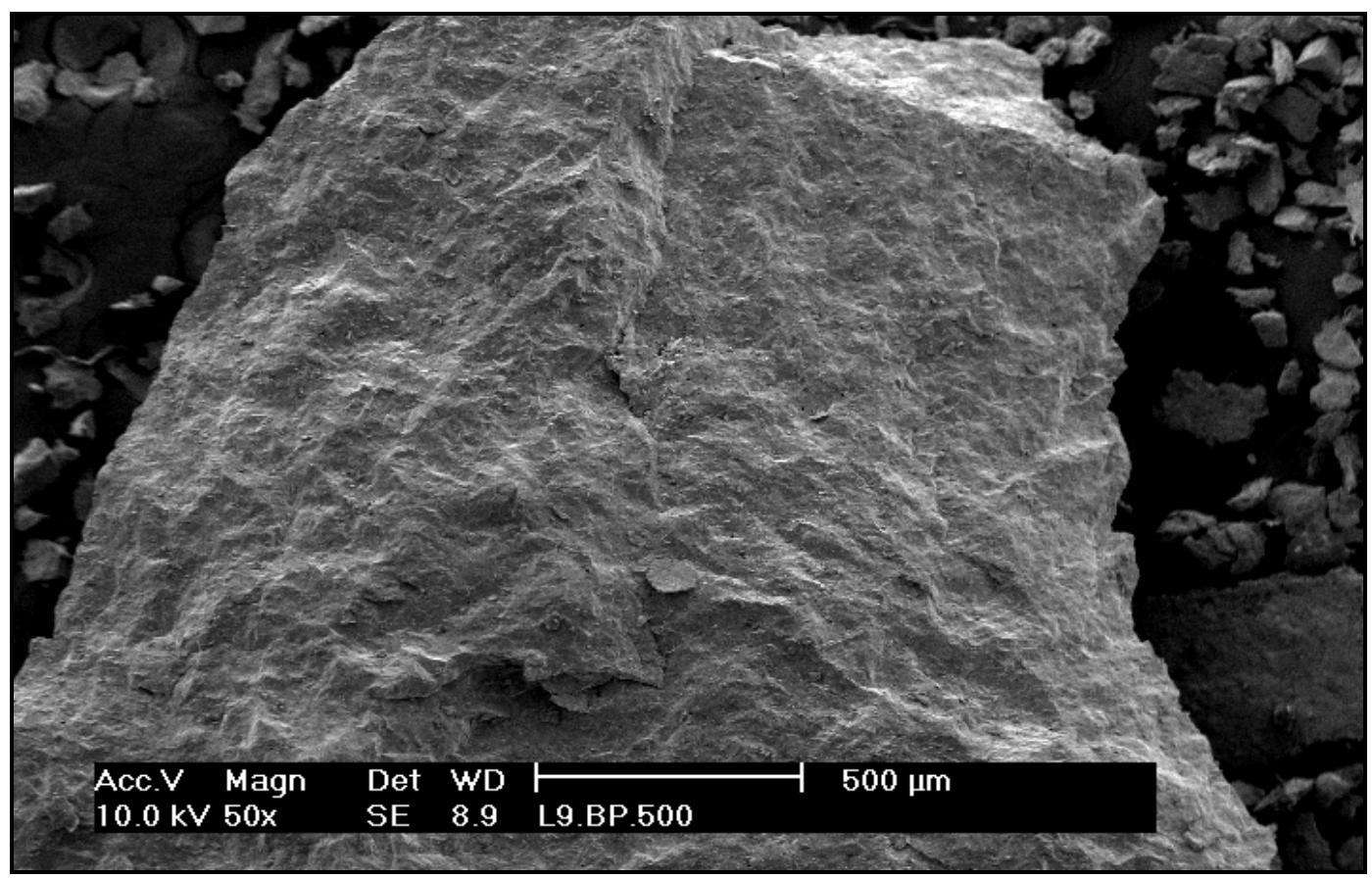

(a)

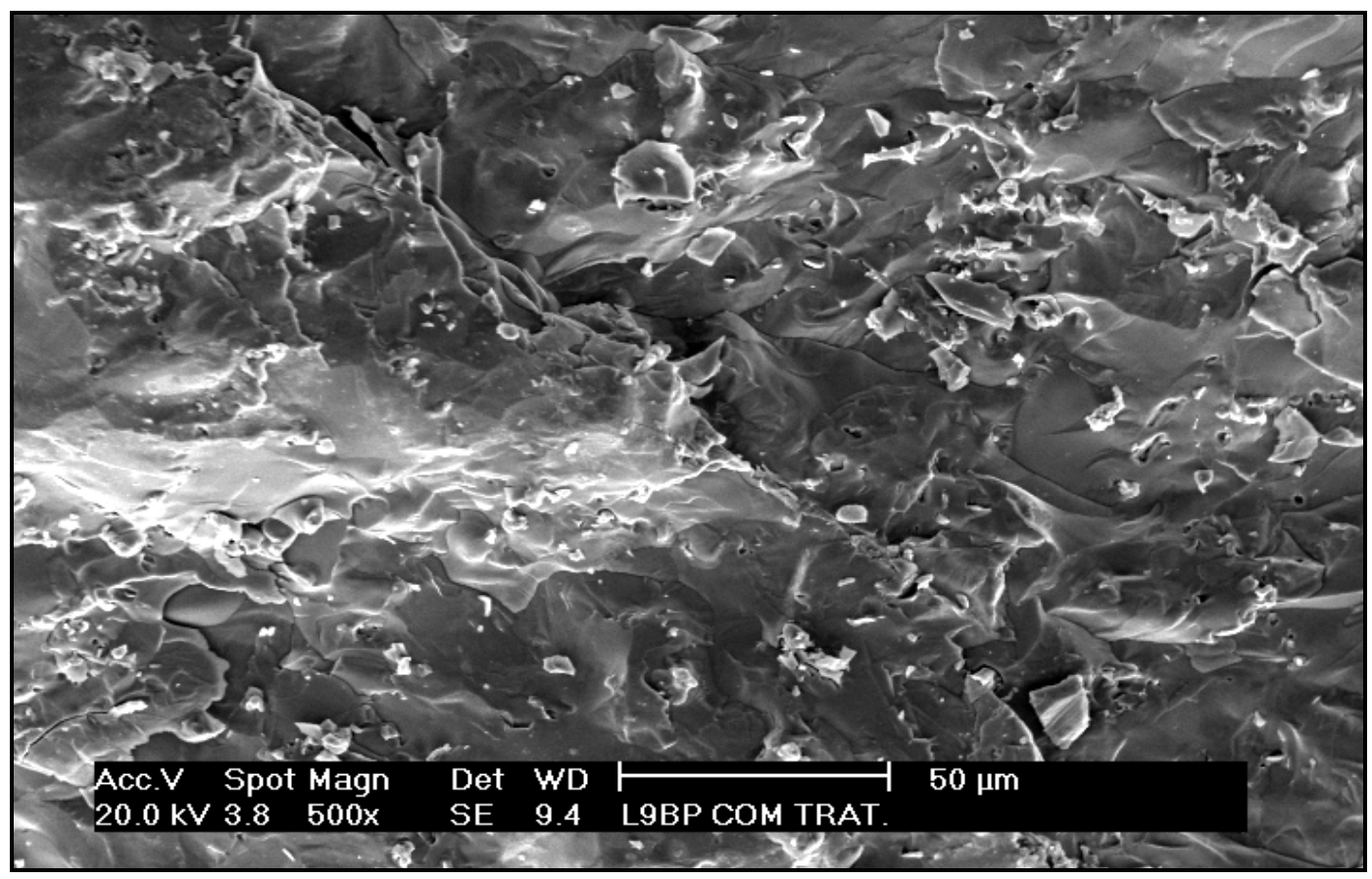

(b)

FIGURA 33 - Liga $\mathrm{La}_{0,4} \mathrm{Mg}_{0,3} \mathrm{Pr}_{0,3} \mathrm{Al}_{0,3} \mathrm{Mn}_{0,4} \mathrm{Co}_{0,5} \mathrm{Ni}_{3,8}$ sob 0,2 MPa de hidrogênio a 500 C com resfriamento rápido; onde: (a) visão gera I (50x) e (b) visão detalhada (500x). 


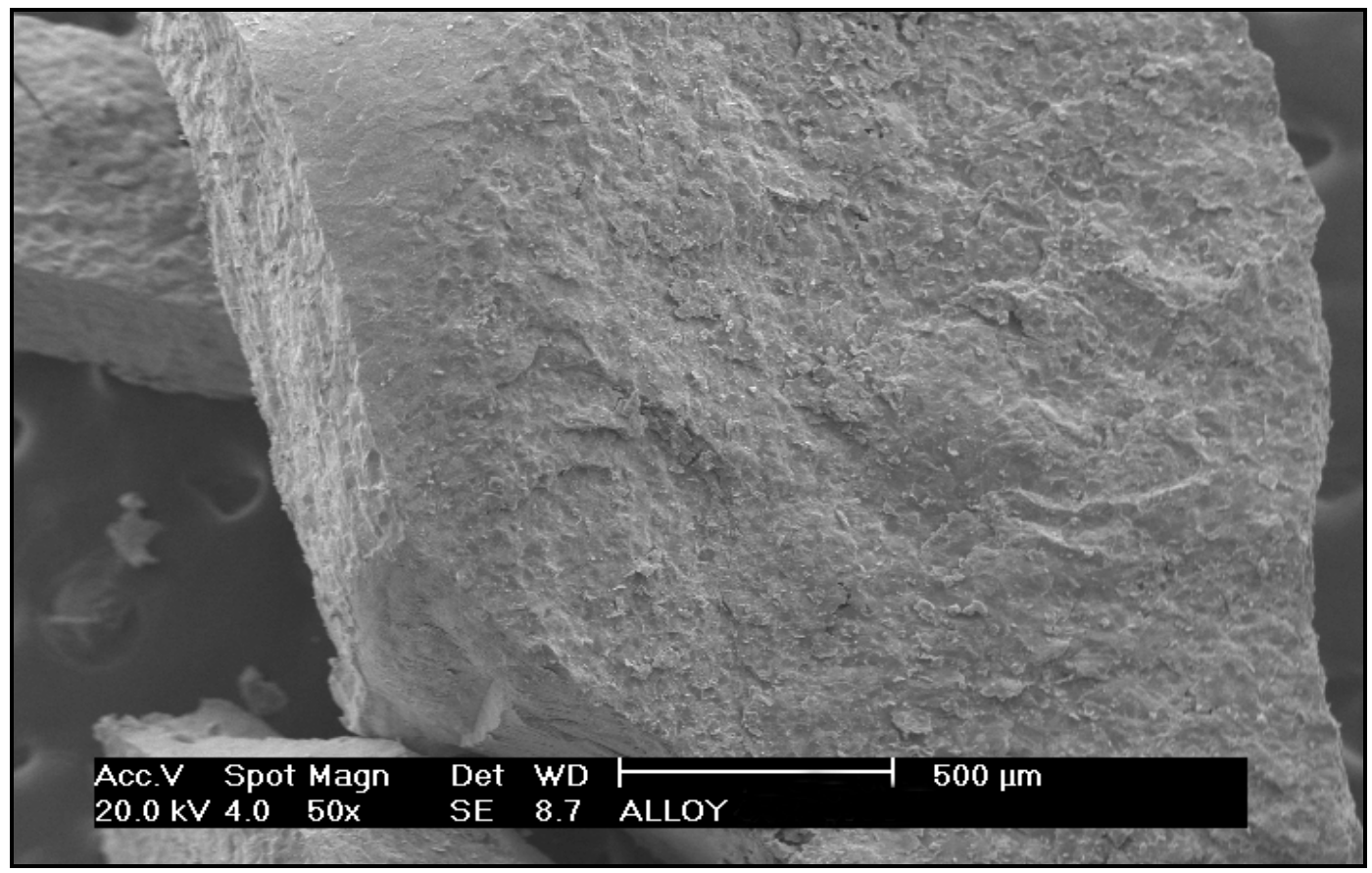

(a)

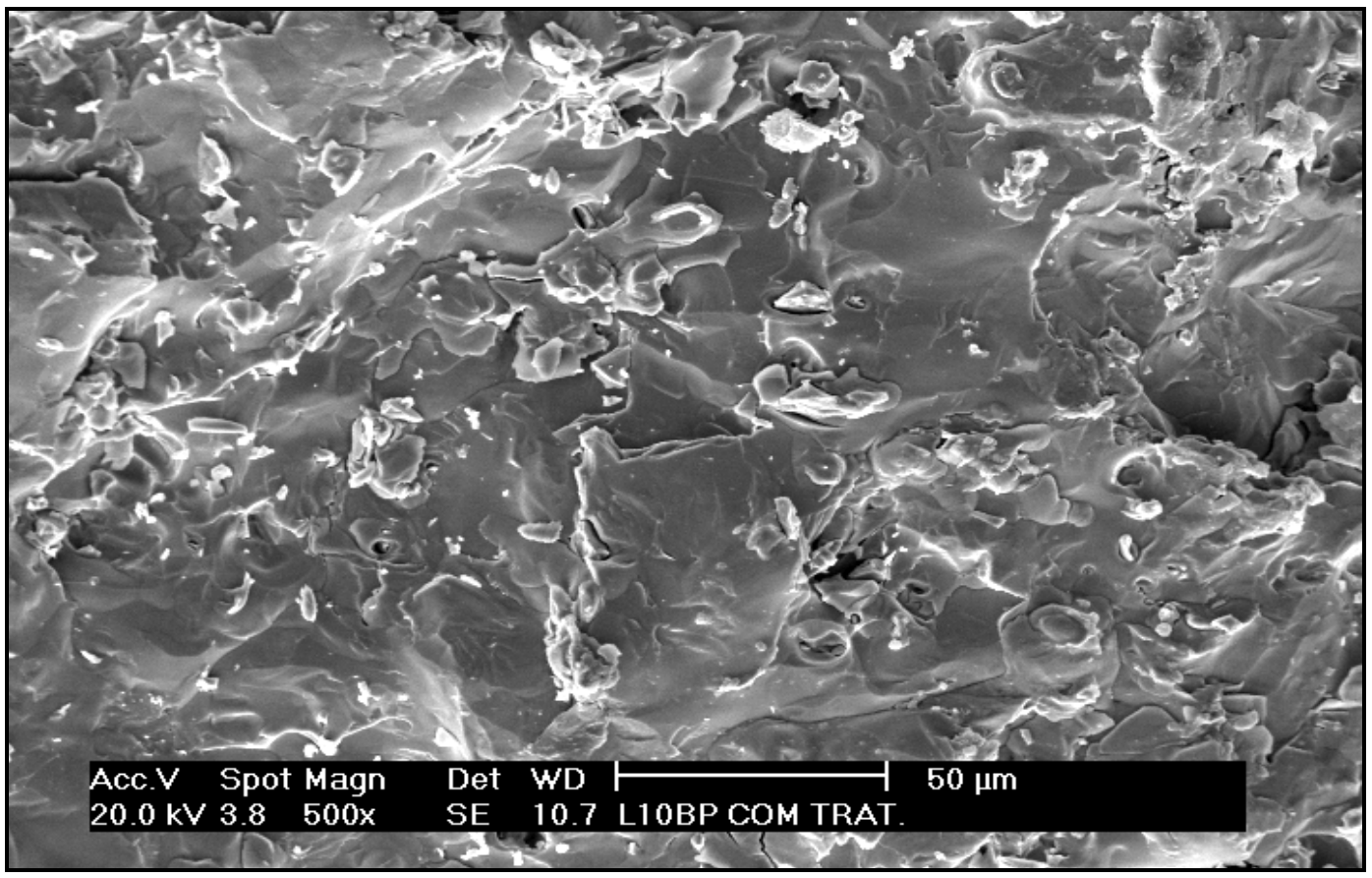

(b)

FIGURA 34 - Liga $\mathrm{La}_{0,2} \mathrm{Mg}_{0,5} \mathrm{Pr}_{0,3} \mathrm{Al}_{0,3} \mathrm{Mn}_{0,4} \mathrm{Co}_{0,5} \mathrm{Ni}_{3,8}$ sob 0,2 MPa de hidrogênio a 500` com resfriamento rápido; onde: (a) visão gera I (50x) e (b) visão detalhada (500x). 


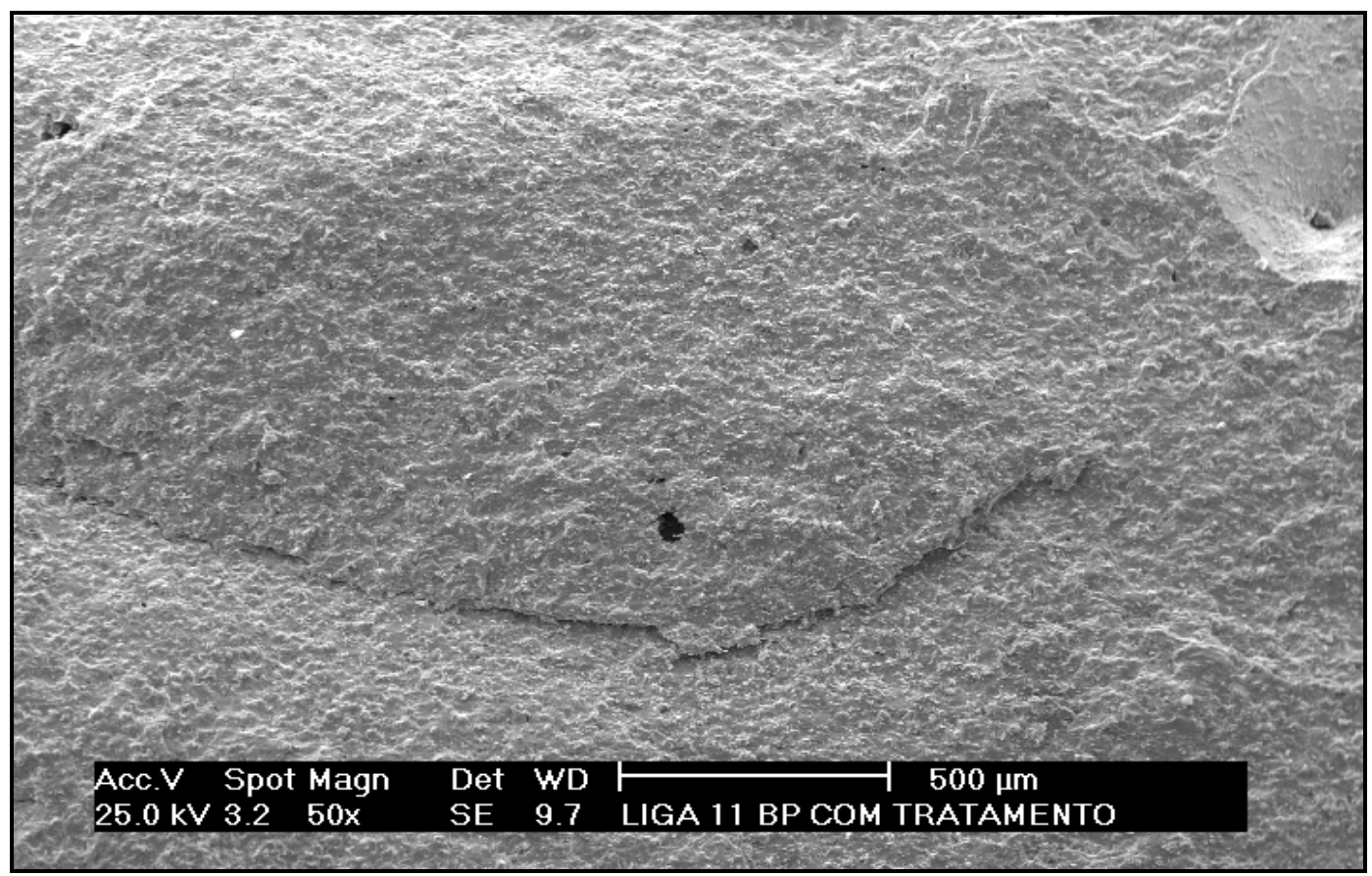

(a)

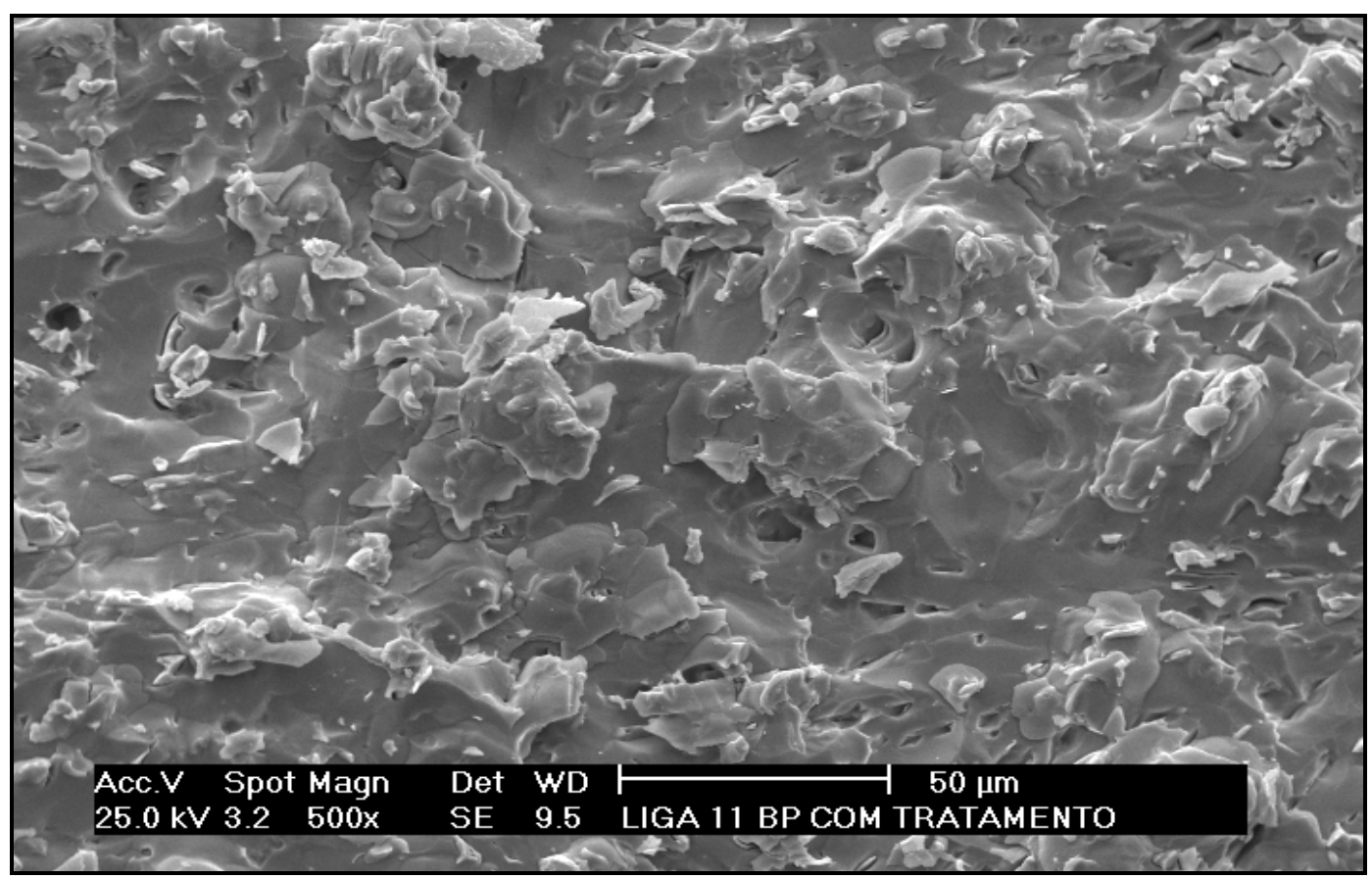

(b)

FIGURA 35 - Liga $\mathrm{Mg}_{0,7} \mathrm{Pr}_{0,3} \mathrm{Al}_{0,3} \mathrm{Mn}_{0,4} \mathrm{Co}_{0,5} \mathrm{Ni}_{3,8}$ sob 0,2 $\mathrm{MPa}$ de hidrogênio a 500 C com resfriamento rápido; onde: (a) visão gera I (50x) e (b) visão detalhada (500x). 
Os resultados mostraram que para a liga com $\mathrm{Mg}_{0,1}$ as partículas apresentaram trincas, mostrando a decriptação da liga por hidrogênio. Para a liga com $\mathrm{Mg}_{0,3}$ não foi possível observar a formação de trincas na superfície da liga, apesar da absorção de hidrogênio, como mostrado na FIG. 33.

$\mathrm{Na}$ FIG. 36 apresenta-se a curva da variação na absorção de hidrogênio em função do tempo que o material ficou exposto, a uma pressão inicial de $1 \mathrm{MPa}$ (10 bar) e a temperatura ambiente.

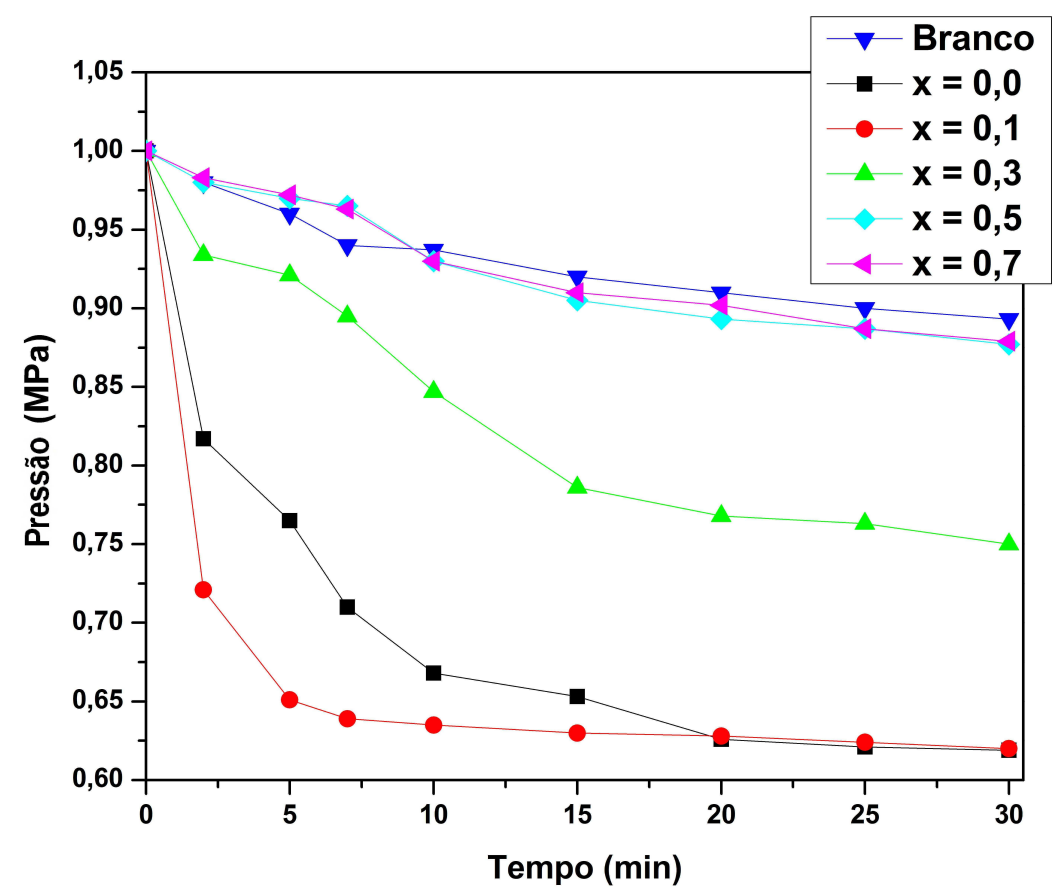

FIGURA 36 - Curvas da absorção de hidrogênio a pressão de $1 \mathrm{MPa}$ em função do tempo à temperatura ambiente das ligas $\mathrm{La}_{0,7-x} \mathrm{Mg}_{x} \operatorname{Pr}_{0,3} \mathrm{Al}_{0,3} \mathrm{Mn}_{0,4} \mathrm{Co}_{0,5} \mathrm{Ni}_{3,8}(x=$ 0 a 0,7$)$.

Com o aumento da pressão de hidrogênio para 1 MPa e a temperatura ambiente é possível observar alta absorção de hidrogenação espontânea para as ligas sem $\mathrm{Mg}, \mathrm{Mg}_{0,1}$ e $\mathrm{Mg}_{0,3}$. Com altos teores de magnésio as ligas não apresentaram absorção de $\mathrm{H}_{2}$. Apresentaram o mesmo comportamento em relação ao branco (sem material).

Nas FIG. 37 - 39 estão mostrados os pós das ligas $\operatorname{La}_{0,7-x} M_{g_{x}}$ $\operatorname{Pr}_{0,3} \mathrm{Al}_{0,3} \mathrm{Mn}_{0,4} \mathrm{Co}_{0,5} \mathrm{Ni}_{3,8}(\mathrm{x}=0$ a 0,3) após a hidrogenação a $1 \mathrm{MPa}$ de hidrogênio a temperatura ambiente. 


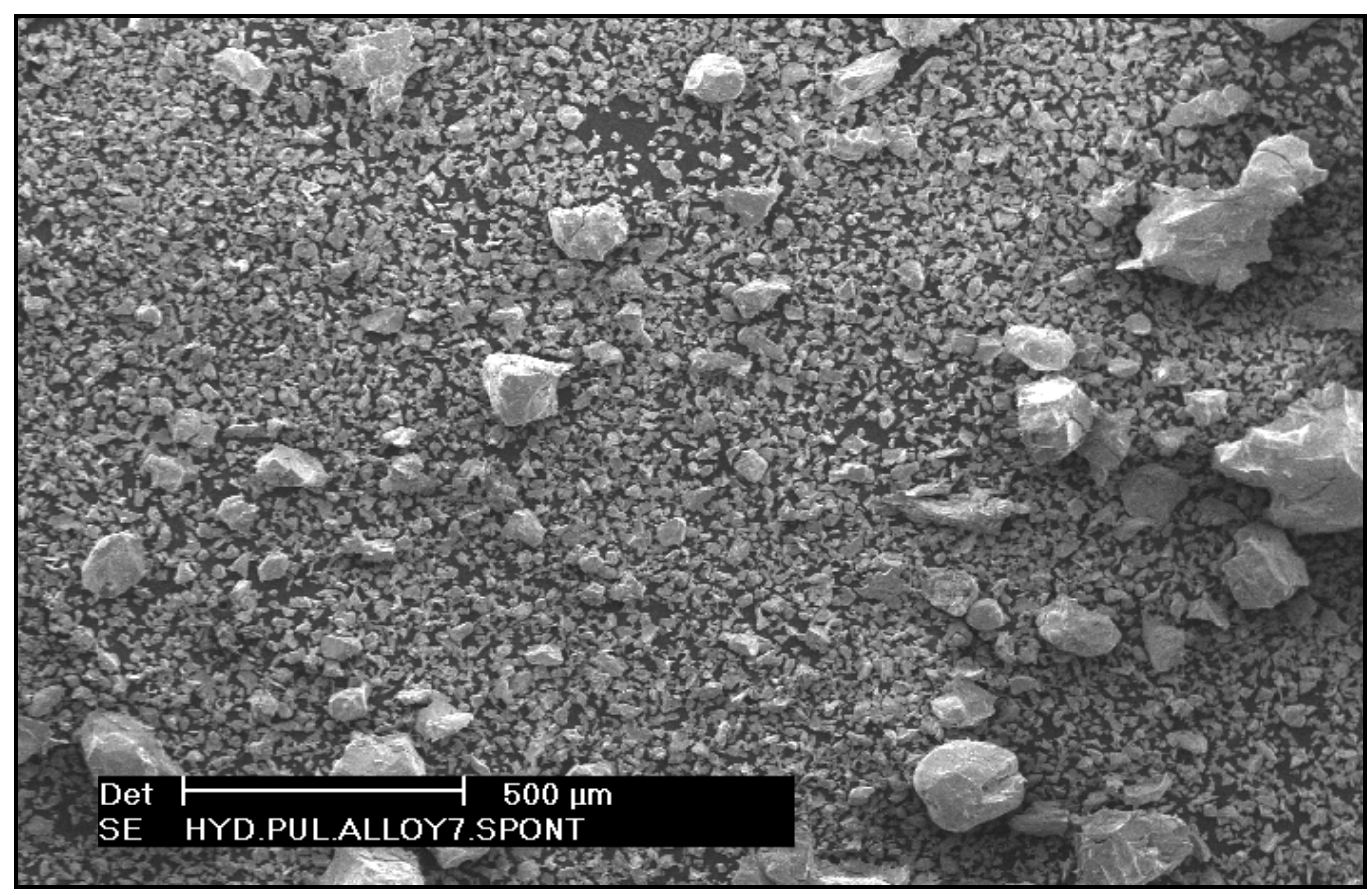

(a)

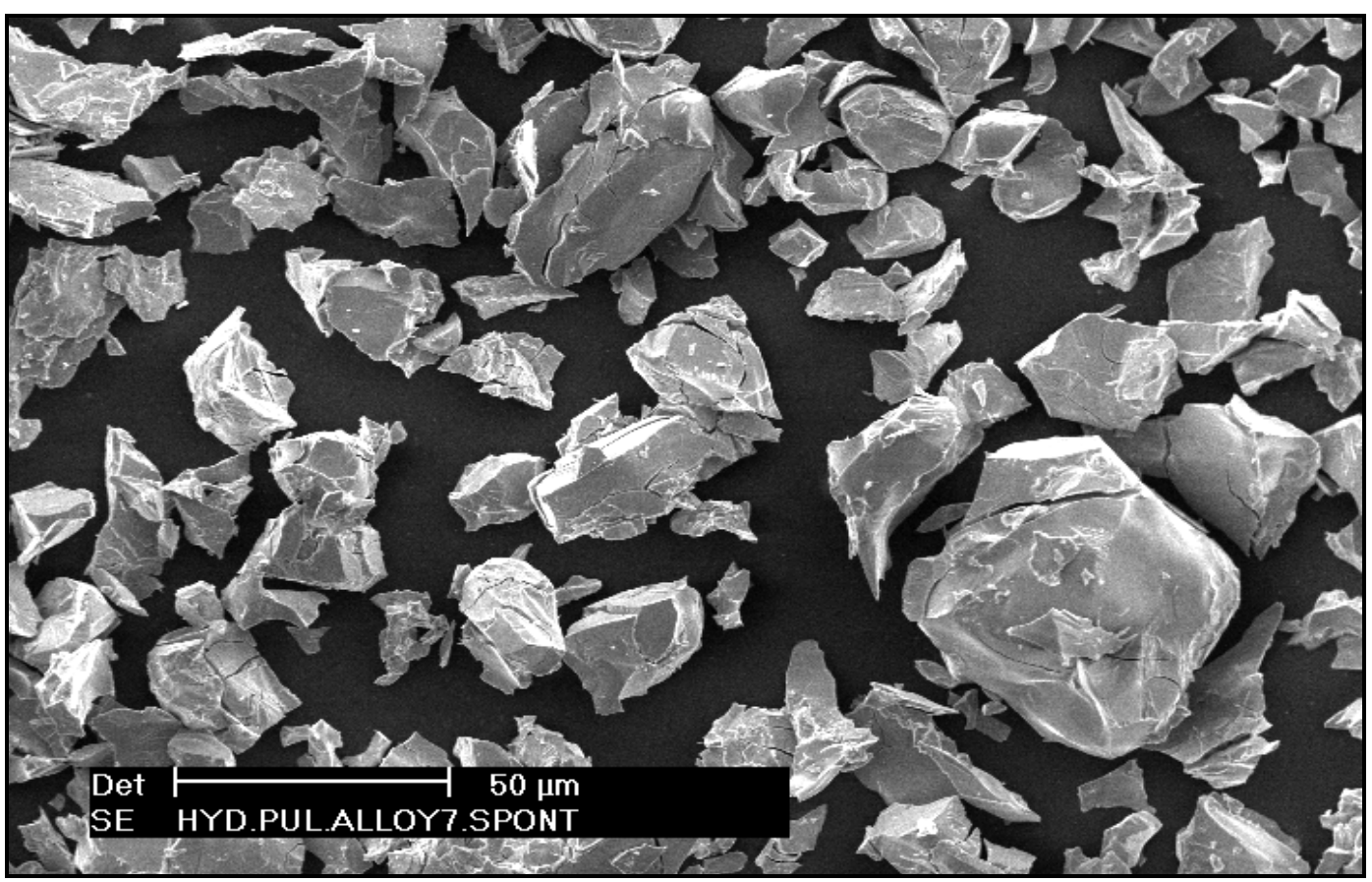

(b)

FIGURA 37 - Pós obtidos da liga $\mathrm{La}_{0,7} \operatorname{Pr}_{0,3} \mathrm{Al}_{0,3} \mathrm{Mn}_{0,4} \mathrm{Co}_{0,5} \mathrm{Ni}_{3,8}$ a $1 \mathrm{MPa}$ de hidrogênio a temperatura ambiente; onde: (a) visão geral (50x) e (b) visão detalhada (500x). 


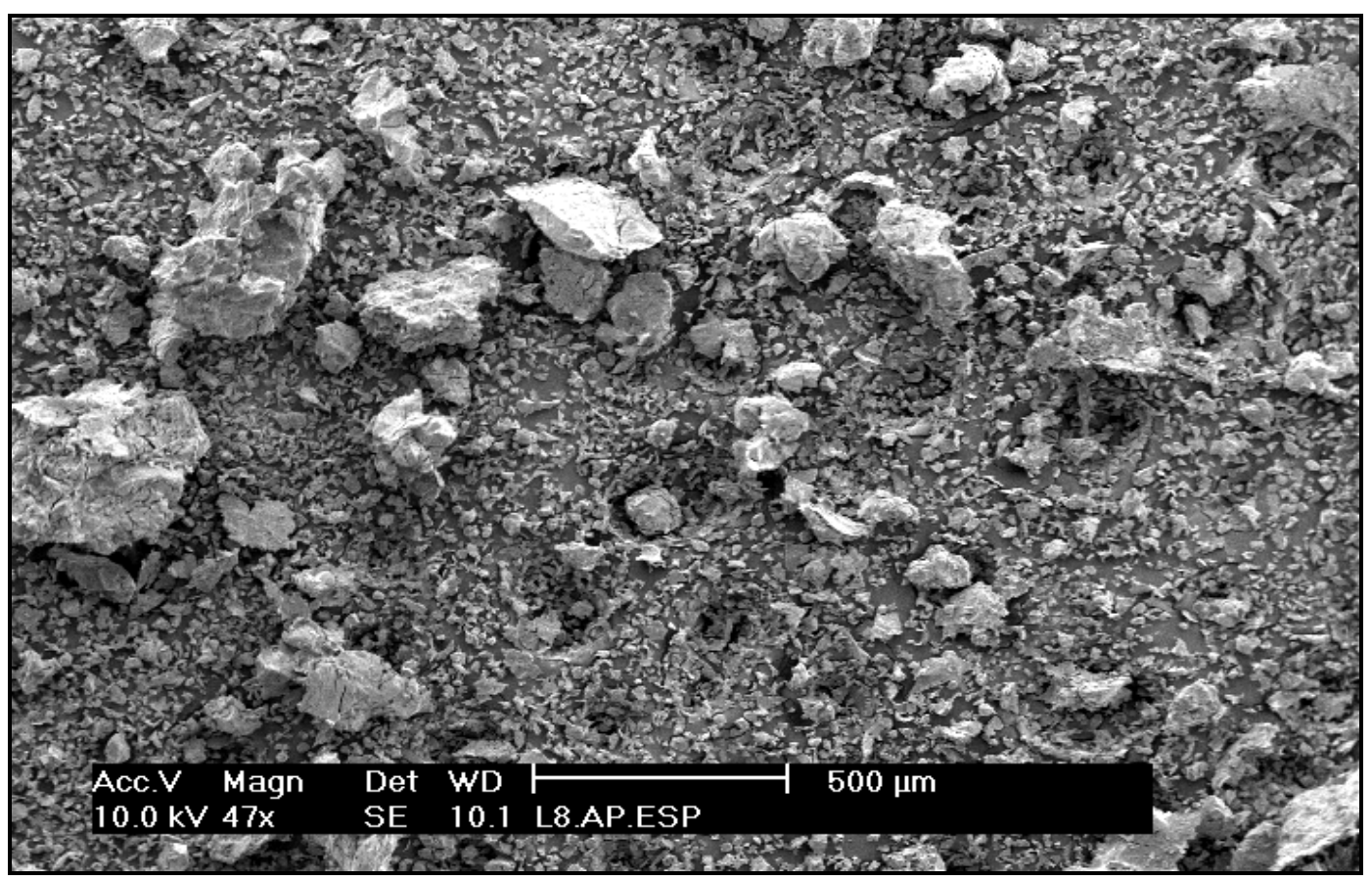

(a)

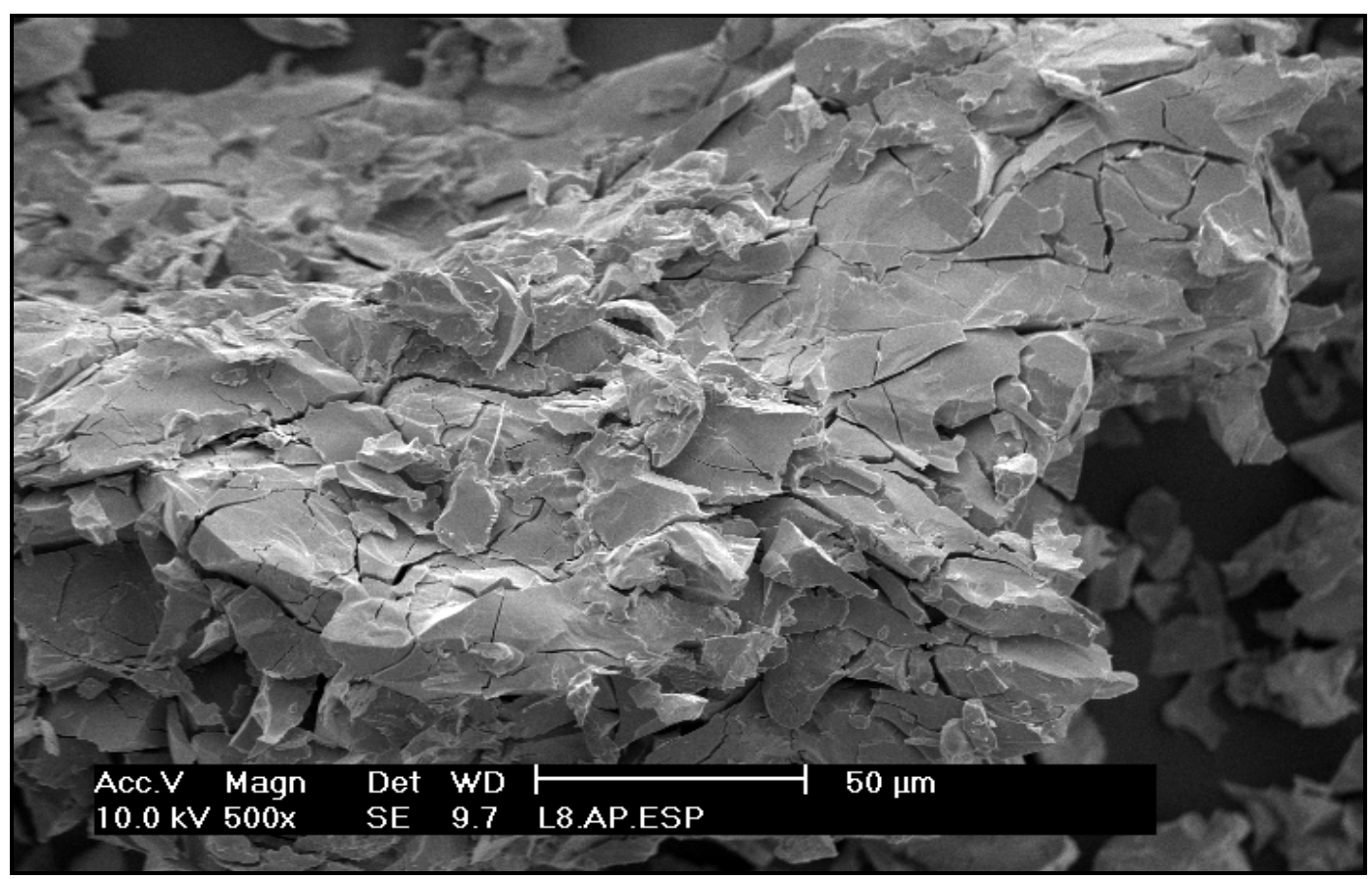

(b)

FIGURA 38 - Pós obtidos da liga $\mathrm{La}_{0,6} \mathrm{Mg}_{0,1} \operatorname{Pr}_{0,3} \mathrm{Al}_{0,3} \mathrm{Mn}_{0,4} \mathrm{Co}_{0,5} \mathrm{Ni}_{3,8}$ a $1 \mathrm{MPa}$ de hidrogênio a temperatura ambiente; onde: (a) visão geral (50x) e (b) visão detalhada (500x). 


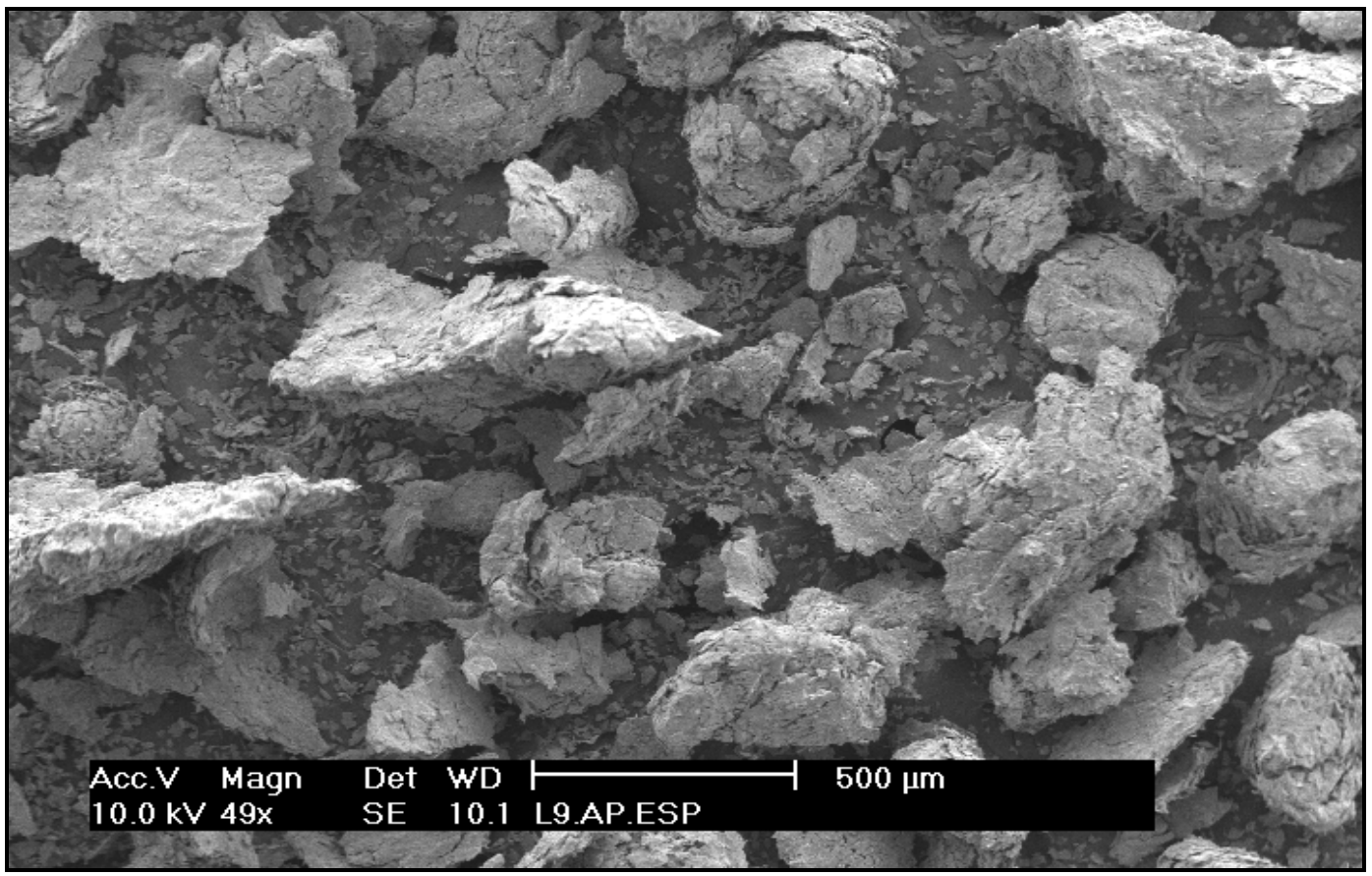

(a)

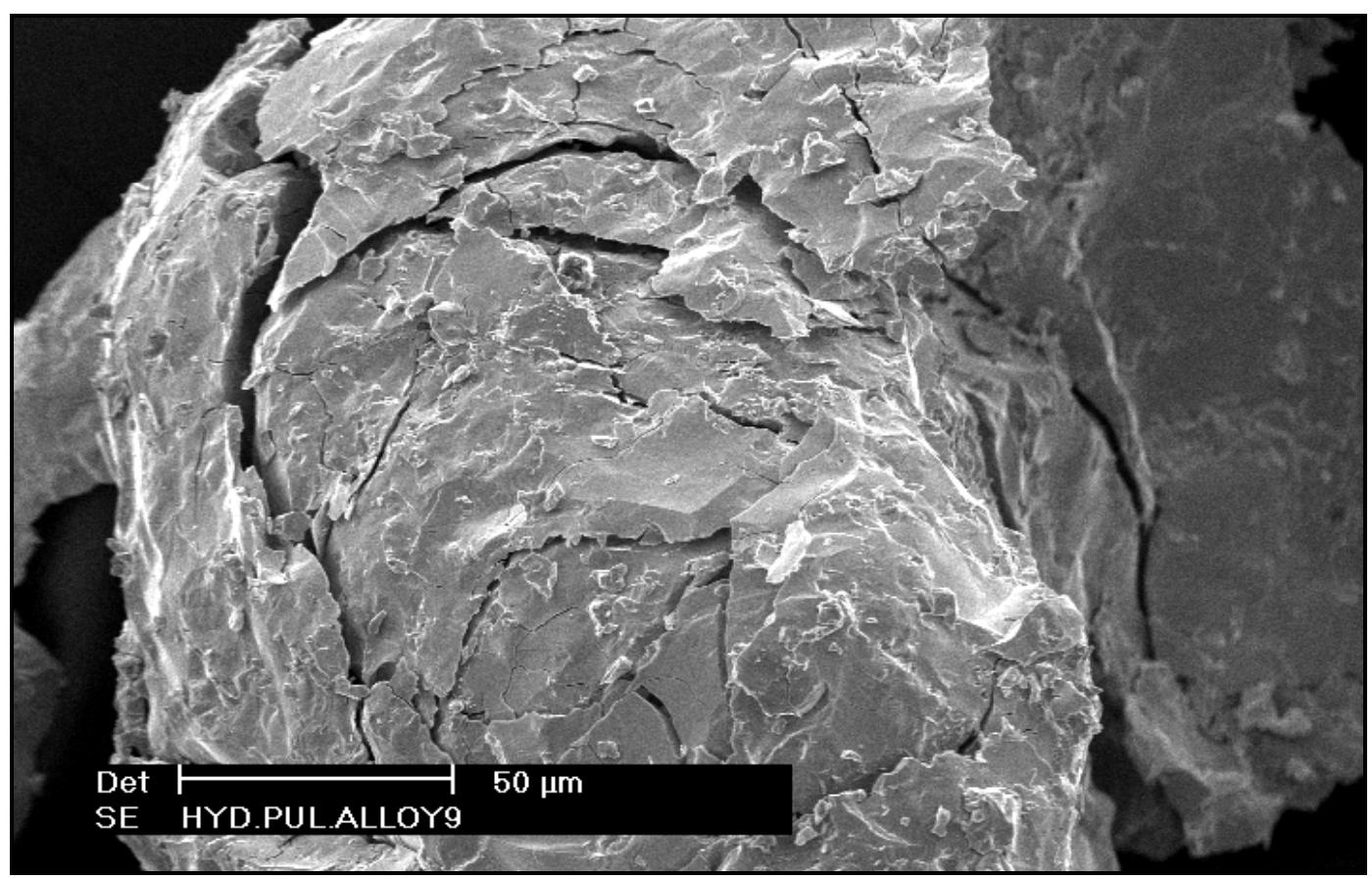

(b)

FIGURA 39 - Pós obtidos da liga $\mathrm{La}_{0,4} \mathrm{Mg}_{0,3} \operatorname{Pr}_{0,3} \mathrm{Al}_{0,3} \mathrm{Mn}_{0,4} \mathrm{Co}_{0,5} \mathrm{Ni}_{3,8}$ a $1 \mathrm{MPa}$ de hidrogênio a temperatura ambiente; onde: (a) visão geral (50x) e (b) visão detalhada (500x). 
$\mathrm{Na}$ FIG. 40 apresenta-se as curvas da variação na absorção de hidrogênio em função do tempo que o material ficou exposto, a uma pressão inicial de $1 \mathrm{MPa}$ (10 bar) à temperatura de $500^{\circ} \mathrm{C}$ e resfriamento rápido, para as ligas com alto teor de $\mathrm{Mg}$. Os resultados mostraram que houve uma pequena absorção de hidrogênio, em relação ao branco (sem material), somente para a liga com $\mathrm{Mg}_{0,5}$.

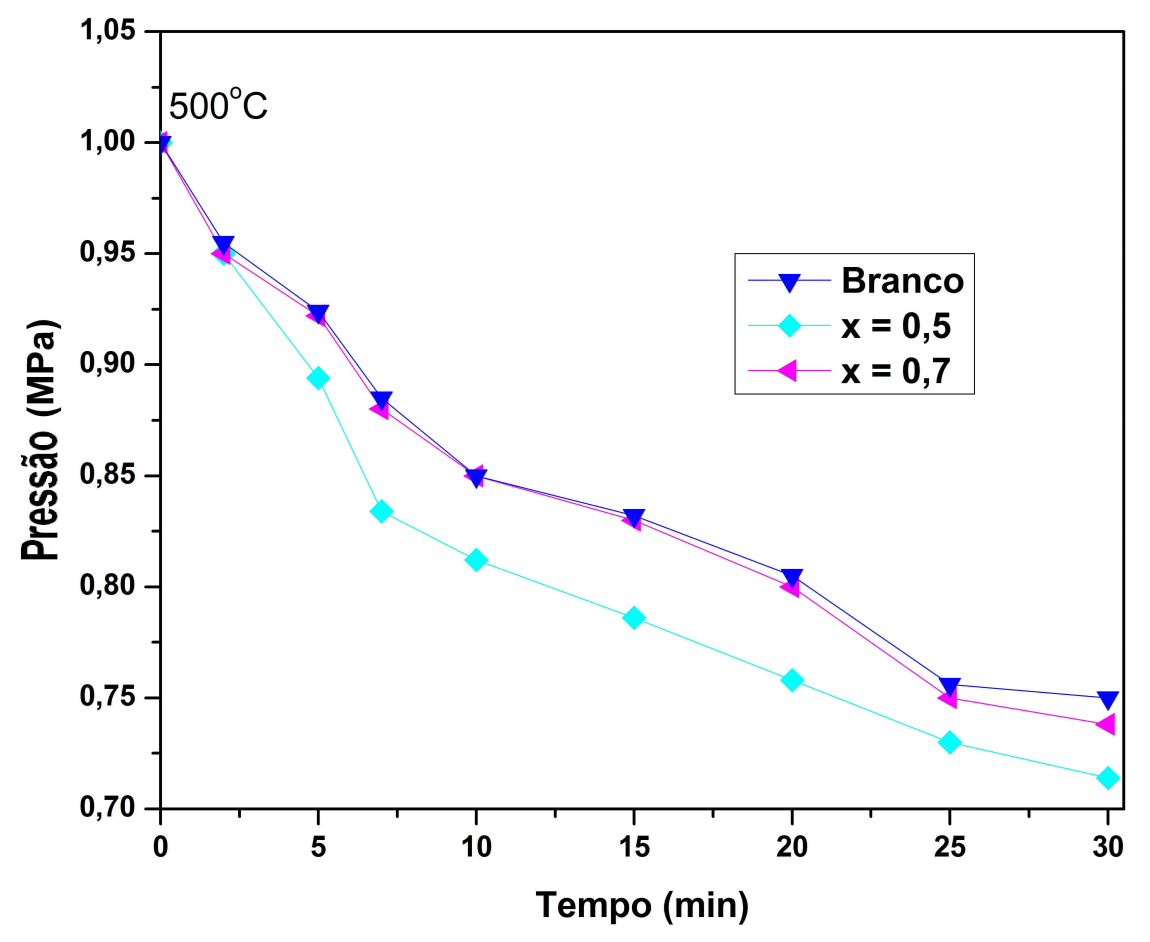

FIGURA 40 - Curva da absorção de hidrogênio de pressão $1 \mathrm{MPa}$ em função do tempo à temperatura de $500{ }^{\circ} \mathrm{com}$ resfriamento rápido das ligas $\mathrm{La}_{0,7-x} M g_{x}$ $\operatorname{Pr}_{0,3} \mathrm{Al}_{0,3} \mathrm{Mn}_{0,4} \mathrm{Co}_{0,5} \mathrm{Ni}_{3,8}(x=0,5$ e 0,7$)$.

Nas FIG. 41 e 42 estão mostrados as fotos obtidas por MEV dos pós das ligas $\mathrm{La}_{0,7-x} \mathrm{Mg}_{\mathrm{x}} \mathrm{Pr}_{0,3} \mathrm{Al}_{0,3} \mathrm{Mn}_{0,4} \mathrm{Co}_{0,5} \mathrm{Ni}_{3,8}(\mathrm{x}=0,5$ e 0,7) após a hidrogenação a 1 $\mathrm{MPa}$ de hidrogênio a temperatura de $500^{\circ} \mathrm{C}$ com resfri amento rápido. 


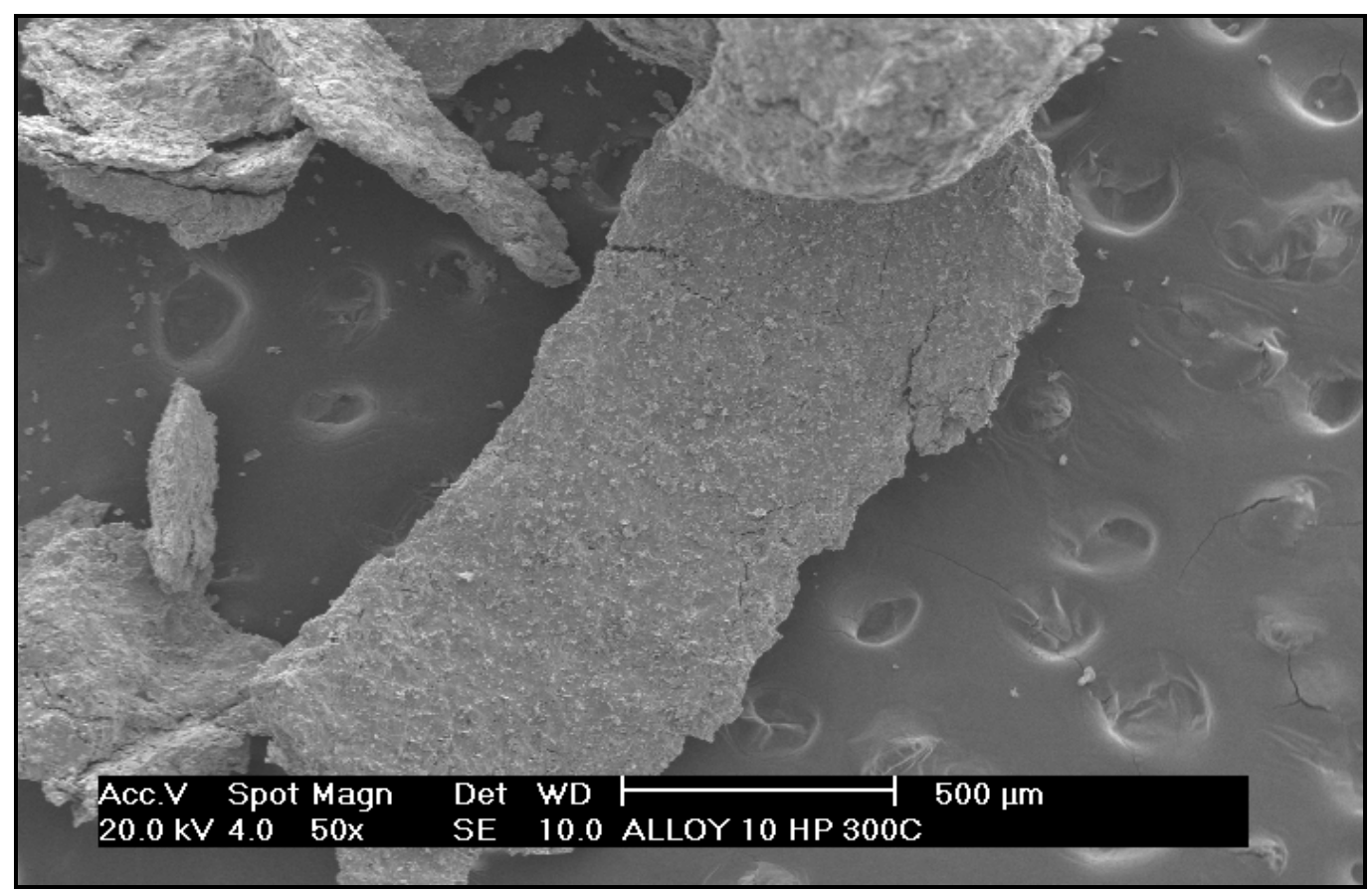

(a)

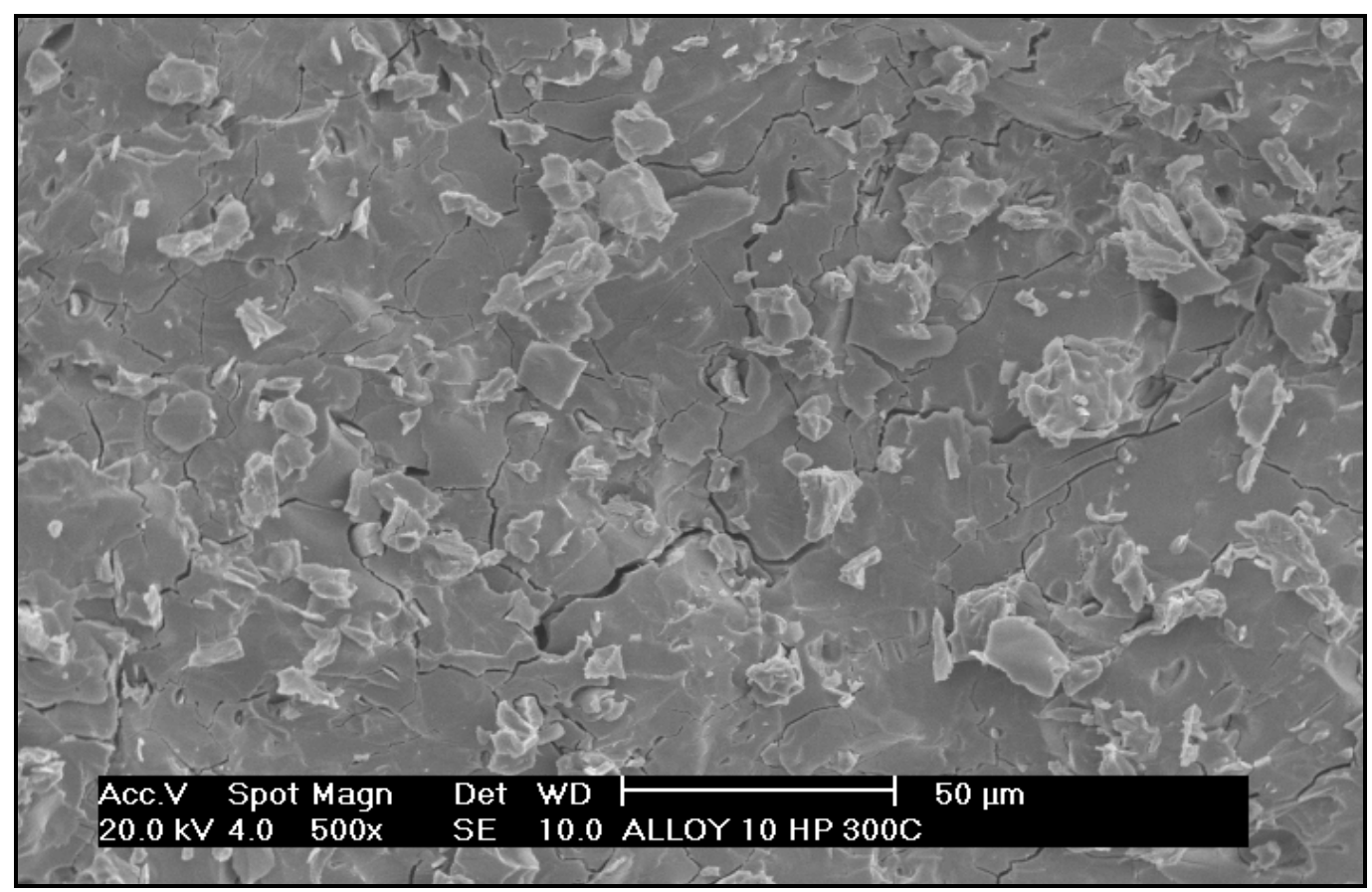

(b)

FIGURA 41 - Liga $\mathrm{La}_{0,2} \mathrm{Mg}_{0,5} \mathrm{Pr}_{0,3} \mathrm{Al}_{0,3} \mathrm{Mn}_{0,4} \mathrm{Co}_{0,5} \mathrm{Ni}_{3,8}$ após a exposição a $1 \mathrm{MPa}$ de hidrogênio a 500 com resfriamento rápido; onde: (a) visão geral (50x) e (b) visão detalhada (500x). 


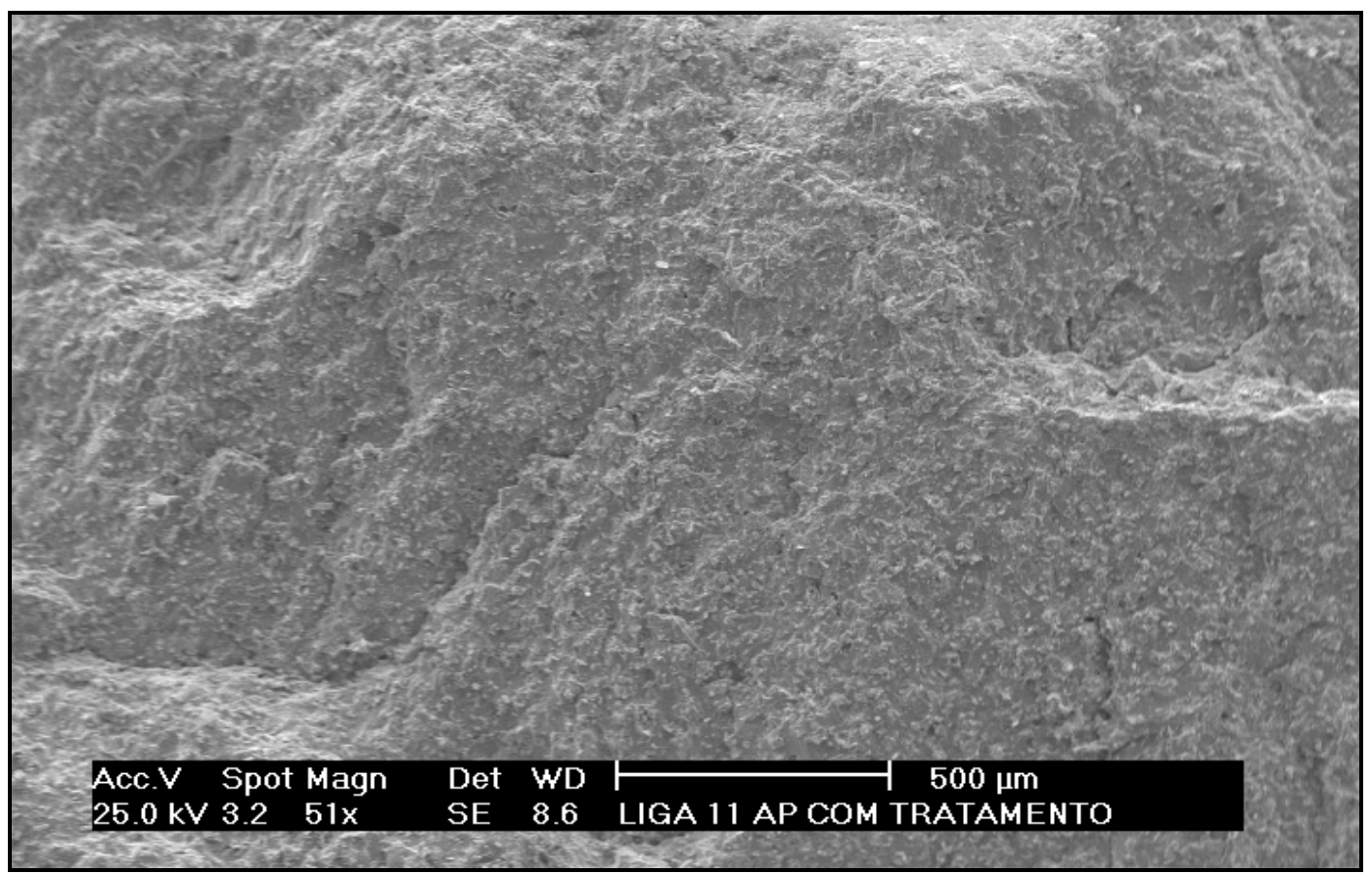

(a)

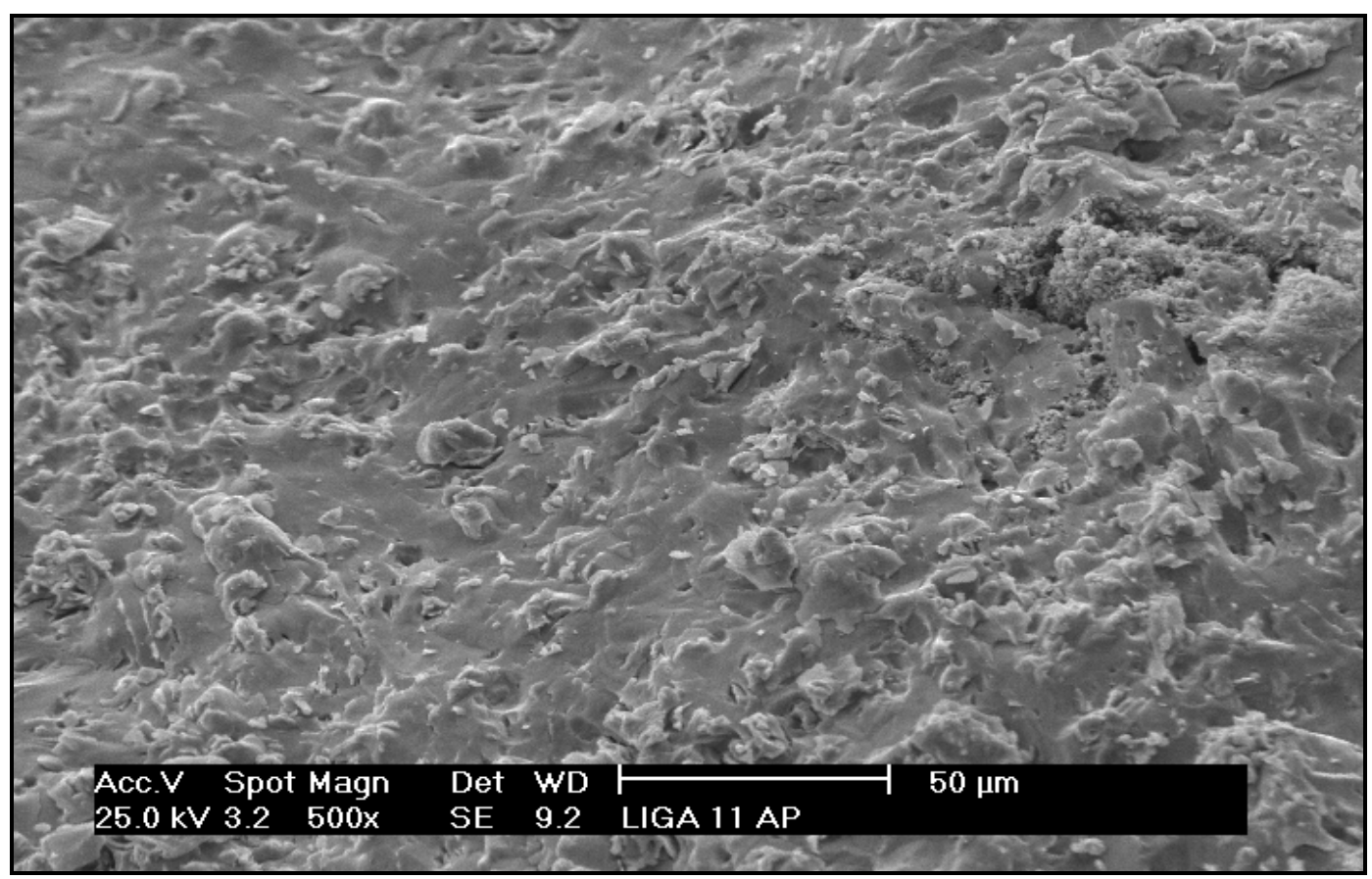

(b)

FIGURA 42 - Liga $\mathrm{Mg}_{0,7} \mathrm{Pr}_{0,3} \mathrm{Al}_{0,3} \mathrm{Mn}_{0,4} \mathrm{Co}_{0,5} \mathrm{Ni}_{3,8}$ após a exposição a $1 \mathrm{MPa}$ de hidrogênio a $500^{\circ} \mathrm{C}$ com resfriamento rápido; onde: (a) visão geral (50x) e (b) visão detalhada (500x).

$\mathrm{O}$ efeito da absorção de $\mathrm{H}_{2}$ pode ser observado pelo surgimento de trincas na superfície da liga com Mg, $_{0,5}$, como mostrada na FIG. 41 (b). Para a liga com $\mathrm{Mg}_{0,7}$ não foi possível observar nenhuma alteração em sua superfície. 
Nas FIG. 43 - 45 estão mostradas as distribuições de tamanho de partículas obtidas por CILAS das ligas sem $\mathrm{Mg}, \mathrm{Mg}_{0,1}$ e $\mathrm{Mg}_{0,3}$ após hidrogenação a $0,2 \mathrm{MPa}$ e $1 \mathrm{MPa}$.

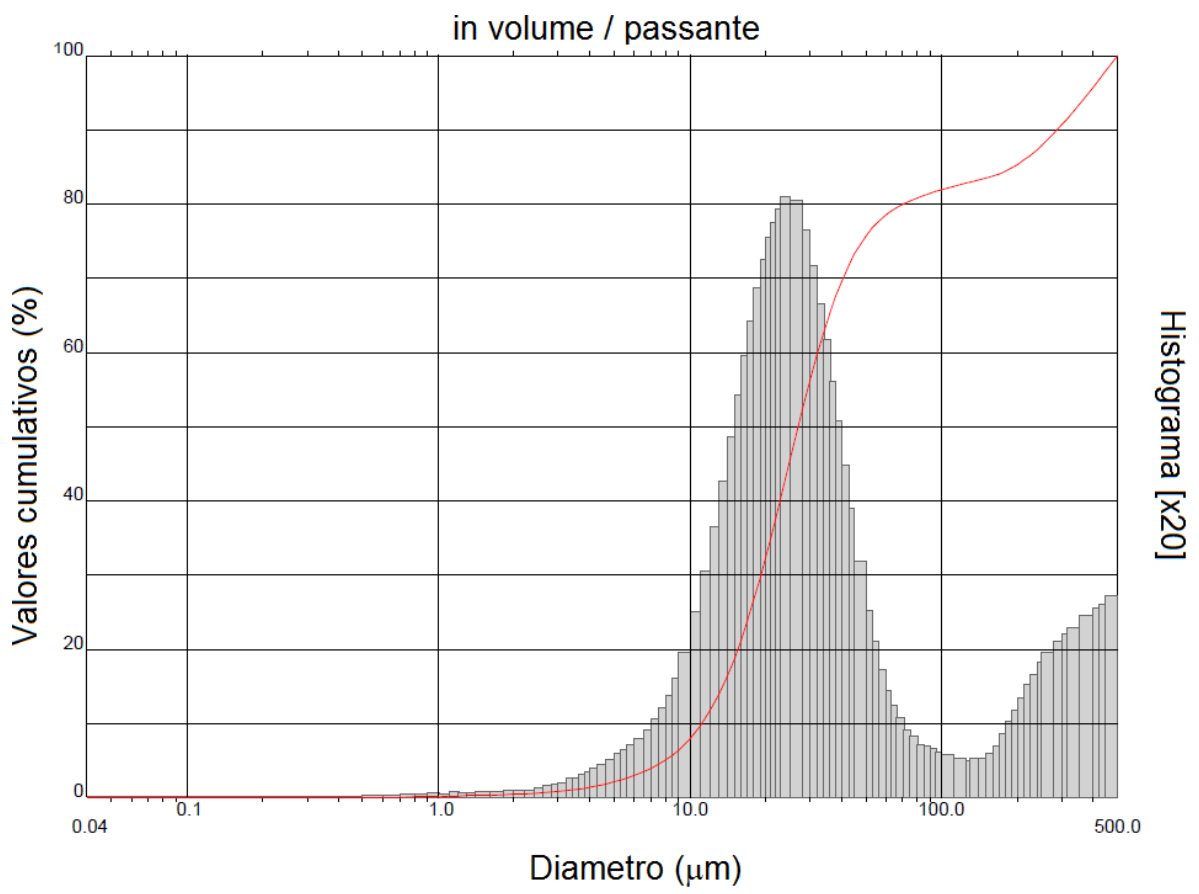

(a)

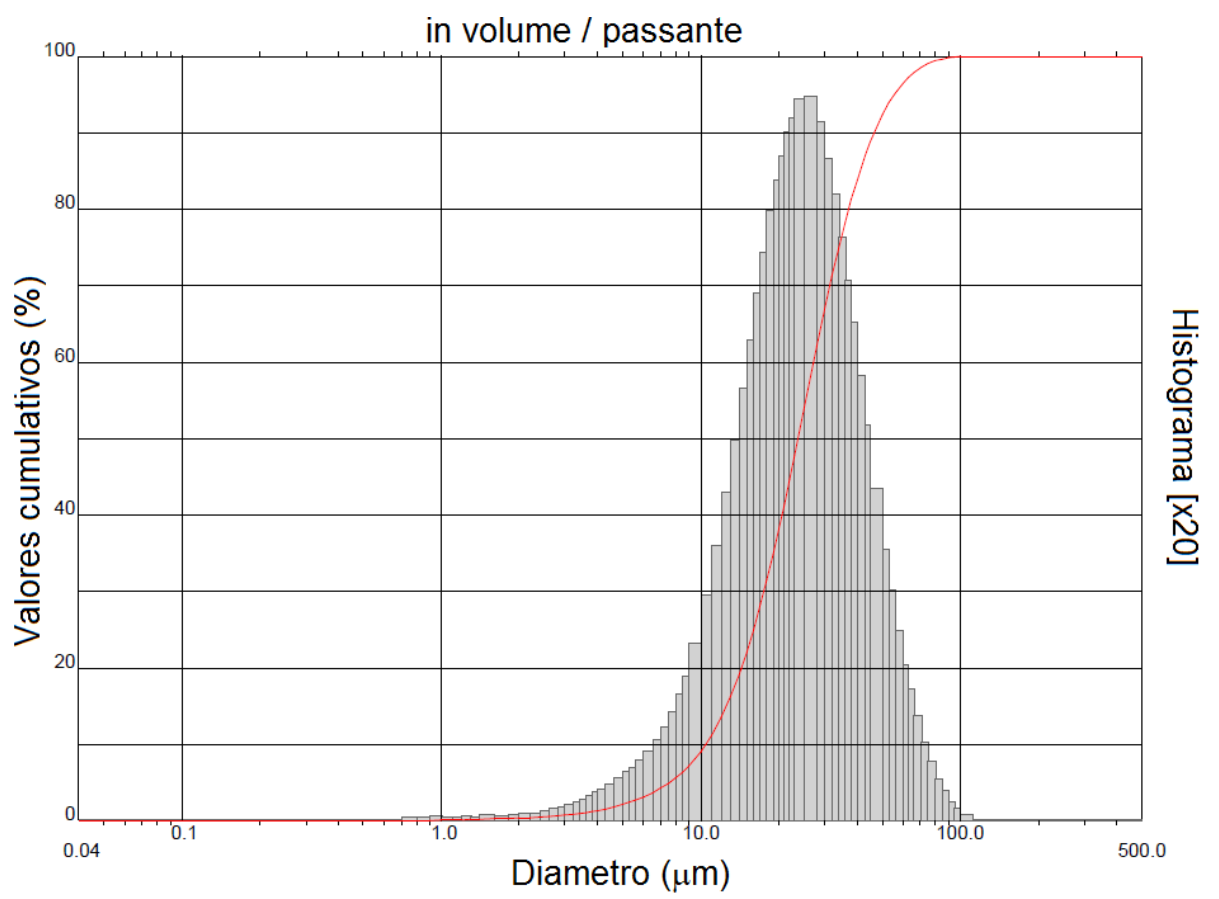

(b)

FIGURA 43 - Distribuição de tamanho de partícula obtida por CILAS para a liga $\mathrm{La} a_{0,7} \mathrm{Pr}_{0,3} \mathrm{Al}_{0,3} \mathrm{Mn}_{0,4} \mathrm{Co}_{0,5} \mathrm{Ni}_{3,8}$, onde: (a) hidrogenação a pressão de 0,2 $\mathrm{MPa}$ e (b) hidrogenação a pressão de $1 \mathrm{MPa}$. 


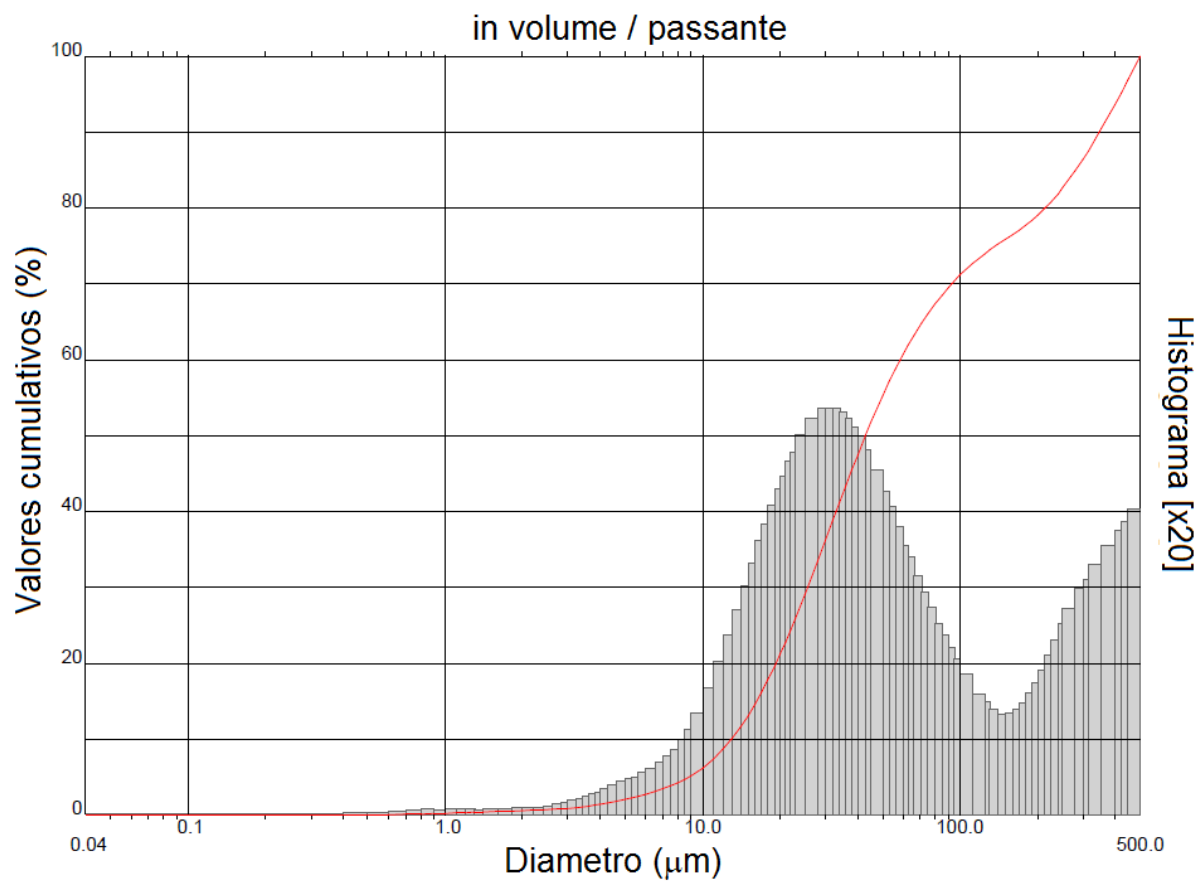

(a)

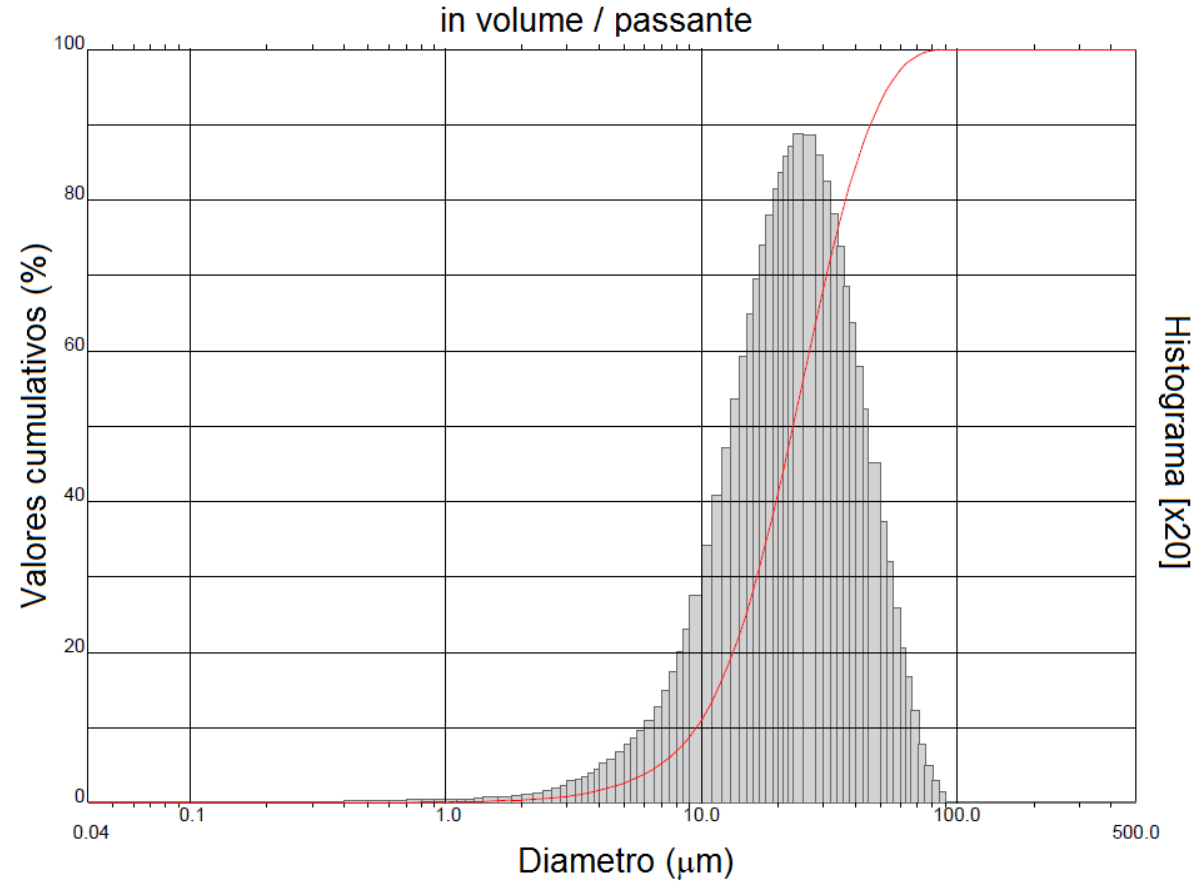

(b)

FIGURA 44 - Distribuição de tamanho de partícula obtida por CILAS para a liga $\mathrm{La}_{0,6} \mathrm{Mg}_{0,1} \mathrm{Pr}_{0,3} \mathrm{Al}_{0,3} \mathrm{Mn}_{0,4} \mathrm{Co}_{0,5} \mathrm{Ni}_{3,8}$, onde: (a) hidrogenação a pressão de 0,2 $\mathrm{MPa}$ a temperatura de $500 \mathrm{C}$ e resfriamento rápido e (b) hidrogenação a pressão de 1 MPa a temperatura ambiente. 


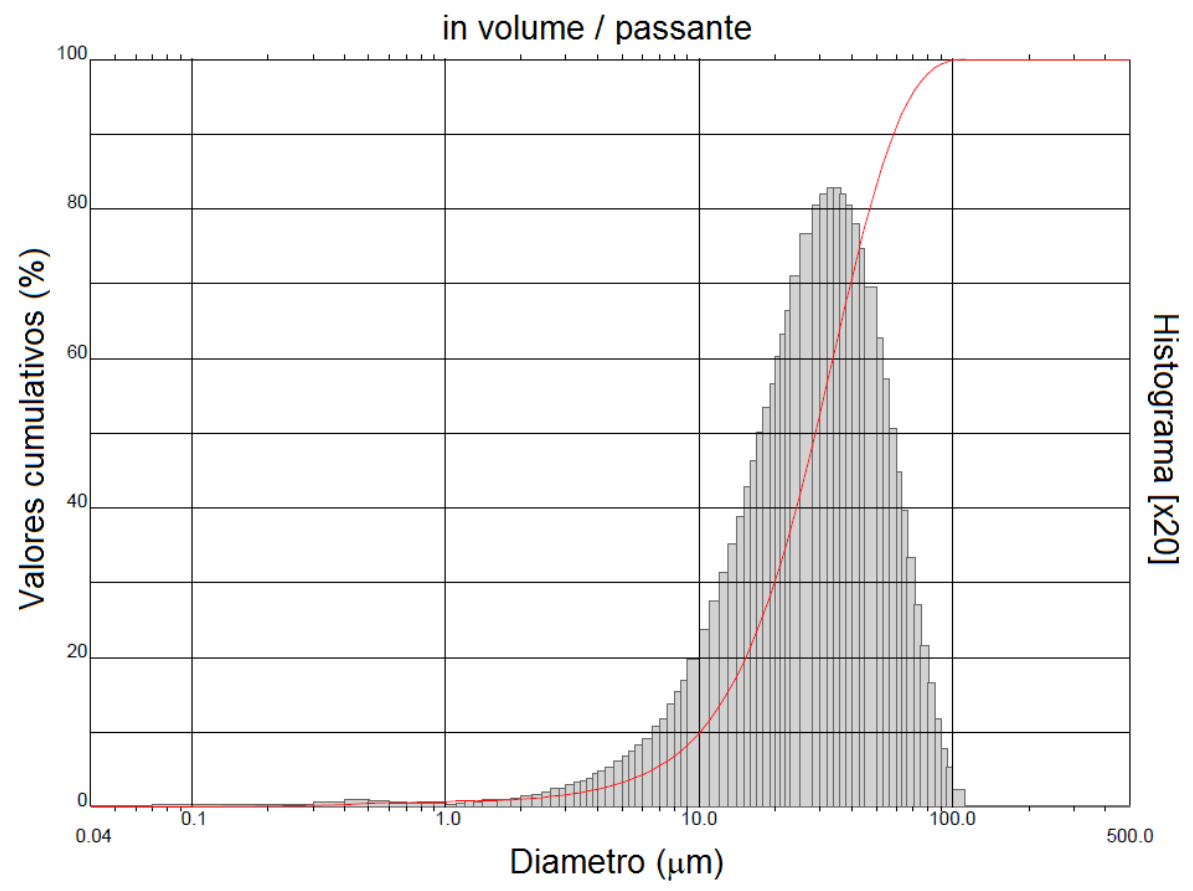

FIGURA 45 - Distribuição de tamanho de partícula obtida por CILAS para a liga liga $\mathrm{La}_{0,4} \mathrm{Mg}_{0,3} \mathrm{Pr}_{0,3} \mathrm{Al}_{0,3} \mathrm{Mn}_{0,4} \mathrm{Co}_{0,5} \mathrm{Ni}_{3,8}$ a pressão de $1 \mathrm{MPa}$ a temperatura ambiente.

Na TAB. 15 estão apresentadas o diâmetro médio de partículas dos pós após hidrogenação a 0,2 MPa e $1 \mathrm{MPa}$ obtidos por CILAS.

TABELA 15 - Tamanho médio de partículas das ligas $\mathrm{La}_{0,7}$ -

${ }_{x} \mathrm{Mg}_{\mathrm{x}} \mathrm{Pr}_{0,3} \mathrm{Al}_{0,3} \mathrm{Mn}_{0,4} \mathrm{Co}_{0,5} \mathrm{Ni}_{3,8}(0$ a 0,3$)$.

\begin{tabular}{cccc}
\hline$X$ & $0,2 \mathrm{MPa}$ & $0,2 \mathrm{MPa}\left(500^{\circ} \mathrm{C}\right)$ & $1 \mathrm{MPa}$ \\
\hline 0,0 & $77,32 \mu \mathrm{m}$ & - & $25,61 \mu \mathrm{m}$ \\
0,1 & - & $108,60 \mu \mathrm{m}$ & $25,66 \mu \mathrm{m}$ \\
0,3 & - & - & $32,03 \mu \mathrm{m}$ \\
\hline
\end{tabular}




\subsection{Capacidade de descarga para baterias seladas}

Na FIG. 46 estão apresentados os valores de capacidade de descarga em função do número de ciclos iniciais ( 15 ciclos) das baterias de Ni-HM fabricadas com as ligas $\mathrm{La}_{0,7-x} \mathrm{Mg}_{\mathrm{x}} \mathrm{Pr}_{0,3} \mathrm{Al}_{0,3} \mathrm{Mn}_{0,4} \mathrm{Co}_{0,5} \mathrm{Ni}_{3,8}(\mathrm{x}=0$ a 0,7 ).

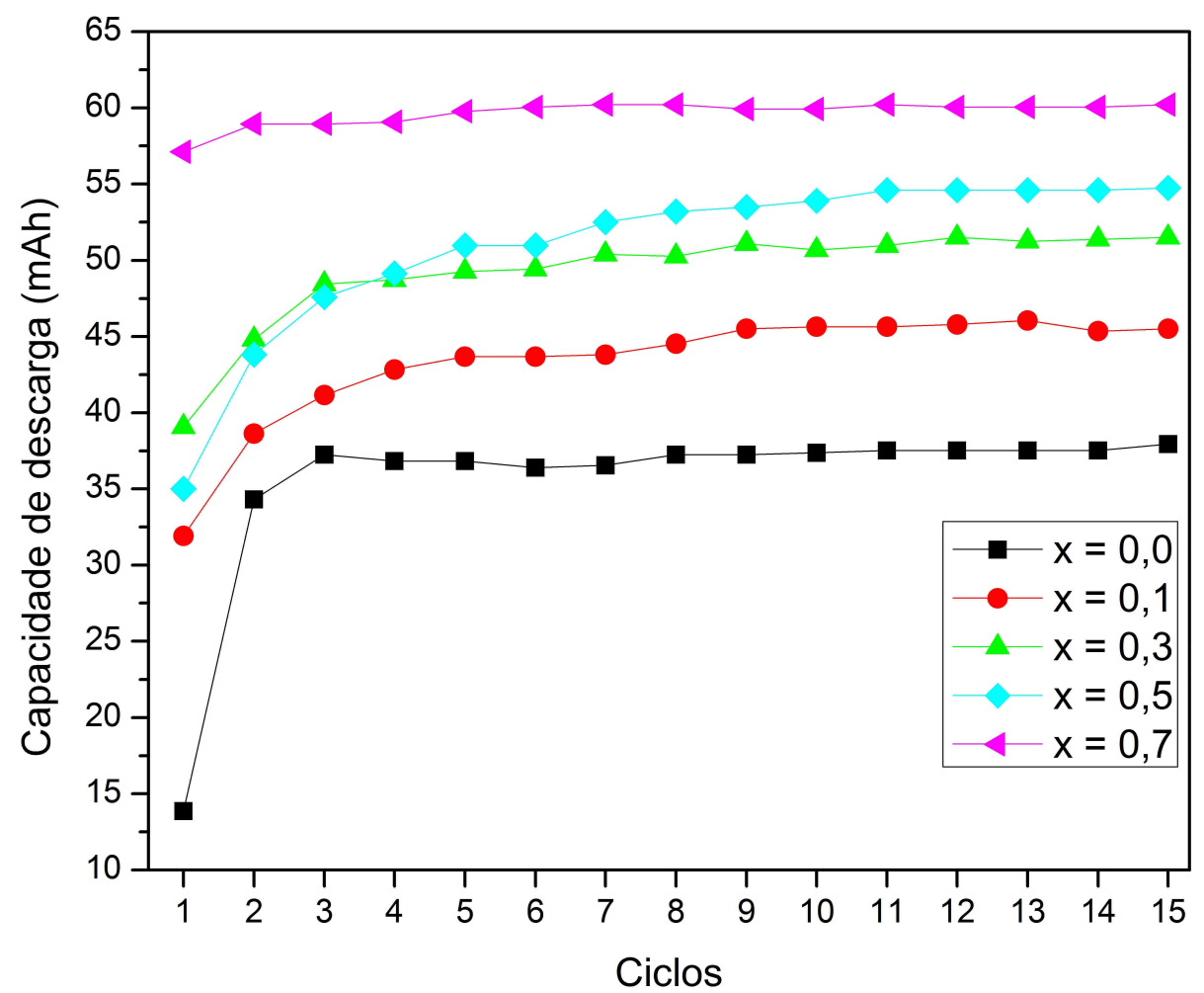

FIGURA 46 - Capacidade de descarga dos 15 ciclos iniciais das baterias fabricadas com as ligas $\mathrm{La}_{0,7-x} \mathrm{Mg}_{x} \mathrm{Pr}_{0,3} \mathrm{Al}_{0,3} \mathrm{Mn}_{0,4} \mathrm{Co}_{0,5} \mathrm{Ni}_{3,8}(x=0$ a 0,7 ).

Na FIG. 47 (a) e (b) estão apresentados os valores obtidos da capacidade de descarga máxima em relação ao aumento da concentração de magnésio nas ligas. Onde (a) mostra capacidade de descarga em mAh e (b) em $\mathrm{mAh} / \mathrm{g}$, foram calculados através da quantidade de material ativo no eletrodo negativo $(0,140 \mathrm{~g})$. 


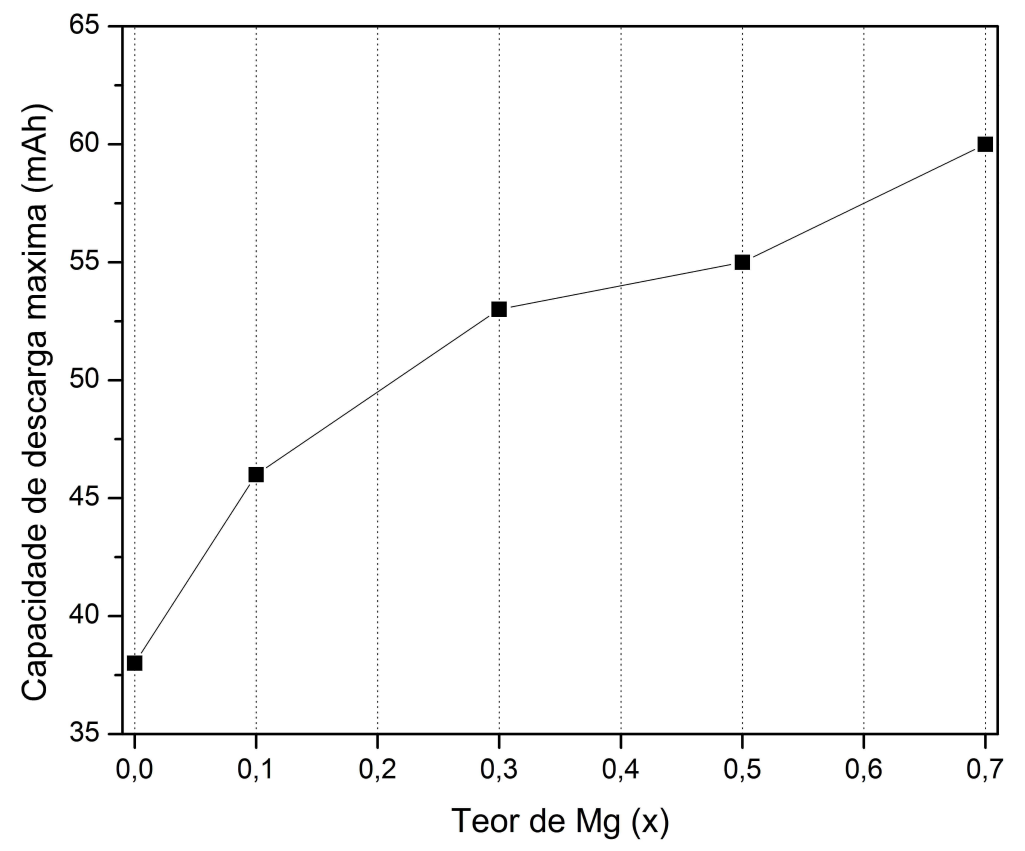

(a)

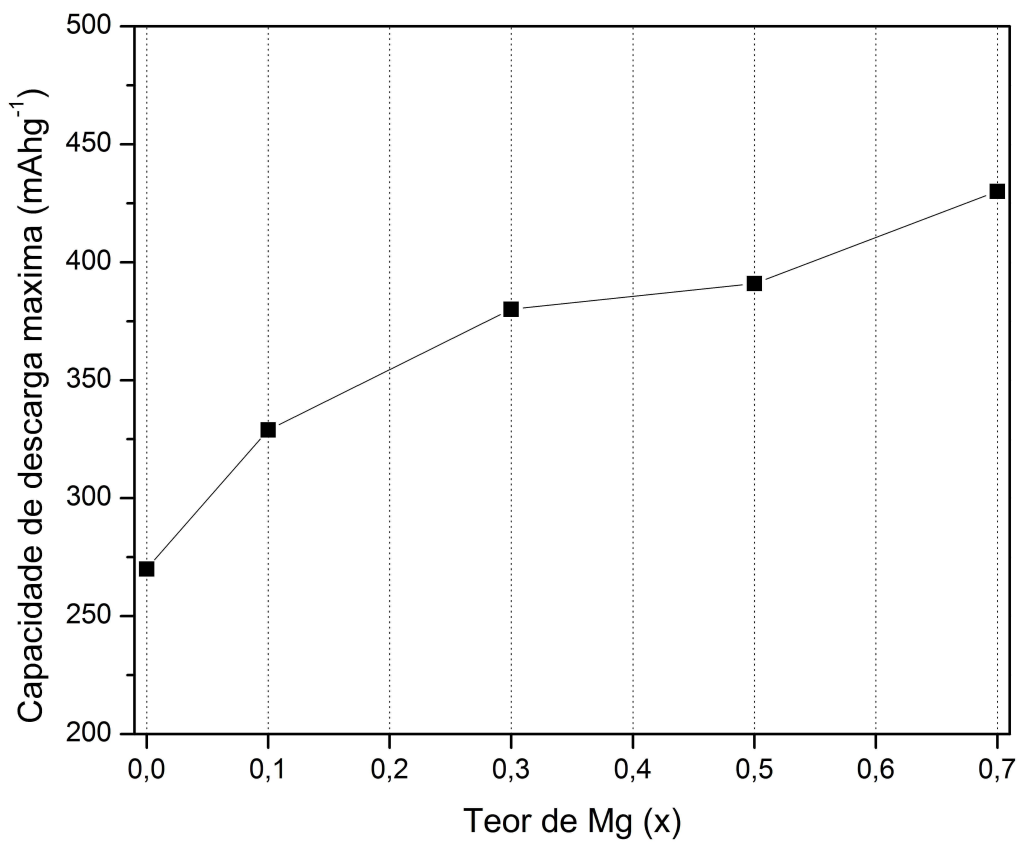

(b)

FIGURA 47 - Capacidade de descarga máxima obtidos das ligas as ligas La ${ }_{x} \mathrm{Mg}_{x} \mathrm{Pr}_{0,3} \mathrm{Al}_{0,3} \mathrm{Mn}_{0,4} \mathrm{Co}_{0,5} \mathrm{Ni}_{3,8}$ ( $x=0$ a 0,7 ) em função do aumento do teor de magnésio, onde: (a) mostra capacidade de descarga em mAh e (b) em mAhg ${ }^{-1}$. 
O aumento da capacidade de descarga com o aumento do teor de $\mathrm{Mg}$ na liga das baterias pode ser atribuído ao aumento da concentração da fase ( $\mathrm{La}, \mathrm{Pr}) \mathrm{Mg}_{2} \mathrm{Ni}_{\text {g. }}$. Esta fase tem sido reportada como uma fase benéfica para as baterias de $\mathrm{Ni}-\mathrm{HM}$, pois possui uma alta capacidade de armazenamento de hidrogênio $[43,49,50]$.

Uma boa capacidade de descarga e um bom desempenho de ativação estão relacionados, principalmente, com distribuição das fases na estrutura da liga e sua respectiva homogeneidade. Além disso, as regiões entre as fases fornecem meios para a difusão de átomos de hidrogênio, melhorando significativamente o desempenho das baterias [66].

Nas FIG. 48 - 52 estão apresentados os valores de capacidade de descarga em função do número de ciclos das baterias fabricadas com as ligas $\mathrm{La}_{0,7-x} \mathrm{Mg}_{\mathrm{x}} \mathrm{Pr}_{0,3} \mathrm{Al}_{0,3} \mathrm{Mn}_{0,4} \mathrm{Co}_{0,5} \mathrm{Ni}_{3,8}$ ( $\mathrm{x}=0$ a 0,7$)$. O número de ciclos $\left(\mathrm{N}_{\mathrm{c}}\right)$ das baterias foi determinado adotando uma perda de (10\%) da capacidade de descarga máxima.

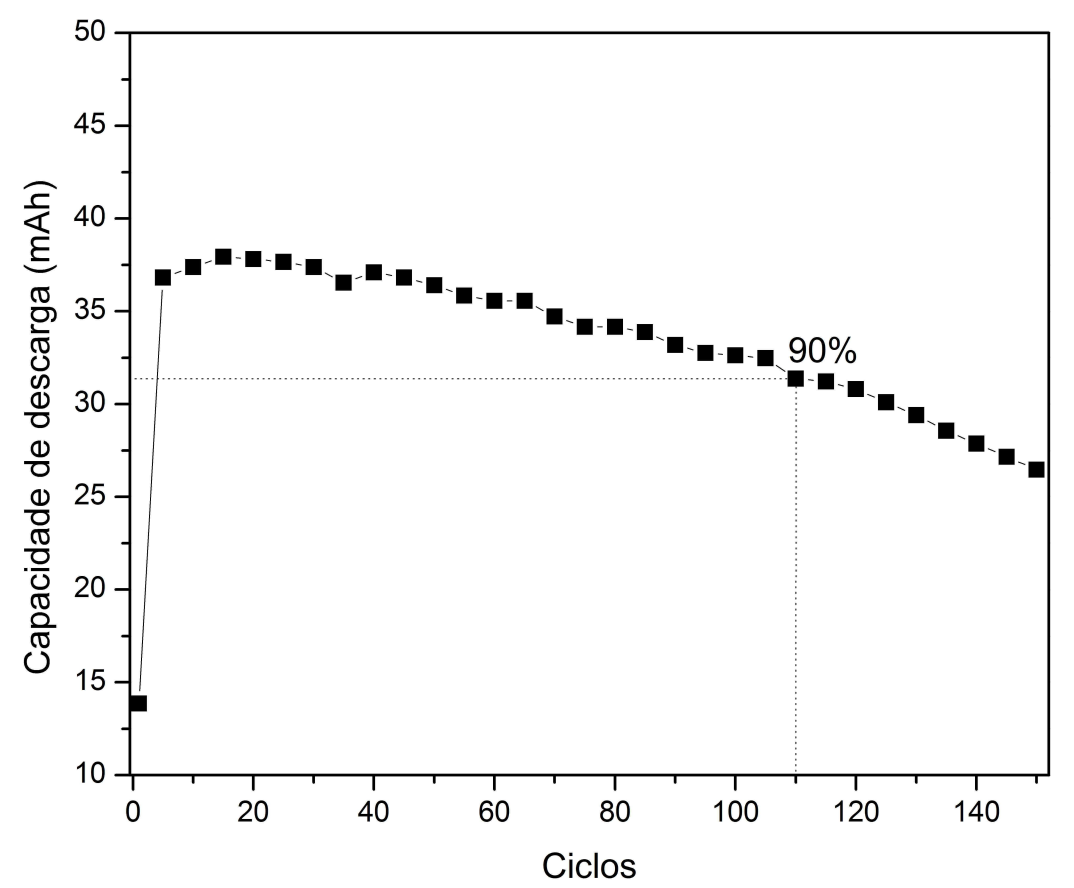

FIGURA 48 - Capacidade de descarga em função do número de ciclos da bateria fabricada com a liga $\mathrm{La}_{0,7} \mathrm{Pr}_{0,3} \mathrm{Al}_{0,3} \mathrm{Mn}_{0,4} \mathrm{Co}_{0,5} \mathrm{Ni}_{3,8}$. 


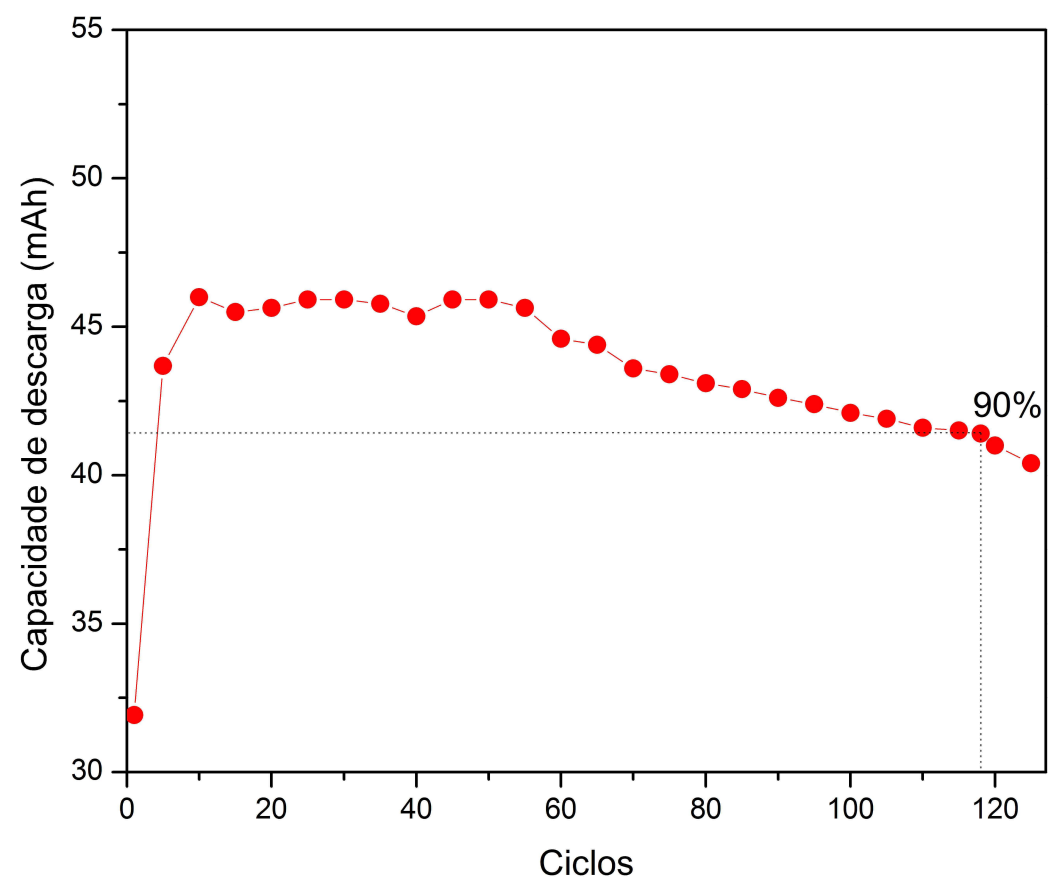

FIGURA 49 - Capacidade de descarga em função do número de ciclos da bateria fabricada com a liga $\mathrm{La}_{0,6} \mathrm{Mg}_{0,1} \mathrm{Pr}_{0,3} \mathrm{Al}_{0,3} \mathrm{Mn}_{0,4} \mathrm{Co}_{0,5} \mathrm{Ni}_{3,8}$.

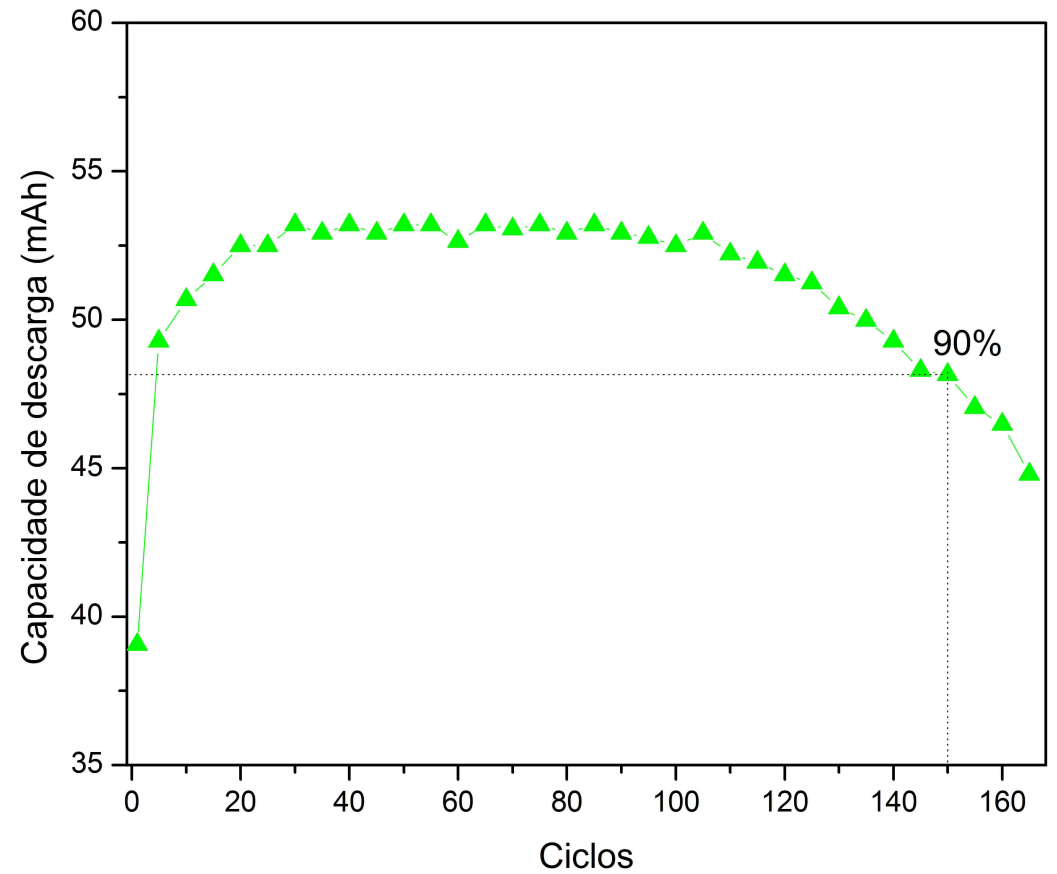

FIGURA 50 - Capacidade de descarga em função do número de ciclos da bateria fabricada com a liga $\mathrm{La}_{0,4} \mathrm{Mg}_{0,3} \mathrm{Pr}_{0,3} \mathrm{Al}_{0,3} \mathrm{Mn}_{0,4} \mathrm{Co}_{0,5} \mathrm{Ni}_{3,8}$. 


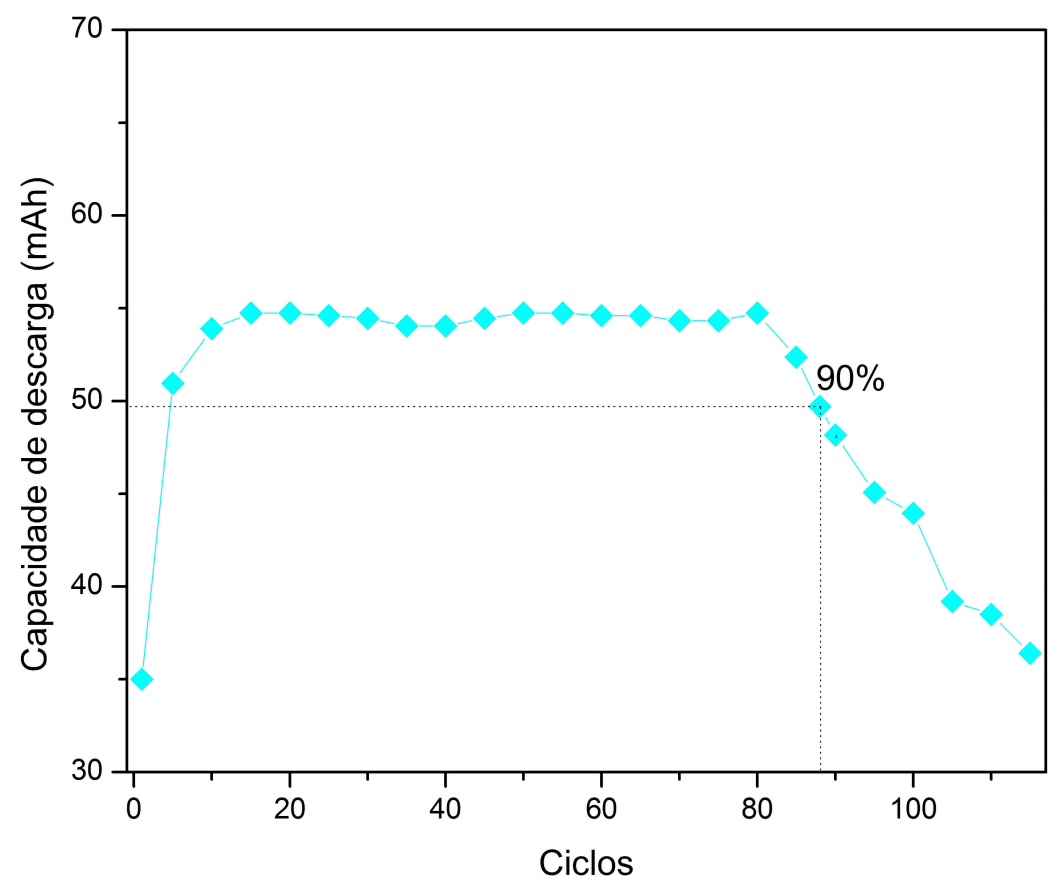

FIGURA 51 - Capacidade de descarga em função do número de ciclos da bateria fabricada com a liga $\mathrm{La}_{0,2} \mathrm{Mg}_{0,5} \mathrm{Pr}_{0,3} \mathrm{Al}_{0,3} \mathrm{Mn}_{0,4} \mathrm{Co}_{0,5} \mathrm{Ni}_{3,8}$.

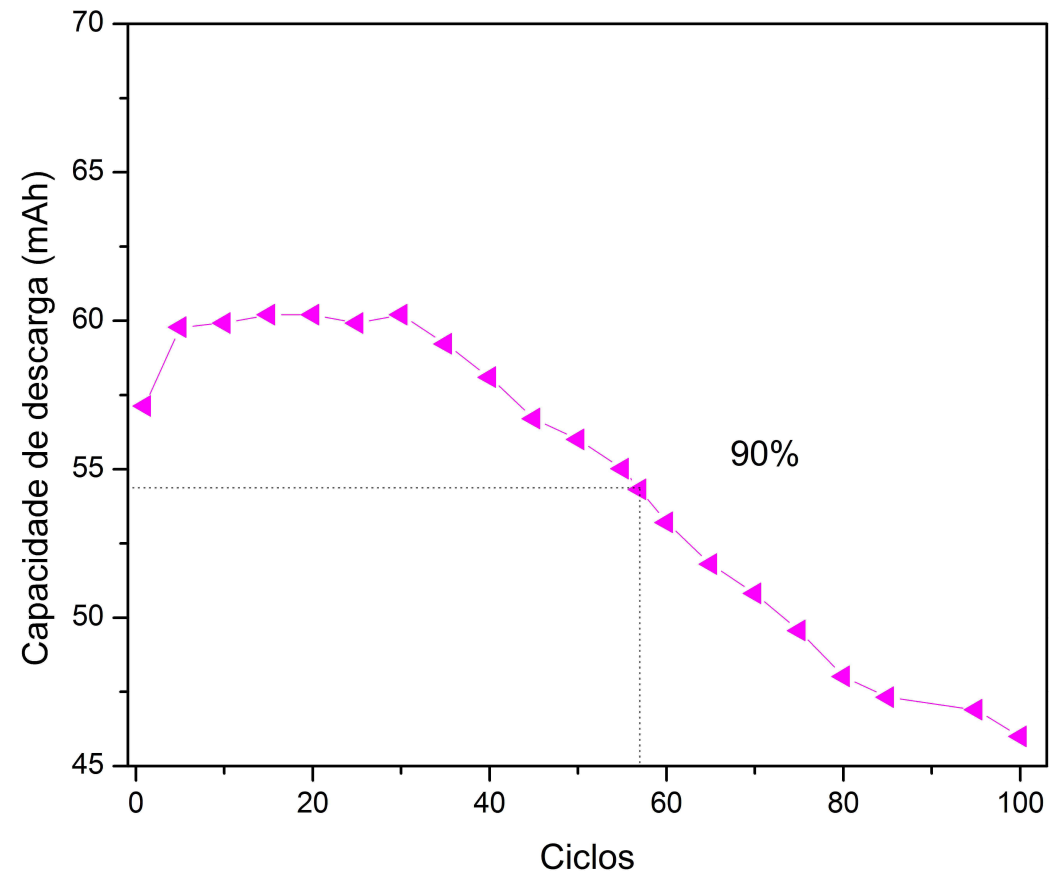

FIGURA 52 - Capacidade de descarga em função do número de ciclos da bateria fabricada com a liga $\mathrm{Mg}_{0,7} \mathrm{Pr}_{0,3} \mathrm{Al}_{0,3} \mathrm{Mn}_{0,4} \mathrm{Co}_{0,5} \mathrm{Ni}_{3,8}$. 
Os resultados mostram que com a substituição do lantânio pelo magnésio o número de ciclos das baterias aumenta de 110 (liga sem magnésio) para $150\left(\mathrm{Mg}_{0,3}\right)$ e depois decai para $57\left(\mathrm{Mg}_{0,7}\right)$.

Na FIG. 53 estão apresentados os valores da retenção da capacidade de descarga em função do aumento no teor de magnésio nas ligas $\mathrm{La}_{0,7-\mathrm{x}} \mathrm{Mg}_{\mathrm{x}}$ $\operatorname{Pr}_{0,3} \mathrm{Al}_{0,3} \mathrm{Mn}_{0,4} \mathrm{Co}_{0,5} \mathrm{Ni}_{3,8}(\mathrm{x}=0$ a 0,7$)$. Estes valores foram calculados para o ciclo $100\left(C_{100}\right)$.

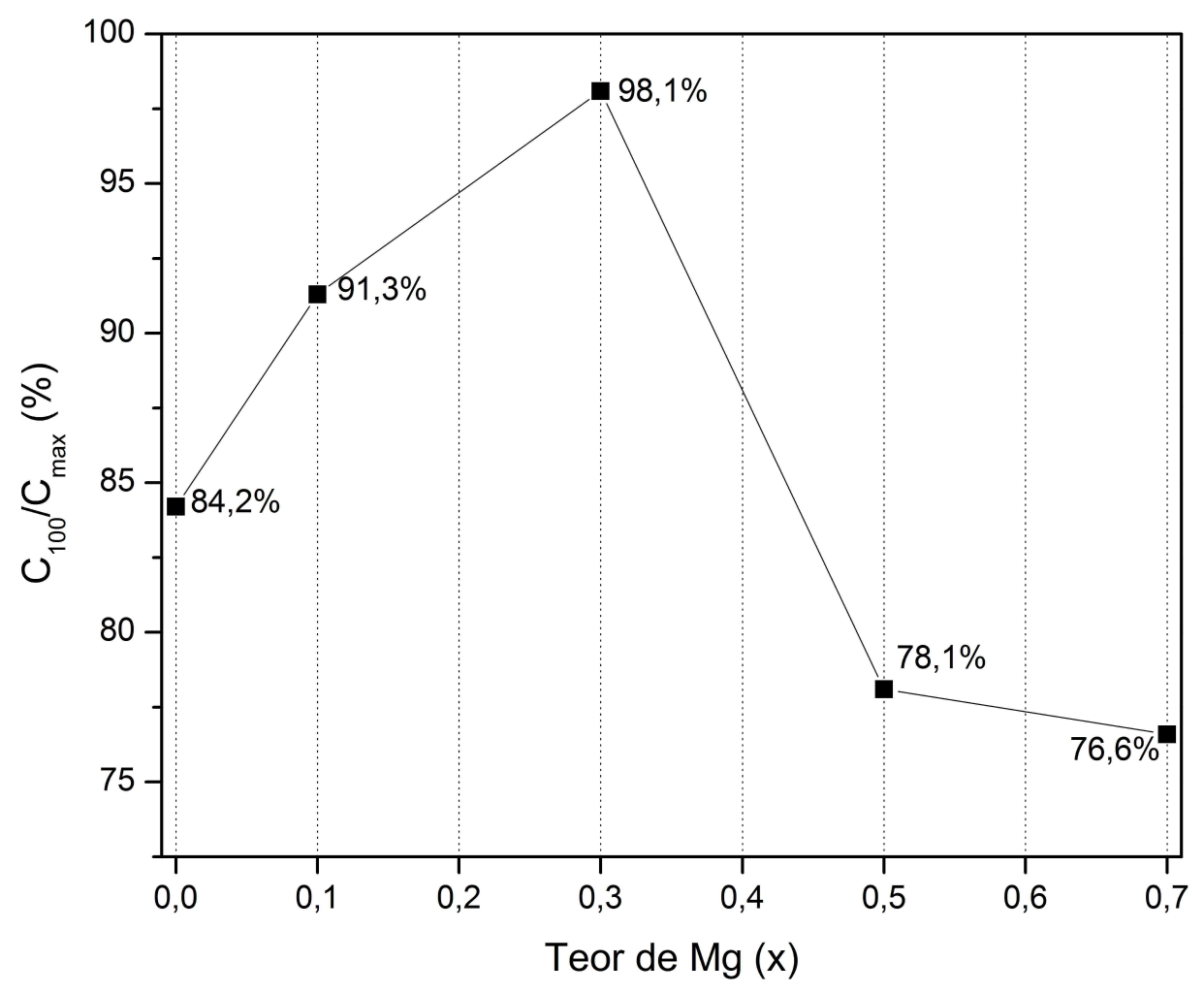

FIGURA 53 - Retenção da capacidade de descarga no ciclo 100 ( $\left.C_{100}\right)$ em função do aumento do teor de magnésio nas ligas $\mathrm{La}_{0,7-x} \mathrm{Mg}_{x} \operatorname{Pr}_{0,3} \mathrm{Al}_{0,3} \mathrm{Mn}_{0,4} \mathrm{Co}_{0,5} \mathrm{Ni}_{3,8}(x=0$ a 0,7$)$. 
$\mathrm{Na}$ TAB. 16 estão apresentados os valores das capacidades de descarga das ligas ( $\mathrm{mAh}$ e $\mathrm{mAhg}^{-1}$ ), os resultados da retenção da capacidade de descarga no $100^{\circ}$ ciclo $\left(\mathrm{C}_{100} / \mathrm{C}_{\text {máx }}\right)$ e o número de ciclos das baterias (perda de $10 \%$ da capacidade de descarga).

TABELA 16 - Capacidade máxima de descarga, retenção da capacidade de descarga e número de ciclos das baterias fabricadas com as ligas $\mathrm{La}_{0,7-\mathrm{x}} \mathrm{Mg}_{\mathrm{x}}$ $\operatorname{Pr}_{0,3} \mathrm{Al}_{0,3} \mathrm{Mn}_{0,4} \mathrm{Co}_{0,5} \mathrm{Ni}_{3,8}(\mathrm{x}=0$ a 0,7$)$.

\begin{tabular}{cccccc}
\hline $\mathrm{x}$ & $\mathrm{C}_{\text {máx }}(\mathrm{mAh})$ & $\mathrm{C}_{\text {máx }}\left(\mathrm{mAhg}^{-1}\right)$ & $\mathrm{C}_{100}(\mathrm{mAh})$ & $\mathrm{C}_{100} / \mathrm{C}_{\text {máx }}(\%)$ & $\mathrm{N}_{\mathrm{c}}$ \\
\hline 0,0 & 38 & 270 & 32 & 84,2 & 110 \\
0,1 & 46 & 329 & 42 & 91,3 & 118 \\
0,3 & 53 & 380 & 52 & 98,1 & 150 \\
0,5 & 55 & 391 & 43 & 78,1 & 88 \\
0,7 & 60 & 430 & 46 & 76,6 & 57 \\
\hline
\end{tabular}

Os resultados obtidos da retenção da capacidade de descarga $\left(\mathrm{C}_{100} / \mathrm{C}_{\text {máx }}\right)$ e do número de ciclos das baterias mostraram a deterioração da estabilidade cíclica dos eletrodos para as ligas com alto teor de magnésio $\left(\mathrm{Mg}_{0,5} \mathrm{e}\right.$ $\left.\mathrm{Mg}_{0,7}\right)$. Este resultado está associado à formação do hidróxido de magnésio na superfície das partículas que reduz drasticamente a capacidade de descarga e a estabilidade cíclica das baterias [55,56,57,63].

Nas FIG. 54 - 58 estão apresentados os valores da resistência interna $\left(R_{\text {in }}\right)$ das baterias fabricadas com as ligas $\mathrm{La}_{0,7-x} \mathrm{Mg}_{\mathrm{x}} \operatorname{Pr}_{0,3} \mathrm{Al}_{0,3} \mathrm{Mn}_{0,4} \mathrm{Co}_{0,5} \mathrm{Ni}_{3,8}(\mathrm{x}=0$ a 0,7$)$ em função do número de ciclos. Os valores estão apresentados em resistência interna inicial $\left(R_{\text {in }}\right.$ Inicial) e resistência interna final $\left(R_{\text {in }}\right.$ Final) por ciclo. 


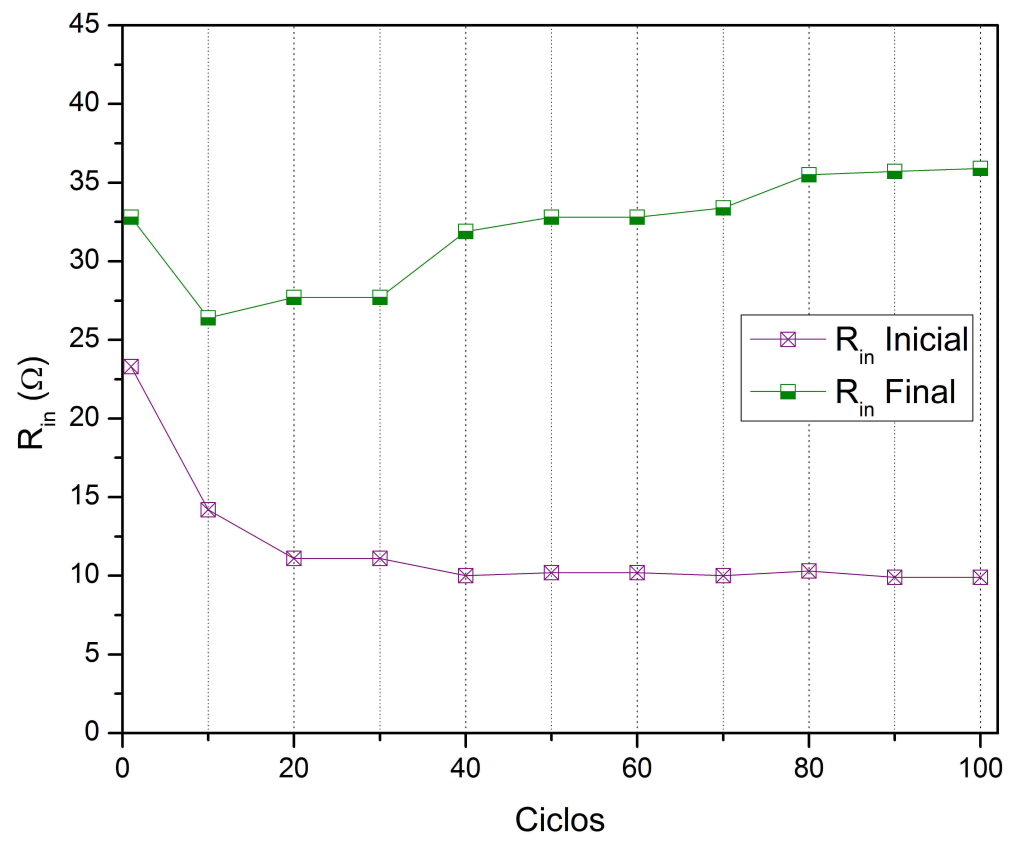

FIGURA 54 - Resistência interna inicial ( $R_{\text {in }}$ Inicial) e resistência interna final ( $R_{\text {in }}$ Final) em função do número de ciclos para a bateria fabricada com a liga $L a_{0,7} \operatorname{Pr}_{0,3} \mathrm{Al}_{0,3} \mathrm{Mn}_{0,4} \mathrm{Co}_{0,5} \mathrm{Ni}_{3,8}$.

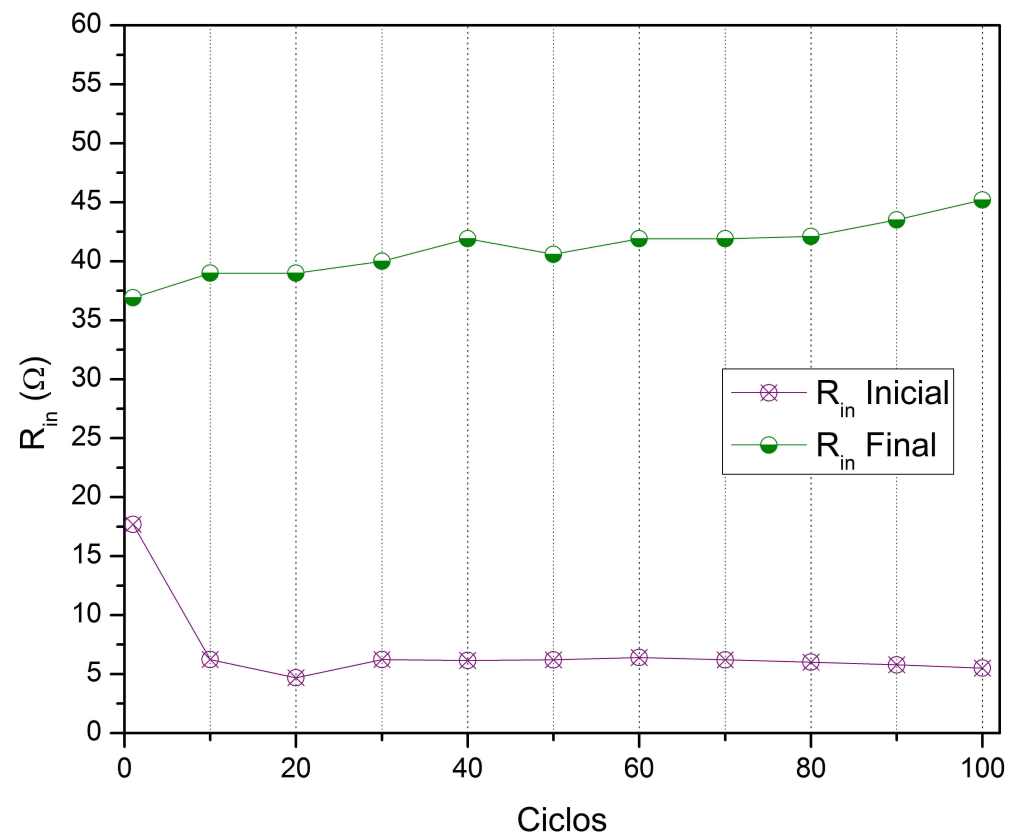

FIGURA 55 - Resistência interna inicial $\left(R_{\text {in }}\right.$ Inicial) e resistência interna final ( $R_{\text {in }}$ Final) em função do número de ciclos para a bateria fabricada com a liga $\mathrm{La}_{0,6} \mathrm{Mg}_{0,1} \mathrm{Pr}_{0,3} \mathrm{Al}_{0,3} \mathrm{Mn}_{0,4} \mathrm{Co}_{0,5} \mathrm{Ni}_{3,8}$. 


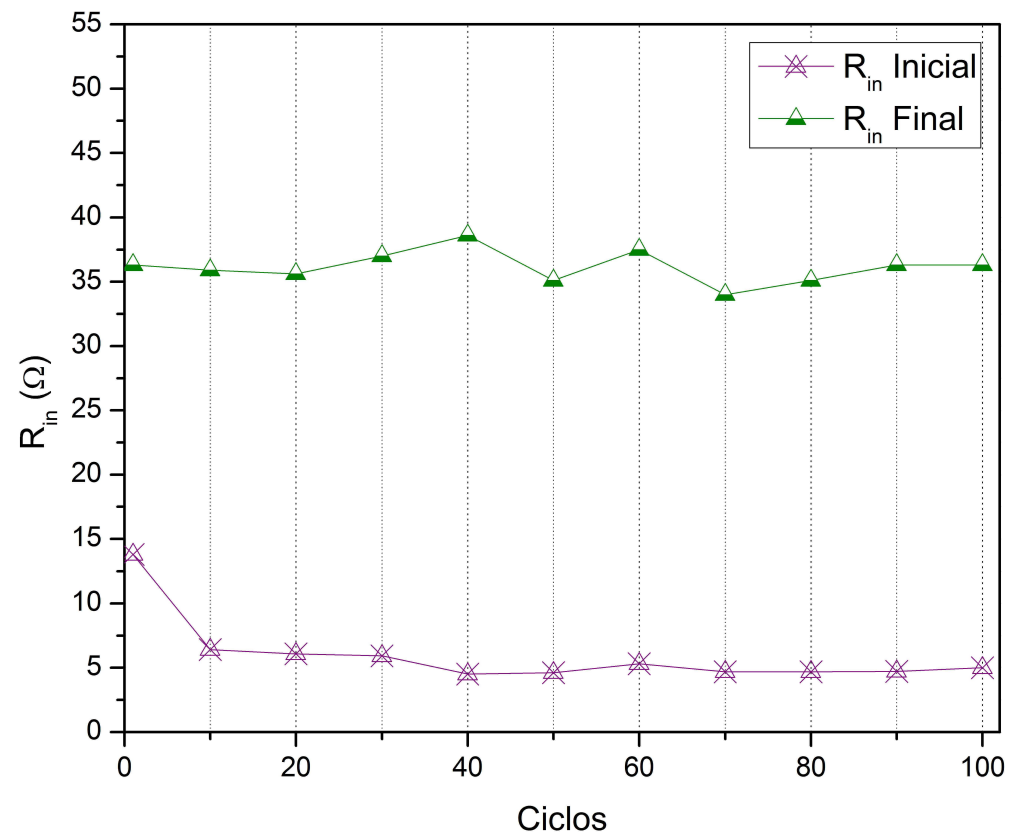

FIGURA 56 - Resistência interna inicial ( $R_{\text {in }}$ Inicial) e resistência interna final ( $R_{\text {in }}$ Final) em função do número de ciclos para a bateria fabricada com a liga $\mathrm{La}_{0,4} \mathrm{Mg}_{0,3} \mathrm{Pr}_{0,3} \mathrm{Al}_{0,3} \mathrm{Mn}_{0,4} \mathrm{Co}_{0,5} \mathrm{Ni}_{3,8}$.

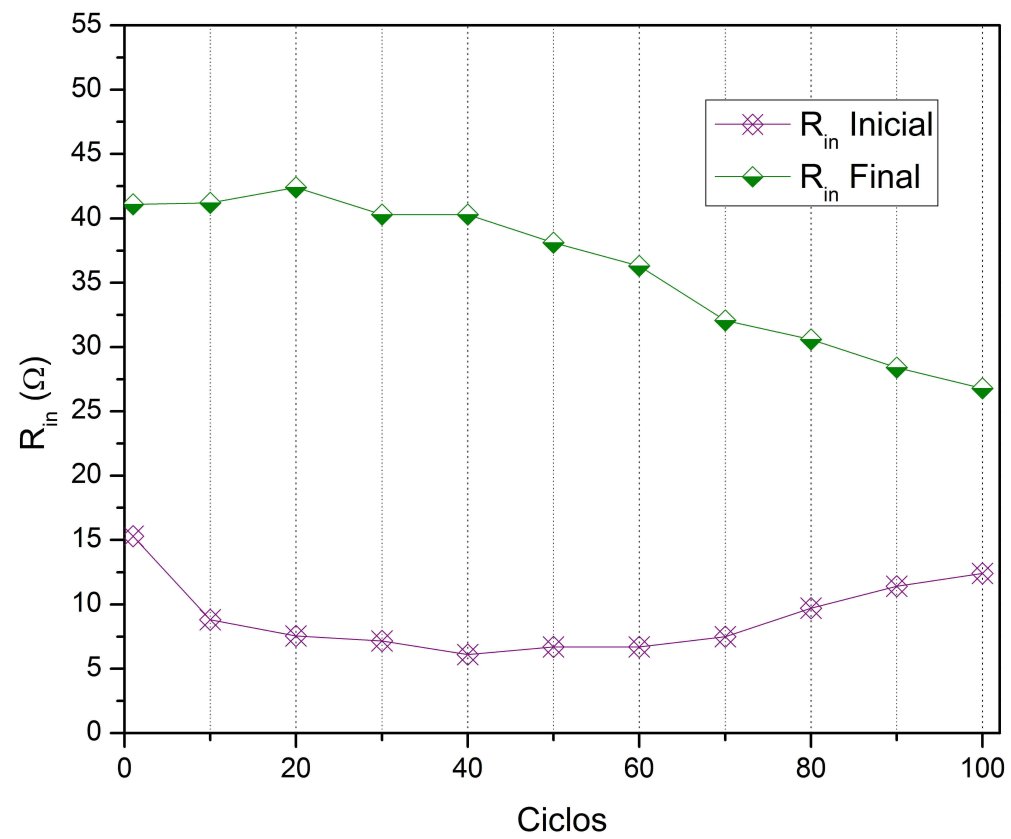

FIGURA 57 - Resistência interna inicial $\left(R_{\text {in }}\right.$ Inicial) e resistência interna final ( $R_{\text {in }}$ Final) em função do número de ciclos para a bateria fabricada com a liga $\mathrm{La}_{0,2} \mathrm{Mg}_{0,5} \mathrm{Pr}_{0,3} \mathrm{Al}_{0,3} \mathrm{Mn}_{0,4} \mathrm{Co}_{0,5} \mathrm{Ni}_{3,8}$. 


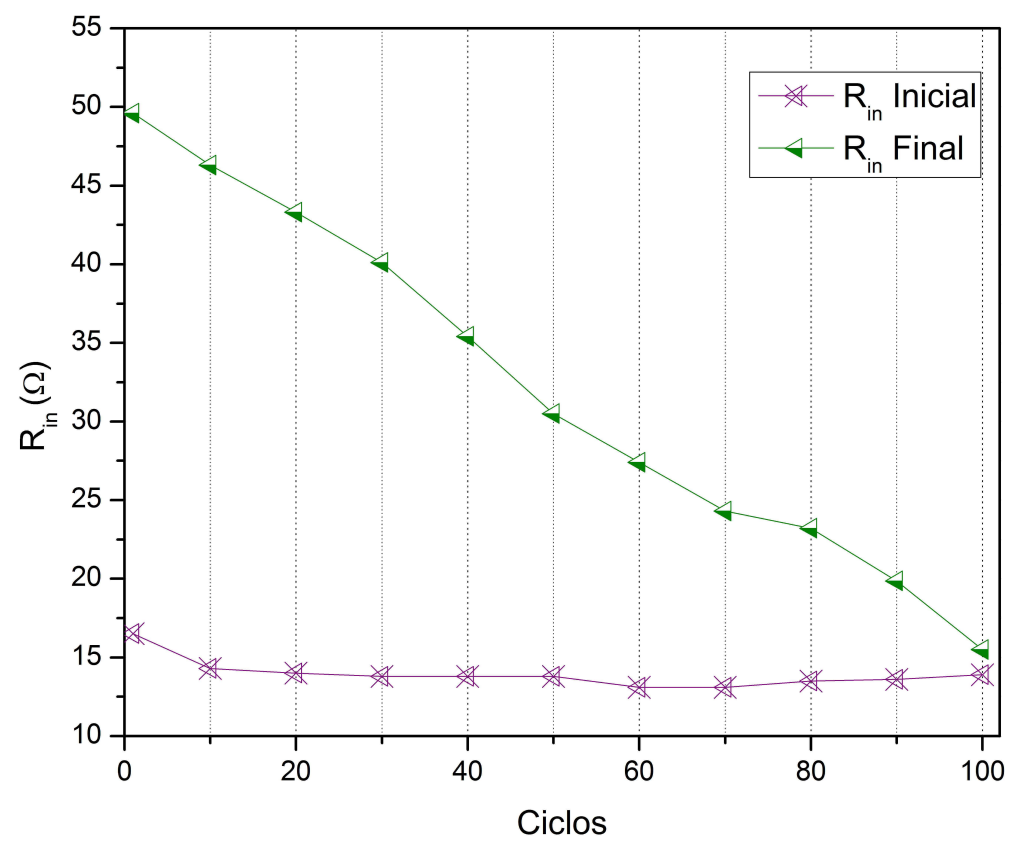

FIGURA 58 - Resistência interna inicial ( $R_{\text {in }}$ Inicial) e resistência interna final ( $R_{\text {in }}$ Final) em função do número de ciclos para a bateria fabricada com a liga $\mathrm{Mg}_{0,7} \mathrm{Pr}_{0,3} \mathrm{Al}_{0,3} \mathrm{Mn}_{0,4} \mathrm{Co}_{0,5} \mathrm{Ni}_{3,8}$.

Na TAB. 17 estão apresentados os valores obtidos das resistências internas iniciais $\left(R_{\text {in }}\right.$ Inicial) e finais ( $R_{\text {in }}$ Final) para as baterias fabricadas com a liga $\mathrm{La}_{0,7-x} \mathrm{Mg}_{\mathrm{x}} \mathrm{Pr}_{0,3} \mathrm{Al}_{0,3} \mathrm{Mn}_{0,4} \mathrm{Co}_{0,5} \mathrm{Ni}_{3,8}(\mathrm{x}=0$ a 0,7$)$ no primeiro e centésimo ciclo.

TABELA 17 - Resistências internas iniciais e finais das baterias fabricadas com as ligas $\mathrm{La}_{0,7-\mathrm{x}} \mathrm{Mg}_{\mathrm{x}} \mathrm{Pr}_{0,3} \mathrm{Al}_{0,3} \mathrm{Mn}_{0,4} \mathrm{Co}_{0,5} \mathrm{Ni}_{3,8}(\mathrm{x}=0$ a 0,7$)$ no $1^{\circ} \mathrm{e} 100^{\circ}$ ciclo.

\begin{tabular}{ccccc}
\hline $\mathrm{x}$ & $\begin{array}{c}\mathrm{R}_{\text {in }} \text { Inicial }(\Omega) \\
1^{\circ} \text { ciclo }\end{array}$ & $\begin{array}{c}\mathrm{R}_{\text {in }} \text { Final }(\Omega) \\
1^{\circ} \text { ciclo }\end{array}$ & $\begin{array}{c}\mathrm{R}_{\text {in }} \text { Inicial }(\Omega) \\
100^{\circ} \text { ciclo }\end{array}$ & $\begin{array}{c}\mathrm{R}_{\text {in }} \text { Final }(\Omega) \\
100^{\circ} \text { ciclo }\end{array}$ \\
\hline 0,0 & 23,3 & 32,8 & 9,9 & 35,9 \\
0,1 & 17,7 & 36,9 & 5,5 & 45,2 \\
0,3 & 13,8 & 36,3 & 5,2 & 36,3 \\
0,5 & 15,3 & 41,1 & 12,4 & 26,8 \\
0,7 & 16,5 & 49,6 & 13,9 & 15,5 \\
\hline
\end{tabular}


A partir dos resultados da resistência interna é possível analisar sua variação em função do número de ciclos e sua média. A resistência interna de uma bateria é um dos fatores que limita sua durabilidade. Para uma bateria obter o melhor desempenho, em relação à durabilidade e número de ciclos, deve apresentar valores baixos de resistência interna e de variação da resistência interna $\left(\Delta \mathrm{R}_{\text {interna }}\right)$.

Nas FIG. 59 - 63 estão apresentados os valores da resistência média ( $R_{\text {interna }}$ Média) e de variação da resistência interna $\left(\Delta R_{\text {interna }}\right)$ em função do numero de ciclos das baterias fabricadas com as ligas $\mathrm{La}_{0,7-x} \mathrm{Mg}_{\mathrm{x}} \mathrm{Pr}_{0,3} \mathrm{Al}_{0,3} \mathrm{Mn}_{0,4} \mathrm{Co}_{0,5} \mathrm{Ni}_{3,8}$ (x $=0$ a 0,7$)$.

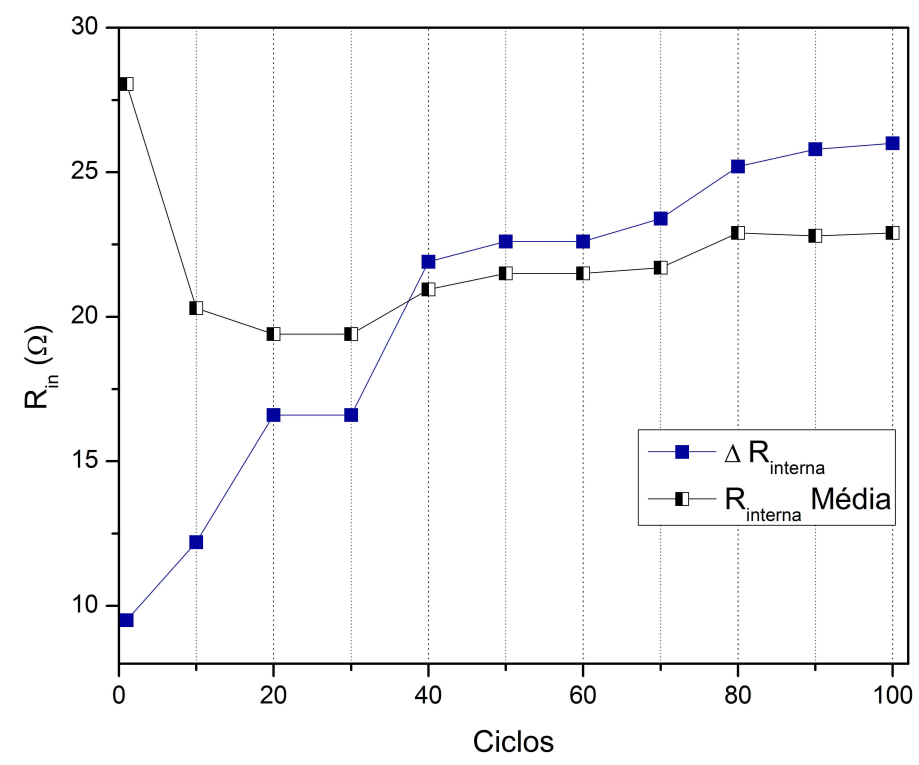

FIGURA 59 - Variação da resistência interna ( $\left.\Delta R_{\text {interna }}\right)$ e resistência interna média

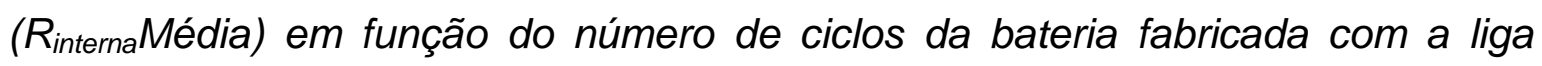
$\mathrm{La}_{0,7} \operatorname{Pr}_{0,3} \mathrm{Al}_{0,3} \mathrm{Mn}_{0,4} \mathrm{Co}_{0,5} \mathrm{Ni}_{3,8}$. 


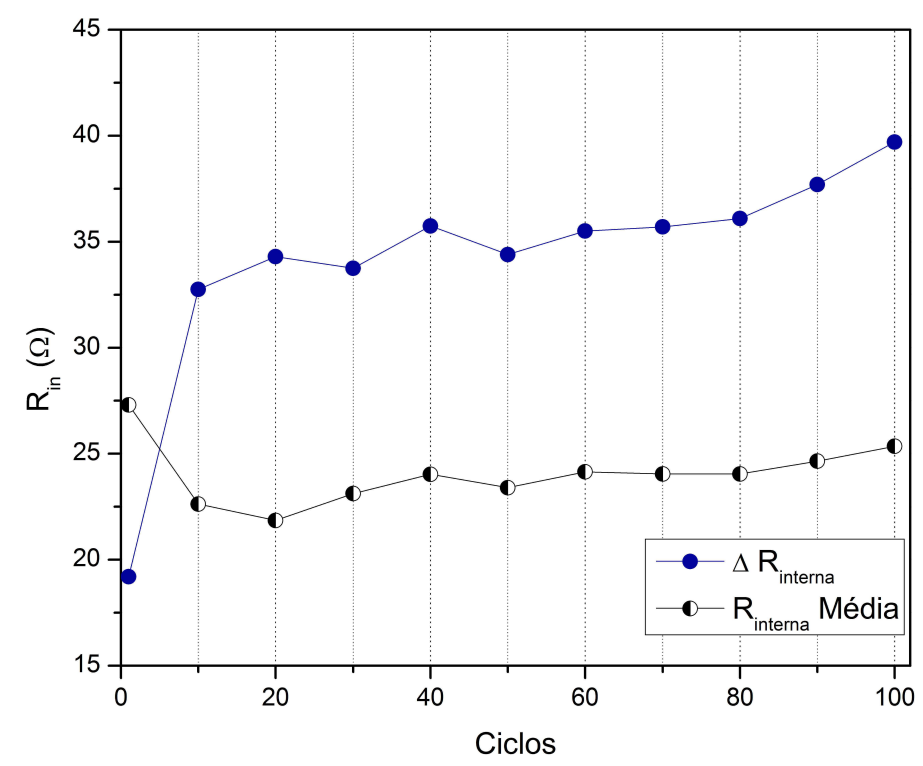

FIGURA 60 - Variação da resistência interna ( $\left.\Delta R_{\text {interna }}\right)$ e resistência interna média ( $R_{\text {interna }}$ Média) em função do número de ciclos da bateria fabricada com a liga $\mathrm{La}_{0,6} \mathrm{Mg}_{0,1} \mathrm{Pr}_{0,3} \mathrm{Al}_{0,3} \mathrm{Mn}_{0,4} \mathrm{Co}_{0,5} \mathrm{Ni}_{3,8}$.

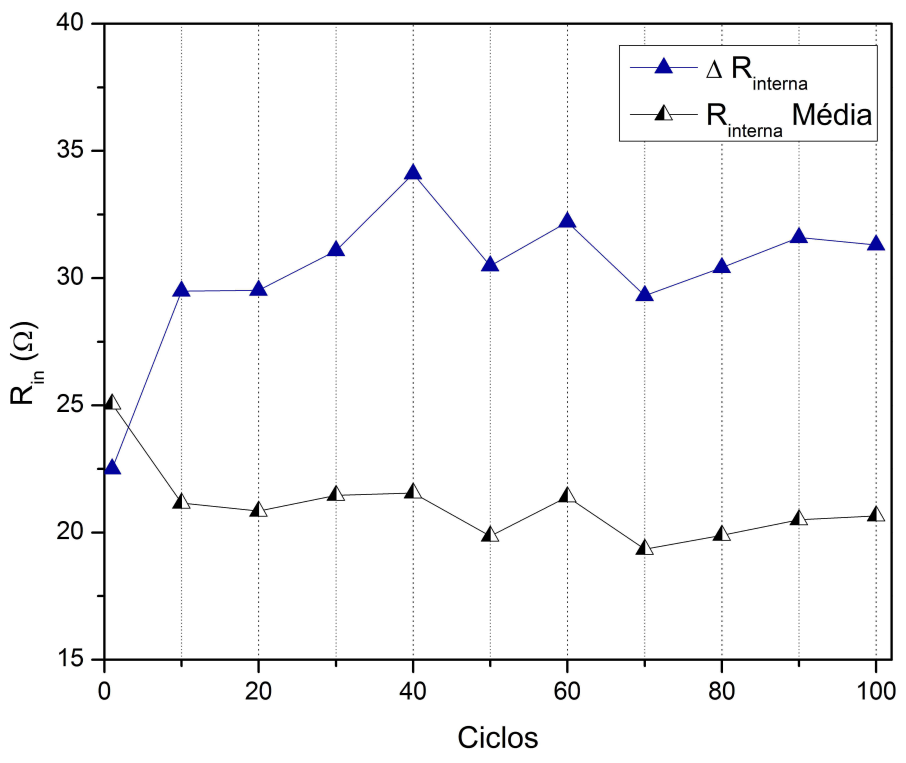

FIGURA 61 - Variação da resistência interna ( $\left.\Delta R_{\text {interna }}\right)$ e resistência interna média ( $R_{\text {interna }}$ Média) em função do número de ciclos da bateria fabricada com a liga $\mathrm{La}_{0,4} \mathrm{Mg}_{0,3} \mathrm{Pr}_{0,3} \mathrm{Al}_{0,3} \mathrm{Mn}_{0,4} \mathrm{Co}_{0,5} \mathrm{Ni}_{3,8}$. 


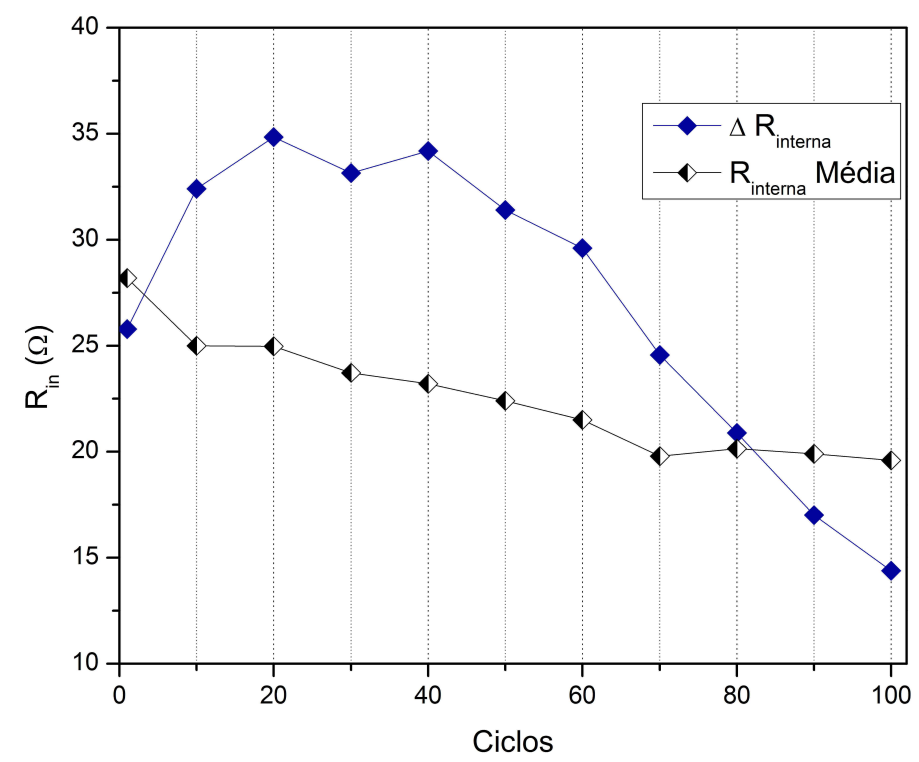

FIGURA 62 - Variação da resistência interna $\left(\Delta R_{\text {interna }}\right)$ e resistência interna média ( $R_{\text {interna }}$ Média) em função do número de ciclos da bateria fabricada com a liga $\mathrm{La}_{0,2} \mathrm{Mg}_{0,5} \mathrm{Pr}_{0,3} \mathrm{Al}_{0,3} \mathrm{Mn}_{0,4} \mathrm{Co}_{0,5} \mathrm{Ni}_{3,8}$.

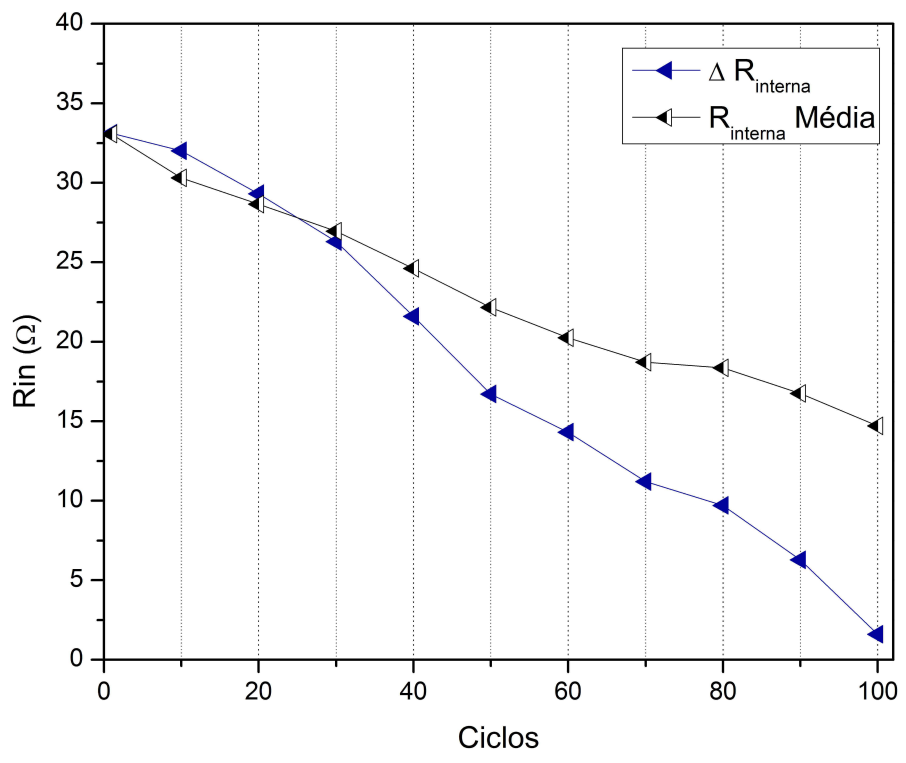

FIGURA 63 - Variação da resistência interna ( $\left.\Delta R_{\text {interna }}\right)$ e resistência interna média ( $R_{\text {interna }}$ Média) em função do número de ciclos da bateria fabricada com a liga $\mathrm{Mg}_{0,7} \mathrm{Pr}_{0,3} \mathrm{Al}_{0,3} \mathrm{Mn}_{0,4} \mathrm{Co}_{0,5} \mathrm{Ni}_{3,8}$. 
$\mathrm{Na}$ TAB. 18 estão apresentados os valores obtidos das variações das resistências internas $\left(\Delta R_{\text {interna }}\right)$ e das resistências internas médias ( $R_{\text {interna }}$ Média) para as baterias fabricadas com a liga $\mathrm{La}_{0,7-\mathrm{x}} \mathrm{Mg}_{\mathrm{x}} \mathrm{Pr}_{0,3} \mathrm{Al}_{0,3} \mathrm{Mn}_{0,4} \mathrm{Co}_{0,5} \mathrm{Ni}_{3,8}(\mathrm{x}=0 \mathrm{a}$ $0,7)$ no primeiro e centésimo ciclo.

TABELA 18 - Variação e média da resistência interna das baterias fabricadas com as ligas $\mathrm{La}_{0,7-\mathrm{x}} \mathrm{Mg}_{\mathrm{x}} \mathrm{Pr}_{0,3} \mathrm{Al}_{0,3} \mathrm{Mn}_{0,4} \mathrm{Co}_{0,5} \mathrm{Ni}_{3,8}(\mathrm{x}=0$ a 0,7$)$ no $1^{\circ} \mathrm{e} 100^{\circ}$ ciclo.

\begin{tabular}{ccccc}
\hline$x$ & $\begin{array}{c}\Delta \mathrm{R}_{\text {interna }}(\Omega) \\
1{ }^{\circ} \text { ciclo }\end{array}$ & $\begin{array}{c}\Delta \mathrm{R}_{\text {interna }}(\Omega) \\
100^{\circ} \text { ciclo }\end{array}$ & $\begin{array}{c}\mathrm{R}_{\text {interna }} \text { Média }(\Omega) \\
1^{\circ} \text { ciclo }\end{array}$ & $\begin{array}{c}\mathrm{R}_{\text {interna }} \text { Média }(\Omega) \\
100^{\circ} \text { ciclo }\end{array}$ \\
\hline 0,0 & 9,5 & 26 & 28,1 & 22,9 \\
0,1 & 19,2 & 39,7 & 27,3 & 25,3 \\
0,3 & 22,5 & 31,3 & 25,1 & 20,6 \\
0,5 & 25,7 & 14,3 & 28,1 & 19,5 \\
0,7 & 33,1 & 1,6 & 33,1 & 14,7 \\
\hline
\end{tabular}

Pelo resultado obtido verificou-se que com o aumento no teor de magnésio houve aumento no $\Delta \mathrm{R}_{\text {interna }}$ no $1^{\circ}$ ciclo, obtendo $33,1 \Omega$ para a liga com $\mathrm{Mg}_{0,7}$. A variação da resistência interna $\left(\Delta \mathrm{R}_{\text {interna }}\right)$ no $100^{\circ}$ ciclo, aumenta para pequenas adições de $\mathrm{Mg}$ e diminui drasticamente com altos teores de $\mathrm{Mg}$ e, este efeito, pode estar relacionado com a formação da camada de $\mathrm{Mg}(\mathrm{OH})_{2}$ na superfície das partículas.

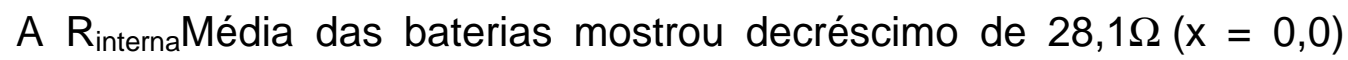
para $25,1 \Omega(\mathrm{x}=0,3)$ e um posterior aumento para $33,1 \Omega(\mathrm{x}=0,7)$.

Não foi possível comparar o efeito da perda da capacidade de descarga com a resistência interna das baterias. O resultado esperado era aumento da resistência interna à medida que a capacidade de descarga diminuísse. Os resultados obtidos para as ligas com alto teor de magnésio $\left(\mathrm{Mg}_{0,5}\right.$ e $\left.\mathrm{Mg}_{0,7}\right)$ não apresentaram este efeito. 


\subsection{Influência da hidrogenação nas baterias de Ni-HM}

Na FIG. 64 está mostrada a capacidade de descarga em função do número de ciclos do eletrodo negativo fabricado com a liga $\mathrm{La}_{0,7} \mathrm{Pr}_{0,3} \mathrm{Al}_{0,3} \mathrm{Mn}_{0,4} \mathrm{Co}_{0,5} \mathrm{Ni}_{3,8}$ moída mecanicamente e hidrogenada a $1 \mathrm{MPa}$.

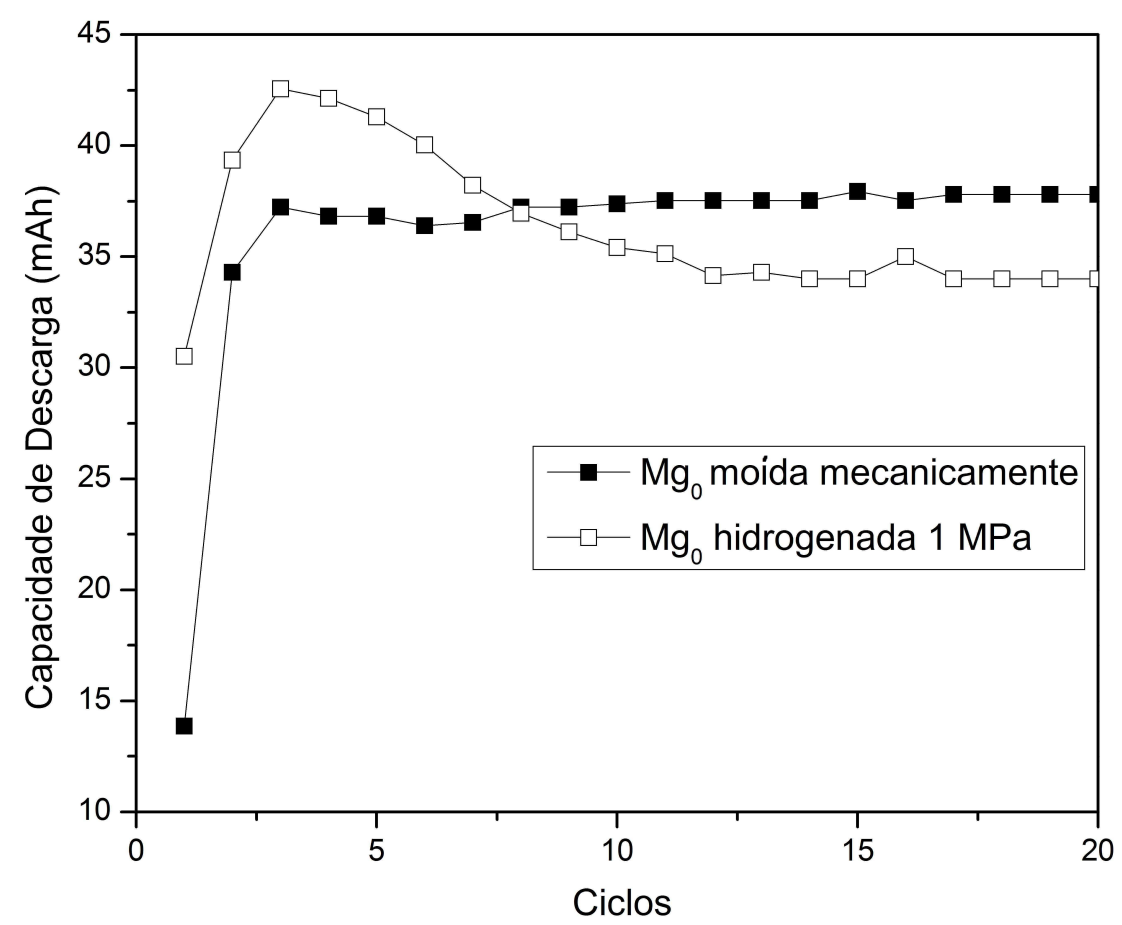

FIGURA 64 - Capacidade de descarga em função do número de ciclos para a liga $\mathrm{La}_{0,7} \mathrm{Pr}_{0,3} \mathrm{Al}_{0,3} \mathrm{Mn}_{0,4} \mathrm{Co}_{0,5} \mathrm{Ni}_{3,8}$ moída mecanicamente e hidrogenada a $1 \mathrm{MPa}$.

Os resultados mostraram que houve um aumento na capacidade de descarga máxima de $38 \mathrm{mAh}$ para $43 \mathrm{mAh}$ para bateria fabricada com a liga após hidrogenação. Porém, após 8 ciclos a capacidade de descarga é menor comparada a da liga moída mecanicamente, mostrando uma diminuição na estabilidade cíclica da bateria fabricada com a liga hidrogenada. 
Na FIG. 65 está mostrada a capacidade de descarga em função do número de ciclos do eletrodo negativo fabricado com a liga $\mathrm{La}_{0,7} \mathrm{Mg}_{0,1} \mathrm{Pr}_{0,3} \mathrm{Al}_{0,3} \mathrm{Mn}_{0,4} \mathrm{Co}_{0,5} \mathrm{Ni}_{3,8}$ moída mecanicamente e hidrogenada a $1 \mathrm{MPa}$.

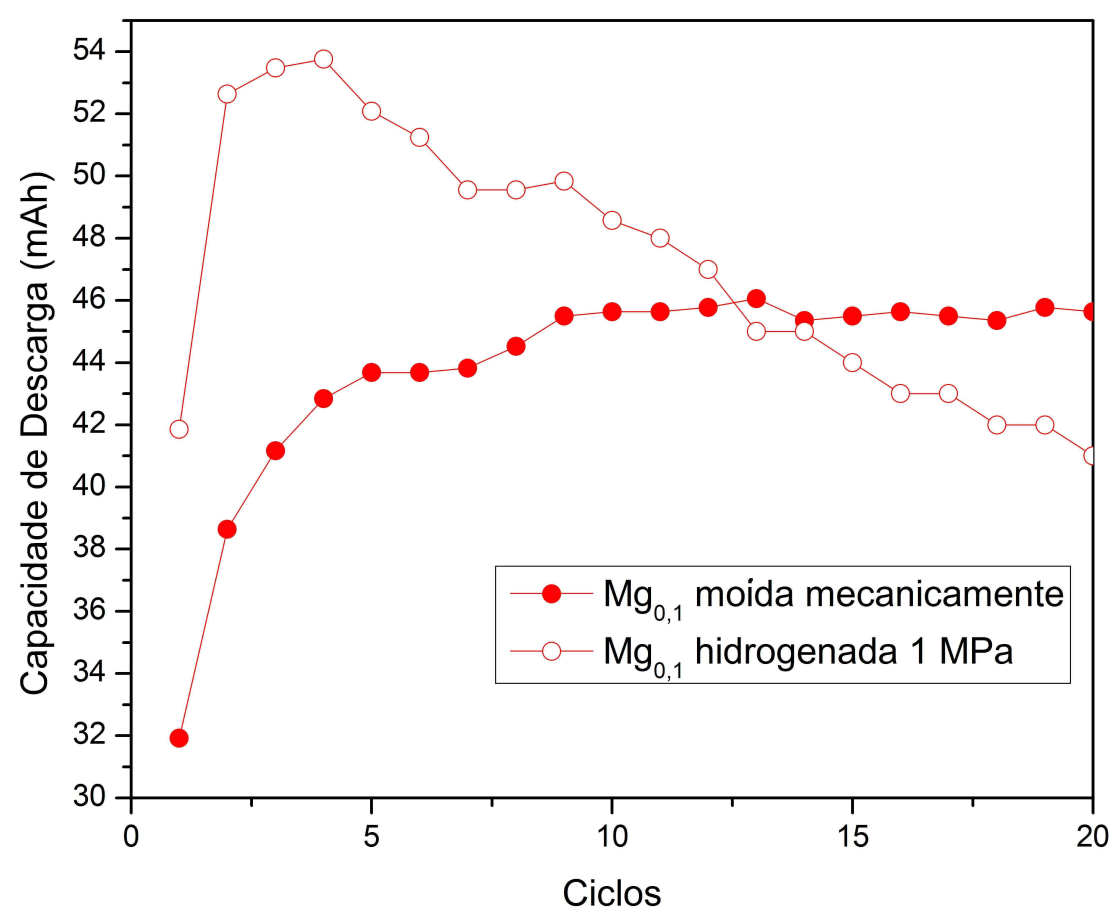

FIGURA 65 - Capacidade de descarga em função do número de ciclos para a liga $\mathrm{La}_{0,7} \mathrm{Mg}_{0,1} \mathrm{Pr}_{0,3} \mathrm{Al}_{0,3} \mathrm{Mn}_{0,4} \mathrm{Co}_{0,5} \mathrm{Ni}_{3,8}$ moída mecanicamente e hidrogenada a $1 \mathrm{MPa}$.

Os resultados obtidos foram semelhantes ao encontrado para a liga sem magnésio, o aumento da capacidade de descarga foi de 46 mAh (liga moída mecanicamente) para $54 \mathrm{mAh}$ (liga hidrogenada). Porém a capacidade de descarga da bateria fabricada com a liga hidrogenada a 1 MPa não se estabiliza. Este fato, de alta capacidade de descarga inicial, pode estar relacionado à série de trincas nas partículas (FIG. 40), que facilita a absorção do hidrogênio no interior da liga durante os primeiros ciclos, mas, por outro lado, aumenta a decrepitação das partículas durante os ciclos de carga e descarga, diminuindo o tamanho de partículas e como conseqüência, uma queda drástica na capacidade de descarga $[64,65]$. 
Na FIG. 66 está mostrada a capacidade de descarga em função do número de ciclos do eletrodo negativo fabricado com a liga $\mathrm{La}_{0,7} \mathrm{Mg}_{0,3} \mathrm{Pr}_{0,3} \mathrm{Al}_{0,3} \mathrm{Mn}_{0,4} \mathrm{Co}_{0,5} \mathrm{Ni}_{3,8}$ moída mecanicamente e hidrogenada a $1 \mathrm{MPa}$.

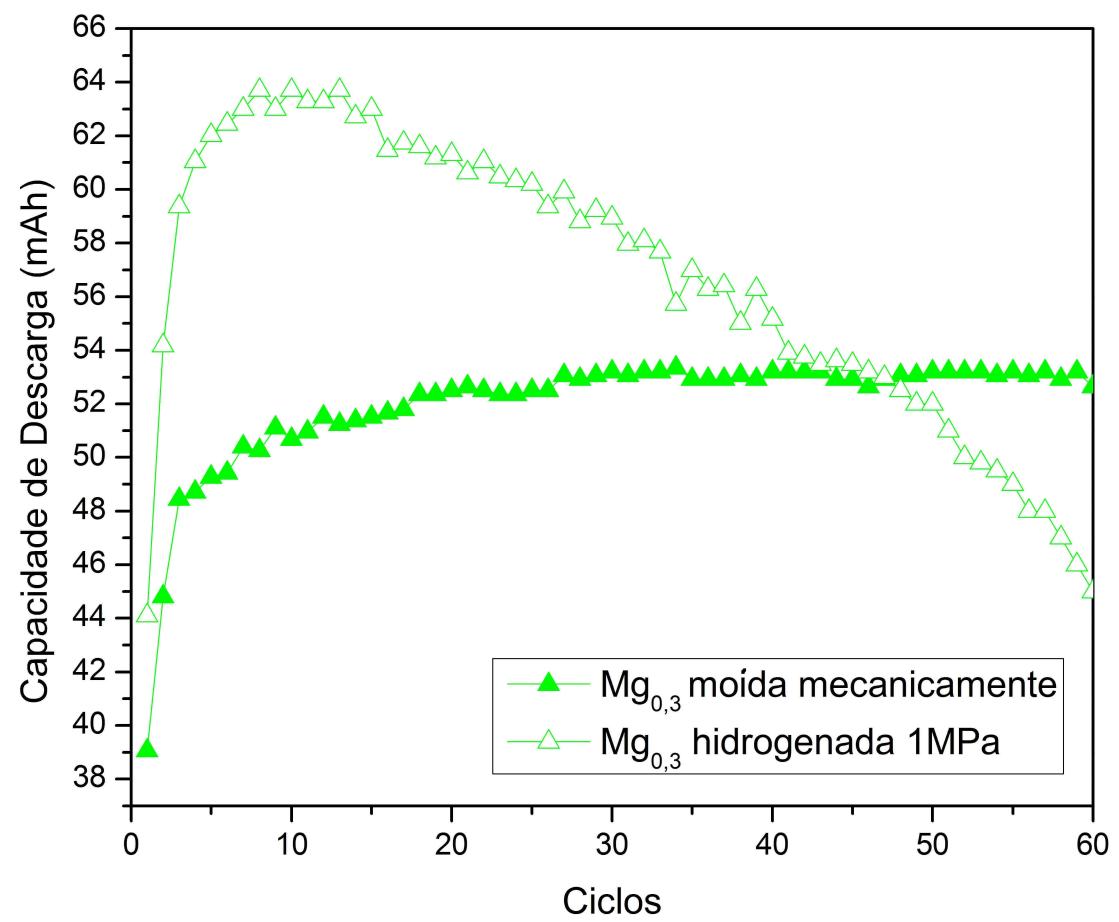

FIGURA 66- Capacidade de descarga em função do número de ciclos para a liga $\mathrm{La}_{0,4} \mathrm{Mg}_{0,3} \mathrm{Pr}_{0,3} \mathrm{Al}_{0,3} \mathrm{Mn}_{0,4} \mathrm{Co}_{0,5} \mathrm{Ni}_{3,8}$ moída mecanicamente e hidrogenada a $1 \mathrm{MPa}$.

Os resultados apresentados se mostraram semelhantes aos da liga com $\mathrm{Mg}_{0,1}$, com alta capacidade de descarga inicial, seguida de queda drástica na capacidade de descarga. A capacidade de descarga máxima aumentou de 53 mAh (liga moída mecanicamente) para 64 mAh (liga hidrogenada).

Nas FIG. 67 - 70 estão apresentadas as imagens obtidas por MEV dos eletrodos negativos da liga $\mathrm{La}_{0,4} \mathrm{Mg}_{0,3} \mathrm{Pr}_{0,3} \mathrm{Al}_{0,3} \mathrm{Mn}_{0,4} \mathrm{Co}_{0,5} \mathrm{Ni}_{3,8}$, antes da ciclagem (FIG. 67 e 69) e após 50 ciclos de carga e descarga (FIG. 68 e 70). 


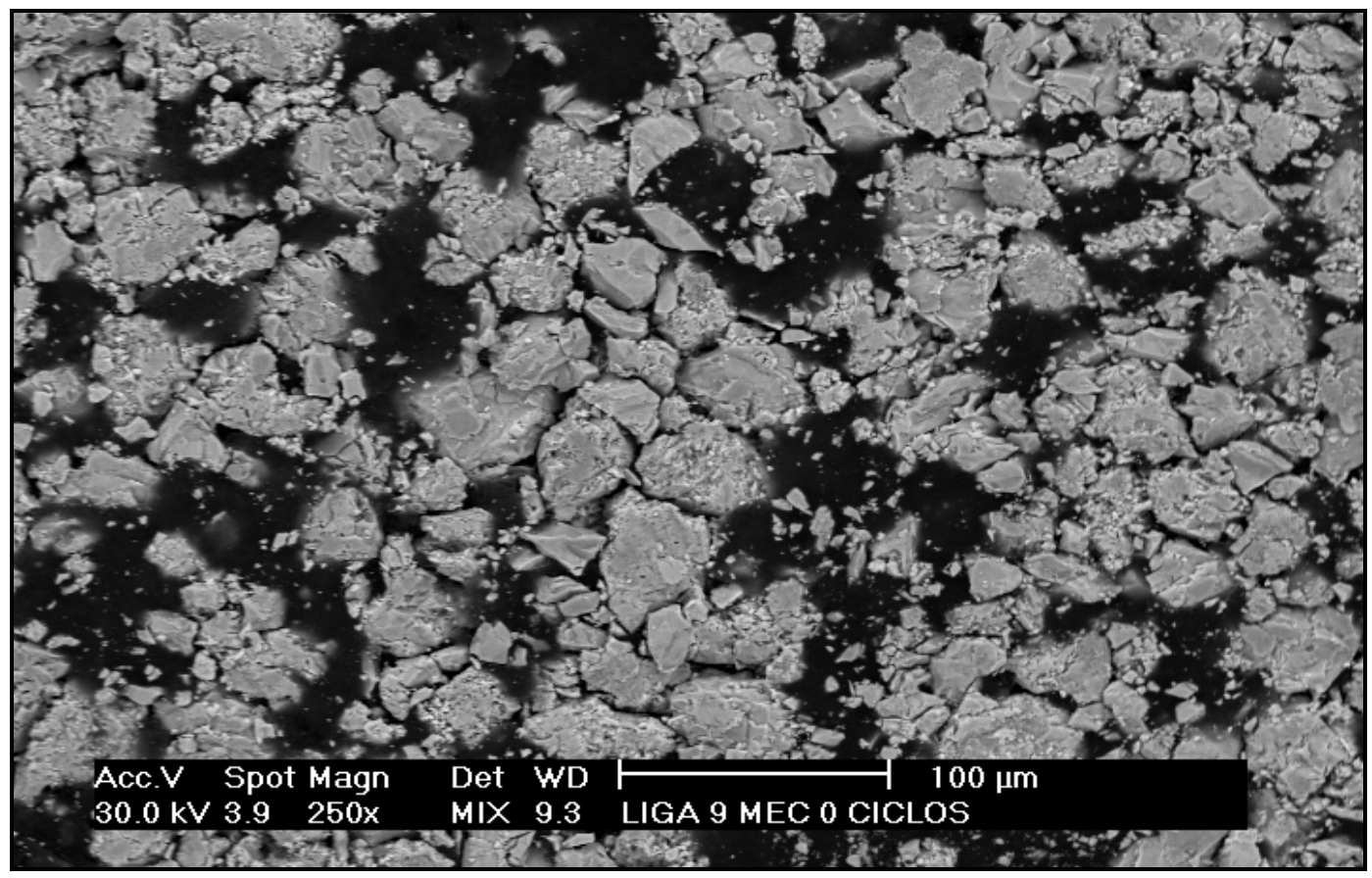

(a)

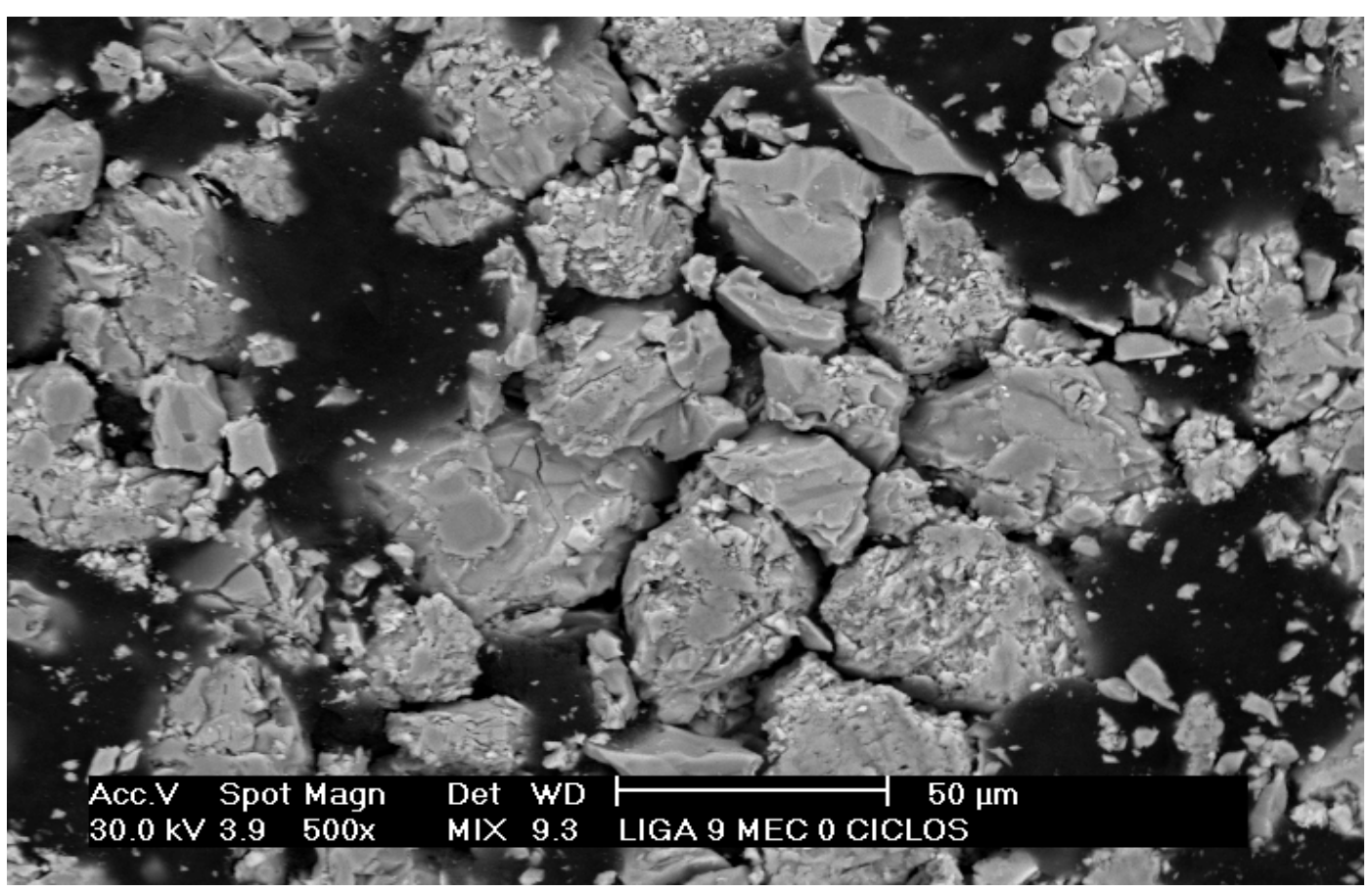

(b)

FIGURA 67 - Eletrodo negativo fabricado com a liga $\mathrm{La}_{0,4} \mathrm{Mg}_{0,3} \mathrm{Pr}_{0,3} \mathrm{Al}_{0,3} \mathrm{Mn}_{0,4} \mathrm{Co}_{0,5} \mathrm{Ni}_{3,8}$ moída mecanicamente, antes da ciclagem (0 ciclos); onde: (a) visão geral (250x) e (b) visão detalhada (500x). 


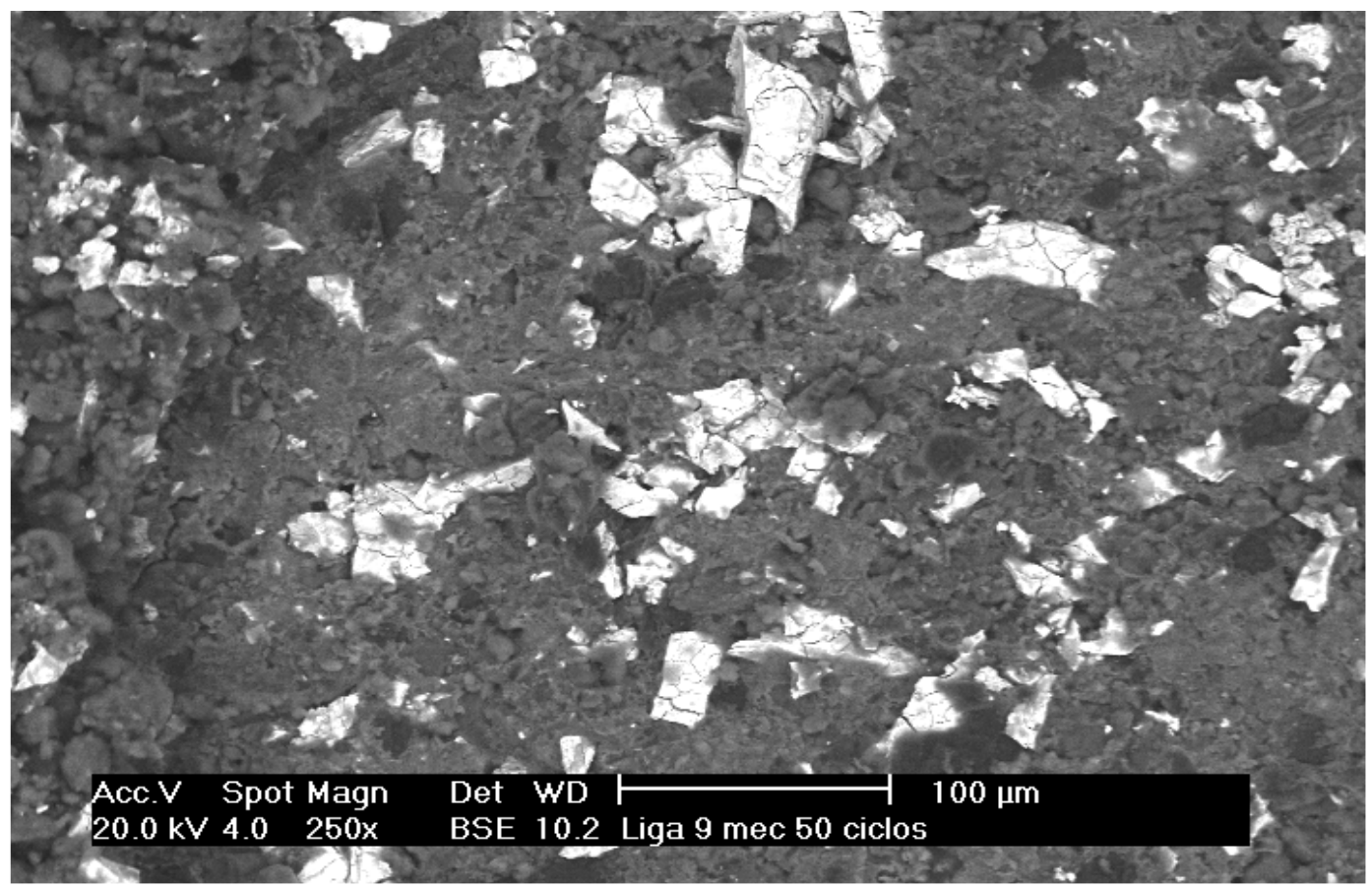

(a)

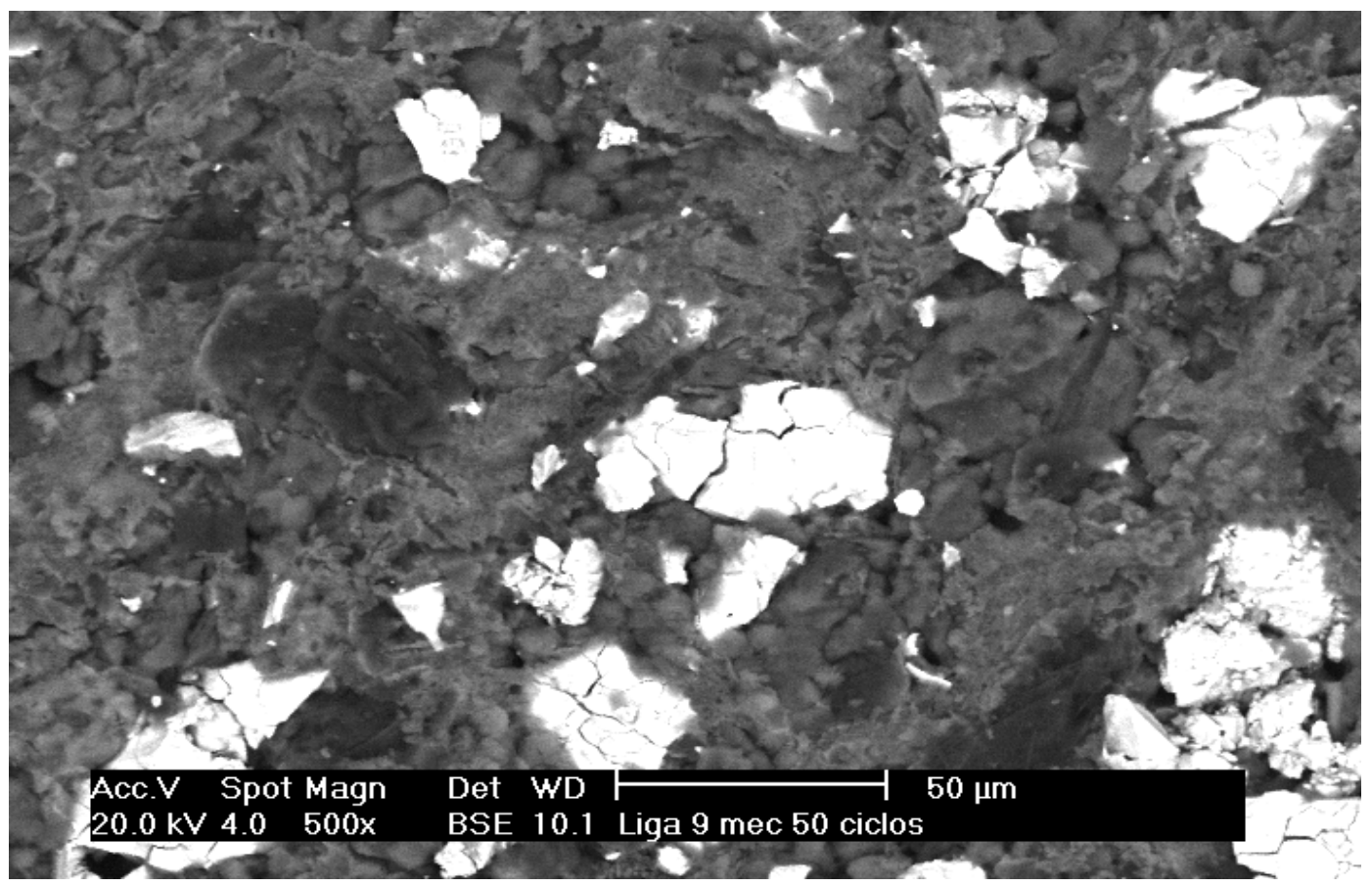

(b)

FIGURA 68 - Eletrodo negativo fabricado com a liga $\mathrm{La}_{0,4} \mathrm{Mg}_{0,3} \mathrm{Pr}_{0,3} \mathrm{Al}_{0,3} \mathrm{Mn}_{0,4} \mathrm{Co}_{0,5} \mathrm{Ni}_{3,8}$ moída mecanicamente após 50 ciclos de carga e descarga; onde: (a) visão geral (250x) e (b) visão detalhada (500x). 


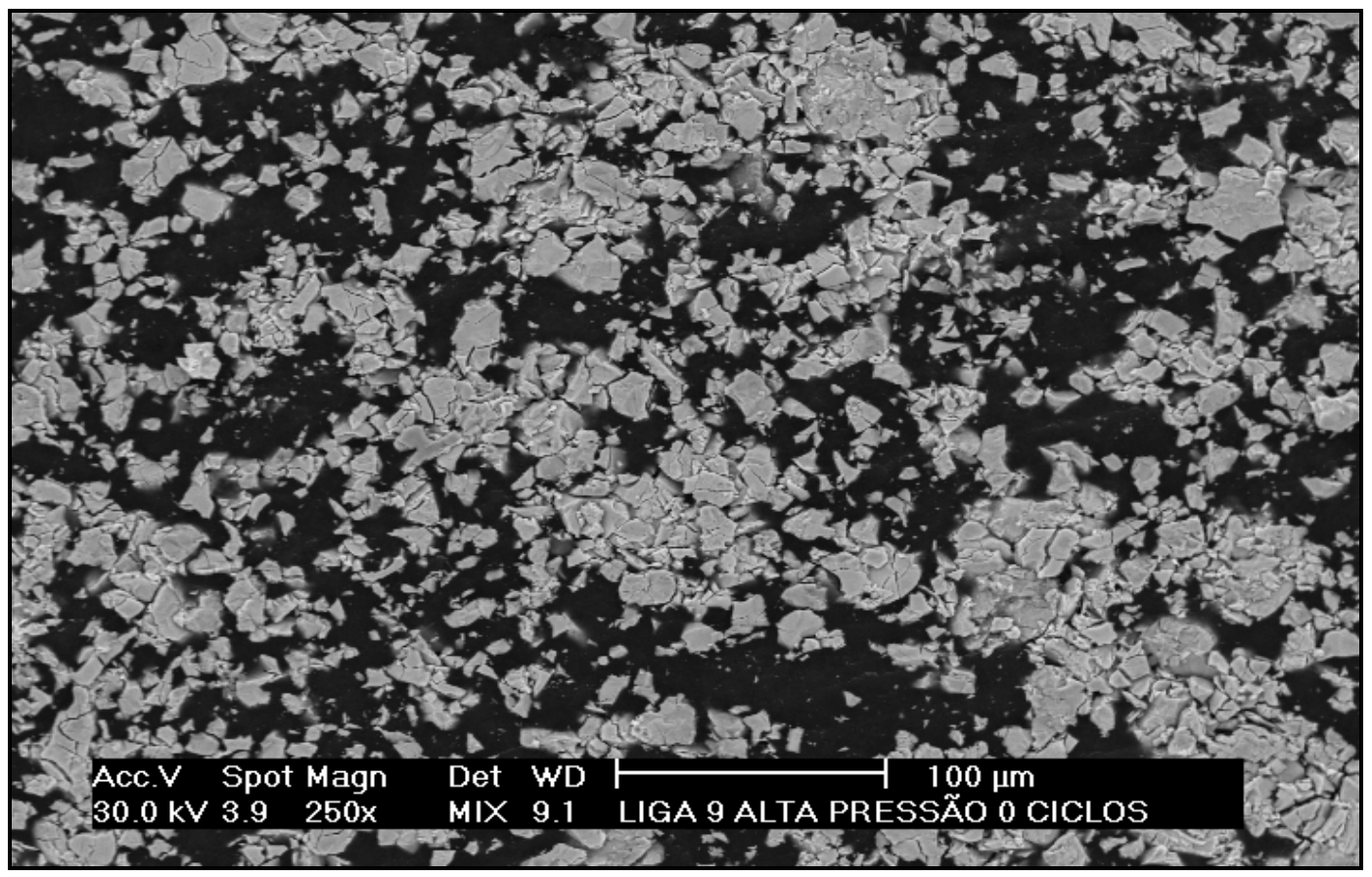

(a)

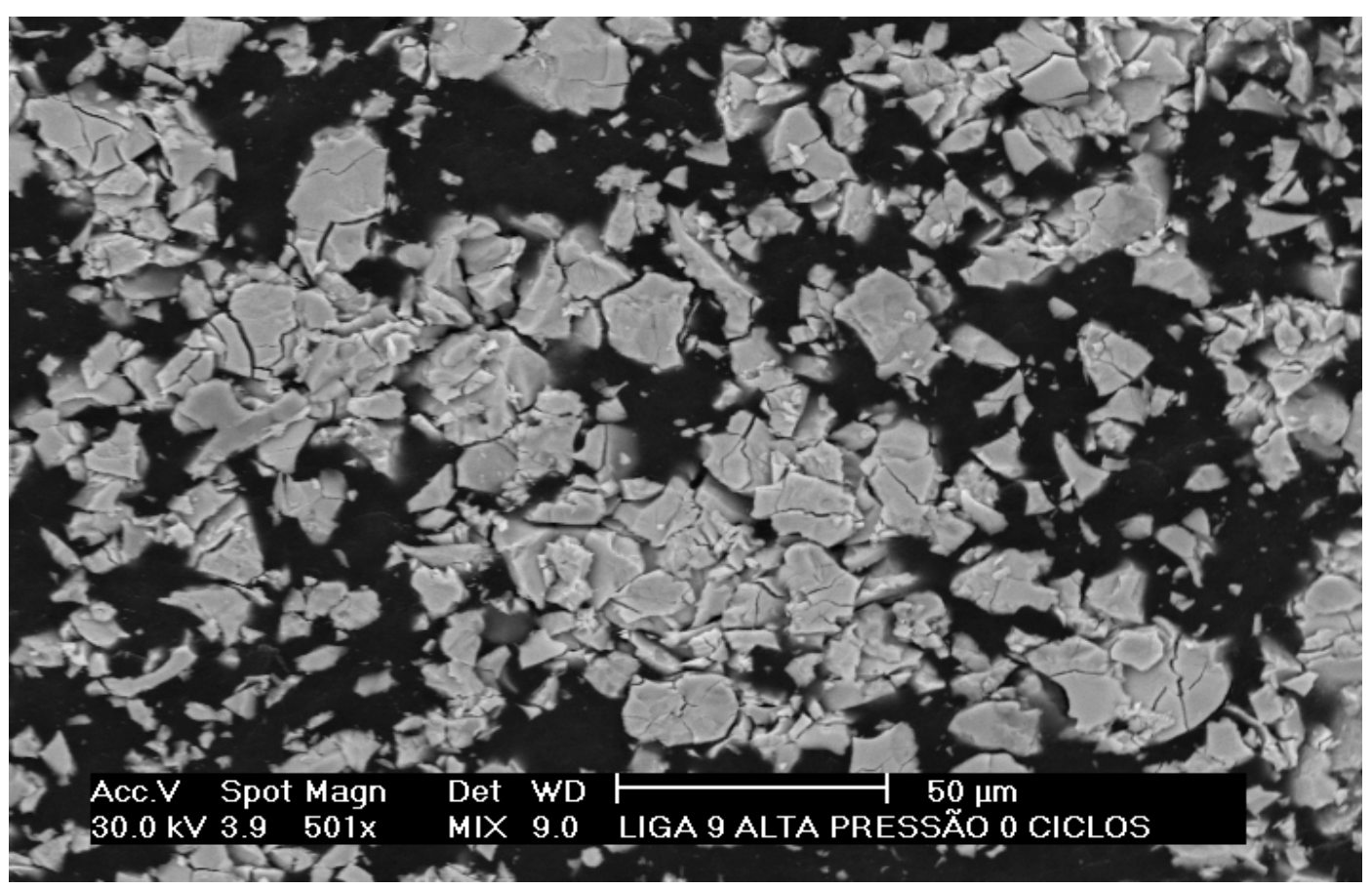

(b)

FIGURA 69 - Eletrodo negativo fabricado com a liga $\mathrm{La}_{0,4} \mathrm{Mg}_{0,3} \mathrm{Pr}_{0,3} \mathrm{Al}_{0,3} \mathrm{Mn}_{0,4} \mathrm{Co}_{0,5} \mathrm{Ni}_{3,8}$ hidrogenada a $1 \mathrm{MPa}$, antes da ciclagem (0 ciclos); onde: (a) visão geral (250x) e (b) visão detalhada (500x). 


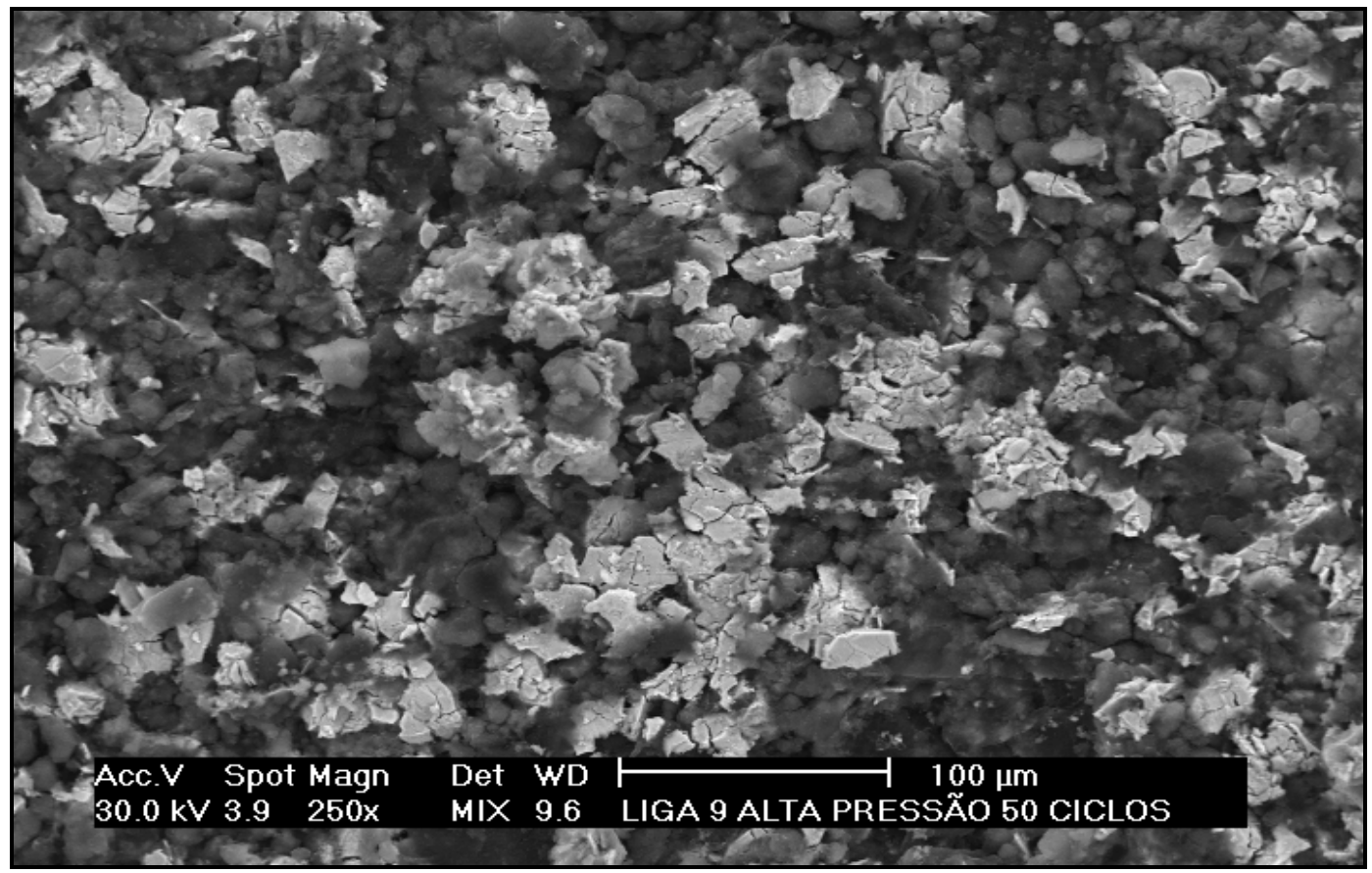

(a)

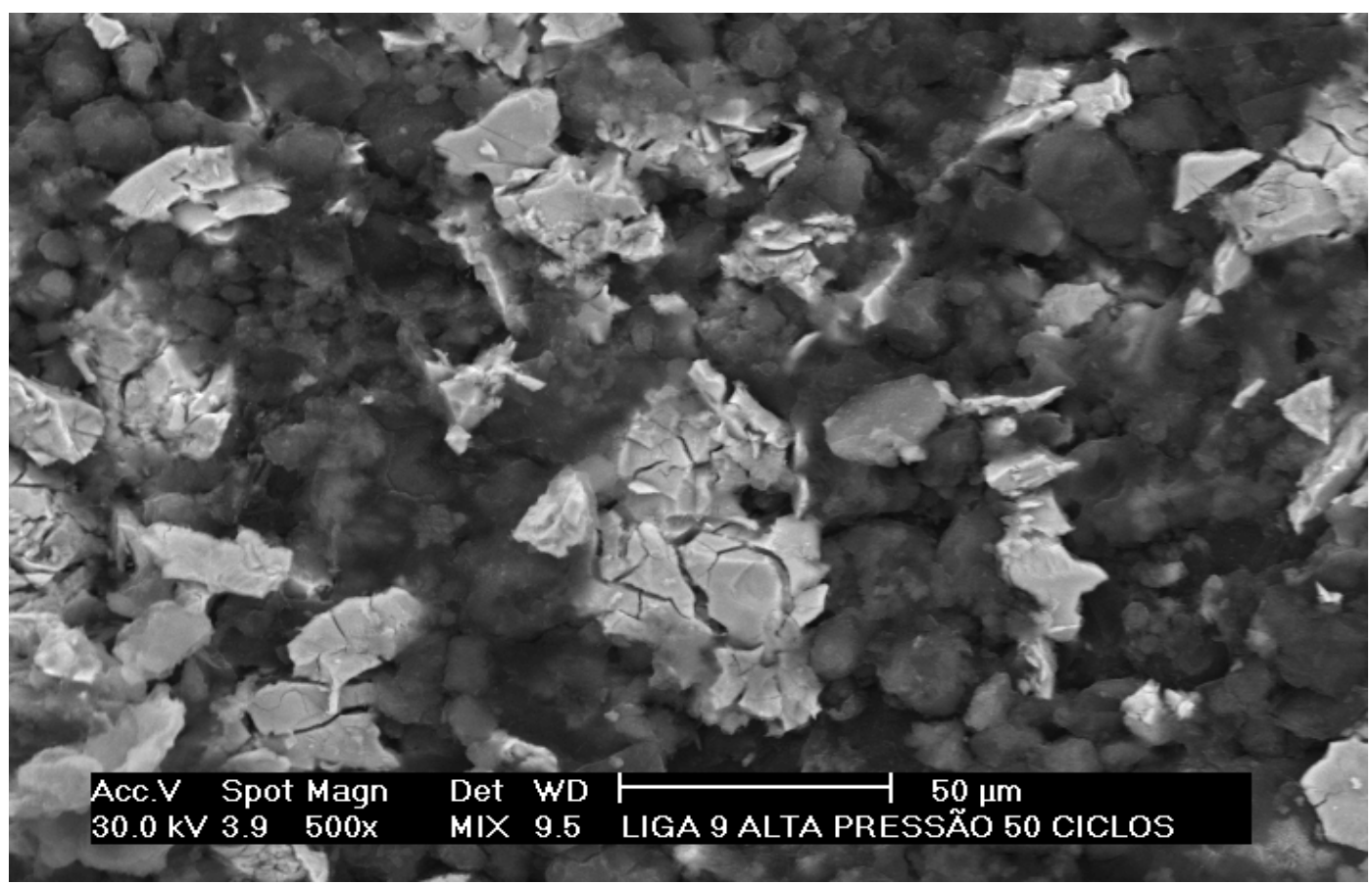

(b)

FIGURA 70 - Eletrodo negativo fabricado com a liga $\mathrm{La}_{0,4} \mathrm{Mg}_{0,3} \mathrm{Pr}_{0,3} \mathrm{Al}_{0,3} \mathrm{Mn}_{0,4} \mathrm{Co}_{0,5} \mathrm{Ni}_{3,8}$ hidrogenada a $1 \mathrm{MPa}$, após 50 ciclos de carga e descarga; onde: (a) visão geral (250x) e (b) visão detalhada (500x). 
As trincas ocorridas após a hidrogenação das ligas (FIG. 69 (b)) possibilitam a absorção de hidrogênio com maior facilidade, mas, por outro lado, a estabilidade da bateria é diminuída devido à maior pulverização das partículas durante os ciclos de carga/descarga (FIG. 70 (b)) em que as baterias estão submetidas $[63,64]$.

\subsection{Capacidade de descarga para célula eletroquímica}

Na FIG. 71 estão mostrados os resultados da capacidade de descarga em função do número de ciclos dos eletrodos negativos das ligas $L_{0,7-}$ ${ }_{x} \mathrm{Mg}_{\mathrm{x}} \mathrm{Pr}_{0,3} \mathrm{Al}_{0,3} \mathrm{Mn}_{0,4} \mathrm{Co}_{0,5} \mathrm{Ni}_{3,8}(\mathrm{x}=0$ a 0,5$)$ realizadas em célula eletroquímica.

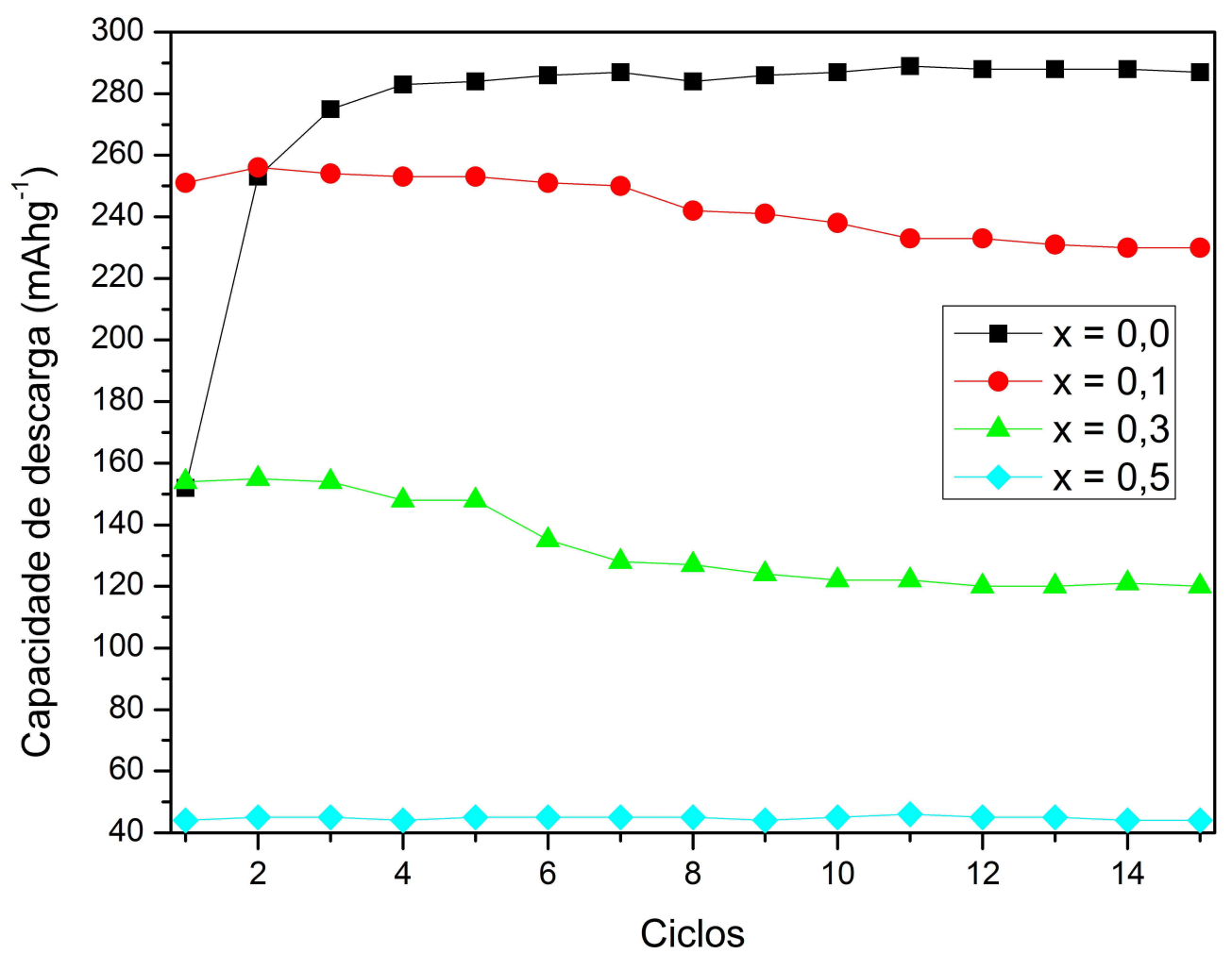

FIGURA 71 - Capacidade de descarga em função do número de ciclos dos eletrodos negativos das ligas $\mathrm{La}_{0,7-x} \mathrm{Mg}_{x} \mathrm{Pr}_{0,3} \mathrm{Al}_{0,3} \mathrm{Mn}_{0,4} \mathrm{Co}_{0,5} \mathrm{Ni}_{3,8} \quad(x=0$ a 0,5$)$ realizadas em célula eletroquímica. 
Os resultados mostram que a maior capacidade de descarga obtida foi para a liga sem magnésio (288 $\mathrm{mAhg}^{-1}$ ) que está próximo da capacidade de descarga obtida pela bateria selada $\left(270 \mathrm{mAhg}^{-1}\right)$ mostrada na TAB. 16. Pode ser observado também que, com o aumento do teor de $\mathrm{Mg}$, a capacidade de descarga diminui drasticamente. Este fato pode estar relacionado pela formação do $\mathrm{Mg}(\mathrm{OH})_{2}$ sobre a superfície de $\mathrm{Mg}-\mathrm{Ni}$ e, neste caso, com maior ocorrência na célula eletroquímica quando comparado com os resultados obtidos nas baterias seladas.

A oxidação do $\mathrm{Mg}$ é um dos mecanismos dominantes na degradação deste material quando utilizados em eletrodos negativos de baterias [55,56,57,63]. Os resultados mostrados na FIG. 71, da célula eletroquímica, podem estar relacionados à formação desta camada de óxido, impedindo a absorção e dessorção do hidrogênio durante os ciclos de carga e descarga. Provavelmente, os maiores valores da capacidade de descarga obtidos para as baterias seladas estão relacionadas com o efeito da pressão interna. Nas baterias seladas a pressão interna é superior e desta forma, aumenta a absorção do hidrogênio pelo eletrodo negativo mesmo na presença da camada de óxido presente na superfície das partículas do material ativo.

Nas FIG. 72 e 73 estão mostradas imagens obtidas por MEV dos eletrodos negativos da liga sem magnésio, antes da ciclagem (FIG. 72) e após 15 ciclos de carga e descarga (FIG. 73). Nas FIG. 74 e 75 estão mostradas imagens obtidas por MEV dos eletrodos negativos da liga com $\mathrm{Mg}_{0,5}$, antes da ciclagem (FIG. 74) e após 15 ciclos de carga e descarga (FIG. 75). 


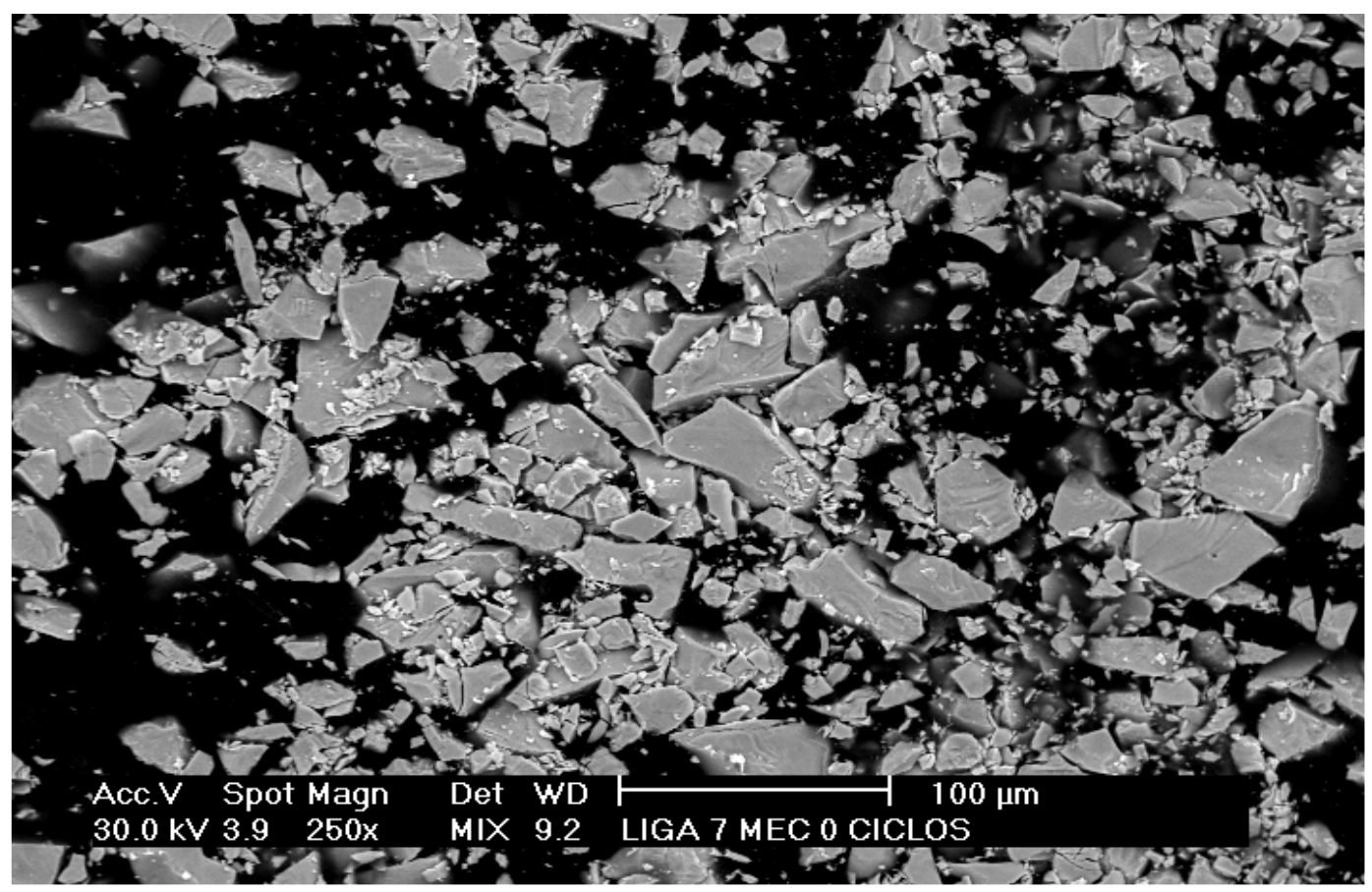

(a)

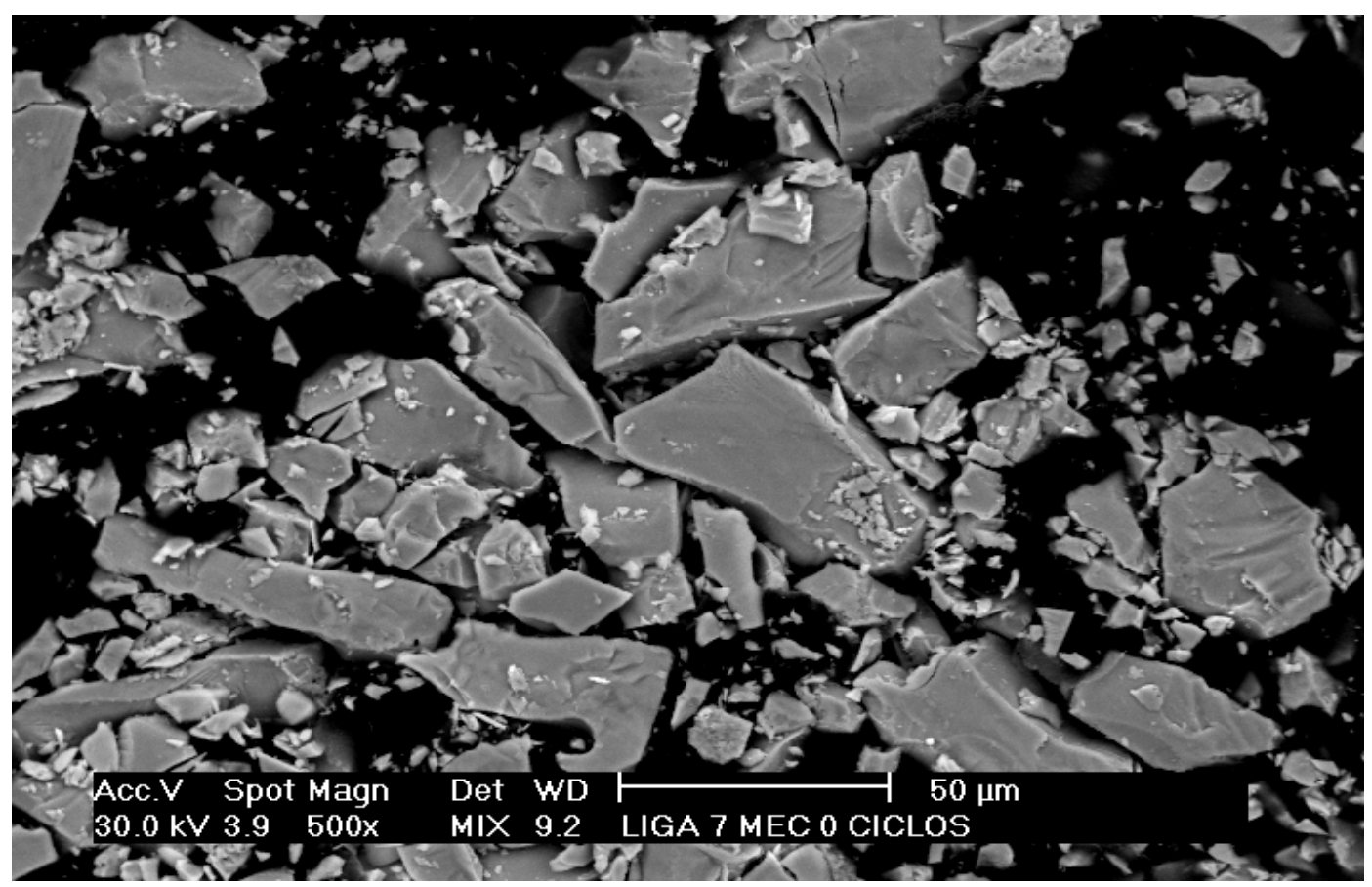

(b)

FIGURA 72 - Eletrodo negativo, em célula eletroquímica, fabricado com a liga sem magnésio, antes da ciclagem; onde: (a) visão geral (250x) e (b) visão detalhada (500x). 


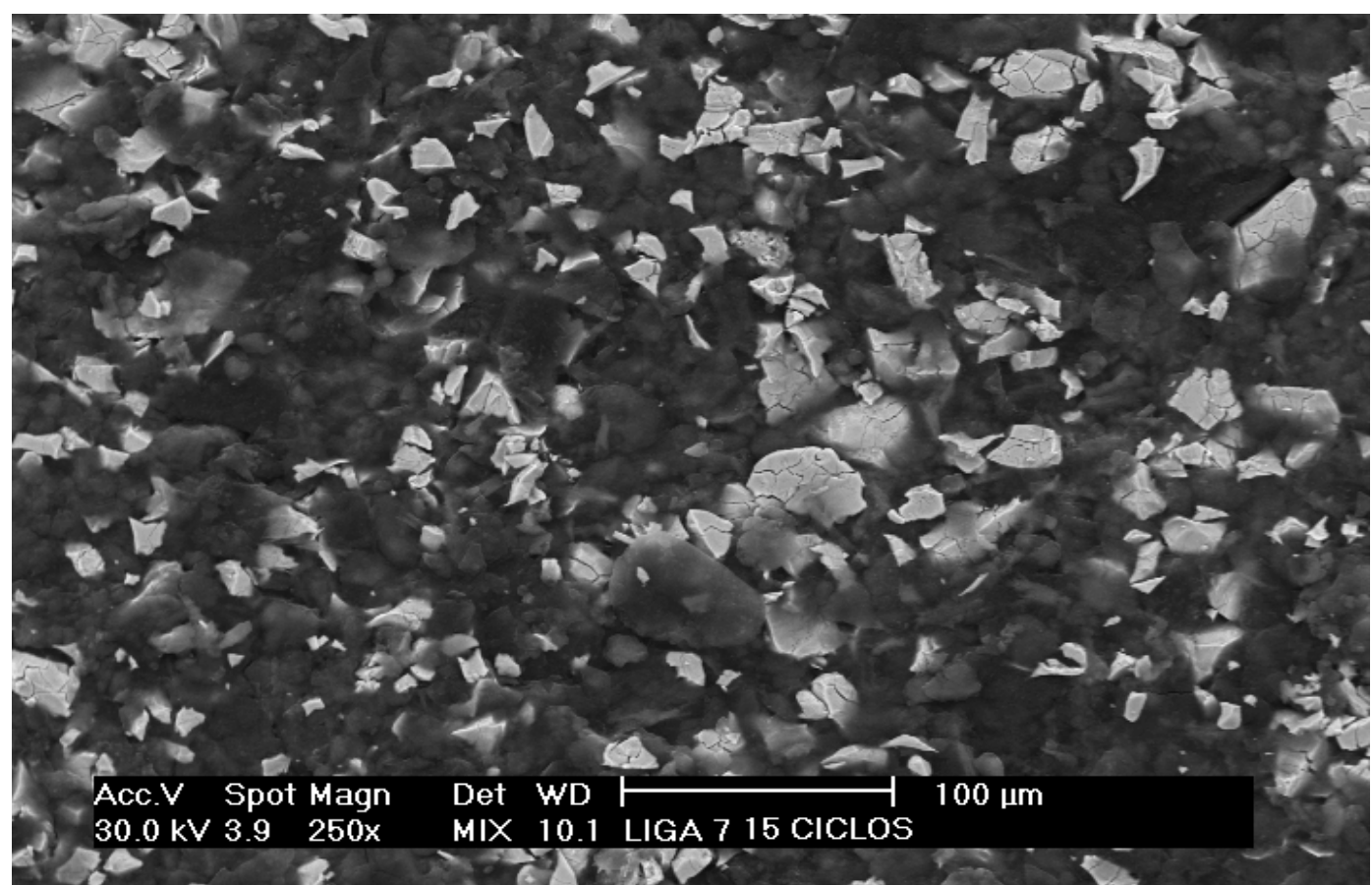

(a)

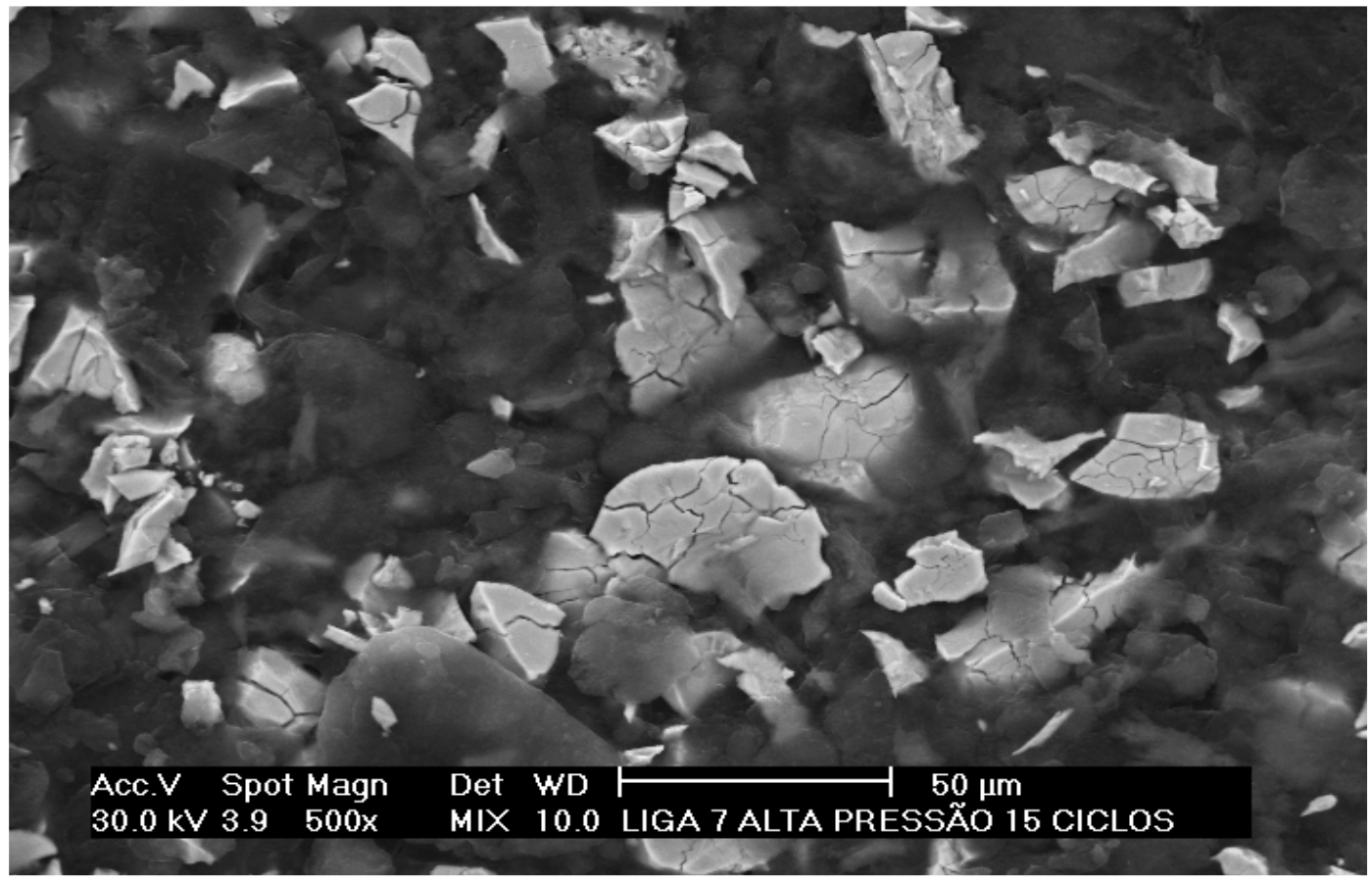

(b)

FIGURA 73 - Eletrodo negativo, em célula eletroquímica, fabricado com a liga sem magnésio, após 15 ciclos de carga e descarga; onde: (a) visão geral (250x) e (b) visão detalhada (500x). 


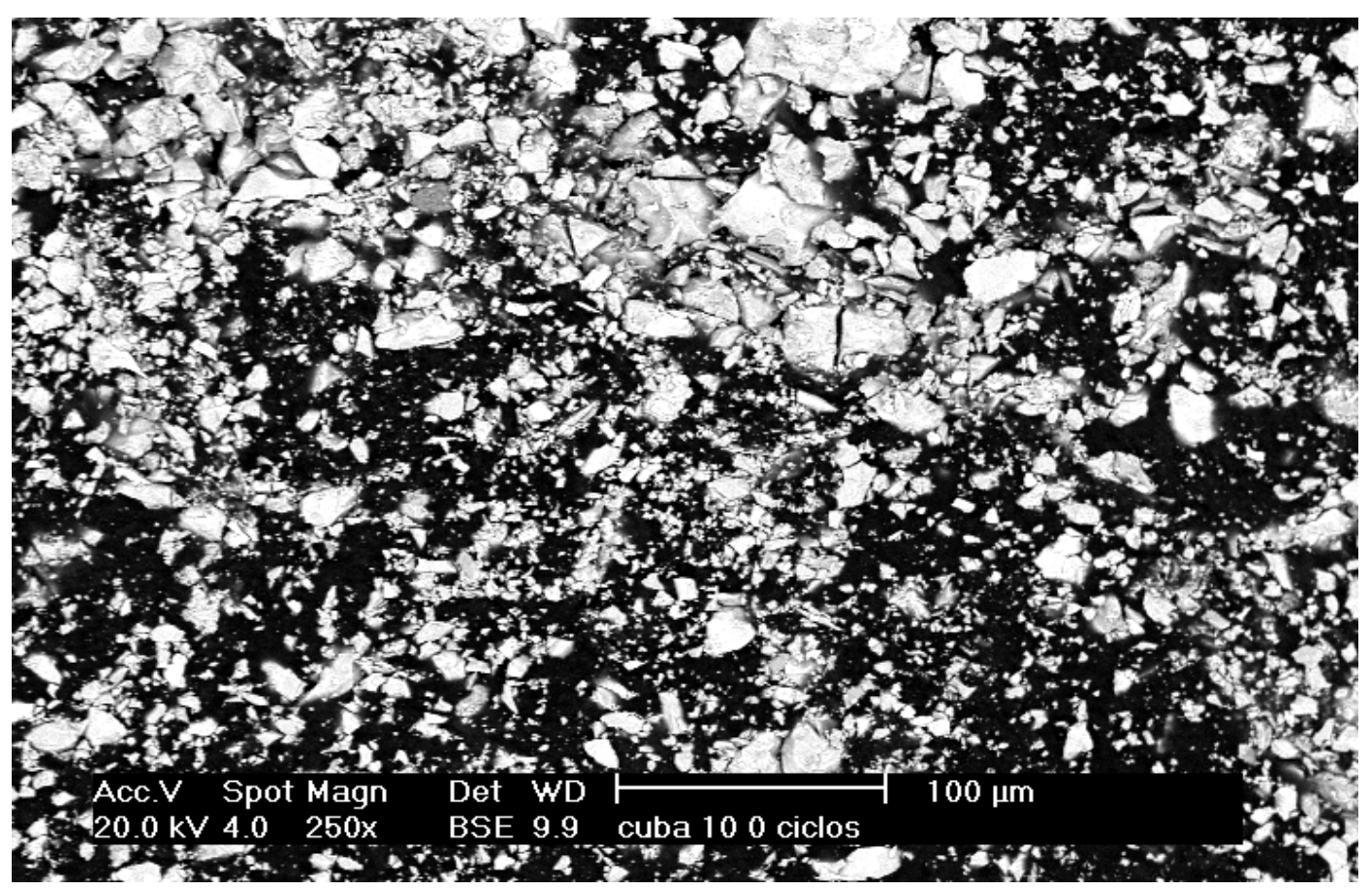

(a)

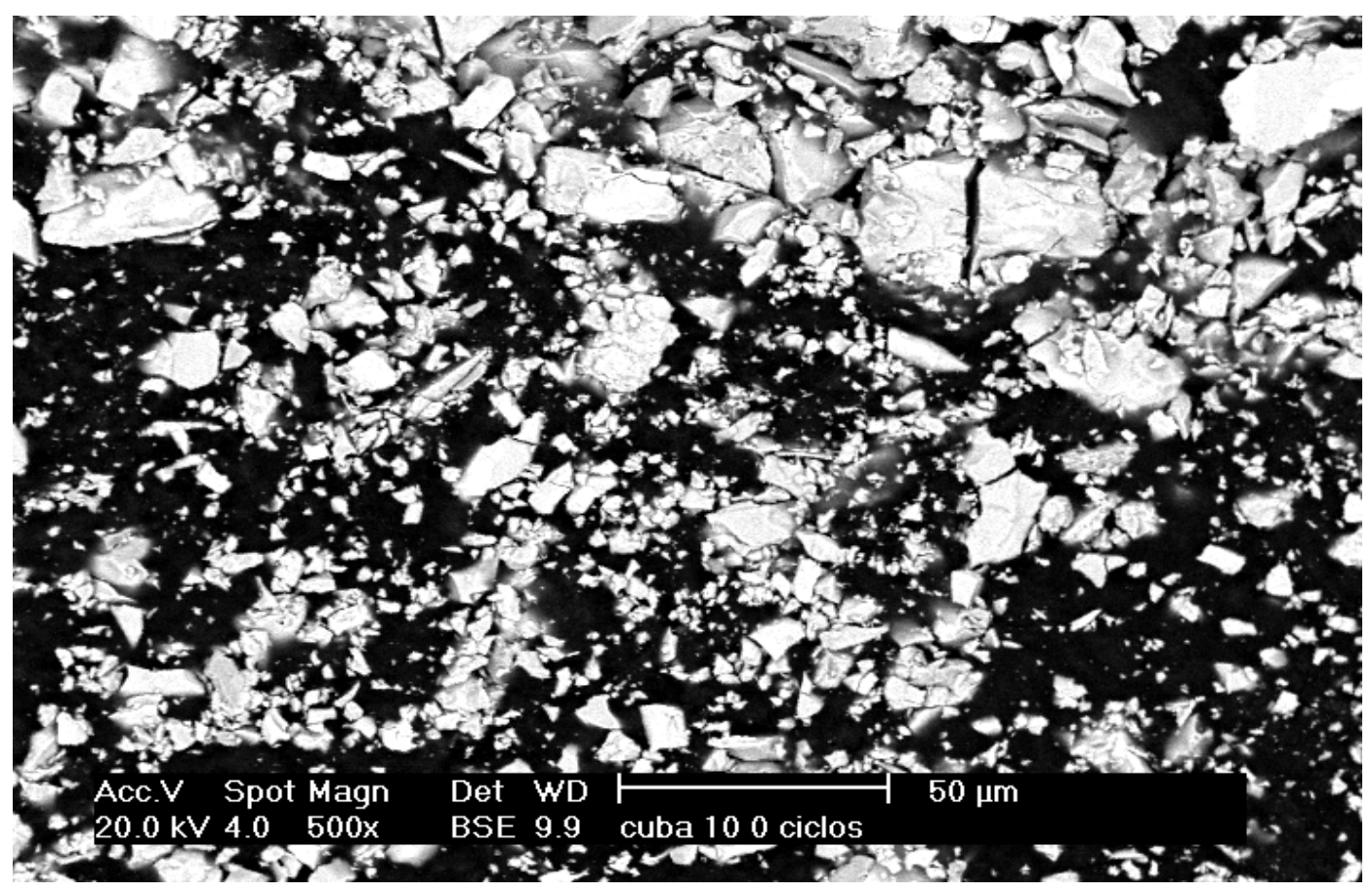

(b)

FIGURA 74 - Eletrodo negativo, em célula eletroquímica, fabricado com a liga Mg, ${ }_{0,5}$, antes da ciclagem; onde: (a) visão geral (250x) e (b) visão detalhada (500x). 


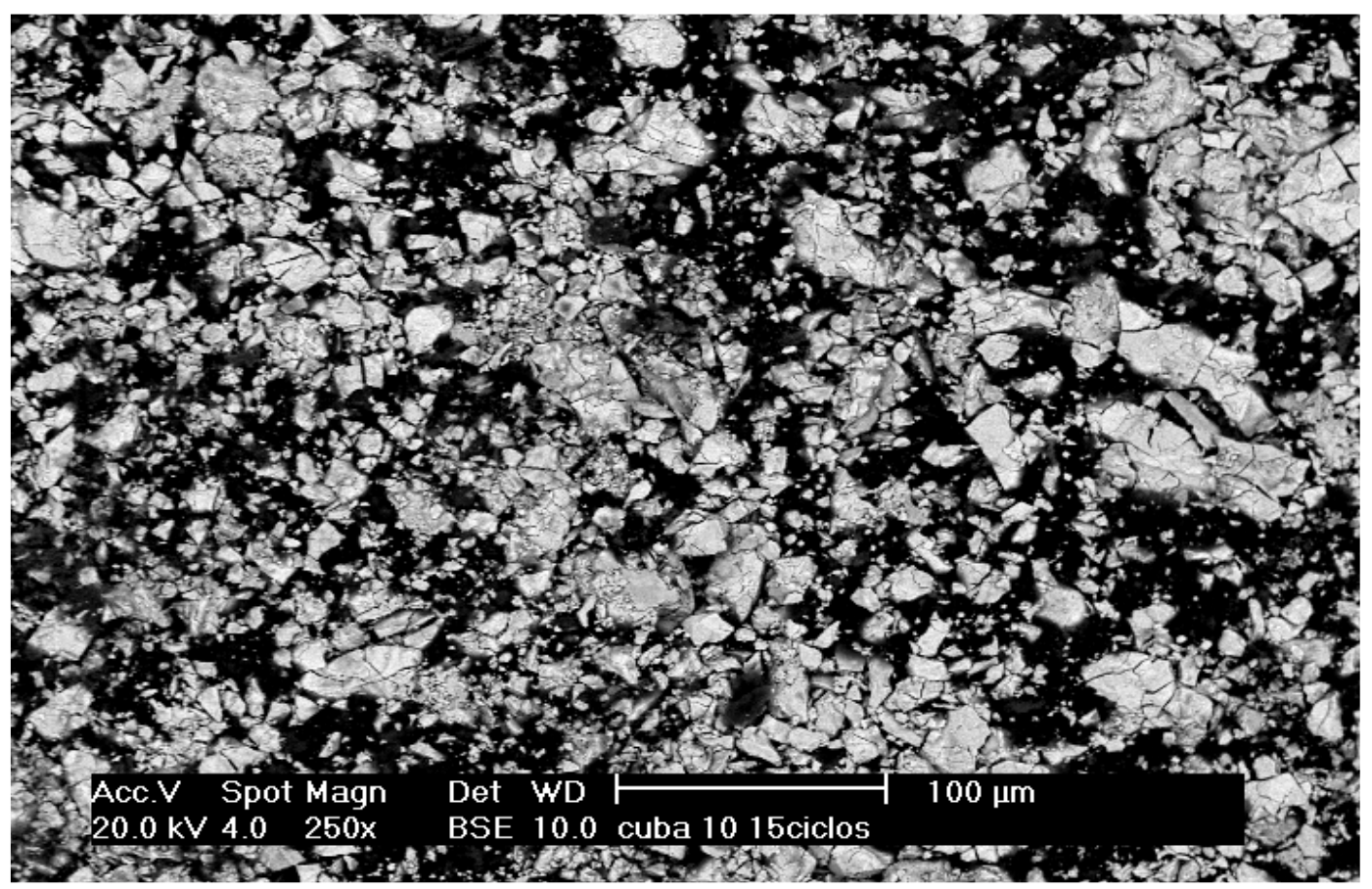

(a)

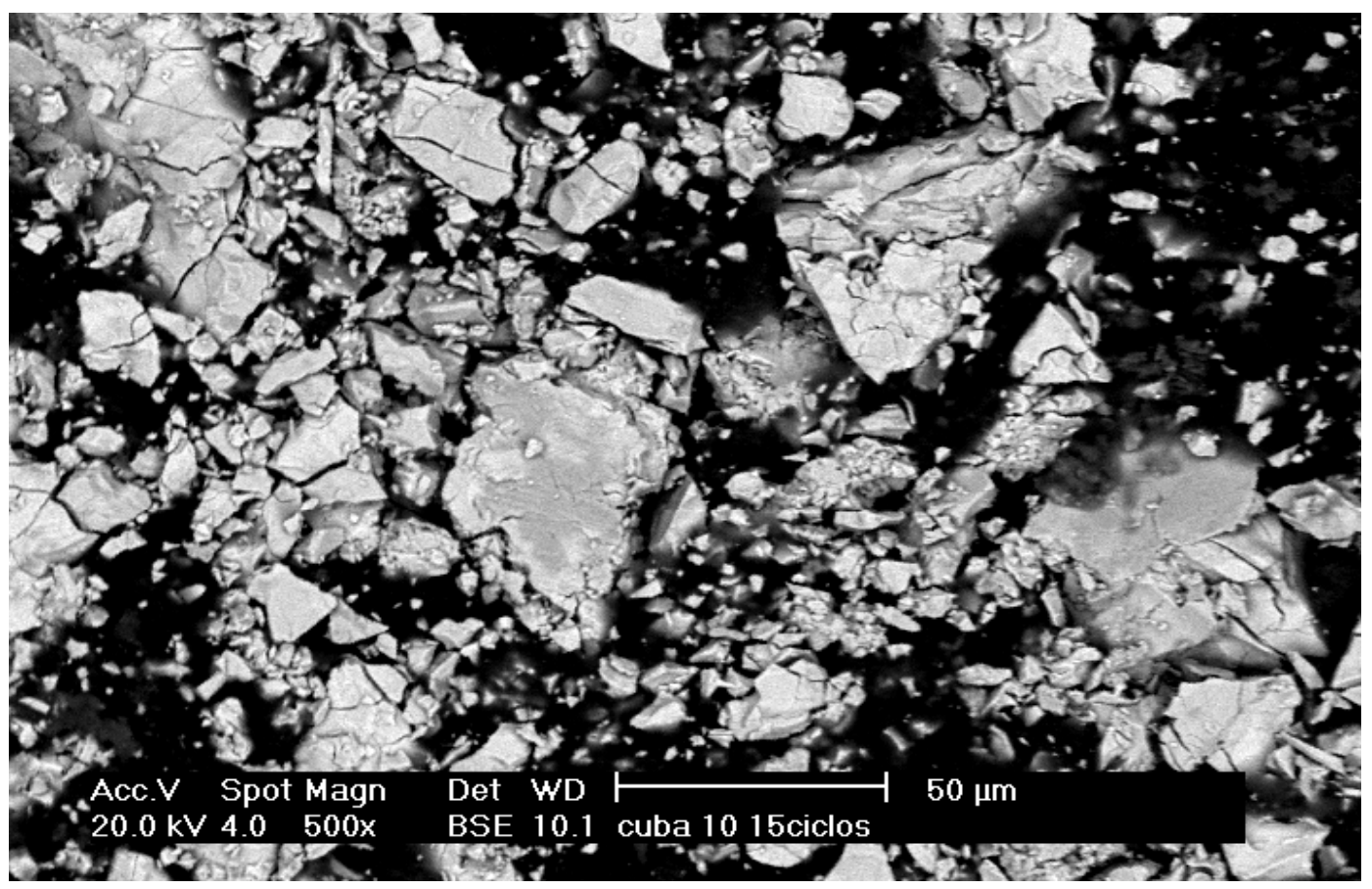

(b)

FIGURA 75 - Eletrodo negativo, em célula eletroquímica, fabricado com a liga Mg, ${ }_{0,5}$, após 15 ciclos de carga e descarga; onde: (a) visão geral (250x) e (b) visão detalhada (500x). 
Os resultados obtidos por MEV dos eletrodos negativos mostraram que para a liga sem magnésio ocorre o efeito da decrepitação das partículas durante os ciclos de carga e descarga, o mesmo efeito não foi observado para a liga com alto teor de magnésio $\left(\mathrm{Mg}_{0,5}\right)$. 


\section{CONCLUSÕES}

As análises de EDS, MEV e difração de Raios- $X$ mostraram a presença de quatro fases: matriz (M) (La,Pr) $\mathrm{Ni}_{5}$ baseada na fase $\mathrm{LaNi}_{5}$, cinza (C) (La,Pr) $\mathrm{Mg}_{2} \mathrm{Ni}_{9}$, cinza escura (CE) $\mathrm{Ni}$ e a fase escura (E) $\mathrm{MgNi}_{2}$. Os resultados da quantificação das fases mostrou aumento da fase ( $\mathrm{La}, \mathrm{Pr}) \mathrm{Mg}_{2} \mathrm{Ni}_{9}$ e diminuição da fase (La,Pr) $\mathrm{Ni}_{5}$ quando aumenta-se o teor de magnésio nas ligas.

Os resultados da hidrogenação das ligas mostraram que há uma maior facilidade de hidretação para as ligas com baixa concentração de magnésio. Com altas concentrações de magnésio $\left(\mathrm{Mg}_{0,5}\right.$ e $\left.\mathrm{Mg}_{0,7}\right)$ a hidrogenação não ocorreu nas pressões estudadas.

A capacidade de descarga máxima das baterias seladas aumentou com o aumento do teor de magnésio, passando de $38 \mathrm{mAh}$ (sem Mg) para 60 $\mathrm{mAh}\left(\mathrm{Mg}_{0,7}\right)$, porém a estabilidade de ciclos diminuiu. Este aumento está relacionado ao incremento da fase $(\mathrm{La}, \mathrm{Pr}) \mathrm{Mg}_{2} \mathrm{Ni}_{9}$, quando é realizada a substituição do lantânio pelo magnésio.

Os resultados da retenção da capacidade de descarga $\left(\mathrm{C}_{100} / \mathrm{C}_{\max }\right)$ mostraram aumento de $84,2 \%(x=0,0)$ para $98,1(x=0,3)$ e depois decai para $76,6(x=0,7)$.

O melhor resultado encontrado para as baterias seladas foi para a liga $\mathrm{La}_{0,4} \mathrm{Mg}_{0,3} \mathrm{Pr}_{0,3} \mathrm{Al}_{0,3} \mathrm{Mn}_{0,4} \mathrm{Co}_{0,5} \mathrm{Ni}_{3,8}$, obtendo uma capacidade de descarga máxima de $53 \mathrm{mAh}\left(380 \mathrm{mAhg}^{-1}\right.$ ) com 150 ciclos (perda 10\% da capacidade de descarga). Não foi possível comparar o efeito da perda da capacidade de descarga com a resistência interna das baterias. 
O resultado apresentado para as baterias, com a liga hidrogenada, mostrou uma melhora na capacidade de descarga inicial quando comparado com a liga moída mecanicamente, mas a estabilidade de ciclos diminuiu devido ao menor tamanho das partículas.

Os baixos valores encontrados da capacidade de descarga das baterias fabricadas em célula eletroquímica mostraram que provavelmente houve a formação de uma camada de $\mathrm{Mg}(\mathrm{OH})_{2}$ que impossibilitou o aumento da capacidade de descarga. 


\section{REFERÊNCIAS BIBLIOGRÁFICAS}

[1] SWARTZENDRUBERT, L.J.; BENNETTT, L.H.; WATSON, MOSSBAUER, R.E. studies of hydrided TiFe. Journal Phys. F: Metal Phys., v. 6, p. L331L334, 1976.

[2] SCHLAPBACH, L.; ZUTTEL, A. Hydrogen-storage materials for mobile applications. Nature., v. 414, p. 353-358, 2001.

[3] VUCHT, J.H.N.V.; KUJIPERS, F.A.; BRUNING, H.C.A.M. Philips Res. Repts., v. 25, p. 133, 1970.

[4] RUESTSCHI, P.; MELI, F.; DESILVESTRO, J. Nickel-metal hydride batteries-. The preferred batteries of the future? Journal of Power Sources., v. 57, p. 85-91, 1995.

[5] DHAR, S.K.; OVSHINSKY, S.R.; GIFFORD, P.R.; CORRIGAN, D.A.; FETCENKO, M.A.; VENKATESAN, S. Nickel/metal hydride technology for consumer and electric vehicle batteries - a review and up-date. Journal of Power Sources., v. 65, p. 1-7, 1997.

[6] PUTOIS, F. Market for nickel-cadmium batteries. Journal of Power Sources., v. 57, p. 67-70, 1995.

[7] GENGA, M.; HAN, J.; FENG, .; NORTHWOOD, D.O. Electrochemical measurements of a metal hydride electrode for the Ni/MH battery. International Journal of Hydrogen Energy., v. 25, p. 203-210, 2000.

[8] BUCHMANN, I. Batteries in a Portable World. Cadex Electronics Inc, 2001. cap. 2, Battery Chemistries. p. 2. 
[9] LINDEN, D.; REDDY, T.B. Handbook of Batteries. $3^{\circ}$ ed. 2001.

[10] FENG, F.; GENG, M.; NORTHWOOD, D.O. Electrochemical behaviour of intermetallic-based metal hydrides used in Ni-metal hydride $(\mathrm{MH})$ batteries: a review. International Journal of Hydrogen Energy., v. 26, p. 725-734, 2001.

[11] SAKAI, T. Hydrogen Storage Alloys for Nickel-metal Hydride Battery. Zeitschift feur Physikalische Chemie., v. 183, p. 333-346, 1994.

[12] ZHANG, L.Y. Rare Earth-Based Metal Hydrides and NiMH Rechargeable Batteries. In: RARE EARTH: SCIENCE TECHONOLOGY AND APPLICATIONS 3rd SYMP. Feb, 1997, Orlando.

[13] KIM, D.M.; JEON, S.W.; LEE, J.Y. A study of the development of a high capacity and high performance $\mathrm{Zr}-\mathrm{Ti}-\mathrm{Mn}-\mathrm{V}-\mathrm{Ni}$ hydrogen storage alloy for $\mathrm{Ni}-\mathrm{MH}$ rechargeable batteries. Journal of Alloys and Compounds., v. 279, p. 209-214, 1998.

[14] PARK, HY.; CHANG, I.; CHO, W.I.; CHO, B.W.; JANG, H.; LEE, S.R.; YUN, K.S. Electrode characteristics of the $\mathrm{Cr}$ and La doped AB2-type hydrogen storage alloys. International Journal of Hydrogen Energy., v. 26, p. 949955, 2001.

[15] KNOSP, B.; VALLET, L.; BLANCHARD, P. Performance of an $\mathrm{AB}_{2}$ alloy in sealed $\mathrm{Ni}-\mathrm{MH}$ batteries for electric vehicles: quantification of corrosion rate and consequences on the battery performance. Journal of Alloys and Compounds., v. 293-295, p. 770-774, 1999.

[16] GENG, M.; HAN, J.; FENG, F. Charging/discharging stability of a metal hydride battery electrode. Journal of the Electrochemical Society., v. 146(7), p. 2371-2375, 1999. 
[17] SHUMIN, H.; ZHONG, Z. The effect of vacuum evaporation plating on phase structure and electrochemical properties of AB5-5 mass\% $\mathrm{LaMg}_{3}$ composite alloy. Electrochimica acta., v. 50, p. 5491-5495, 2005.

[18] SEO, C.Y.; CHOI, S.J.; CHOI, J.; PARK C.N.; LEE J.Y. Effect of vanadium content on electrochemical properties of la-based AB5-type metal hydride electrodes. International Journal of Hydrogen Energy., v. 28, p. 967-975, 2003.

[19] NAKAMURA, Y.; OGURO, K.; UEHARA, I.; AKIBA, E. X-ray diffraction peak broadening and degradation in LaNi5-based alloys. International Journal of Hydrogen Energy., v. 25, p. 531-537, 2000.

[20] Energizer Battery Manufacturing Inc. Nickel Metal Hydride (NiMH) Handbook and Application Manual. 2010.

[21] PAN, H.; MA, S.; SHEN, J.; TAN, J.; DENG, J.; GAO, M. Effect of the substitution of Pr for La on the microstructure and electrochemical properties of $\mathrm{La}_{0,7-x} \operatorname{Pr}_{x} \mathrm{Mg}_{0,3} \mathrm{Ni}_{2,45} \mathrm{Co}_{0,75} \mathrm{Mn}_{0,1} \mathrm{Al}_{0,2} \quad(\mathrm{x}=0,0-0,3)$ hydrogen storage electrode alloys. International Journal of Hydrogen Energy., v. 32, p. 2949-2956, 2007.

[22] MA, S.; GAO, M.; LI, R.; PAN, H.; LEI, Y. A study on the structural and electrochemical properties of $\mathrm{La}_{0,7-x} \mathrm{Nd}_{x} \mathrm{Mg}_{0,3} \mathrm{Ni}_{2,45} \mathrm{Co}_{0,75} \mathrm{Mn}_{0,1} \mathrm{Al}_{0,2}$ (x = 0,0 $3,0)$ hydrogen storage alloys. Journal of Alloys and Compounds., v. 457, p. 457-464, 2008.

[23] PAN, H.; JIN, Q.; GAO, M.; LIU, Y.; LI, R.; LEI, Y. Effect of the cerium content on the structural and electrochemical properties of the $\mathrm{La}_{0,7-x} \mathrm{Ce}_{x} \mathrm{Mg}_{0,3} \mathrm{Ni}_{2,875} \mathrm{Mn}_{0,1} \mathrm{Co}_{0,525}(\mathrm{x}=0$ - 0,5) hydrogen storage alloys. Journal of Alloys and Compounds., v. 373, p. 237-245, 2004. 
[24] ZHANG, X.B.; SUN, D.Z.; YIN, W.Y.; CHAI, Y.J.; ZHAO, M.S. Effect of La/Ce ratio on the structure and electrochemical characteristics of $\mathrm{La}_{0,7-x} \mathrm{Ce}_{x} \mathrm{Mg}_{0,3} \mathrm{Ni}_{2,8} \mathrm{Co}_{0,5} \quad(\mathrm{x}=0,1 \quad$ - 0,5$)$ hydrogen storage alloys. Electrochimica Acta., v. 50, p. 1957-1964, 2005.

[25] PAN, H.; YUE, Y.; GAO, M.; WU, X.; CHEN, N.; LEI, Y.; WANG, Q. The effect of substitution of $\mathrm{Zr}$ for $\mathrm{La}$ on the electrochemical properties of $\mathrm{La}_{0,7-x} \mathrm{Zr}_{x} \mathrm{Mg}_{0,3} \mathrm{Ni}_{2,45} \mathrm{Mn}_{0,1} \mathrm{Co}_{0,75} \mathrm{Al}_{0,2}$ hydrogen storage electrode alloys. Journal of Alloys and Compounds., v. 397, p. 269-275, 2005.

[26] DONG, Z.; WU, Y.; MA, L.; SHEN, X.; WANG, L. Electrochemical Properties of $\left(\mathrm{La}_{1-\mathrm{x}} \mathrm{Ti}_{\mathrm{x}}\right)_{0,67} \mathrm{Mg}_{0,33} \mathrm{Ni}_{2,75} \mathrm{Co}_{0,25}(\mathrm{x}=0-0,20$. at\%) hydrogen storage alloys. Materials Research Bulletin., v. 45, p. 256-261, 2010.

[27] LIU, Y.; PAN, H.; GAO, M.; ZHU, Y.; LEI, Y.; WANG, Q. The e\&ect of Mn substitution for $\mathrm{Ni}$ on the structural and electrochemical properties of $\mathrm{La}_{0,7} \mathrm{Mg}_{0,3} \mathrm{Ni}_{2,55-\mathrm{x}} \mathrm{CO}_{0,45} \mathrm{Mn}_{\mathrm{x}}$ hydrogen storage electrode alloys. International Journal of Hydrogen Energy., v. 29, p. 297-305, 2004.

[28] LIU, Y.; PAN, H.; GAO, M.; ZHU, Y.; LEI, Y. Hydrogen storage and electrochemical properties of the $\mathrm{La}_{0,7} \mathrm{Mg}_{0,3} \mathrm{Ni}_{3,825-x} \mathrm{Co}_{0,675} \mathrm{Mn}_{\mathrm{x}}$ hydrogen storage electrode alloys. Journal of Alloys and Compounds., v. 365, p. 246-252, 2004.

[29] LIU,Y.; PAN, H.; ZHU, Y.; LI, R.; LEI, Y. Influence of Mn content on the structural and electrochemical properties of the $\mathrm{La}_{0,7} \mathrm{Mg}_{0,3} \mathrm{Ni}_{4,25-\mathrm{x}} \mathrm{Co}_{0,75} \mathrm{Mn}_{\mathrm{x}}$ hydrogen storage alloys. Materials Science and Engineering., v. A372, p. 163-172, 2004.

[30] JIANG, L.; LI, G.; XU, L.; JIANG, W.; LAN, Z.; GUO, J. Effect of substituting $\mathrm{Mn}$ for $\mathrm{Ni}$ on the hydrogen storage and electrochemical properties of $\mathrm{ReNi}_{2,6}$ ${ }_{x} \mathrm{Mn}_{\mathrm{x}} \mathrm{Co}_{0,9}$ alloys. International Journal of Hydrogen Energy., v. 35, p. 204209, 2010. 
[31] ZHANG, X.B.; SUN, D.Z.; YIN, W.Y.; CHAI, Y.J.; ZHAO, M.S. Effect of Mn content on the structure and electrochemical characteristics of $\mathrm{La}_{0,7} \mathrm{Mg}_{0,3} \mathrm{Ni}_{2,975-\mathrm{x}} \mathrm{Co}_{0,525} \mathrm{Mn}_{\mathrm{x}} \quad(\mathrm{x}=0$ - 0,4$)$ hydrogen storage alloys. Electrochimica Acta., v. 50, p. 2911-2918, 2005.

[32] LIU, Y.; PAN, H.; GAO, M.; LI, RUI.; LEI, Y. Effect of Co content on the structural and electrochemical properties of the $\mathrm{La}_{0,7} \mathrm{Mg}_{0,3} \mathrm{Ni}_{3,4-x} \mathrm{Mn}_{0,1} \mathrm{Co}_{\mathrm{x}}$ hydride alloys I. Electrochemical properties. Journal of Alloys and Compounds., v. 376, p. 296-303, 2004.

[33] LIAO, B.; LEI, Y.Q.; CHEN, L.X.; LU, G.L.; PAN, H.G.; WANG, Q.D. Effect of Co substitution for $\mathrm{Ni}$ on the structural and electrochemical properties of $\mathrm{La}_{2} \mathrm{Mg}\left(\mathrm{Ni}_{1-\mathrm{x}} \mathrm{Co}_{\mathrm{x}}\right)_{9} \quad(\mathrm{x}=0,1-0,5)$ hydrogen storage electrode alloys. Electrochimica Acta., v. 50, p. 1057-1063, 2004.

[34] LIU, Y.; PAN, H.; GAO, M.; LI, R.; LEI, Y. Effect of Co content on the structural and electrochemical properties of the $\mathrm{La}_{0,7} \mathrm{Mg}_{0,3} \mathrm{Ni}_{3,4-x} \mathrm{Mn}_{0,1} \mathrm{Co}_{x}$ hydride alloys. Journal of Alloys and Compounds., v. 376, p. 304-313, 2004.

[35] LIAO, B.; LEI, Y.Q.; CHEN, L.X.; LU, G.L.; PAN, H.G.; WANG, Q.D. The effect of $\mathrm{Al}$ substitution for $\mathrm{Ni}$ on the structure and electrochemical properties of AB3-type $\mathrm{La}_{2} \mathrm{Mg}\left(\mathrm{Ni}_{1-\mathrm{x}} \mathrm{Al} \mathrm{I}_{\mathrm{x}}\right)_{9}(\mathrm{x}=0$ - 0,05) alloys. Journal of Alloys and Compounds., v. 404-406, p. 665-668, 2005.

[36] PAN, H.; LIU, Y.; GAO, M.; LEI, WANG, Q. Electrochemical properties of the $\mathrm{La}_{0,7} \mathrm{Mg}_{0,3} \mathrm{Ni}_{2,65-x} \mathrm{Mn}_{0,1} \mathrm{Co}_{0,75} \mathrm{Al}_{\mathrm{x}}(\mathrm{x}=0$ - 0,5) hydrogen storage alloy electrodes. Journal of Electrochemical Society., v. 152, p. A326-A332, 2005.

[37] LIU, Y.; PAN, H.; GAO, M.; MIAO H, LEI, Y.; WANG, Q. Function of Al on the cycling behavior of the La-Mg-Ni-Co-type alloy electrodes. International Journal of Hydrogen Energy., v. 33, p. 124-133, 2008. 
[38] SAKINTUNA, B.; LAMARI-DARKRIM, F.; HISCHER, M. Metal hydride materials for solid hydrogen storage: A review. International Journal of Hydrogen Energy., v. 32, p. 1121-1140, 2007.

[39] GOO, N.; LEE, K. The electrochemical hydriding properties of $\mathrm{Mg}-\mathrm{Ni}-\mathrm{Zr}$ amorphous alloy. International Journal of Hydrogen Energy., v. 27, p. 433-438, 2002.

[40] NIU, H.; NOTHWOOD, D. Enhanced electrochemical properties of ball-milled $\mathrm{Mg}_{2} \mathrm{Ni}$ electrodes. International Journal of Hydrogen Energy., v. 27, p. 6977, 2002.

[41] SOUZA, E.C.; TICIANELLI, E.A. Structural and electrochemical properties of MgNi-based alloys with $\mathrm{Ti}, \mathrm{Pt}$ and $\mathrm{Pd}$ additives. International Journal of Hydrogen Energy., v. 32, p. 4917-4924, 2007.

[42] OESTERRICHER, H.; BITTNER, H. HYDRIDE FORMATION IN La ${ }_{1-x} \mathrm{Mg}_{x} \mathrm{Ni}_{2}$. Journal of the Less-Common Metals., v. 13, p. 339-344, 1980.

[43] KADIR, K.; SAKAI, T.; UEHARA, I. Structural investigation and hydrogen capacity of $\mathrm{YMg}_{2} \mathrm{Ni}_{9}$ and $\left(\mathrm{Y}_{0,5} \mathrm{Ca}_{0,5}\right)(\mathrm{MgCa}) \mathrm{Ni}_{9}$ : new phases in the $\mathrm{AB}_{2} \mathrm{C}_{9}$ system isostructural with $\mathrm{LaMg}_{2} \mathrm{Ni}_{9}$. Journal of Alloys and Compounds., v. 287, p. 264-270, 1999.

[44] KADIR, K.; SAKAI, T.; UEHARA, I. Structural investigation and hydrogen capacity of $\mathrm{YMg}_{2} \mathrm{Ni}_{9}$ and $\left(\mathrm{Y}_{0,5} \mathrm{Ca}_{0,5}\right)(\mathrm{MgCa}) \mathrm{Ni}_{9}$ : new phases in the $\mathrm{AB}_{2} \mathrm{C}_{9}$ system isostructural $\mathrm{LaMg}_{2} \mathrm{Ni}_{9}$. Journal of Alloys and Compounds., v. 287, p. 264-270, 1999.

[45] KADIR, K.; SAKAI, T.; UEHARA, I. Structural investigation and hydrogen capacity of $\mathrm{LaMg}_{2} \mathrm{Ni}_{9}$ and $\left(\mathrm{La}_{0,65} \mathrm{Ca}_{0,35}\right)\left(\mathrm{Mg}_{1,32} \mathrm{Ca}_{0,68}\right) \mathrm{Ni}_{9}$ of the $\mathrm{AB}_{2} \mathrm{C}_{9}$ type structure. Journal of Alloys and Compounds., v. 302, p. 112-117, 2000. 
[46] CHEN, J.; TAKESHITA, H.T.; TANAKA, H.; KURIYAMA, N.; SAKAI, T.; UEHARA, I.; HARUTA, M. Hydriding properties of $\mathrm{LaNi}_{3}$ and $\mathrm{CaNi}_{3}$ and their substitutes with $\mathrm{PuNi}_{3}$-type structure. Journal of Alloys and Compounds., v. 302, p. 304-313, 2000.

[47] PAN, H.; LIU, Y.; GAO, M.; ZHU, Y.; LEI, Y.; WANG, Q. A $n$ investigation on the structural and electrochemical properties of $\mathrm{La}_{0,7} \mathrm{Mg}_{0,3}\left(\mathrm{Ni}_{0,85} \mathrm{Co}_{0,15}\right)_{x}(\mathrm{x}=$ 3,15 - 3,80) hydrogen storage electrode alloys. Journal of Alloys and Compounds., v. 351, p. 228-234, 2003.

[48] LIU, Y.; PAN, H.; GAO, M.; ZHU, Y.; LEI, Y. Hydrogen storage and electrochemical properties of the $\mathrm{La}_{0,7} \mathrm{Mg}_{0,3} \mathrm{Ni}_{3,825-x} \mathrm{Co}_{0,675} \mathrm{Mn}_{\mathrm{x}}$ hydrogen storage electrode alloys. Journal of Alloys and Compounds., v. 365, p. 246-252, 2004.

[49] LIAO, B.; LEI, Y.Q.; LU, G.L.; CHEN, L.X.; PAN, H.G.; WANG, Q.D. The electrochemical properties of $\operatorname{Lax}_{3} \mathrm{Mg}_{3-X \mathrm{Ni}_{9}}(\mathrm{x}=1,0-2,0)$ hydrogen storage alloys. Journal of Alloys and Compounds., v. 356-357, p. 746-749, 2003.

[50] LIAO, B.; LEI, Y.Q.; LU, G.L.; CHEN, L.X.; PAN, H.G.; WANG, Q.D. The electrochemical properties of $\operatorname{Lax}_{x} \mathrm{Mg}_{3-x} \mathrm{Ni}_{9}(\mathrm{x}=1,0-2,0)$ hydrogen storage alloys. Journal of Power Sources., v. 129, p. 358-367, 2004.

[51] ZHANG, A.; HAN, S.; LI, Y.; JING, T. Electrochemical properties of $\mathrm{Ml}_{1-x} \mathrm{Mg}_{\mathrm{x}} \mathrm{Ni}_{3,0} \mathrm{Mn}_{0,10} \mathrm{Co}_{0,55} \mathrm{Al}_{0,10}(\mathrm{x}=0,05$ - 0,30) hydrogen storage alloys. Journal of Power Sources., v. 431, p. 208-211, 2007.

[52] GOO, N.; LEE, K. The electrochemical hydriding properties of $\mathrm{Mg}-\mathrm{Ni}-\mathrm{Zr}$ amorphous alloy. International Journal of Hydrogen Energy., v. 27, p. 433-438, 2002.

[53] NIU, H.; NOTHWOOD, D. Enhanced electrochemical properties of ball-milled $\mathrm{Mg}_{2} \mathrm{Ni}$ electrodes. International Journal of Hydrogen Energy., v. 27, p. 6977, 2002. 
[54] HAN, S.; LEE, P.; LEE, J.; ZUTTEL, A.; SCLAPBACH, L. Effects of Ti on the cycle life of amorphous MgNi-based alloy prepared by ball milling. Journal of Alloys and Compounds., v. 306, p. 219-226, 2000.

[55] LIU, J.; YUAN, H.; CAO, J.; WANG, Y. Effect of Ti-Al substitution on the electrochemical properties of amorphous MgNi-based secondary hydride electrodes. Journal of Alloys and Compounds., v. 392, p. 300-305, 2005.

[56] ROUE, L.; RONGEAT, C. On the cycle life improvement of amorphous MgNibased alloy for $\mathrm{Ni}-\mathrm{MH}$ batteries. Journal of Alloys and Compounds., v. 404-406, p. 679-681, 2005.

[57] MA, T.; HATANO, Y.; ABE T.; WATANABE, K. Effects of Pd addition on electrochemical properties of MgNi. Journal of Alloys and Compounds., v. 372, p. 251-258, 2004.

[58] MA, T.; HATANO, Y.; ABE T.; WATANABE, K. Effects of bulk modification by $\mathrm{Pd}$ on electrochemical properties of MgNi. Journal of Alloys and Compounds., v. 391, p. 313-317, 2005.

[59] NAKAMURA, Y.; NAKAMURA, H.; FUJITANI, S.; YONEZU, I. Homogenizing behaviour in a hydrogen-absorbing $\mathrm{LaNi}_{4,55} \mathrm{Al}_{0,45}$ alloy through annealing and rapid quenching. Journal of Alloys and Compounds., v. 210, p. 299-303, 1994.

[60] PAN, H.; CHEN, N.; GAO, M.; LI, R.; LEI, Y.; WANG, Q. Effects of annealing temperature on structure and the electrochemical properties of $\mathrm{La}_{0,7} \mathrm{Mg}_{0,3} \mathrm{Ni}_{2,45} \mathrm{Co}_{0,75} \mathrm{Mn}_{0,1} \mathrm{Al}_{0,2}$ hydrogen storage alloy. Journal of Alloys and Compounds., v. 397, p. 306-312, 2005.

[61] YU, C, Z.; YAN, G, J.; LAI, W, H.; DONG, Q, H. A stydy of the main factors affecting Ni-MH battery activation. Journal of Alloys and Compounds., v. 293-295, p. 799-803, 1999. 
[62] ZARPELON, L.M.C.; GALEGO, E.; TAKIISHI, H.; FARIA, R.N. Microstructure and composition of Rare Earth-transition Metal-Aluminium-Magnesium alloys. Materials Research., v. 11, p. 17-21, 2008.

[63] CAI, Z.; LU, D.; LI, W.; LIANG, Y.; ZHOU, H. Study on anodic oxidation of magnesium in $6 \mathrm{M} \mathrm{KOH}$ solution by alternative current impedance. International Journal of Hydrogen Energy., v. 34, p. 467-472, 2009.

[64] CASINI, J.C.S.; ZARPELON, L.M.C.; FERREIRA, E.A.; TAKIISHI, H.; FARIA, R.N. Hydrogenation and Discharge Capacity of a $\mathrm{La}_{0,7} \mathrm{Mg}_{0,3} \mathrm{Al}_{0,3} \mathrm{Mn}_{0,4} \mathrm{Co}_{0,5} \mathrm{Ni}_{3,8}$ Alloy for Nickel-Metal Hydride Batteries. Materials Science Forum., v. 660-661, p. 128-132, 2010.

[65] LIU, Y.; PAN, H.; YUE, Y.; WU, X.; CHEN, W.; LEI, Y. Cycling durability and degradation behavior of $\mathrm{La}-\mathrm{Mg}-\mathrm{Ni}-\mathrm{Co}$-type metal hydride electrodes. Journal of Alloys and Compounds., v. 395, p. 291-299, 2005.

[66] ZHANG, Y, H.; WANG, G, Q.; DONG, X, P.; GUO, S, H.; WANG, X, L. Investigation on the microstructure and electrochemical performances of $\mathrm{La}_{2} \mathrm{Mg}\left(\mathrm{Ni}_{0,85} \mathrm{Co}_{0,15}\right)_{9} \mathrm{~B}_{\mathrm{x}}(\mathrm{x}=0$ - 0,2) hydrogen storage electrode alloys. Journal of Alloys and Compounds., v. 379, p. 298-304, 2004. 